\title{
Intracellular traffic jam : cholesterol accumulation as cause for chronic inflammatory diseases
}

Citation for published version (APA):

Hendrikx, T. (2015). Intracellular traffic jam : cholesterol accumulation as cause for chronic inflammatory diseases. [Doctoral Thesis, Maastricht University]. Maastricht University.

https://doi.org/10.26481/dis.20150206th

Document status and date:

Published: 01/01/2015

DOI:

$10.26481 /$ dis.20150206th

Document Version:

Publisher's PDF, also known as Version of record

\section{Please check the document version of this publication:}

- A submitted manuscript is the version of the article upon submission and before peer-review. There can be important differences between the submitted version and the official published version of record.

People interested in the research are advised to contact the author for the final version of the publication, or visit the DOI to the publisher's website.

- The final author version and the galley proof are versions of the publication after peer review.

- The final published version features the final layout of the paper including the volume, issue and page numbers.

Link to publication

\footnotetext{
General rights rights.

- You may freely distribute the URL identifying the publication in the public portal. please follow below link for the End User Agreement:

www.umlib.nl/taverne-license

Take down policy

If you believe that this document breaches copyright please contact us at:

repository@maastrichtuniversity.nl

providing details and we will investigate your claim.
}

Copyright and moral rights for the publications made accessible in the public portal are retained by the authors and/or other copyright owners and it is a condition of accessing publications that users recognise and abide by the legal requirements associated with these

- Users may download and print one copy of any publication from the public portal for the purpose of private study or research.

- You may not further distribute the material or use it for any profit-making activity or commercial gain

If the publication is distributed under the terms of Article $25 \mathrm{fa}$ of the Dutch Copyright Act, indicated by the "Taverne" license above, 


\section{Intracellular traffic jam: cholesterol accumulation as cause for chronic inflammatory diseases}


Copyright Tim Hendrikx, Maastricht 2015

Layout: Tiny Wouters

Cover design: Wouter Mulders

Production: proefschriftmaken.nl

ISBN: 978-94-6295-060-3

Het drukken van dit proefschrift werd mede mogelijk gemaakt door een financiële bijdrage geleverd van de "Maag Lever Darm Stichting", de "Nederlandse Vereniging voor Hepatologie" en "Kupffer cell foundation". 


\section{Intracellular traffic jam: cholesterol accumulation as cause for chronic inflammatory diseases}

\section{PROEFSCHRIFT}

ter verkrijging van de graad van doctor aan de Universiteit Maastricht op gezag van de Rector Magnificus, Prof. dr. L.L.G. Soete volgens het besluit van het College van Decanen, in het openbaar te verdedigen op vrijdag 6 februari 2015 om 14.00 uur

door

Tim Hendrikx 
Promotores:

Prof. Dr. J.F.C. Glatz

Prof. Dr. M.H. Hofker

Co-promotor:

Dr. R. Shiri-Sverdlov

Beoordelingscommissie:

Prof. Dr. A.M. Schols (voorzitter)

Dr. D.M.A.E. Jonkers

Dr. S.W.M. Olde Damink

Prof. Dr. P.C.N. Rensen (LUMC) 


\section{Contents}

$\begin{array}{lll}\text { Chapter } 1 \text { General introduction } & 7\end{array}$

Chapter 2 Lysosomal cholesterol accumulation: driver on the road 17 to inflammation during atherosclerosis and non-alcoholic steatohepatitis

Obes Rev. 2014;15:424-433

Chapter 3 Macrophage specific caspase-1/11 deficiency protects against

cholesterol crystallization and hepatic inflammation in hyperlipidemic mice

PLoS One. 2013;8:e78792

Chapter 4 Bone marrow specific caspase-1/11 deficiency inhibits

atherosclerosis development in $\mathrm{Ldlr}^{-/-}$mice

Submitted

Chapter 5 27-Hydroxycholesterol: a potential treatment for non-alcoholic steatohepatitis in mice

Gastroenterology 2013;144:167-178

Chapter 6 Hematopoietic overexpression of Cyp27a1 reduces hepatic inflammation independently of 27-hydroxycholesterol levels in $\mathrm{Ldlr}^{-/-}$mice

J Hepatol. 2014 Oct 1. pii: S0168-8278(14)00718-1

Chapter 7 Protective role of plant sterol and stanol esters in liver inflammation: insights from mice and humans PLoS One. 2014 Oct 30;9(10):e110758.

Chapter 8 General discussion

Summary

Samenvatting

Valorisation

Dankwoord

Curriculum Vitae 

Chapter 1

General introduction 
Chapter 1 


\section{The metabolic syndrome}

The Metabolic syndrome (MetS) is associated with abdominal obesity, blood lipid disorders, inflammation, insulin resistance or full-blown diabetes, and increased risk of developing cardiovascular disease (Figure 1.1). As is true for most diseases, both environmental and genetic factors play an important role in the development of the MetS. Physical inactivity, sedentary lifestyle, an atherogenic diet (high carbohydrates, low fibre, high saturated fat), high alcohol intake, and smoking all contribute significantly to the risk of developing the MetS. ${ }^{1}$ About $5 \%$ of people with normal body weight, $22 \%$ of those who have overweight and $60 \%$ of those who are considered obese are estimated to have MetS. Genetic factors influence each individual component of the syndrome, and the syndrome itself. Individuals diagnosed with MetS have significantly higher risk for developing type 2 diabetes, coronary heart disease and stroke, some forms of cancer and fatty liver disease (Figure 1.1). The MetS is especially related to the development of insulin resistance, ${ }^{2}$ which may be considered the pathogenic denominator that links all different components of the MetS. ${ }^{3}$ Relevantly, the MetS is considered as a major health hazard, as its incidence is increasingly rapidly and nowadays even children are diagnosed with MetS.

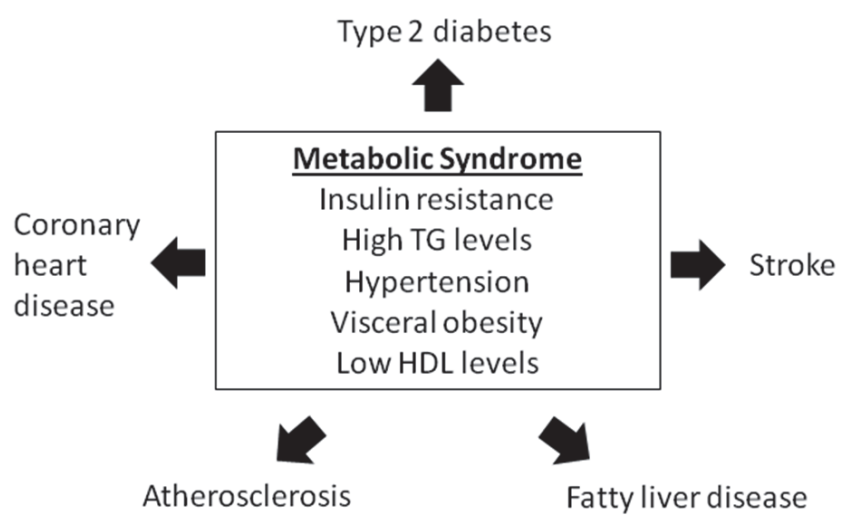

Figure 1.1 The metabolic syndrome. The mean features of the metabolic syndrome are insulin resistance, visceral obesity, high triglyceride (TG) levels, hypertension and low HDLcholesterol levels. Clinical consequences include type 2 diabetes, coronary heart disease, stroke, atherosclerosis and fatty liver disease. 


\section{Atherosclerosis}

The MetS is known to be a significant predictor of atherosclerosis; a chronic inflammatory disease of the arterial wall responsible for the most severe forms of cardiovascular diseases and carries important socio-economic burden. Atherosclerosis starts developing from a young age and slowly leads to the formation of lesions (made of excess fat deposits) and narrowing of the arteries over the years. It is characterized by the thickening and hardening of the arteries. At later stages of the disease, growth factor released by macrophages in the plaque cause proliferation of smooth muscle cells and the plaque becomes fibrotic. Ultimately, the plaque may burst and rupture of these atherosclerotic lesions is the cause of severe cardiovascular manifestations that appear later in life, such as myocardial infarction and stroke. ${ }^{4}$ Although several causal risk factors including gender, age, total and LDL-cholesterol levels, systolic blood pressure, smoking and type 2 diabetes are identified, approximately half of cardiovascular events occur in individuals without these established risk factors. ${ }^{5,6}$ The total number of annual deaths due to cardiovascular disease is more than 17 million, approximately $29 \%$ of all deaths, making it the most common reason of death in the Western world. ${ }^{7,8}$

\section{Non-alcoholic steatohepatitis (NASH)}

Besides atherosclerosis, the MetS was found to be a strong predictor for the development of non-alcoholic fatty liver disease (NAFLD). The term NAFLD is used to describe a variety of liver diseases of different severity, from pure steatosis to nonalcoholic steatohepatitis (NASH) and cirrhosis and, rarely, hepatocellular carcinoma [9]. NASH is viewed as the hepatic event of the metabolic syndrome and is characterized by hepatic triglyceride (TG) accumulation (i.e. steatosis), in combination with hepatic inflammation. While steatosis is rather benign and still reversible, it is the presence of inflammation that sets the stage for further damage, leading to irreversible severe liver dysfunction as observed during cirrhosis and liver cancer. As obesity and insulin resistance reach epidemic proportions in industrialized countries, the prevalence of NASH is further increasing. Estimates of NAFLD prevalence vary between 20 and $30 \%$ in Western populations, rising to as high as $90 \%$ in morbidly obese individuals. NASH is less common, affecting only $2-3 \%$ of the general population and up to $37 \%$ of the morbidly obese. ${ }^{9}$ 


\section{Hyperlipidemic $L d l r^{-/-}$mice as model to study NASH and atherosclerosis}

Nowadays, an emerging trend in NASH research is to utilize the mouse models traditionally targeted for studies of atherosclerosis. In this thesis, we used a mouse model deficient for the low-density lipoprotein receptor $\left(L d l r^{-/-}\right)$. The $L d l r^{-/}$mice are genetically modified animals lacking the low density lipoprotein receptor, an important gene in lipid metabolism, and are one of the most widely used animal models for studying atherosclerosis. Previously, it was shown that deficiency of the LDL receptor resulted in mildly elevated cholesterol levels in mice upon a high-fat, high-cholesterol (HFC) diet. The largest amount of cholesterol was present in the IDL/LDL fraction, whereas a very small part was confined to the VLDL fraction. ${ }^{10}$ In contrast to the lipoprotein profile in normal mice, in which most cholesterol is present in the HDL fraction, this profile is more comparable to the human plasma lipoprotein profile, in which cholesterol is mainly confined to the LDL fraction. Therefore, the $\mathrm{LdIr}^{-/}$mouse serve as physiological mouse model to study the progression of NASH and atherosclerosis. ${ }^{11}$

\section{Similar mechanism during atherosclerosis and NASH}

Although atherosclerosis and NASH are seen as two separate potential consequences of the MetS, recent insights show that the underlying mechanisms leading to the inflammatory response in both diseases are similar. ${ }^{12}$ Central players in the disease process are macrophages and cholesterol. During atherosclerosis, macrophages play an essential role by communicating inflammatory signals among metabolic tissues and by scavenging modified lipids. In the vessel wall, monocyte recruitment and macrophage maturation accompanied by uptake of cholesterol in the form of modified low-density lipoproteins (LDL) via scavenger receptors (e.g. scavenger receptor $A$ and $C D 36$ ) gives rise to lipid-laden (foam) cells in the atheroma. ${ }^{13}$ The same process of accumulation of lipid-loaded macrophages was observed in the liver during NASH. ${ }^{14}$ Upon high fat feeding, we found that hyperlipidemic mice demonstrated bloated foamy Kupffer cells. ${ }^{14}$ These Kupffer cells are typical macrophages in the liver that also express scavenger receptors, thereby being capable of taking up modified lipoproteins. We have previously observed that upon targeted deletion of scavenger receptor $A$ and $C D 36$ in macrophages, the hepatic inflammatory response was dramatically decreased in a mouse model of NASH. ${ }^{15,16}$ Likewise, absence of scavenger receptors in macrophages of hyperlipidemic mouse models decreased atherosclerosis. ${ }^{13}$ In conclusion, atherosclerosis and NASH are two diseases with similar underlying mechanisms in which macrophages and cholesterol play a key role in driving the inflammatory response. 


\section{Disturbed intracellular cholesterol trafficking}

Macrophage-derived foam cells during atherosclerosis predominantly contain enlarged lysosomes filled with cholesterol and cholesterol crystals, instead of cholesterol ester storage into the cytoplasm. ${ }^{17,18}$ Electron microscopic observations of lesions confirmed that much of the accumulated lipids in foam cells occurred within large, lipid-engorged lysosomes. ${ }^{19}$ These findings were confirmed in both human lesions and atherosclerotic lesions in animal models of the disease. ${ }^{20-22}$

Similar to the arteries, investigation of the foamy Kupffer cells in livers of hyperlipidemic mice fed HFC diet, revealed accumulation of cholesterol inside lysosomes of Kupffer cells and cholesterol crystal formation. ${ }^{15,23}$ Remarkably, hepatic inflammation was found to be associated with increased cholesterol storage inside lysosomes of Kupffer cells, whereas mice with cytoplasmic cholesterol accumulation had reduced hepatic inflammation (Figure 1.2). These data provide evidence that lysosomal cholesterol accumulation in Kupffer cells is crucial for inflammation in the context of $\mathrm{NASH}{ }^{15,23}$ More evidence regarding the involvement of lysosomal cholesterol accumulation in inflammation is provided in chapter 2. Taken together, these studies suggest that not the foamy appearance of macrophages but the intracellular cholesterol distribution plays a critical role in the onset of inflammation and in the pathogenesis of atherosclerosis and NASH. So far, the mechanisms by which lysosomal cholesterol accumulation can trigger the inflammatory response during atherosclerosis and NASH are not completely understood. This thesis is aimed at investigating the underlying mechanisms by which lysosomal cholesterol accumulation lead to inflammation.
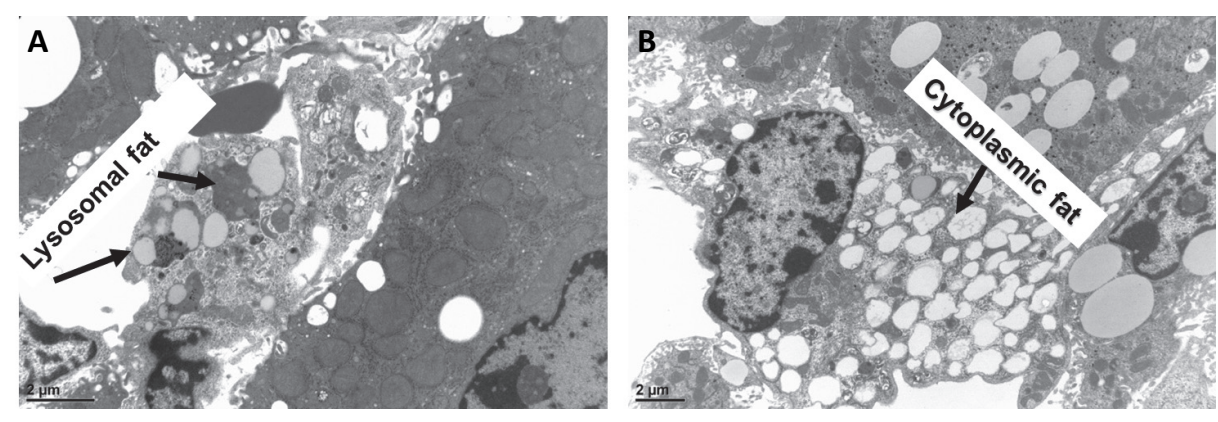

Figure 1.2 Electron microscopy pictures of Kupffer cells of $L d l r^{-/}$mice upon HFC feeding, thereby developing hepatic inflammation and representing NASH. Lysosomal cholesterol accumulation in Kupffer cells is correlated with increased hepatic inflammation (A), whereas reduced hepatic inflammation is associated with more cholesterol deposition in the cytoplasm (B). 


\section{Aim and outline of thesis}

In this thesis, we aimed to establish the mechanisms by which lysosomal cholesterol accumulation leads to inflammation during NASH and atherosclerosis. Furthermore, different methods to potentially modulate the intracellular cholesterol distribution and thereby reducing the inflammatory response were studied.

Chapter 2 gives an overview of recent knowledge regarding the potential mechanisms by which lysosomal cholesterol accumulation can trigger inflammation during atherosclerosis and NASH. Furthermore, potential targets for therapy intervention are described.

One of the potential mechanisms by which lysosomal cholesterol can lead to inflammation is via the activation of so-called inflammasomes. Therefore, in chapter 3, we investigated the role of hematopoietic inflammasome activation during NASH development. To evaluate the involvement of inflammasome activation, $\mathrm{Ld}_{\mathrm{r}}{ }^{-/}$mice were transplanted with bone marrow from caspase- $1 / 11^{-/}$mice and fed a HFC diet.

In chapter 4 we evaluated the effect of hematopoietic caspase- $1 / 11^{-/}$on atherosclerosis development. This chapter shows the specific contribution of caspase$1 / 11$ activation in cells from the hematopoietic system to cardiovascular disease.

Previously, 27-hydroxycholesterol was shown to stimulate cholesterol transport from lysosomes to cytoplasm in vitro. In Chapter 5, the potential of 27-hydroxycholesterol to modulate lysosomal cholesterol accumulation and thereby reduce hepatic inflammation in vivo was tested. For this purpose, 27-hydroxycholesterol was administered subcutaneously to $L d l r^{-/-}$mice that received regular chow or an HFC diet for 3 weeks.

As 27-hydroxycholesterol is formed by the enzyme Cyp27a1, in chapter 6 we investigated whether hematopoietic overexpression of Cyp27a1 is able to reduce hepatic inflammation during NASH. By transplanting $\mathrm{Ldll}^{-/-}$mice with bone marrow from mice overexpressing Cyp27a1, we were able to study the effect of hematopoietic Cyp27a1 overexpression on hepatic inflammation.

In chapter 7, Ldlr ${ }^{-/}$mice were given HFC diet with or without supplementation of plant sterols or stanols (which are similar in structure to 27-hydroxycholesterol). This approach was tested as a possible therapeutic option for the prevention of NASH.

Finally, chapter 8 includes a detailed discussion regarding the major findings of this thesis and places them in the current state of the field. 


\section{References}

1. Sarafidis PA, Nilsson PM. The metabolic syndrome: a glance at its history. J Hypertens. 2006;24:621-6.

2. Israili ZH, Lyoussi B, Hernández-Hernández R, Velasco M. Metabolic syndrome: treatment of hypertensive patients. Am J Ther. 2007;14:386-402.

3. Ferrannini E, Haffner SM, Mitchell BD, Stern MP. Hyperinsulinaemia: the key feature of a cardiovascular and metabolic syndrome. Diabetologia. 1991;34:416-22.

4. Ross R. The pathogenesis of atherosclerosis: a perspective for the 1990s. Nature. 1993;362:801-9.

5. Moore KJ, Sheedy FJ, Fisher EA. Macrophages in atherosclerosis: a dynamic balance. Nat Rev Immunol. 2013;13:709-21.

6. Weber C, Noels H. Atherosclerosis: current pathogenesis and therapeutic options. Nat Med. 2011;17: 1410-22.

7. Roger VL, Go AS, Lloyd-Jones DM, Benjamin EJ, Berry JD, Borden WB, Bravata DM, Dai S, Ford ES, Fox CS, Fullerton HJ, Gillespie C, Hailpern SM, Heit JA, Howard VJ, Kissela BM, Kittner SJ, Lackland DT, Lichtman JH, Lisabeth LD, Makuc DM, Marcus GM, Marelli A, Matchar DB, Moy CS, Mozaffarian D, Mussolino ME, Nichol G, Paynter NP, Soliman EZ, Sorlie PD, Sotoodehnia N, Turan TN, Virani SS, Wong ND, Woo D, Turner MB; American Heart Association Statistics Committee and Stroke Statistics Subcommittee. Heart disease and stroke statistics--2012 update: a report from the American Heart Association. Circulation. 2012;125: e2-e220.

8. Canto JG, Kiefe Cl, Rogers WJ, Peterson ED, Frederick PD, French WJ, Gibson CM, Pollack CV Jr, Ornato JP, Zalenski RJ, Penney J, Tiefenbrunn AJ, Greenland P; NRMI Investigators. Number of coronary heart disease risk factors and mortality in patients with first myocardial infarction. JAMA. 2011;306:2120-7.

9. Parekh S, Anania FA. Abnormal lipid and glucose metabolism in obesity: implications for nonalcoholic fatty liver disease. Gastroenterology. 2007;132:2191-207.

10. Ishibashi S, Brown MS, Goldstein JL, Gerard RD, Hammer RE, Herz J. Hypercholesterolemia in low density lipoprotein receptor knockout mice and its reversal by adenovirus-mediated gene delivery. J Clin Invest. 1993;92:883-93.

11. Bieghs V, Van Gorp PJ, Wouters K, Hendrikx T, Gijbels MJ, van Bilsen M, Bakker J, Binder CJ, Lütjohann D, Staels B, Hofker MH, Shiri-Sverdlov R. LDL receptor knock-out mice are a physiological model particularly vulnerable to study the onset of inflammation in non-alcoholic fatty liver disease. PLoS One. 2012;7:e30668.

12. Bieghs V, Rensen PC, Hofker MH, Shiri-Sverdlov R. NASH and atherosclerosis are two aspects of a shared disease: central role for macrophages. Atherosclerosis. 2012;220:287-93.

13. Moore KJ, Freeman MW. Scavenger receptors in atherosclerosis: beyond lipid uptake. Arterioscler Thromb Vasc Biol. 2006;26:1702-11.

14. Wouters K, van Gorp PJ, Bieghs V, Gijbels MJ, Duimel H, Lütjohann D, Kerksiek A, van Kruchten R, Maeda N, Staels B, van Bilsen M, Shiri-Sverdlov R, Hofker MH. Dietary cholesterol, rather than liver steatosis, leads to hepatic inflammation in hyperlipidemic mouse models of nonalcoholic steatohepatitis. Hepatology. 2008;48:474-86.

15. Bieghs V, Verheyen F, van Gorp PJ, Hendrikx T, Wouters K, Lütjohann D, Gijbels MJ, Febbraio M, Binder CJ, Hofker MH, Shiri-Sverdlov R. Internalization of modified lipids by CD36 and SR-A leads to hepatic inflammation and lysosomal cholesterol storage in Kupffer cells. PLoS One. 2012;7:e34378.

16. Bieghs V, Wouters K, van Gorp PJ, Gijbels MJ, de Winther MP, Binder CJ, Lütjohann D, Febbraio M, Moore KJ, van Bilsen M, Hofker MH, Shiri-Sverdlov R. Role of scavenger receptor A and CD36 in dietinduced nonalcoholic steatohepatitis in hyperlipidemic mice. Gastroenterology. 138:2477-86, 2486 e1-3.

17. Griffin EE, Ullery JC, Cox BE, Jerome WG. Aggregated LDL and lipid dispersions induce lysosomal cholesteryl ester accumulation in macrophage foam cells. J Lipid Res. 2005;46:2052-60.

18. Duewell P, Kono H, Rayner KJ, Sirois CM, Vladimer G, Bauernfeind FG, Abela GS, Franchi L, Nuñez G, Schnurr M, Espevik T, Lien E, Fitzgerald KA, Rock KL, Moore KJ, Wright SD, Hornung V, Latz E. NLRP3 inflammasomes are required for atherogenesis and activated by cholesterol crystals. Nature. 2010;464:1357-61. 
19. Haley NJ, Shio H,. Fowler S. Characterization of lipid-laden aortic cells from cholesterol-fed rabbits. I. Resolution of aortic cell populations by metrizamide density gradient centrifugation. Laboratory investigation; a journal of technical methods and pathology. 1977;37:287-96.

20. Goldfischer S, Schiller B, Wolinsky H. Lipid accumulation in smooth muscle cell lysosomes im primate atherosclerosis. Am J Pathol. 1975;78: 497-504.

21. Jerome WG, Lewis JC. Early atherogenesis in White Carneau pigeons. II. Ultrastructural and cytochemical observations. Am J Pathol. 1985;119:210-22.

22. Peters TJ, Muller M, De Duve C. Lysosomes of the arterial wall. I. Isolation and subcellular fractionation of cells from normal rabbit aorta. J Exp Med. 1972;136:1117-39.

23. Bieghs V, van Gorp PJ, Walenbergh SM, Gijbels MJ, Verheyen F, Buurman WA, Briles DE, Hofker MH, Binder CJ, Shiri-Sverdlov R. Specific immunization strategies against oxidized LDL: A novel way to reduce non-alcoholic steatohepatitis in mice. Hepatology. 2012;56:894-903. 


\section{Chapter 2}

Lysosomal cholesterol accumulation: driver on the road to inflammation during atherosclerosis and non-alcoholic steatohepatitis

T Hendrikx, SMA Walenbergh, MH Hofker, R Shiri-Sverdlov

Obes Rev. 2014;15:424-433 


\section{Abstract}

Many studies show an association between the accumulation of cholesterol inside lysosomes and the progression towards inflammatory disease states that are closely related to obesity. While in the past the knowledge regarding lysosomal cholesterol accumulation was limited to its association with plaque severity during atherosclerosis, recently a growing body of evidence indicates a causal link between lysosomal cholesterol accumulation and inflammation. These findings make lysosomal cholesterol accumulation an important target for intervention in metabolic diseases that are characterized by the presence of an inflammatory response.

In this review, we aim to show the importance of cholesterol trapping inside lysosomes to the development of inflammation by focusing on cardiovascular disease and non-alcoholic steatohepatitis (NASH) in particular. We summarize current data supporting the hypothesis that lysosomal cholesterol accumulation is playing a key role in the development of inflammation during atherosclerosis and NASH. In addition, potential mechanisms by which disturbed lysosomal function can trigger the inflammatory response, the challenges in improving cholesterol trafficking in macrophages and recent successful research directions will be discussed. 


\section{Introduction}

Nowadays, obesity is seen as one of the leading health concerns worldwide. The dramatically increasing occurrence of obesity in Western countries is accompanied by an increase in the prevalence of related conditions such as cardiovascular disease, stroke, type 2 diabetes, fatty liver disease and certain types of cancer. Also among children, obesity is causing a broad range of health problems including high blood pressure and elevated blood cholesterol levels. Therefore, there is a critical need to improve treatment options for obesity-related inflammatory disorders. In order to do so, the etiology of the diseases needs to be clarified. A common feature of obesity and related conditions is the presence of inflammation in different tissues, such as the vessel wall during atherosclerosis and the liver during non-alcoholic steatohepatitis (NASH). Although the exact mechanism that triggers and sustains this inflammatory state is not known, macrophages have been shown to play a central role. Interestingly, recent investigations have indicated lysosomal cholesterol accumulation in macrophages as a novel pathway that contributes to the inflammatory response during cardiovascular disease and $\mathrm{NASH}^{1-3}$. In this manuscript, we will discuss the role of cholesterol trapping inside lysosomes of macrophages during atherosclerosis and $\mathrm{NASH}$ and its contribution to the sustained inflammatory response. Additionally, we will describe potential targets for improving cholesterol trafficking in macrophages and recent successful research directions.

\section{Foam cell formation}

The central role of macrophages in triggering inflammation in different tissues has been extensively reviewed by others. ${ }^{4,5}$ Upon activation by different stimuli, tissue resident macrophages secrete pro-inflammatory cytokines, resulting in the recruitment and activation of macrophages from the circulation. During atherosclerosis and $\mathrm{NASH}$, which are characterized by the presence of inflammation, the accumulation of lipid-laden macrophages, termed foam cells, is critical for, and increases with the progression of disease. ${ }^{6,7}$ These so-called lipid-laden macrophages are formed upon uptake of lipoproteins containing triglycerides (TG) and cholesterol. Lipoproteins rich in TG can induce TG accumulation leading to foam cell formation via receptor-mediated uptake of triglyceride-rich lipoproteins (TGRLs) and free fatty acids. These free fatty acids are generated from triglyceride-rich chylomicrons and very low-density lipoproteins (VLDL), which are metabolized in the cells or stored as TG. $^{8}$

Besides TGRLs, cholesterol-rich low-density lipoproteins (LDL) are also known to be involved in foam cell formation. Importantly, a clear separation must be addressed between the uptake of non-modified LDL and the uptake of LDL particles that are modified. Non-modified LDL is taken up by cells via receptor-mediated endocytosis, a 
mechanism by which cells recognize extracellular ligands by the LDL receptor (LDLR) and subsequently internalize these ligands by inward budding of the plasma membrane. ${ }^{9}$ Upon binding to the LDLR, LDL is internalized as clathrin coated vesicles that are then converted into endosomes. Here, a more acidic $\mathrm{pH}$ (4.5 to 5) exists, which leads to the dissociation of the ligand-receptor complex. The LDLR is recycled to the surface of the cell, and the endosomes combine with lysosomes which contains acid hydrolases that can easily degrade all components of LDL. After hydrolysis, cholesterol is transferred into the cytoplasm via Niemann-Pick type C (NPC) proteins where it can be further degraded to bile acids or secreted via cholesterol efflux transporters. The cholesterol derived from LDL in the lysosome was found to be responsible for the regulation of processes that stabilize cholesterol content of the cell. ${ }^{9}$ First of all, it suppresses the activity of 3-hydroxy-3methylglutaryl coenzyme A reductase (HMG-CoA reductase), which catalyzes a rate-limiting step in cholesterol production. ${ }^{10}$ Next to that, LDL-derived cholesterol is able to activate a cholesterolesterifying enzyme, acyl CoA: cholesterol acyl-transferase (ACAT), thereby storing excess cholesterol as cholesteryl droplets in the cytoplasm. ${ }^{11}$ Additionally, the LDL receptor is subject of feedback regulation as LDL suppresses the transcription of the LDL receptor gene, thereby regulating the number of LDL receptors on the cell surface. ${ }^{10}$ Taken together, several mechanisms exist to prevent the formation of foam cells from non-modified LDL uptake.

Unlike the uptake of non-modified LDL, in vitro studies have shown that the uptake of oxidatively modified LDL by macrophages can contribute to cholesterol accumulation and subsequent formation of foam cells. ${ }^{12,13}$ These oxidized LDL fractions are taken up by scavenger receptors (SRs), present on macrophages, which were proven not to be downregulated in response to an increase in cellular cholesterol content, indicating that SR-mediated LDL uptake is the main cause for foam cell formation. ${ }^{14}$ The two main scavenger receptors responsible for the uptake of modified LDL by macrophages are scavenger receptor $A$ (SR-A) and CD36. ${ }^{14}$ Next to SR-mediated uptake of modified LDL, but to a much lesser extent, the phagocytic uptake of aggregated LDL by macrophages is an additional proposed mechanism that contributes to foam cell formation. ${ }^{15}$ In summary, whereas the processes involved in LDL uptake are tightly regulated and protect cells from becoming foam cells, the uptake of modified LDL was found to be responsible for the development of foamy macrophages.

During obesity, apart from increased levels of cholesterol-rich LDL, also increased oxidative stress is present, leading to the increased conversion of LDL to oxLDL. ${ }^{16,17}$ Under healthy conditions, the fraction of oxLDL in the plasma is very small compared to LDL $(0.001 \%){ }^{18,19}$ In patients with the metabolic syndrome, the fraction of oxLDL was shown to be increased to $0.6-1.8 \%$ compared to controls, ${ }^{20}$ whereas patients with acute coronary heart disease had fractions up to $5 \% .{ }^{21}$ While the uptake of cholesterol-rich LDL is tightly regulated and inhibited upon excess amounts, uptake of oxLDL is not inhibited. ${ }^{22}$ As such, it is important to keep the fraction of oxLDL as low as possible. 


\section{Disturbed intracellular cholesterol trafficking in macrophages during inflammation}

Circulating modified cholesterol-rich LDL is taken up by macrophages and initially directed to lysosomes for degradation. Lysosomes are ubiquitous membrane-bound organelles that contain acid hydrolases, i.e. digestive enzymes that are responsible for the correct degradation of the lysosomal content. Under normal conditions, cholesterol becomes hydrolyzed and the free cholesterol that is formed can be transferred by the Niemann-Pick type C (NPC) proteins 1 and 2 from the lysosome to the cytoplasm. The majority of cholesterol is then used for bile acid formation or mobilized to the plasma membrane, whereas excess cholesterol is either stored as cholesteryl esters (CE) in cytoplasmic lipid droplets or excreted during reverse cholesterol transport via the ATP-binding cassette transporters (ABCs) A1, G1, B4, or via the scavenger receptor class $B$ type I (SR-BI). By this means, the cells are provided with sufficient cholesterol for cellular functions, without overloading. ${ }^{23}$

While previously it was believed that foamy macrophages are responsible for the observed inflammatory response, recent studies suggest that the intracellular cholesterol distribution plays an important role in triggering inflammation. Specifically, cholesterol accumulation inside lysosomes is found to be associated with an inflammatory state. ${ }^{1,24}$ An important lysosomal enzyme that hydrolyzes CE and TG from internalized lipoproteins is lysosomal acid lipase (LAL). In humans, LAL is encoded by the LIPA gene and mutations of this gene lead to LAL deficiency and subsequent lysosomal cholesterol accumulation, which involves premature cardiovascular disease. ${ }^{25}$ Moreover, mice with a deficiency in LAL are, analogous to patients with LAL deficiency, characterized by lysosomal cholesterol accumulation and inflammation. ${ }^{26}$ Likewise, exogenous LAL administration in LDL receptor knockout $\left(\right.$ Ldl $\left.^{-1-}\right)$ mice on an high-fat, high-cholesterol (HFC) diet resulted in decreased lysosomal cholesterol storage and to a significant reduction in hepatic inflammation and atherosclerotic lesion size. ${ }^{27}$

While non-modified LDL is degraded normally and stored mainly in extra-lysosomal compartments, cholesterol delivered to macrophages in the form of oxLDL, which is increasingly present during obesity, fails to efflux normally and was found to result in lysosomal cholesterol accumulation. ${ }^{13}$ In an in vitro set-up, the uptake of oxLDL by macrophages was shown to partially inactivate lysosomal enzymes, thereby leading to increased cholesterol storage inside lysosomes. ${ }^{28}$ It was recently shown that the uptake of oxLDL, and not native LDL, by macrophages is a trigger for inflammation. ${ }^{2,3,12,29-31}$ Thus, unlike the uptake of native LDL, oxLDL uptake by macrophages results in the accumulation of cholesterol in lysosomes, thereby triggering the inflammatory response.

Lysosomal cholesterol accumulation is observed in two important aspects related to obesity, being atherosclerosis and NASH. In foam cells of advanced atherosclerotic plaques, most of the cholesterol appears to be trapped in lysosomes. Electron 
microscopic observations of lesions confirmed that much of the accumulated lipids in foam cells occurred within large, lipid-engorged lysosomes. ${ }^{32}$ These findings were confirmed in both human lesions and atherosclerotic lesions in animal models of the disease. ${ }^{33-35}$ More recently, our group has shown that also in the liver the uptake of oxLDL by Kupffer cells, resident macrophages of the liver, is correlated with lysosomal cholesterol accumulation and increased hepatic inflammation during NASH development in $\mathrm{Ldlr}^{-/}$mice. ${ }^{29,36}$ Taken together, these studies suggest that the intracellular cholesterol distribution plays a critical role in the onset of inflammation and in the pathogenesis of conditions related to obesity, such as atherosclerosis and NASH.

\section{Mechanisms linking lysosomal cholesterol accumulation and inflammation}

Currently, several mechanisms can link lysosomal cholesterol accumulation and inflammation. In this review, we focus on the effect of cholesterol trapping in lysosomes that concerns autophagy, inflammasome activation and lysosomal cathepsin release (Figure 2.1).

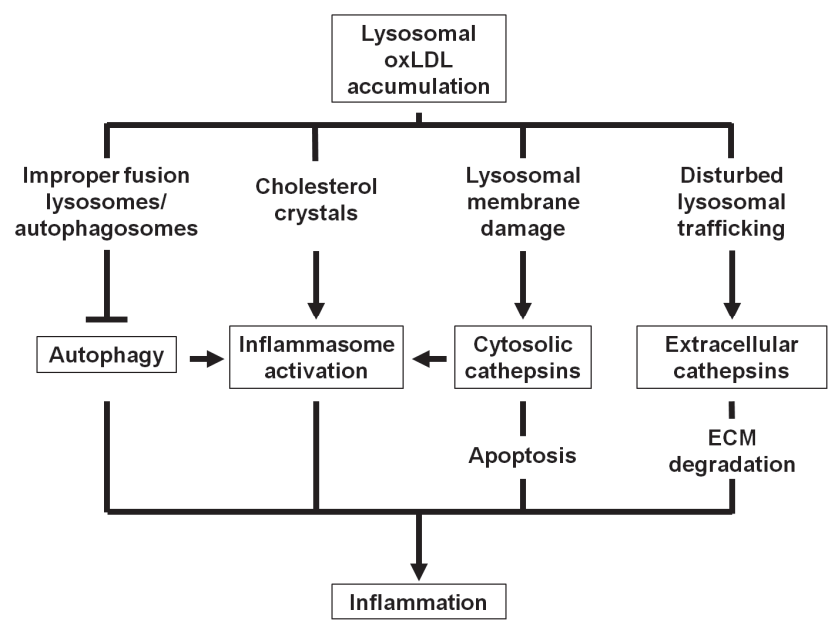

Figure 2.1 Potential mechanisms linking lysosomal oxLDL accumulation and inflammation. Lysosomal oxLDL accumulation can lead to inflammation via several mechanisms. First, lysosomal cholesterol trapping can lead to inhibition of autophagy due to improper fusion between lysosomes and autophagosomes. Next, as a result of lysosomal cholesterol accumulation, cholesterol crystals will be formed and subsequent inflammasome activation will occur. Due to lysosomal membrane damage, cathepsins may be released into the cytosol leading to mitochondrial dysfunction and apoptosis. Alternatively, cathepsins may be secreted from the cell due to disturbed lysosomal trafficking, thereby degrading the extracellular matrix (ECM). Finally, apart from cholesterol crystals, cytosolic cathepsins and reduced autophagy can activate inflammasomes, thereby potentially leading to increased inflammation. 


\section{Autophagy}

Autophagy is an important process for the degradation of cellular components such as misfolded proteins or damaged cell organelles. The accumulation of cholesterol inside lysosomes can result in lysosomal dysfunction and inhibition of autophagy, as a block in autophagy is observed during different lysosomal storage disorders (reviewed elsewhere). ${ }^{37-40}$ Lysosomes play a fundamental role during autophagy as these organelles fuse with autophagosomes to digest their content. This process can produce energy under starvation but is also involved in maintenance of homeostasis through the degradation and resynthesis of damaged components. Recent studies have discovered new protective functions for autophagy, such as the regulation of intracellular lipid stores, ${ }^{41}$ as well as a role in immunity, cell death and inflammation. ${ }^{37}$ A possible explanation for disturbed autophagy is that lipid accumulation alters membrane structure, thereby leading to improper fusion between lysosomes and autophagosomes. Changes in membrane lipid composition significantly reduced the number of fusion events between lysosomes and autophagosomes, both in vitro as well as in vivo. ${ }^{42}$ In addition, it was shown that cholesterol abnormalities in lysosomal storage disorders affect soluble $\mathrm{N}$-ethylmaleimide attachment protein receptors (SNAREs), which are key components of the fusion machinery between lysosomes and autophagosomes. ${ }^{43}$

Besides evidence of disturbed autophagy in lysosomal storage disorders, it may also play a prominent role in obesity and related complications. During obesity, adipose tissue expansion occurs due to increased size and number of adipocytes. Interestingly, autophagy was found to regulate adipose mass and differentiation as decreased autophagy in adipocytes was reported to result in conversion of white adipocytes to brown adipocytes. ${ }^{44}$ Autophagy deficiency in adipose tissue was found to be protective against HFC-induced obesity in mice and resulted in increased amount of brown adipose tissue, thereby stimulating weight loss and improving insulin sensitivity. ${ }^{44}$ In line with these studies, recent data show that autophagy in adipocytes of obese individuals is enhanced. ${ }^{45}$

Several other studies exploring the role of autophagy indicate that macrophage autophagy is protective against inflammation. ${ }^{46-48}$ Recently, different groups shed light on the role of autophagy during atherosclerosis. Increased apoptosis and oxidative stress in lesional macrophages, more plaque necrosis and worsened lesional efferocytosis was found in hyperlipidemic mice deficient for autophagy after an highfat diet, indicating a protective role of autophagy in advanced atherosclerosis. ${ }^{46}$ Additionally, Razani et al. showed that autophagy becomes dysfunctional upon plaque progression in $\mathrm{ApoE}^{-/-}$mice during atherogenesis. These data indicate a protective role for macrophage autophagy during atherogenesis.

As for the liver, dysfunctional autophagy due to lysosomal cholesterol accumulation may play an important role during the development of NAFLD and NASH. Recently, the involvement of autophagy during hepatocyte lipid metabolism was 
demonstrated. ${ }^{41}$ Lipid droplets and autophagic components were shown to be associated during nutrient deprivation and inhibition of autophagy in cultured hepatocytes and mouse liver increased triglyceride storage in lipid droplets, indicating an essential function for autophagy in hepatic lipid stores. ${ }^{41}$ Besides the regulation of lipid content by autophagy, it was found that autophagic activity is highly dependent on nutritional status. Whereas autophagy levels are elevated upon starvation and short-term exposure to high lipid levels, chronic lipid exposure was found to be correlated with impaired autophagy. Both in genetic (ob/ob) and dietary (high-fat induced) mice models having long term lipid availability resulted in inhibition of hepatic autophagy. ${ }^{49}$ Mice upon HFC diet were found to have impaired hepatic autophagic function as demonstrated by decreased mobilization of lipid into the autophagic compartment. Thus, besides that dysfunctional autophagy may promote hepatic steatosis, excessive lipid accumulation in hepatocytes may be a mechanism leading to decreased autophagic function. The ability of excessive lysosomal lipid accumulation to impair autophagy provides another mechanism for the progression of simple steatosis to NASH and its complications.

Taken together, these data indicate that dysfunctional autophagy due to lysosomal cholesterol accumulation is involved in triggering inflammation in different organs during obesity-related disorders.

\section{Inflammasome activation}

Other evidence suggests a link between lysosomal cholesterol accumulation, lysosomal damage and the activation of the inflammasome. ${ }^{50-52}$ Inflammasomes are multi-protein complexes that control the activation of caspase-1, which is constitutively expressed in the cytosol in the inactive pro-form. Upon activation by different stimuli, caspase-1 triggers the maturation and release of the proinflammatory cytokines interleukin-1 $\beta$ and interleukin-18 to engage in the innate immune defense (i.e. promoting lymphocyte activation, leukocyte infiltration, and NF-KB activation). ${ }^{52}$ Upon the different known stimuli for inflammasome activation are signals such as cholesterol crystals, metabolic stress and the production of reactive oxygen species (ROS). ${ }^{52,53}$ In macrophages incubated with $\mathrm{CE}$, the accumulation of free cholesterol in lysosomes after phagocytic uptake was found to result in the formation of cholesterol crystals. ${ }^{54}$ Electron microscopy and acid phosphatase cytochemistry of lysosomes in cholesteryl ester-loaded cells confirmed that cholesterol crystal formation occurred within lipid-loaded lysosomes. ${ }^{54}$ On top, cholesterol crystallization was found in association with inflammatory cells. ${ }^{55}$ These data suggest that lysosomal cholesterol accumulation in macrophages is associated with cholesterol crystal formation and may lead to inflammation via subsequent inflammasome activation. Also during cardiovascular disease cholesterol crystallization and inflammasome activation was observed. In atherosclerotic lesions, cholesterol crystals are formed in 
macrophages and were shown to induce phagolysosomal membrane rupture, leading to the release of the phagolysosomal content into the cytosol. ${ }^{51}$ In addition, phagolysosomal damage caused by cholesterol crystals, both in vitro and in vivo, activates the NLRP3 inflammasome, indicating a potential mechanism of inflammation in the vascular wall. ${ }^{51,56}$ The involvement of inflammasome activation in atherosclerosis has been further described in numerous studies. ${ }^{47,51,57,58}$ Although in one study no difference was found between the inflammasome deficient and wildtype controls in the field of atherosclerosis, ${ }^{59}$ other studies using specific knockout models for different parts of the inflammasome (NLRP3, Caspase-1, ASC) showed that inflammasome activation is involved in sustaining the inflammatory response during atherosclerosis. ${ }^{47,51,57,58}$ Bone-marrow transplantation with NLRP3-deficient and ASC (also known as PYCARD)-deficient bone marrow into $\mathrm{Ldlr}^{-/}$mice resulted in markedly decreased early atherosclerosis after receiving a high-cholesterol diet, indicating that macrophage specific inflammasome activation plays an important role during atherosclerosis. ${ }^{51}$ In line with these observations from in vivo studies, it was recently found that in aortas of patients with coronary atherosclerosis, NLRP3 was overexpressed. Moreover, the aortic NLRP3 expression is correlated with the severity of coronary artery disease and the atherosclerotic risk factors, further indicating the importance of inflammasome activation due to lysosomal cholesterol accumulation during cardiovascular disease. ${ }^{60}$

Cholesterol crystals were also found in the livers of $\mathrm{Ldll}^{-/}$mice upon HFC feeding. ${ }^{1}$ These findings suggest that also during $\mathrm{NASH}$, inflammasome activation may play an important role in triggering the observed inflammatory response. Previously, using Caspase $-1^{-1}$ mice the role of inflammasomes during the development of NASH was investigated. $^{61,62}$ Caspase-1 deficiency resulted in protection from diet-induced hepatic steatosis, inflammation and early fibrogenesis. Furthermore, $1 L 16^{-/-}$mice had less steatohepatitis and fibrosis compared to controls upon HFC feeding, indicating the involvement of inflammasome-mediated IL1 $\beta$ signaling. Interestingly, also in patients suffering from NASH cholesterol crystals were recently found to be present in the liver, whereas in patients with simple steatosis this was not the case. ${ }^{63}$ This further indicates the association between cholesterol crystal formation, potentially due to lysosomal cholesterol accumulation, and inflammation, suggesting that inflammasome activation may also be involved in human NASH.

\section{Lysosomal cathepsin release}

Cathepsins, named after the Greek kathepsein (to digest), were discovered in the second half of the $20^{\text {th }}$ century as part of the lysosomal cysteine proteases. Initially, they were shown to localize in lysosomes and endosomes and to function there to degrade internalized content and to be involved in the clearance of misfolded proteins. Further, cathepsins are known to be optimally active in a slightly acidic 
environment and are mostly unstable at neutral $\mathrm{pH}$. However, recent discoveries have found that cathepsins can be secreted and exert different functions in the extracellular spaces. Importantly, cathepsins were shown to play an important role in apoptosis, antigen presentation in the immune system, collagen turnover in bone and cartilage and hormone processing (reviewed elsewhere) ${ }^{64}$ and to be involved in several inflammatory diseases including obesity ${ }^{65,66}$ and atherosclerosis. ${ }^{67}$

Relevantly, lysosomal cholesterol accumulation may induce leakage of cathepsins out of the lysosomes. First, cathepsins may be released into the cytosol due to increased lysosomal membrane permeability. Indeed, oxLDL uptake in human macrophages was found to immediately damage the lysosomal membrane, leading to the release and relocation of acidic lysosomal enzymes as indicated by increased cytosolic activity of cathepsin $L$ and relocation of cathepsin $D$ to the cytoplasm. ${ }^{28}$ Cytosolic cathepsins were found to be involved in apoptosis and, in contrast to caspases, are already active when released from the lysosome. ${ }^{68-70}$ Therefore, relocation of cathepsins into the cytosol, where they may act as cleavage enzymes for apoptosis, may contribute to the development of the necrotic core and therefore may be considered an atherosclerosis-stimulating factor. ${ }^{71}$ Next to that, cytosolic cathepsins are able to activate inflammasomes, thereby potentially leading to inflammation. ${ }^{56}$

In addition, lysosomal cholesterol accumulation can lead to inhibition of trafficking of lysosomes along the plasma membrane, thereby potentially increasing the secretion of lysosomal enzymes into the circulation. ${ }^{72}$ Extracellularly, cathepsins were shown to play an import role in remodeling of the extracellular matrix (ECM). ${ }^{73}$ The ECM consists of elastins, collagens and proteoglycans, which all are known as substrates for cathepsins. $^{73}$ Relevantly, it was shown that inflammatory cytokines, augment cathepsin expression and activity resulting in extracellular matrix proteolysis. ${ }^{67,74}$ By degrading the ECM, cathepsins may be involved in different pathologies as this may facilitate the migration and invasion of macrophages. Taken together, these data indicate that lysosomal cholesterol trapping can lead to inflammation via intracellular or extracellular release of cathepsins.

Many studies have described that cathepsins play a role during atherosclerosis (reviewed elsewhere). ${ }^{75}$ While normal arteries express little or no cathepsins, in atherosclerotic vessels these proteins are abundantly expressed and secreted. More specific, it was shown that cathepsin $\mathrm{S}$ and $\mathrm{K}$ mRNAs and proteins were present in much higher levels in atherosclerotic lesions than in normal arteries. ${ }^{67} \mathrm{~A}$ similar increase in expression of lysosomal cathepsins $S, L$ and $B$ was found in atherosclerotic lesions in Apo E-deficient mice. Cathepsin protein expression was localized in macrophages and/or in lipid-rich areas. ${ }^{76}$ Additionally, cathepsins show differential expression in various stages of atherosclerosis, and in vivo studies using knockout mice revealed that deficiency of cathepsin $\mathrm{S}, \mathrm{K}$ or $\mathrm{L}$ reduces diet-induced atherosclerosis. ${ }^{77-79}$ Also in human atherosclerotic lesions it has been reported that several cathepsins, including cathepsins $B, D, L$, and $S$, are expressed in a lesion- 
dependent manner. ${ }^{80}$ These data further indicate that lysosomal cathepsins are involved in atherosclerosis development in humans.

Cathepsin release was also found to play an import role during the development of liver diseases. In a dietary murine model of NAFLD, inactivation of cathepsin B protects against development of hepatic steatosis ${ }^{81}$ and cathepsin B knockout animals were shown to be protected against hepatic injury ${ }^{82}$. Furthermore, cathepsin $B$ is found to be implicated in progression of liver fibrosis ${ }^{83}$ and the release of cathepsin $B$ into the cytoplasm is also observed in human liver specimens with NAFLD and correlates with disease severity ${ }^{81}$. Similarly, we have recently shown that lysosomal cholesterol storage in Kupffer cells of $\mathrm{Ldll}^{-/-}$mice is correlated with increased activity of cathepsin D in the liver ${ }^{1}$. Mechanistically, cathepsin B release into the cytosol may contribute to the progression from NAFLD to NASH by leading to mitochondrial dysfunction and apoptosis. ${ }^{81,82}$ In vitro, it was found that mitochondrial dysfunction occurred several hours after lysosomal permeabilization and cathepsin B redistribution into the cytoplasm. Relevantly, either pharmacological or genetic inhibition of cathepsin B preserved mitochondrial function. Moreover, cathepsin B inactivation protected mitochondria, decreased oxidative stress, and attenuated hepatic injury in vivo. ${ }^{82}$ Taken together, these data indicate that the release of lysosomal cathepsins into the cytoplasm may induce mitochondrial dysfunction, thereby leading to cell death and trigger inflammation. In conclusion, improper functioning of cathepsins may play an important role in conditions involving liver injury such as NASH.

\section{Lysosomal cholesterol accumulation as potential target for therapy}

As different mechanisms were described for the involvement of cholesterol trapping inside lysosomes of macrophages in triggering inflammation, the usage of lysosomal cholesterol accumulation as a potential target for novel therapy options in described disorders is highlighted.

A possible way to elucidate the effect of lysosomal cholesterol accumulation is stimulating the transport of cholesterol from lysosomes into the cytoplasm. However, this is a challenging issue as it was previously shown that lysosomal cholesterol derived from oxLDL is resistant to efflux. ${ }^{84-86}$ Moreover, it was shown that, although acLDL-derived CE is usually efficiently hydrolyzed and cleared, a 3-day pre-incubation of macrophages with oxLDL impaired the subsequent ability of lysosomes to hydrolyze acLDL-derived $\mathrm{CE}^{3}{ }^{3}$ Besides, studies in both arteries and cells in culture suggest that the cholesterol in lysosomes is trapped and cannot be decreased simply by inhibiting further uptake of lipoproteins or by increasing efflux of extra-lysosomal cholesterol stores. ${ }^{84,87,88}$ Thus, to therapeutically target lysosomal cholesterol accumulations, unique new methods must be investigated. 
The intracellular trafficking of cholesterol from the lysosome to the cytoplasm is mainly regulated by the proteins NPC1 and NPC2. Whereas NPC1 is a protein that resides in the membrane of endosomes and lysosomes, NPC2 is present inside lysosomes and binds cholesterol. ${ }^{89}$ A mutation in either of the genes for NPC1 $195 \%$ of cases) and NPC2 (5\% of cases) results in Niemann-Pick disease type C, which is an autosomal recessive, lysosomal lipid storage disease. The organs of humans and mice carrying the $\mathrm{Npc}^{-/}$genotype are characterized by two kinds of pathological alterations. First, there is an elevation of the concentration of unesterified cholesterol in the lysosomes of all cells in the body. Second, this mutation results in inflammation in many tissues like the spleen, liver, and lung. ${ }^{90}$ In $\mathrm{Npc}^{-1}$ mice, the administration of 2-hydroxypropyl- $\beta$-cyclodextrin was shown to overcome the lysosomal transport defect and led cholesterol flow to the cytosolic compartment, thereby reducing lysosomal cholesterol accumulation. ${ }^{90}$ This reduction in lysosomal cholesterol content was associated with reduced sterol synthesis and expression of macrophageassociated inflammatory genes. ${ }^{90}$ These findings were confirmed by others where treatment of NPC1 or NPC2 mutated cells with 2-hydroxypropyl- $\beta$-cyclodextrin resulted in the release of cholesterol stored in lysosomes. ${ }^{91,92}$ Another promising treatment option is the neurosteroid allopregnanolone, as a single dose at postnatal day 7 almost doubled lifespan in $\mathrm{Npc}^{-/-}$mice. ${ }^{93}$ Allopregnanolone was shown to reduce cholesterol accumulation, improve autophagic/lysosomal function and reduce inflammation, ${ }^{94}$ further supporting the use of this drug in diseases characterized by lysosomal cholesterol accumulation such as atherosclerosis and NASH. So far, the usage of allopregnanolone in the treatment of atherosclerosis or NASH has not been investigated. Therefore, it is highly recommended that future studies will determine the effect of allopreganolone in described diseases.

Other mediators of intracellular cholesterol transport are liver $\mathrm{X}$ receptor (LXR) activating oxysterols such as 27 -hydroxycholesterol (27HC). $27 \mathrm{HC}$ is an intermediate in bile acid synthesis and the major oxysterol present in the human circulation. In line with greatly reduced $27 \mathrm{HC}$ production in NPC1-deficient cells, incubation with $27 \mathrm{HC}$ was shown to dramatically reduce lysosomal cholesterol in $\mathrm{NpC1}^{-/}$fibroblasts. ${ }^{95}$ Similarly, injecting $\mathrm{Ldll}^{-/}$mice with $27 \mathrm{HC}$ during or after an HFC diet resulted in reduced lysosomal cholesterol accumulation in Kupffer cells and consequently reduced hepatic inflammation ${ }^{1}$. Recently, also 25 -hydroxycholesterol $(25 \mathrm{HC})$, another oxysterol, was shown to correct the transport defect in NPC1 mutant cells. ${ }^{96}$ These data support the view that oxysterols can prevent and reduce lysosomal cholesterol accumulation in macrophages, thereby reducing the inflammatory response.

Finally, it was recently demonstrated that TG delivered to cultured macrophages as part of TG-rich particles, dramatically reduced lysosomal CE accumulation and improves lysosomal function, possibly by decreasing lysosomal $\mathrm{pH}$ and restoring lysosomal CE hydrolysis. ${ }^{97}$ Interestingly, it was shown that macrophages hydrolyze CE more efficiently when it is introduced into lysosomes of macrophages as a mixed CE and TG particle, compared to CE-containing particles alone. ${ }^{98}$ Knowing that TG-rich 
particles can be taken up by macrophage foam cells, thereby influencing the ability of foam cells to metabolize the overload of lysosomal CE, make these particles an interesting therapeutic option for multiple related disorders. Collectively, these findings are promising since so far lysosomal oxLDL has been shown to be highly resistant to removal. ${ }^{85,86}$

\section{Conclusion}

Recently, more evidence points towards the shared etiology of different obesityrelated diseases such as atherosclerosis and NASH. Whereas the presence of lipidladen macrophages is known to play a major role in these conditions, the exact molecular mechanisms remain unclear. Multiple studies suggest that the presence of lysosomal cholesterol accumulation in macrophages, and not the total amount of intracellular lipids is critical for the observed inflammatory response. So far, several mechanisms were shown to be involved in linking lysosomal cholesterol accumulation and inflammation. Future research should focus on mechanisms stimulating cholesterol transport out of the lysosomes, as increasing evidence is showing the importance of intracellular cholesterol distribution in relation to inflammation, thereby affecting multiple disorders. Although it is still possible that other forms of lipids are also involved, most evidence points towards the oxidized form of LDL as major contributor to lysosomal cholesterol accumulation. Therefore, research should focus on the specific role of oxLDL in triggering inflammation due to lysosomal cholesterol trapping. Besides the stimulation of cholesterol transport out of the lysosomes, future research should focus on potential ways to block the uptake of oxLDL particles specifically in order to prevent accumulation of cholesterol in lysosomes. Furthermore, it should be investigated whether dietary intervention is a valid therapeutic option for reducing lysosomal cholesterol accumulation. Finally, to guarantee a systemic beneficial effect, it is recommended that studies will focus on the crosstalk between the different organs which are affected by lysosomal cholesterol accumulation. 


\section{References}

1. Bieghs V, Hendrikx T, van Gorp PJ, Verheyen F, Guichot YD, Walenbergh SM, Jeurissen ML, Gijbels M, Rensen SS, Bast A, Plat J, Kalhan SC, Koek GH, Leitersdorf E, Hofker MH, Lütjohann D, Shiri-Sverdlov R. The cholesterol derivative 27-hydroxycholesterol reduces steatohepatitis in mice. Gastroenterology. 2013;144:167-78 e1.

2. Bieghs V, Walenbergh SM, Hendrikx T, van Gorp PJ, Verheyen F, Olde Damink SW, Masclee AA, Koek $\mathrm{GH}$, Hofker MH, Binder CJ, Shiri-Sverdlov R. Trapping of oxidized LDL in lysosomes of Kupffer cells is a trigger for hepatic inflammation. Liver Int. 2013;33:1056-61.

3. Jerome WG, Cox BE, Griffin EE, Ullery JC. Lysosomal cholesterol accumulation inhibits subsequent hydrolysis of lipoprotein cholesteryl ester. Microsc Microanal. 2008;14:138-49.

4. Olefsky JM, Glass CK. Macrophages, inflammation, and insulin resistance. Annu Rev Physiol. 2010;72: 219-46.

5. Bhargava $\mathrm{P}$, Lee $\mathrm{CH}$. Role and function of macrophages in the metabolic syndrome. Biochem J. 2012; 442:253-62.

6. Wouters K, van Gorp PJ, Bieghs V, Gijbels MJ, Duimel H, Lütjohann D, Kerksiek A, van Kruchten R, Maeda N, Staels B, van Bilsen M, Shiri-Sverdlov R, Hofker MH. Dietary cholesterol, rather than liver steatosis, leads to hepatic inflammation in hyperlipidemic mouse models of nonalcoholic steatohepatitis. Hepatology. 2008;48:474-86.

7. Gerrity RG. The role of the monocyte in atherogenesis: II. Migration of foam cells from atherosclerotic lesions. Am J Pathol. 1981;103:191-200.

8. Sofer O, Fainaru M, Schafer Z, Goldman R. Regulation of lipoprotein lipase secretion in murine macrophages during foam cell formation in vitro. Effect of triglyceride-rich lipoproteins. Arterioscler Thromb. 1992;12:1458-66.

9. Goldstein JL, Brown MS. The LDL receptor. Arterioscler Thromb Vasc Biol. 2009;29:431-8.

10. Brown MS, Goldstein JL. A proteolytic pathway that controls the cholesterol content of membranes, cells, and blood. Proc Natl Acad Sci U S A. 1999;96:11041-8.

11. Brown MS, Dana SE, Goldstein JL. Cholesterol ester formation in cultured human fibroblasts. Stimulation by oxygenated sterols. J Biol Chem. 1975;250:4025-7.

12. Griffin EE, Ullery JC, Cox BE, Jerome WG. Aggregated LDL and lipid dispersions induce lysosomal cholesteryl ester accumulation in macrophage foam cells. J Lipid Res. 2005;46:2052-60.

13. Jerome WG, Cash C, Webber R, Horton R, Yancey PG. Lysosomal lipid accumulation from oxidized low density lipoprotein is correlated with hypertrophy of the Golgi apparatus and trans-Golgi network. J Lipid Res. 1998;39:1362-71.

14. Kunjathoor VV, Febbraio M, Podrez EA, Moore KJ, Andersson L, Koehn S, Rhee JS, Silverstein R, Hoff $\mathrm{HF}$, Freeman MW. Scavenger receptors class A-I/II and CD36 are the principal receptors responsible for the uptake of modified low density lipoprotein leading to lipid loading in macrophages. $J$ Biol Chem. 2002;277:49982-8.

15. Khoo JC, Miller E, McLoughlin P, Steinberg D. Enhanced macrophage uptake of low density lipoprotein after self-aggregation. Arteriosclerosis. 1988;8:348-58.

16. Couillard C, Ruel G, Archer WR, Pomerleau S, Bergeron J, Couture P, Lamarche B, Bergeron N. Circulating levels of oxidative stress markers and endothelial adhesion molecules in men with abdominal obesity. J Clin Endocrinol Metab. 2005;90:6454-9.

17. Weinbrenner T, Schröder H, Escurriol V, Fito M, Elosua R, Vila J, Marrugat J, Covas MI. Circulating oxidized LDL is associated with increased waist circumference independent of body mass index in men and women. Am J Clin Nutr. 2006;83:30-5; quiz 181-2.

18. Holvoet P, De Keyzer D, Jacobs DR, Jr. Oxidized LDL and the metabolic syndrome. Future Lipidol. 2008; 3:637-49.

19. Shoji T, Nishizawa Y, Fukumoto M, Shimamura K, Kimura J, Kanda H, Emoto M, Kawagishi T, Morii H. Inverse relationship between circulating oxidized low density lipoprotein (oxLDL) and anti-oxLDL antibody levels in healthy subjects. Atherosclerosis. 2000;148:171-7.

20. Holvoet P1, Kritchevsky SB, Tracy RP, Mertens A, Rubin SM, Butler J, Goodpaster B, Harris TB. The metabolic syndrome, circulating oxidized LDL, and risk of myocardial infarction in well-functioning elderly people in the health, aging, and body composition cohort. Diabetes. 2004;53:1068-73. 
21. Holvoet P, Vanhaecke J, Janssens S, Van de Werf F, Collen D. Oxidized LDL and malondialdehydemodified LDL in patients with acute coronary syndromes and stable coronary artery disease. Circulation. 1998;98:1487-94.

22. Lougheed M, Moore ED, Scriven DR, Steinbrecher UP. Uptake of oxidized LDL by macrophages differs from that of acetyl LDL and leads to expansion of an acidic endolysosomal compartment. Arterioscler Thromb Vasc Biol. 1999;19:1881-90.

23. Soccio RE, Breslow JL. Intracellular cholesterol transport. Arterioscler Thromb Vasc Biol. 2004;24: 1150-60.

24. Bieghs V, Verheyen F, van Gorp PJ, Hendrikx T, Wouters K, Lütjohann D, Gijbels MJ, Febbraio M, Binder CJ, Hofker MH, Shiri-Sverdlov R. Internalization of modified lipids by CD36 and SR-A leads to hepatic inflammation and lysosomal cholesterol storage in Kupffer cells. PLoS One. 2012;7:e34378.

25. Du H, Heur M, Witte DP, Ameis D, Grabowski GA. Lysosomal acid lipase deficiency: correction of lipid storage by adenovirus-mediated gene transfer in mice. Hum Gene Ther. 2002;13:1361-72.

26. Du H, Heur M, Duanmu M, Grabowski GA, Hui DY, Witte DP, Mishra J. Lysosomal acid lipase-deficient mice: depletion of white and brown fat, severe hepatosplenomegaly, and shortened life span. J Lipid Res. 2001;42:489-500.

27. Du H, Schiavi S, Wan N, Levine M, Witte DP, Grabowski GA. Reduction of atherosclerotic plaques by lysosomal acid lipase supplementation. Arterioscler Thromb Vasc Biol. 2004;24:147-54.

28. Li W, Yuan XM, Olsson AG, Brunk UT. Uptake of oxidized LDL by macrophages results in partial lysosomal enzyme inactivation and relocation. Arterioscler Thromb Vasc Biol. 1998;18:177-84.

29. Bieghs V, van Gorp PJ, Walenbergh SM, Gijbels MJ, Verheyen F, Buurman WA, Briles DE, Hofker MH, Binder CJ, Shiri-Sverdlov R. Specific immunization strategies against oxidized low-density lipoprotein: a novel way to reduce nonalcoholic steatohepatitis in mice. Hepatology. 2012;56:894-903.

30. Walenbergh SM, Koek GH, Bieghs V, Shiri-Sverdlov R. Non-alcoholic steatohepatitis: the role of oxidized low-density lipoproteins. J Hepatol. 2013;58:801-10.

31. Hoff HF, O'Neil J, Pepin JM, Cole TB. Macrophage uptake of cholesterol-containing particles derived from LDL and isolated from atherosclerotic lesions. Eur Heart J. 1990;11 Suppl E:105-15.

32. Haley NJ, Shio H, Fowler S. Characterization of lipid-laden aortic cells from cholesterol-fed rabbits. I. Resolution of aortic cell populations by metrizamide density gradient centrifugation. Lab Invest. 1977; 37:287-96.

33. Goldfischer S, Schiller B, Wolinsky H. Lipid accumulation in smooth muscle cell lysosomes im primate atherosclerosis. Am J Pathol. 1975;78:497-504.

34. Jerome WG, Lewis JC. Early atherogenesis in White Carneau pigeons. II. Ultrastructural and cytochemical observations. Am J Pathol. 1985;119:210-22.

35. Peters TJ, Muller M, De Duve C. Lysosomes of the arterial wall. I. Isolation and subcellular fractionation of cells from normal rabbit aorta. J Exp Med. 1972;136:1117-39.

36. Bieghs V, Walenbergh SM, Hendrikx T, van Gorp PJ, Verheyen F, Olde Damink SW, Masclee AA, Koek $\mathrm{GH}$, Hofker MH, Binder CJ, Shiri-Sverdlov R. Trapping of oxidized LDL in lysosomes of Kupffer cells is a trigger for hepatic inflammation. Liver Int. 2013;33:1056-61.

37. Choi AM, Ryter SW, Levine B. Autophagy in human health and disease. N Engl J Med. 2013;368: 65162.

38. Settembre C, Fraldi A, Jahreiss L, Spampanato C, Venturi C, Medina D, de Pablo R, Tacchetti C, Rubinsztein DC, Ballabio A. A block of autophagy in lysosomal storage disorders. Hum Mol Genet. 2008;17:119-29.

39. Settembre C, Fraldi A, Rubinsztein DC, Ballabio A. Lysosomal storage diseases as disorders of autophagy. Autophagy. 2008;4:113-4.

40. Raben N, Shea L, Hill V, Plotz P. Monitoring autophagy in lysosomal storage disorders. Methods Enzymol. 2009;453:417-49.

41. Singh R, Kaushik S, Wang Y, Xiang Y, Novak I, Komatsu M, Tanaka K, Cuervo AM, Czaja MJ. Autophagy regulates lipid metabolism. Nature. 2009;458:1131-5.

42. Koga H, Kaushik S, Cuervo AM. Altered lipid content inhibits autophagic vesicular fusion. Faseb J. 2010;24:3052-65.

43. Fraldi A, Annunziata F, Lombardi A, Kaiser HJ, Medina DL, Spampanato C, Fedele AO, Polishchuk R, Sorrentino NC, Simons K, Ballabio A. Lysosomal fusion and SNARE function are impaired by cholesterol accumulation in lysosomal storage disorders. Embo J. 2010; 29: 3607-20. 
44. Singh R, Xiang Y, Wang Y, Baikati K, Cuervo AM, Luu YK, Tang Y, Pessin JE, Schwartz GJ, Czaja MJ. Autophagy regulates adipose mass and differentiation in mice. J Clin Invest. 2009;119:3329-39.

45. Ost A, Svensson K, Ruishalme I, Brännmark C, Franck N, Krook H, Sandström P, Kjolhede P, Strålfors P. Attenuated mTOR signaling and enhanced autophagy in adipocytes from obese patients with type 2 diabetes. Mol Med. 2010;16:235-46.

46. Liao X, Sluimer JC, Wang Y, Subramanian M, Brown K, Pattison JS, Robbins J, Martinez J, Tabas I. Macrophage autophagy plays a protective role in advanced atherosclerosis. Cell Metab. 2012;15: 545-53.

47. Razani B, Feng C, Coleman T, Emanuel R, Wen H, Hwang S, Ting JP, Virgin HW, Kastan MB, Semenkovich CF. Autophagy links inflammasomes to atherosclerotic progression. Cell Metab. 2012;15:534-44.

48. Christian P, Sacco J, Adeli K. Autophagy: Emerging roles in lipid homeostasis and metabolic control. Biochim Biophys Acta. 2013;1831:819-24.

49. Yang L, Li P, Fu S, Calay ES, Hotamisligil GS. Defective hepatic autophagy in obesity promotes ER stress and causes insulin resistance. Cell Metab. 2010;11:467-78.

50. Hornung V, Latz E. Critical functions of priming and lysosomal damage for NLRP3 activation. Eur J Immunol. 2010;40:620-3.

51. Duewell P, Kono H, Rayner KJ, Sirois CM, Vladimer G, Bauernfeind FG, Abela GS, Franchi L, Nuñez G, Schnurr M, Espevik T, Lien E, Fitzgerald KA, Rock KL, Moore KJ, Wright SD, Hornung V, Latz E. NLRP3 inflammasomes are required for atherogenesis and activated by cholesterol crystals. Nature. 2010;464:1357-61.

52. Latz E. The inflammasomes: mechanisms of activation and function. Curr Opin Immunol. 2010;22: 28-33.

53. Zhou R, Yazdi AS, Menu P, Tschopp J. A role for mitochondria in NLRP3 inflammasome activation. Nature. 2011;469:221-5.

54. Tangirala RK, Jerome WG, Jones NL, Small DM, Johnson WJ, Glick JM, Mahlberg FH, Rothblat GH. Formation of cholesterol monohydrate crystals in macrophage-derived foam cells. J Lipid Res. 1994;35:93-104.

55. Nair PN, Sjogren U, Sundqvist G. Cholesterol crystals as an etiological factor in non-resolving chronic inflammation: an experimental study in guinea pigs. Eur J Oral Sci. 1998;106:644-50.

56. Rajamäki K, Lappalainen J, Oörni K, Välimäki E, Matikainen S, Kovanen PT, Eklund KK. Cholesterol crystals activate the NLRP3 inflammasome in human macrophages: a novel link between cholesterol metabolism and inflammation. PLoS One. 2010;5:e11765.

57. Gage J, Hasu M, Thabet M, Whitman SC. Caspase-1 deficiency decreases atherosclerosis in apolipoprotein E-null mice. Can J Cardiol. 2012;28:222-9.

58. Usui F, Shirasuna K, Kimura H, Tatsumi K, Kawashima A, Karasawa T, Hida S, Sagara J, Taniguchi S, Takahashi M. Critical role of caspase-1 in vascular inflammation and development of atherosclerosis in Western diet-fed apolipoprotein E-deficient mice. Biochem Biophys Res Commun. 2012;425:162-8.

59. Menu P, Pellegrin M, Aubert JF, Bouzourene K, Tardivel A, Mazzolai L, Tschopp J. Atherosclerosis in ApoE-deficient mice progresses independently of the NLRP3 inflammasome. Cell Death Dis. 2011;2:e137.

60. Zheng F, Xing S, Gong Z, Xing Q. NLRP3 Inflammasomes Show High Expression in Aorta of Patients with Atherosclerosis. Heart Lung Circ. 2013;22:746-50.

61. Dixon L, Berk M, Thapaliya S, Papouchado BG, Feldstein AE. Caspase-1-mediated regulation of fibrogenesis in diet-induced steatohepatitis. Lab Invest. 2012;92:713-23.

62. Dixon LJ, Flask CA, Papouchado BG, Feldstein AE, Nagy LE. Caspase-1 as a central regulator of high fat diet-induced non-alcoholic steatohepatitis. PLoS One. 2013;8:e56100.

63. Ioannou GN, Haigh WG, Thorning D, Savard C. Hepatic cholesterol crystals and crown-like structures distinguish NASH from simple steatosis. J Lipid Res. 2013;54:1326-34.

64. Conus S, Simon HU. Cathepsins and their involvement in immune responses. Swiss Med Wkly. 2010; 140: w13042.

65. Yang M, Sun J, Zhang T, Liu J, Zhang J, Shi MA, Darakhshan F, Guerre-Millo M, Clement K, Gelb BD, Dolgnov G, Shi GP. Deficiency and inhibition of cathepsin $K$ reduce body weight gain and increase glucose metabolism in mice. Arterioscler Thromb Vasc Biol. 2008;28:2202-8. 
66. Yang M, Zhang Y, Pan J, Sun J, Liu J, Libby P, Sukhova GK, Doria A, Katunuma N, Peroni OD, GuerreMillo M, Kahn BB, Clement K, Shi GP. Cathepsin L activity controls adipogenesis and glucose tolerance. Nat Cell Biol. 2007;9:970-7.

67. Sukhova GK, Shi GP, Simon DI, Chapman HA, Libby P. Expression of the elastolytic cathepsins S and K in human atheroma and regulation of their production in smooth muscle cells. J Clin Invest. 1998; 102:576-83.

68. Appelqvist $\mathrm{H}$, Waster $\mathrm{P}$, Kagedal $\mathrm{K}$, Ollinger $\mathrm{K}$. The lysosome: from waste bag to potential therapeutic target. J Mol Cell Biol. 2013;5:214-26.

69. Chwieralski CE, Welte T, Buhling F. Cathepsin-regulated apoptosis. Apoptosis. 2006;11:143-9.

70. Li W, Yuan XM. Increased expression and translocation of lysosomal cathepsins contribute to macrophage apoptosis in atherogenesis. Ann N Y Acad Sci. 2004;1030:427-33.

71. Droga-Mazovec G, Bojic L, Petelin A, Ivanova S, Romih R, Repnik U, Salvesen GS, Stoka V, Turk V, Turk B. Cysteine cathepsins trigger caspase-dependent cell death through cleavage of bid and antiapoptotic Bcl-2 homologues. J Biol Chem. 2008;283:19140-50.

72. Kornfeld S. Trafficking of lysosomal enzymes in normal and disease states. J Clin Invest. 1986;77:1-6.

73. Porter K, Lin Y, Liton PB. Cathepsin B is up-regulated and mediates extracellular matrix degradation in trabecular meshwork cells following phagocytic challenge. PLoS One. 2013;8:e68668.

74. Liu J, Sukhova GK, Yang JT, Sun J, Ma L, Ren A, Xu WH, Fu H, Dolganov GM, Hu C, Libby P, Shi GP. Cathepsin $\mathrm{L}$ expression and regulation in human abdominal aortic aneurysm, atherosclerosis, and vascular cells. Atherosclerosis. 2006;184:302-11.

75. Lutgens SP, Cleutjens KB, Daemen MJ, Heeneman S. Cathepsin cysteine proteases in cardiovascular disease. Faseb J. 2007;21:3029-41.

76. Jormsjö S, Wuttge DM, Sirsjö A, Whatling C, Hamsten A, Stemme S, Eriksson P. Differential expression of cysteine and aspartic proteases during progression of atherosclerosis in apolipoprotein E-deficient mice. Am J Pathol. 2002;161:939-45.

77. Lutgens $E$, Lutgens SP, Faber BC, Heeneman S, Gijbels MM, de Winther MP, Frederik P, van der Made I, Daugherty A, Sijbers AM, Fisher A, Long CJ, Saftig P, Black D, Daemen MJ, Cleutjens KB. Disruption of the cathepsin $\mathrm{K}$ gene reduces atherosclerosis progression and induces plaque fibrosis but accelerates macrophage foam cell formation. Circulation. 2006;113:98-107.

78. Sukhova GK, Zhang Y, Pan JH, Wada Y, Yamamoto T, Naito M, Kodama T, Tsimikas S, Witztum JL, Lu ML, Sakara Y, Chin MT, Libby P, Shi GP. Deficiency of cathepsin S reduces atherosclerosis in LDL receptor-deficient mice. J Clin Invest. 2003;111:897-906.

79. Kitamoto S, Sukhova GK, Sun J, Yang M, Libby P, Love V, Duramad P, Sun C, Zhang Y, Yang X, Peters C, Shi GP. Cathepsin L deficiency reduces diet-induced atherosclerosis in low-density lipoprotein receptor-knockout mice. Circulation. 2007;115:2065-75.

80. Hakala JK, Oksjoki R, Laine P, Du H, Grabowski GA, Kovanen PT, Pentikäinen MO. Lysosomal enzymes are released from cultured human macrophages, hydrolyze LDL in vitro, and are present extracellularly in human atherosclerotic lesions. Arterioscler Thromb Vasc Biol. 2003;23:1430-6.

81. Feldstein AE, Werneburg NW, Canbay A, Guicciardi ME, Bronk SF, Rydzewski R, Burgart LJ, Gores GJ. Free fatty acids promote hepatic lipotoxicity by stimulating TNF-alpha expression via a lysosomal pathway. Hepatology. 2004;40:185-94.

82. Li Z, Berk M, McIntyre TM, Gores GJ, Feldstein AE. The lysosomal-mitochondrial axis in free fatty acidinduced hepatic lipotoxicity. Hepatology. 2008;47:1495-503.

83. Moles A, Tarrats N, Fernandez-Checa JC, Mari M. Cathepsins B and D drive hepatic stellate cell proliferation and promote their fibrogenic potential. Hepatology. 2009;49:1297-307.

84. Yancey PG, Jerome WG. Lysosomal cholesterol derived from mildly oxidized low density lipoprotein is resistant to efflux. J Lipid Res. 2001;42:317-27.

85. Dhaliwal BS, Steinbrecher UP. Cholesterol delivered to macrophages by oxidized low density lipoprotein is sequestered in lysosomes and fails to efflux normally. $J$ Lipid Res. 2000;41:1658-65.

86. Lougheed M, Zhang HF, Steinbrecher UP. Oxidized low density lipoprotein is resistant to cathepsins and accumulates within macrophages. J Biol Chem. 1991;266:14519-25.

87. Jerome WG, Lewis JC. Early atherogenesis in White Carneau pigeons: effect of a short-term regression diet. Exp Mol Pathol. 1990;53:223-38. 
88. Yancey PG, Miles S, Schwegel J, Jerome WG. Uptake and trafficking of mildly oxidized LDL and acetylated LDL in THP-1 cells does not explain the differences in lysosomal metabolism of these two lipoproteins. Microsc Microanal. 2002;8:81-93.

89. Subramanian K, Balch WE. NPC1/NPC2 function as a tag team duo to mobilize cholesterol. Proc Natl Acad Sci U S A. 2008;105:15223-4.

90. Liu B, Ramirez CM, Miller AM, Repa JJ, Turley SD, Dietschy JM. Cyclodextrin overcomes the transport defect in nearly every organ of NPC1 mice leading to excretion of sequestered cholesterol as bile acid. J Lipid Res. 2010;51:933-44.

91. Abi-Mosleh L, Infante RE, Radhakrishnan A, Goldstein JL, Brown MS. Cyclodextrin overcomes deficient lysosome-to-endoplasmic reticulum transport of cholesterol in Niemann-Pick type C cells. Proc Natl Acad Sci U S A. 2009;106:19316-21.

92. Taylor AM, Liu B, Mari Y, Repa JJ. Cyclodextrin mediates rapid changes in lipid balance in Npc1-/- mice without carrying cholesterol through the bloodstream. J Lipid Res. 2012;53:2331-42.

93. Griffin LD, Gong W, Verot L, Mellon SH. Niemann-Pick type C disease involves disrupted neurosteroidogenesis and responds to allopregnanolone. Nat Med. 2004;10:704-11.

94. Liao G, Cheung S, Galeano J, Ji AX, Qin Q, Bi X. Allopregnanolone treatment delays cholesterol accumulation and reduces autophagic/lysosomal dysfunction and inflammation in Npc1-/- mouse brain. Brain Res. 2009;1270:140-51.

95. Frolov A, Zielinski SE, Crowley JR, Dudley-Rucker N, Schaffer JE, Ory DS. NPC1 and NPC2 regulate cellular cholesterol homeostasis through generation of low density lipoprotein cholesterol-derived oxysterols. J Biol Chem. 2003;278:25517-25.

96. Ohgane K, Karaki F, Dodo K, Hashimoto Y. Discovery of oxysterol-derived pharmacological chaperones for NPC1: implication for the existence of second sterol-binding site. Chem Biol. 2013;20:391-402.

97. Ullery-Ricewick JC, Cox BE, Griffin EE, Jerome WG. Triglyceride alters lysosomal cholesterol ester metabolism in cholesteryl ester-laden macrophage foam cells. J Lipid Res. 2009;50:2014-26.

98. Mahlberg FH, Glick JM, Jerome WG, Rothblat GH. Metabolism of cholesteryl ester lipid droplets in a J774 macrophage foam cell model. Biochim Biophys Acta. 1990;1045:291-8. 


\section{Chapter 3}

\section{Macrophage specific caspase-1/11 deficiency protects against cholesterol crystallization and hepatic inflammation in hyperlipidemic mice}

T Hendrikx, V Bieghs, SMA Walenbergh, PJ van Gorp, F Verheyen, MLJ Jeurissen, MMF Steinbusch, N Vaes, CJ Binder, GH Koek, R Stienstra, MG Netea, MH Hofker,

R Shiri-Sverdlov

PLoS One. 2013;8:e78792 


\section{Abstract}

\section{Background \& Aims}

While non-alcoholic steatohepatitis (NASH) is characterized by hepatic steatosis combined with inflammation, the mechanisms triggering hepatic inflammation are unknown. In $\mathrm{Ldll}^{-/-}$mice, we have previously shown that lysosomal cholesterol accumulation in Kupffer cells (KCs) correlates with hepatic inflammation and cholesterol crystallization. Previously, cholesterol crystals have been shown to induce the activation of inflammasomes. Inflammasomes are protein complexes that induce the processing and release of pro-inflammatory cytokines IL- $1 \mathrm{~b}$ and IL-18 via caspase-1 activation. Whereas caspase-1 activation is independent of caspase-11 in the canonical pathway of inflammasome activation, caspase-11 was found to trigger caspase-1dependent IL-1b and IL-18 in response to non-canonical inflammasome activators. So far, it has not been investigated whether inflammasome activation stimulates the formation of cholesterol crystals. We hypothesized that inflammasome activation in KCs stimulates cholesterol crystallization, thereby leading to hepatic inflammation.

\section{Methods}

$\mathrm{Ldll}^{-/-}$mice were transplanted (tp) with wild-type $(\mathrm{Wt})$ or caspase- $1 / 11^{-/-}(\mathrm{dKO})$ bone marrow and fed either regular chow or a high-fat, high-cholesterol (HFC) diet for 12 weeks. In vitro, bone marrow derived macrophages (BMDM) from Wt or caspase- $1 / 11^{-/-}$mice were incubated with oxLDL for $24 \mathrm{~h}$ and autophagy was assessed.

\section{Results}

In line with our hypothesis, caspase- $1 / 11^{-/}$-tp mice had less severe hepatic inflammation than Wt-tp animals, as evident from liver histology and gene expression analysis in isolated KCs. Mechanistically, KCs from caspase- $1 / 11^{-/-}$-tp mice showed less cholesterol crystals, enhanced cholesterol efflux and increased autophagy. In Wt BMDM, oxLDL incubation led to disturbed autophagy activity whereas BMDM from caspase- $1 / 11^{-1-}$ mice had normal autophagy activity.

\section{Conclusion}

Altogether, these data suggest a vicious cycle whereby disturbed autophagy and decreased cholesterol efflux leads to newly formed cholesterol crystals and thereby maintain hepatic inflammation during NASH by further activating the inflammasome. 


\section{Introduction}

Non-alcoholic fatty liver disease (NAFLD) constitutes a spectrum of liver diseases characterized by hepatic lipid accumulation (steatosis), which when combined with hepatic inflammation is known as non-alcoholic steatohepatitis (NASH). While steatosis itself is generally considered a rather harmless and reversible condition that is present in about two thirds of patients with metabolic syndrome, the presence of inflammation in a fatty liver drives disease progression and allows the disease to develop to more advanced stages - such as fibrosis, cirrhosis or hepatocellular carcinoma - ultimately requiring liver transplantation. ${ }^{1}$ Currently, the mechanisms underlying hepatic inflammation are unknown. Consequently, therapeutic options are poor and non-invasive markers to detect NASH do not exist. It is therefore important to investigate the underlying mechanisms that trigger the hepatic inflammatory response in the progression to NASH.

Previously, in mice lacking the low-density lipoprotein receptor $\left(\operatorname{Ldll}^{--}\right)$, we have shown that hepatic inflammation is initiated by Kupffer cells (KCs), ${ }^{2}$, which scavenge oxidized lipoproteins rich in cholesterol, leading to an accumulation of cholesterol inside the lysosomes of KCs and the formation of cholesterol crystals. ${ }^{3,4}$ Cholesterol crystals have been shown to induce the activation of inflammasomes. ${ }^{5}$ Inflammasomes are large multi-protein complexes that, via caspase-1 activation, trigger the maturation of the pro-inflammatory cytokines interleukin-1b (IL-1b) and interleukin-18 (IL-18), which then engage in innate immune defense and sustain inflammation. ${ }^{6-8}$. Whereas caspase- 1 activation is independent of caspase- 11 in the canonical pathway of inflammasome activation, pro-inflammatory caspase-11 was found to be essential for LPS-induced IL-1b secretition in vivo and trigger caspase-1 dependent IL-1b and IL-18 in response to non-canonical inflammasome activators. ${ }^{10}$ So far, the contribution of hematopoietic inflammasome activation to the formation of cholesterol crystals has not been investigated. We hypothesized that inflammasome activation in KCs stimulates the formation of cholesterol crystals, thereby leading to inflammation in the liver.

To test this hypothesis, we transferred bone marrow cells from donor mice lacking caspase-1 and caspase-11 (dKO) into lethally irradiated hyperlipidemic Ldlr $^{-1 /}$ recipient mice. In line with our hypothesis, when these mice were fed an HFC diet, deletion of caspase-1/11 in KCs resulted in less hepatic inflammation compared to controls, which was independent of the development of hepatic steatosis. Interestingly, lysosomal dysfunction and cholesterol crystallization inside KCs was lower in caspase- $1 / 11^{-/}$-tp mice on HFC diet than in Wt-tp mice. Mechanistically, we show that cholesterol efflux and autophagy are involved in inflammasome induced cholesterol crystallization. Additionally, we strengthen our in vivo findings in vitro, as BMDM from Wt mice had affected autophagic activity whereas caspase- $1 / 11^{-/}$BMDM had normal autophagic 
activity upon oxLDL incubation. These data suggest a vicious cycle whereby disturbed autophagy and decreased cholesterol efflux leads to newly formed cholesterol crystals that further enhance the activation of the inflammasome and thereby maintain hepatic inflammation. Taken together, our data propose that inflammasome activation contributes to the sustained inflammatory response in the liver via the formation of cholesterol crystals. Therefore, inhibiting the inflammatory cascade induced by inflammasome activation in $\mathrm{KCs}$ or abrogating the cholesterol crystallization process by restoring autophagy or cholesterol efflux may be beneficial for the treatment of NASH.

\section{Methods}

\section{Mice, diet and bone marrow transplantation}

Mice were housed under standard conditions and given unlimited access to food and water. Experiments were performed according to Dutch regulations and approved by the Committee for Animal Welfare of Maastricht University. Female 10-12 week old $\mathrm{LdIr}^{-/}$mice were lethally irradiated and transplanted with $\mathrm{Wt}$ or caspase- $1 / 11^{-/}$bone marrow as previously described. ${ }^{2}$ Caspase- $1 / 11^{-/}$mice were a kind gift from Prof. Netea, Department of Medicine, Radboud University Nijmegen Medical Centre and Nijmegen Institute for Infection, Inflammation and Immunity (N4i), Nijmegen, The Netherlands. All mice were backcrossed ten generations to $\mathrm{C} 57 \mathrm{BI} / 6 \mathrm{~J} \mathrm{mice}$, and agematched wild-type $\mathrm{C} 57 \mathrm{BI} / 6 \mathrm{~J}$ mice were used as controls throughout the different experiments. Besides caspase-1, these mice are known to have defective caspase-11, essentially making them doubly deficient in caspase- 1 and caspase- $11 .^{10}$ Efficiency of the bone marrow transplantation was approximately 98\% (data not shown). After 9 weeks of recovery, mice were given either chow or HFC diet for 3 months (Wt-tp chow: $n=11$; HFC: $n=12$; caspase- $1 / 11^{-/}$-tp chow: $n=11$; HFC: $\left.n=14\right)$. The HFC diet contained $21 \%$ milk butter, $0.2 \%$ cholesterol, $46 \%$ carbohydrates and $17 \%$ casein. Collection of blood and tissue specimens, biochemical determination of plasma and liver lipids, liver histology, electron microscopy, Kupffer cell isolation, cathepsin D activity assay, in vitro macrophage culture, western blotting, RNA isolation, cDNA synthesis and qPCR were performed as described previously. ${ }^{2-4,11-13}$

\section{Autophagy analysis}

In electron microscopy pictures autophagy analysis was performed by counting lipid droplets with a double membrane (autophagosomes) in 40 Kupffer cells from each transplanted group and calculating the average autophagosome number per Kupffer cell. In order to score cholesterol crystallization in Kupffer cells, electron microscopy pictures of 30 Kupffer cells from each experimental group were investigated for the 
amount of cholesterol crystals present. Each Kupffer cell was given a score in the range 0 to 5 ; 0 indicates that no cholesterol crystals were present while 5 indicates the highest amount of cholesterol crystals present.

\section{Statistical analysis}

The data were analyzed using Graphpad Prism 4.0.3 (GraphPad Software, Inc., La Jolla, CA, USA). The unpaired t-test was performed for comparing Wt-tp and caspase- $1 / 11^{-/}$ -tp mice for each diet group and for comparing $\mathrm{Wt}$ and caspase- $1 / 11^{-1-}$ BMDM. The data were expressed as the mean and standard error of the mean (SEM) and were considered significantly different at $* p<0.05 ; * * p<0.01 ; * * *<<0.001$.

\section{Results}

\section{Hematopoietic deletion of caspase-1/11 has no effect on plasma and liver lipid levels}

As expected, the levels of triglycerides (TG), total cholesterol (TC) and free fatty acids (FFA) in both plasma and liver were higher after 3 months of HFC feeding than after 3 months of chow diet. However, no differences in plasma lipid concentrations were found between Wt-tp and caspase-1/11 ${ }^{-/-}$-tp mice on HFC diet (Figure 3.1A). In line with these data, HFC feeding resulted in equal levels of steatosis in the two transplanted groups, as indicated by biochemical measurements of lipids in the liver (Figure 3.1B) and oil red $\mathrm{O}$ staining (Figure 3.1C). No difference in weight between the different groups was observed. Taken together, these data demonstrate that hematopoietic inflammasome activation has no effect on lipid concentrations in plasma and liver.

\section{Less hepatic inflammation in caspase- $1 / 11^{-/-}$-tp mice on HFC diet}

To determine the effect of caspase-1 and caspase-11 deletion in KCs on hepatic inflammation during the development of $\mathrm{NASH}$, we performed immunohistochemical analysis using inflammatory markers. Scoring of stained sections for infiltrated macrophages (Mac1) $(p=0.007)$, neutrophils (NIMP) $(p=0.0043)$ and T cells (KT3) $(p=0.0028)$ revealed there to be less hepatic inflammation in caspase- $1 / 11^{-1-}$-tp mice than in Wt-tp mice on HFC diet (Figure 3.2A, B, C). Clustering of inflammatory cells, when present, was also more pronounced in the livers of Wt-tp mice than in those of caspase-1/11 $1^{-1-}$-tp animals (Figure 3.2D). 

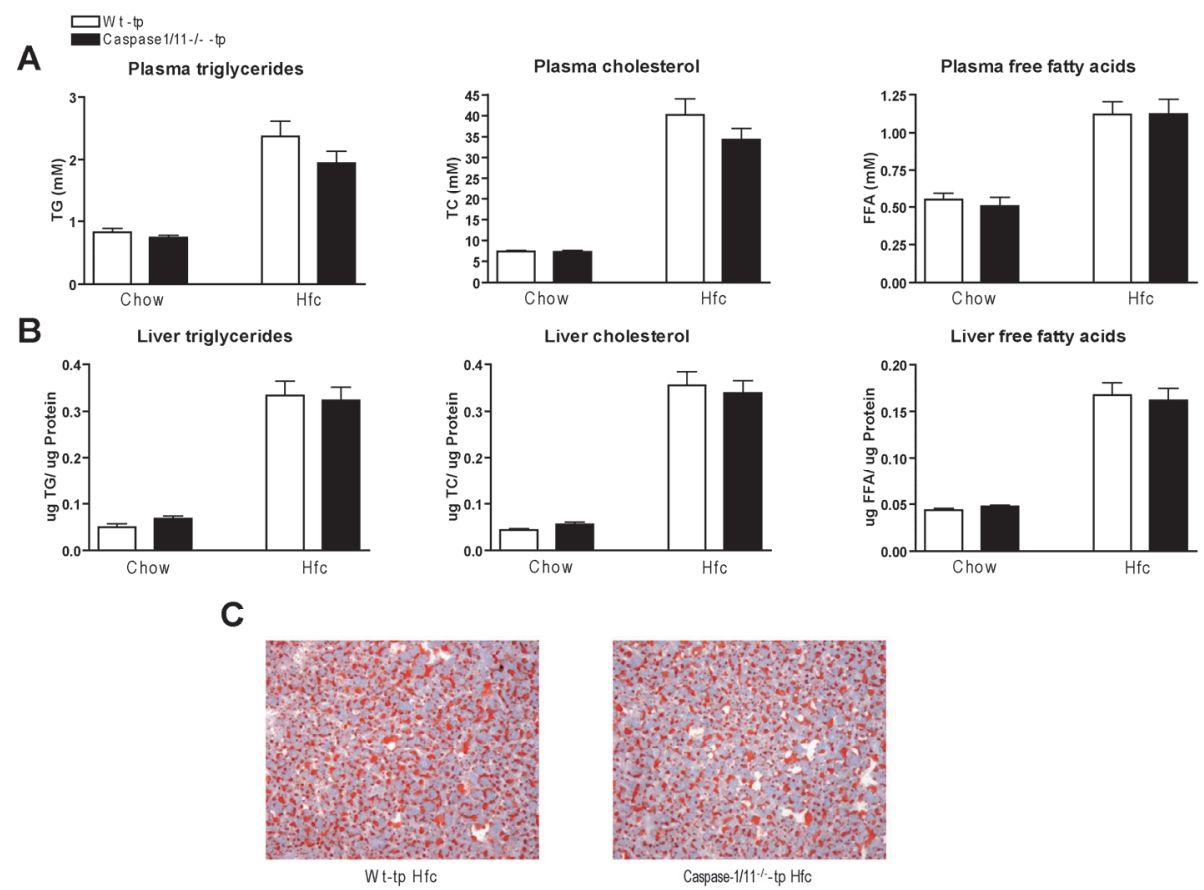

Figure 3.1 Plasma and liver lipid levels. (A) Plasma total triglycerides (TG), total cholesterol (TC) and free fatty acids (FFA) after 3 months on a chow or HFC diet in Wt-tp and caspase-1/11 $1^{--t p}$ mice. (B) Liver TG, TC and FFA after 3 months on chow or HFC diet. (C) Representative images (100x magnification) of the Oil Red O staining of liver sections from Wt-tp and caspase- $1 / 11^{-/-}$-tp mice on HFC for 3 months. Data are represented as mean +/- SEM.

To determine the direct contribution of inflammasome activation in KCs to the inflammatory response in the liver, we analyzed inflammatory gene expression in isolated KCs from both transplanted groups. Isolated KCs from caspase- $1 / 11^{-1-}$-tp mice had lower expression of Tnf- $a(p=0.0421), I L-16(p=0.007), I L 18(p=0.005)$ and $C c / 5$ $(p=0.003)$ than those from Wt-tp mice on HFC diet (Figure 3.2E). These gene expression data support our histological findings and confirm that the milder hepatic inflammation observed in caspase-1/11 $1^{-/}$-tp mice is a result of caspase- 1 and caspase11 deletion, specifically in KCs.

Although fibrosis development was only moderate, scoring of the Sirius Red-stained liver sections revealed collagen content to be lower in the livers of caspase-1/11 $1^{--}$-tp mice than in those of Wt-tp mice ( $p=0.0481$ ) (Figure S3.1A-C). However, hepatic gene expression of the fibrosis-related genes transforming growth factor $\beta$ (Tgf- $\beta$ ) and collagen 1A1 (Col1a1) was not significantly different between the transplanted groups (Figure S1D). No differences in plasma ALT levels were observed between Wt-tp and caspase-1/11 $1^{-/-}$-tp mice (Figure S3.1E). 

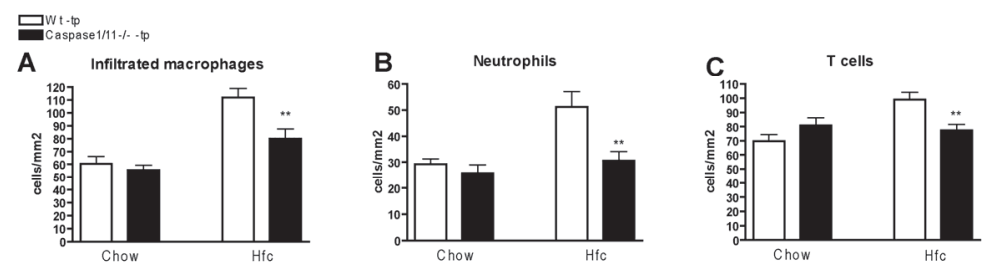

D
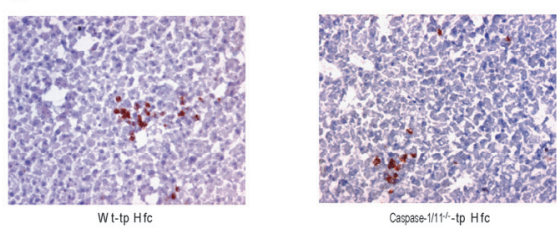

Cospose-1/11\%-to HfC
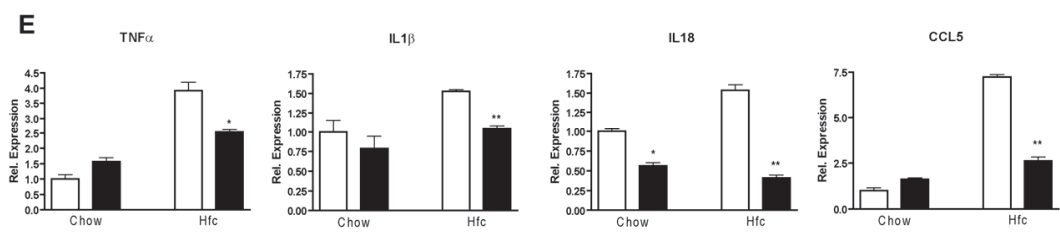

Figure 3.2 Parameters of hepatic inflammation. (A-C) Liver sections were stained for infiltrated macrophages and neutrophils (Mac-1), neutrophils (NIMP) and T cells $\left(\mathrm{CD}^{+}\right) .(D)$ Representative pictures of Mac-1 staining (200x magnification) after 3 months of HFC feeding in Wt-tp and caspase-1/11/-tp mice. (E) Gene expression of pro-inflammatory cytokines tumor necrosis factor alpha (TNF $\alpha$ ), interleukin 1 beta (IL1 $\beta$ ), interleukin 18 (IL18) and chemokine ( $\mathrm{C}-\mathrm{C}$ motif) ligand 5 (CCL5) in isolated $\mathrm{KC}$. Data are represented as mean +/- SEM and were set relative to the Wt-tp group on chow diet. ${ }^{*}$ and ${ }^{* *}$ Significantly different from Wt-tp on HFC diet. ${ }^{*} \mathrm{p}<0.05,{ }^{*} \mathrm{p}<0.01$.

\section{Despite no difference in the foamy appearance of Kupffer cells, caspase-1/11 $1^{-1-}$-tp mice have reduced lysosomal dysfunction and less cholesterol crystallization than Wt-tp mice on HFC}

To determine whether inflammasome activation affects the foamy appearance of KCs, staining of liver sections against CD68, a macrophage marker that stains $\mathrm{KCs}$, was performed. The comparison of CD68 positive cells revealed no difference between Wt-tp and caspase-1/11 $1 /-$ tp animals (Figure 3.3A+B). These data were confirmed by gene expression analysis of $\mathrm{Cd} 68$, which also showed an increase after 3 months of HFC diet and no difference between both transplanted groups upon HFC (Figure 3.3C). Additionally, no difference in steatosis was observed (data not shown). These data suggest that inflammasome activation has no effect on the foamy appearance of KCs. 
A

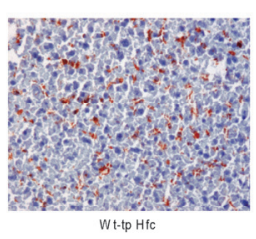

B

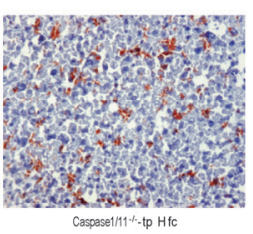

C 믄

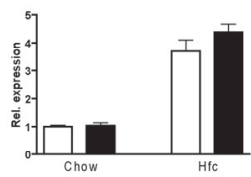

D

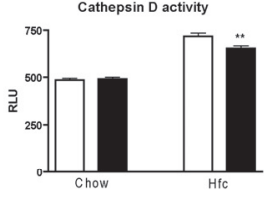

E

$\mathbf{F}$
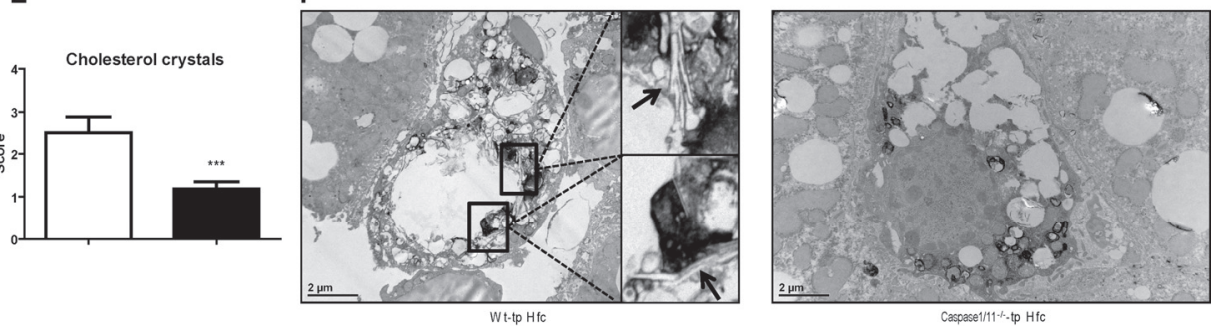

Figure 3.3 Foamy appearance of Kupffer cells, cathepsin D activity and electron microscopy of KCs. $(A, B)$ Representative pictures of CD68 staining (200x magnification) after 3 months of HFC feeding in Wt-tp and caspase-1/11 $1 /$-tp mice, respectively. (C) Gene expression analysis of macrophage and Kupffer cell marker $C d 68$ in liver of Wt-tp and caspase- $1 / 11^{-1-}$-tp mice. (D) Activity of the lysosomal enzyme cathepsin D in livers of Wt-tp and caspase- $1 / 11^{-/}$-tp mice. (E) Scoring for the amount of cholesterol crystallization inside Kupffer cells; 0 indicates that no cholesterol crystals were present while 5 indicates the highest amount of cholesterol crystals present. (F) Representative electron microscopy pictures of KCs from Wt-tp and caspase-1/11 /-tp mice on HFC diet. Lysosomes are indicated in black by acid phosphatase staining and cholesterol crystals are indicated by arrows. Data are represented as mean +/- SEM and were set relative to the Wt-tp group on chow diet. *Significantly different from Wt-tp on HFC diet. $* p<0.05$.

To assess lysosomal dysfunction, the hepatic activity of the lysosomal enzyme cathepsin D was measured. In line with the differences in hepatic inflammation, the livers of caspase- $1 / 11^{-/}$-tp mice had less cathepsin D activity than those of Wt-tp mice on HFC diet (Figure 3.3D) ( $p=0.0042)$. Despite a significant effect, the difference in cathepsin D activity is small and it is not clear whether it is biological relevant. Since lysosomal dysfunction and disturbed lysosomal enzyme activity is associated with the presence of cholesterol crystals, electron microscopy was performed to study any differences in $\mathrm{KC}$ structure and cholesterol crystallization. As demonstrated in Figure 3.3E+F, KCs of caspase- $1 / 11^{-/}$-tp mice on HFC diet had considerably fewer cholesterol crystals than KCs of Wt-tp mice. Scoring electron microscopy pictures from 30 Kupffer cells from each experimental group revealed that caspase- $1 / 11^{-/}$-tp mice had significantly less cholesterol crystals inside their Kupffer cells than Wt-tp mice after 3 months of HFC (Figure 3.3E). These data indicate that inflammasome activation stimulates cholesterol crystallization and is associated with disturbed lysosomal function. 


\section{Caspase-1/11 $1^{-/}$-tp mice have increased cholesterol efflux and restored autophagy compared to Wt-tp mice on HFC}

ATP binding cassette transporter a1 (Abca1) and ATP binding cassette transporter g1 (Abcg1) are two well-known cholesterol transporters responsible for cholesterol efflux. To investigate whether the stimulation of cholesterol crystallization by caspase1 is related to cholesterol efflux, gene expression analysis of Abca1 and Abcg1 in isolated KCs was performed. On both chow and HFC diet, expression of Abca1 $(p=0.0099 ; p=0.0001)$ and Abcg1 ( $p=0.0025 ; p=0.0006)$ was increased in KCs of caspase-1/11 $1 /$-tp mice compared to Wt-tp mice (Figure 3.4A). Interestingly, in KCs of caspase-1/11 $1^{-}$-tp mice on HFC diet, increased expression of Abca1 ( $p=0.0005$ ) and Abcg1 ( $p=0.0009$ ) was found compared to mice on chow diet, whereas HFC diet had no effect in KCs of Wt-tp mice (Figure 3.4A).

A
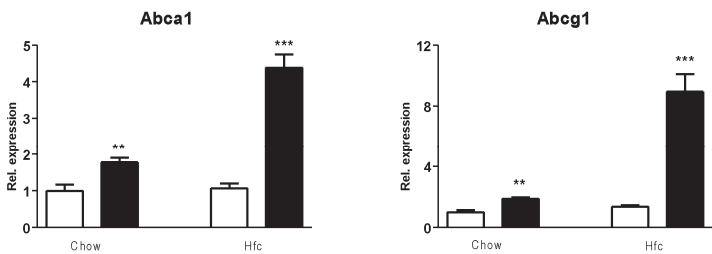

B
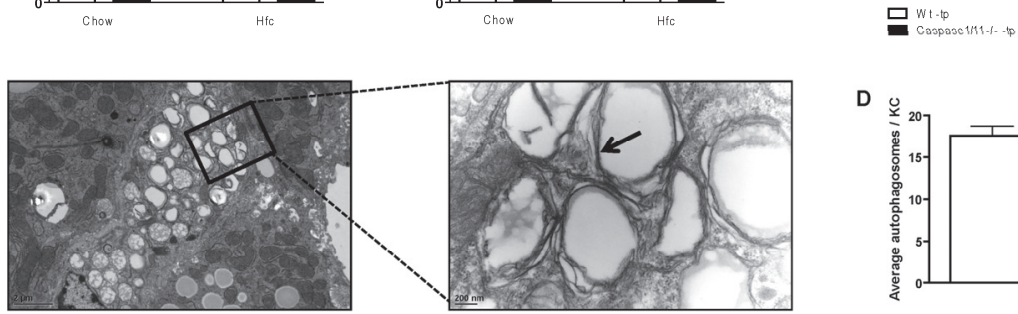

c
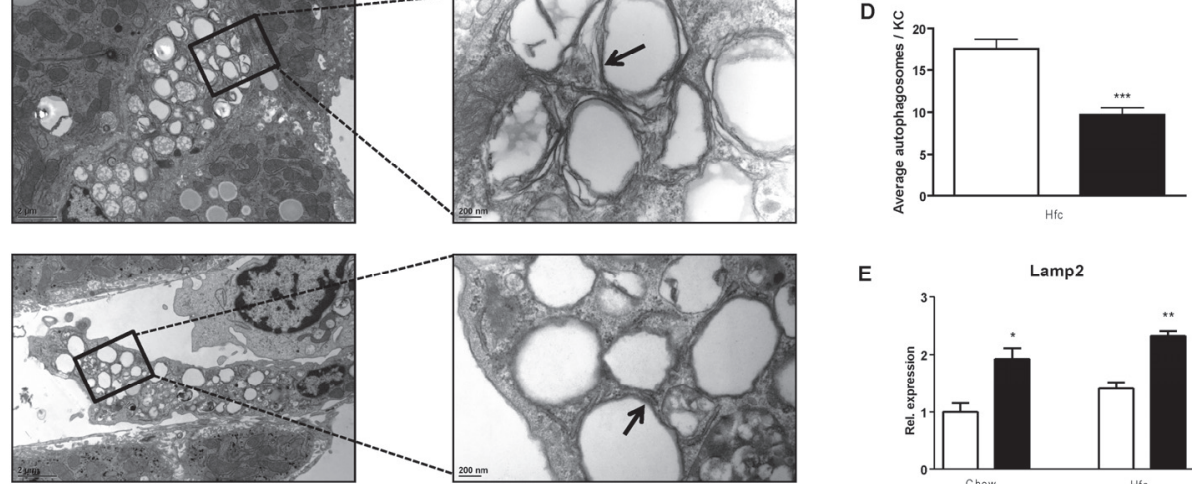

E

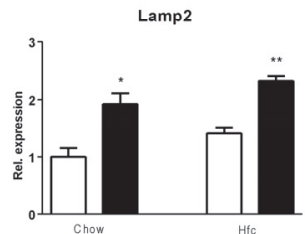

Figure 3.4 Parameters for cholesterol efflux and autophagy. (A) Gene expression analysis of $A B C$ transporter a1 (Abca1) and ABC-transporter g1 (Abcg1) in isolated KCs. $(B, C)$ Representative electron microscopy images of KCs from Wt-tp (B) and caspase- $1 / 11^{-1-}$-tp (C) mice on HFC diet. Double membranes surrounding lipid droplets (autophagosomes) are indicated by arrows. (D) Average autophagosome number per Kupffer cell. (E) Gene expression analysis of lysosomalassociated membrane protein 2 (Lamp2) in isolated KCs. Data are represented as mean +/SEM and were set relative to the Wt-tp group on chow diet. *Significantly different from Wt-tp on HFC diet. ${ }^{* *} \mathrm{p}<0.01,{ }^{* * *} \mathrm{p}<0.001$. 
To investigate whether the decreased cholesterol efflux in KCs of Wt -tp mice is related to disturbed autophagy, electron microscopy was used to quantify the number of lipid-containing autophagosomes present inside $\mathrm{KCs}$ (Figure 3.4B+C). We determined the average amount of autophagosomes per $\mathrm{KC}$ from each transplanted group and found that the higher degree of cholesterol crystallization observed in Wttp mice on HFC diet is accompanied by a higher average autophagosome number per $\mathrm{KC}$ relative to caspase- $1 / 11^{--}$-tp mice on HFC diet (Figure 3.4D) $(p<0.001)$, indicative of abnormal autophagy. Furthermore, expression of Lamp2 in isolated KCs from caspase$1 / 11^{-/}$-tp mice was increased compared to Wt-tp mice, both on chow $(p=0.0181)$ and HFC diet $(p=0.0094)$ (Figure 3.4E). Altogether, these data indicate that increased hepatic inflammation and cholesterol crystallization in Wt-tp mice is associated with disturbed cholesterol efflux and affected autophagic activity in KCs.

To further examine the effect of inflammasome activation on autophagy in macrophages, bone marrow derived macrophages (BMDM) from Wt and caspase$1 / 11^{\%}$ mice were incubated with oxLDL for $24 \mathrm{~h}$. Incubation with oxLDL increased LC3-II levels in macrophages from Wt and caspase-1/11/ mice (Figure 3.5A). After $24 \mathrm{~h}$ oxLDL incubation in Wt macrophages, levels of LC3-II increased to a higher extent than in caspase-1/11 $/$ macrophages (Figure 3.5B), while no difference was observed in levels of p62 (Figure 3.5C), suggesting that although some components of the autophagic process are not affected, the final fusion/degradation step with the lysosome is impaired. These data further strengthen our in vivo findings that inflammasome activation in macrophages is associated with affected autophagic activity.

A

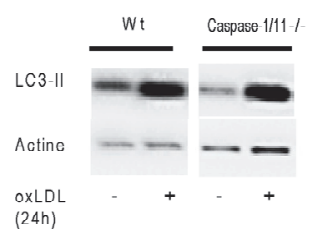

$B \square$ Caspadst-1/11-/

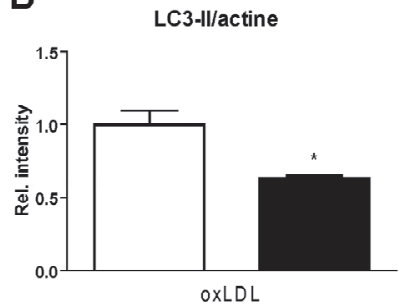

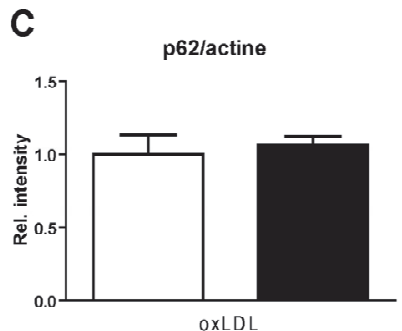

Figure 3.5 Autophagy in $\mathrm{Wt}$ and caspase-1/11 $1^{--}$bone marrow derived macrophages. (A) Western blots of LC3-II in Wt and caspase- $1 / 11^{\%}$ bone marrow derived macrophages (BMDM) with and without oxLDL incubation for 24h. $(B, C)$ Quantification of western blot for LC3-II and p62 levels in BMDM from Wt and caspase-1/11/- mice after oxLDL incubation (24h), corrected for actine levels. Data from three separate experiments are represented as mean +/- SEM and were set relative to Wt BMDM. *Significantly different from Wt BMDM. * $p<0.05$. 


\section{Discussion}

In the present study, we investigated whether inflammasome activation in Kupffer cells stimulates the formation of cholesterol crystals and thereby contributes to the inflammatory response during NASH. Our results indeed indicate for the first time an important role for inflammasome activation in Kupffer cells in stimulating cholesterol crystallization, thereby triggering hepatic inflammation. Our data suggest that insufficient cholesterol efflux and disturbed autophagy are two important mechanisms underlying the formation of inflammasome mediated cholesterol crystals. Inflammasomes thus contribute to a vicious cycle whereby, upon activation, new crystals are formed which then further enhance inflammasome activation.

\section{Inflammasome activation in KCs plays a major role in hepatic inflammation}

Despite much effort, the exact role of inflammasome activation during the development of NASH remains poorly understood. Recent studies describing the role of caspase-1 and caspase 11 during NASH produced conflicting results. On the one hand, when compared with control mice, caspase- $1 / 11^{-/}$mice receiving a methionine and choline-deficient (MCD) diet for 6 weeks were observed to have lower expression levels of genes involved in inflammation and fibrosis ${ }^{14}$ In line with our findings, Dixon et al. also showed that KC depletion by clodronate injection suppressed caspase-1 activation and reduced fibrogenesis, suggesting that $K C s$ are the most important cellular source of active caspase-1 during MCD-induced NASH. ${ }^{14}$ In another recent study from the same group, it was shown that mice deficient for caspase-1 and caspase-11 were protected from high fat-induced steatosis, inflammation and early fibrogenesis. ${ }^{15}$ Conversely, another study showed that the inflammasome negatively regulates NASH progression. Here, caspase-1/11\% mice fed an MCD diet for 4 weeks had higher levels of ALT and AST, as well as more microvesicular and macrovesicular hepatic steatosis, and more hepatic inflammation than their C57BI6 wild-type controls fed the same diet. ${ }^{16}$ Additional evidence came from an experiment in the same study in which bone marrow from $\mathrm{N}_{\mathrm{rpp}} 3^{-/}$or $\mathrm{Asc}^{-/}$mice was transplanted into wild-type mice, from which the authors concluded that ablation of these genes in hematopoietic cells has no effect on hepatic inflammation after MCD feeding. ${ }^{16}$

Although the reason for these contradictive findings is not clear, a difference in gut microbiota or in housing conditions are fitting explanations. For example, gut microbiota are known to undergo changes in obese individuals, as well as in obese mouse models, ${ }^{17}$ and diet is known to influence gut microbiota composition in both animal models and humans. ${ }^{18,19}$ It is therefore reasonable to hypothesize that the contradiction regarding the role of inflammasome activation in hematopoietic cells may be related to the fact that we used an HFC diet while Henao-Mejia et al. used an $M C D$ diet. After all, different dietary regimes can lead to diverse inflammatory effects: 
MCD feeding results in more acute inflammation and severe liver damage, whereas mice fed an HFC diet have more chronic low-grade hepatic inflammation. It is therefore possible that the causes of inflammasome activation depend on the specific type and trigger of inflammation.

Another explanation for the observed differences could be related to the fact that the present study used hyperlipidemic $L d l r^{--}$mice with a human-like lipid profile while the other study used normolipidemic wild-type (C57BI6) mice. The drastic differences between these mice with regard to plasma lipid levels may also affect activation of the inflammasome via the effect on autophagy for example. Increased lipid levels have been shown to repress autophagic function, ${ }^{20}$ thereby possibly enhancing IL-1b secretion as autophagy is able to control IL-1b production. ${ }^{21-23}$

While we have investigated the inflammasome in relation to NASH, others have studied its relation to atherosclerosis. Our current data are in line with most findings regarding the role of inflammasomes in atherosclerosis. ${ }^{24,25}$ Studies have shown that ApoE $E^{-/}$Caspase-1/11/- double deficient mice have fewer signs of atherosclerosis than $A p o E^{-/}$mice, meaning that inflammasome activation is also a key factor in the inflammatory response during atherosclerosis. ${ }^{24,25}$ It is also important to note that, in the same model as used here, $\mathrm{Ld}_{\mathrm{I}} \mathrm{r}^{-/}$mice reconstituted with bone marrow from $\mathrm{N}_{\mathrm{rp} 3} 3^{-\%}$ or $\mathrm{Asc}^{-\%}$ mice had less atherosclerosis after an HFC diet, indicating a reduced inflammatory response during disturbed inflammasome activation and thereby confirming our results, ${ }^{5}$ We suggest that the involvement of inflammasomes in inflammation is influenced by the status of immune responses, as well as by the specific disease models investigated. Our data support the strong involvement of inflammasome activation in hematopoietic cells, especially $\mathrm{KCs}$, in the context of hepatic inflammation. Of note, it is important to keep in mind that in addition to Kupffer cells, other hematopoietic cells are also lacking caspase-1 and caspase-11 in the caspase- $1 / 11^{-/}$-tp mice. These cells secrete myeloid precursors and as such can directly contribute to the reduction in the inflammatory response. ${ }^{26}$ Moreover, KCs can also indirectly influence the phenotype of neighboring hepatocytes and other immune cells via the production of inflammatory cytokines such as TNF and interleukins, and cross-talking with other liver cell types. ${ }^{27}$ Therefore, it is very likely that in addition to Kupffer cells, other liver cells modulate directly and indirectly the hepatic intracellular inflammatory signaling pathway.

\section{Inflammasome activation promotes cholesterol crystallization via reduced cholesterol efflux}

During atherosclerosis, intracellular lipid accumulation in foam cells can result in the formation of cholesterol crystals. ${ }^{28}$ Since atherosclerosis and NASH share similar hallmarks ${ }^{29}$ it is likely that cholesterol is also crystallized inside KCs during NASH development. Indeed, previously we confirmed that cholesterol crystallization in KCs is associated with hepatic inflammation in hyperlipidemic $\mathrm{Ldlr}^{-/-}$mice fed an HFC 
diet. $^{30}$ Additionally, it was recently shown that also human NASH patients have cholesterol crystallization and the formation of "crown-like" structures in activated KCs. In this way they were able to distinguish NASH from simple steatosis, as in these patients cholesterol crystals were not formed. ${ }^{31}$ Others have shown that crystalline structures activate the inflammasome by causing lysosomal damage ${ }^{32,33}$ and that cholesterol crystals can lead to lysosomal rupture and subsequently the release of cathepsin B and the generation of ROS, both described as activators of the inflammasome. ${ }^{34}$ In the current study, we have demonstrated for the first time that inflammasome activation contributes to the promotion of cholesterol crystallization in the liver.

Although the exact mechanisms behind this are not yet clear, we propose that reduced cholesterol efflux and disturbed autophagy, the process by which cytoplasmic components are broken down and recycled, represent an important link between lysosomal cholesterol accumulation, inflammasome activation and cholesterol crystal formation. From literature it is known that reduced cholesterol efflux is associated with foam cell formation, whereas increased cholesterol crystals are found in foamy macrophages. In macrophages, cholesterol efflux via ABCA1 and ABCG1 prevent the excessive accumulation of lipids, thereby protecting against the formation of atherosclerotic lesions. ${ }^{35}$ Moreover, animal studies show that in transgenic mice disruption of ABCA1 gene induces atherosclerosis, ${ }^{36}$ in which it was shown that cholesterol crystals activate the inflammasome. ${ }^{5}$

\section{Disturbed autophagy as driver for hepatic inflammation}

We propose that autophagy is dysfunctional as indicated by increased levels of both LC3-II and p62 in our Wt macrophages in our in vitro set-up. Due to the fact that LC3-II and $\mathrm{p} 62$ are both degraded in the autolysosome, the lysosomal-dependent turnover of these proteins has emerged as a measure of autophagic flux. ${ }^{37}$ Thus, accumulation of LC3-II and p62 indicates autophagic flux inhibition at any point beyond autophagosome formation, while increased $p 62$ alone indicates reduced autophagy. ${ }^{37}$ Therefore, our novel findings indicate that autophagy activity in KCs is affected upon HFC and may therefore lead to hepatic inflammation in this way. Additionally, it was recently highlighted that cholesterol efflux by lipid-loaden macrophages is dependent on autophagy, as macrophages with impaired autophagy were not able to clear accumulated cholesterol in vivo. Furthermore, autophagy-mediated cholesterol efflux was shown to be primarily Abca1 dependent. ${ }^{38}$ These data can explain our observations regarding reduced cholesterol efflux and abnormal autophagy, as shown by the accumulation of autophagosomes and reduced Lamp2 expression in KCs. Lamp2 deficiency was previously shown to be associated with accumulation of autophagic vacuoles in different tissues such as muscle, heart and liver. ${ }^{39}$ In humans, a mutated Lamp2 gene results in Danon disease, characterized by intracytoplasmic vacuoles containing autophagic material and glycogen in skeletal and cardiac muscle 
cells. $^{40}$ Since autophagy is disturbed in lysosomal storage disorders ${ }^{41}$ and dysfunctional autophagy results in inflammasome activation and increased accumulation of cholesterol crystals ${ }^{42}$, further increases in cholesterol crystallization may result in a vicious cycle of inflammation through further activation of the inflammasome. Such a mechanism might explain the sustained inflammatory response seen in the liver.

A number of other studies provide further evidence that disturbed autophagy may also contribute to hepatic inflammation. Firstly, autophagy has been shown to control IL-1b production by targeting pro-IL-1b for lysosomal degradation and by regulating NLRP3 inflammasome activation. ${ }^{23}$ Secondly, it has been shown to regulate hepatocyte lipid metabolism, a process called lipophagy. ${ }^{20,43}$ Taken together with our current findings this suggests a link between abnormal autophagy, inflammasome activation and cholesterol crystallization during the development of NASH.

In summary, our data demonstrate that inflammasome mediated cholesterol crystallization in $\mathrm{KCS}$ is an important factor during the progression of hepatic inflammation in NASH. Of note, in addition to caspase-1, the mice that we have used are also lacking caspase-11. Caspase-11 was found to be important in non-canonical inflammasome activation, which is mainly involved in inflammation driven by gramnegative bacteria. ${ }^{44}$ As inflammasome activation by cholesterol crystals is known to be caspase- 1 dependent, ${ }^{45}$ it is most likely that caspase- 11 plays a minor role in this process. Nevertheless, as it was shown that caspase- 11 is involved in inflammation and autophagosome autophagosome fusion, ${ }^{44,46}$ we cannot exclude the possibility that caspase-11 is also playing a role in cholesterol crystallization and triggering hepatic inflammation during NASH. More in general, blocking inflammasome activation in KCs can be seen as a potential target for therapy options in obesity related diseases. Future studies should focus on the mechanisms that link autophagy, inflammasomes and cholesterol crystals in relation to the development of hepatic inflammation. 


\section{Supplemental figure}

A

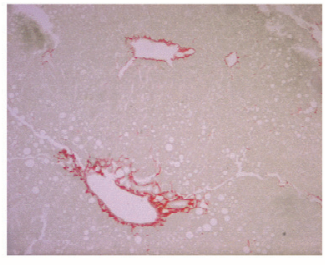

W t-tp Hic

D

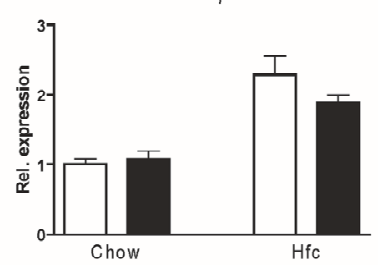

B

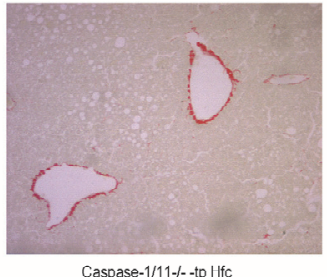

Caspase-1/11-/- -tp Hitc

Col1a1

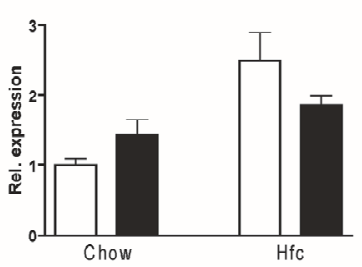

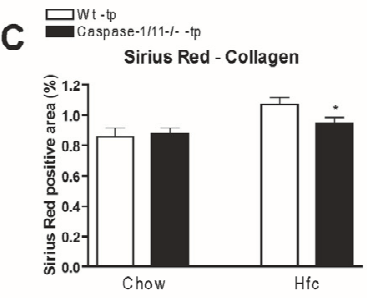

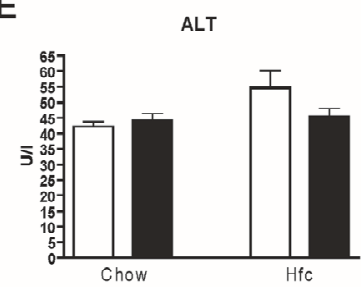

E

Figure S3.1 Parameters of fibrosis. $(A, B)$ Representative images (200x magnification) of Sirius Red positive sections after 3 months of HFC diet in Wt-tp and caspase- $1 / 11^{-1}$-tp mice, respectively. (C) Quantification of the Sirius Red staining. (D) Gene expression analysis of transforming growth factor beta (Tgf- $B)$ and collagen $1 \mathrm{~A} 1$ (Col1a1) in whole liver. (E) ALT measurements in plasma from $\mathrm{Wt}$-tp and caspase-1/11 $1^{-1-}$-tp mice. Data were set relative to the $\mathrm{Wt}$-tp group on chow diet. *Significantly different from Wt-tp on HFC diet. ${ }^{*} p<0.05$. 


\section{References}

1. Farrell GC, van Rooyen D, Gan L, Chitturi S. NASH is an Inflammatory Disorder: Pathogenic, Prognostic and Therapeutic Implications. Gut Liver. 2012;6:149-71.

2. Bieghs V, Wouters K, van Gorp PJ, Gijbels MJ, de Winther MP, Binder CJ, Lütjohann D, Febbraio M, Moore KJ, van Bilsen M, Hofker MH, Shiri-Sverdlov R. Role of scavenger receptor A and CD36 in dietinduced nonalcoholic steatohepatitis in hyperlipidemic mice. Gastroenterology. 2010;138:2477-86, 2486 e1-3.

3. Bieghs V, Verheyen F, van Gorp PJ, Hendrikx T, Wouters K, Lütjohann D, Gijbels MJ, Febbraio M, Binder CJ, Hofker MH, Shiri-Sverdlov R. Internalization of modified lipids by CD36 and SR-A leads to hepatic inflammation and lysosomal cholesterol storage in Kupffer cells. PloS One. 2012;7:e34378.

4. Bieghs V, Hendrikx T, van Gorp PJ, Verheyen F, Guichot YD, Walenbergh SM, Jeurissen ML, Gijbels M, Rensen SS, Bast A, Plat J, Kalhan SC, Koek GH, Leitersdorf E, Hofker MH, Lütjohann D, Shiri-Sverdlov R. The cholesterol derivative 27-hydroxycholesterol reduces steatohepatitis in mice. Gastroenterology. 2013;144:167-78.

5. Duewell P1, Kono H, Rayner KJ, Sirois CM, Vladimer G, Bauernfeind FG, Abela GS, Franchi L, Nuñez G, Schnurr M, Espevik T, Lien E, Fitzgerald KA, Rock KL, Moore KJ, Wright SD, Hornung V, Latz E. NLRP3 inflammasomes are required for atherogenesis and activated by cholesterol crystals. Nature. 2010; 464:1357-61.

6. Lukens JR, Dixit VD, Kanneganti TD. Inflammasome activation in obesity-related inflammatory diseases and autoimmunity. Discov Med. 2011;12:65-74.

7. Martinon F, Burns K, Tschopp J. The inflammasome: a molecular platform triggering activation of inflammatory caspases and processing of prolL-beta. Mol Cell. 2002;10:417-26.

8. Stutz A, Golenbock DT, Latz E. Inflammasomes: too big to miss. J Clin Invest 2009;119:3502-11.

9. Wang S, Miura M, Jung YK, Zhu H, Li E, Yuan J. Murine caspase-11, an ICE-interacting protease, is essential for the activation of ICE. Cell. 1998;92:501-9.

10. Kayagaki N, Warming S, Lamkanfi M, Vande Walle L, Louie S, Dong J, Newton K, Qu Y, Liu J, Heldens S, Zhang J, Lee WP, Roose-Girma M, Dixit VM. Non-canonical inflammasome activation targets caspase11. Nature. 2011;479:117-21.

11. Wouters K, van Gorp PJ, Bieghs V, Gijbels MJ, Duimel H, Lütjohann D, Kerksiek A, van Kruchten R, Maeda N, Staels B, van Bilsen M, Shiri-Sverdlov R, Hofker MH. Dietary cholesterol, rather than liver steatosis, leads to hepatic inflammation in hyperlipidemic mouse models of nonalcoholic steatohepatitis. Hepatology. 2008;48:474-86.

12. Wisse E, Braet F, Duimel H, Vreuls C, Koek G, Olde Damink SW, van den Broek MA, De Geest B, Dejong $\mathrm{CH}$, Tateno C, Frederik P. Fixation methods for electron microscopy of human and other liver. World $\mathrm{J}$ Gastroenterol. 2010;16:2851-66.

13. Jansen HJ, van Essen P, Koenen T, Joosten LA, Netea MG, Tack CJ, Stienstra R. Autophagy activity is up-regulated in adipose tissue of obese individuals and modulates proinflammatory cytokine expression. Endocrinology. 2012;153: 5866-74.

14. Dixon L, Berk M, Thapaliya S, Papouchado BG, Feldstein AE. Caspase-1-mediated regulation of fibrogenesis in diet-induced steatohepatitis. Lab Invest. 2012;92:713-23.

15. Dixon LJ, Flask CA, Papouchado BG, Feldstein AE, Nagy LE. Caspase-1 as a central regulator of high fat diet-induced non-alcoholic steatohepatitis. PLoS One. 2013;8:e56100.

16. Henao-Mejia J, Elinav E, Jin C, Hao L, Mehal WZ, Strowig T, Thaiss CA, Kau AL, Eisenbarth SC, Jurczak MJ, Camporez JP, Shulman GI, Gordon JI, Hoffman HM, Flavell RA. Inflammasome-mediated dysbiosis regulates progression of NAFLD and obesity. Nature. 2012;482:179-85.

17. Musso G, Gambino R, Cassader M. Obesity, diabetes, and gut microbiota: the hygiene hypothesis expanded? Diabetes Care. 2010;33:2277-84.

18. Claesson MJ, Jeffery IB, Conde S, Power SE, O'Connor EM, Cusack S, Harris HM, Coakley M, Lakshminarayanan B, O'Sullivan O, Fitzgerald GF, Deane J, O'Connor M, Harnedy N, O'Connor K, O'Mahony D, van Sinderen D, Wallace M, Brennan L, Stanton C, Marchesi JR, Fitzgerald AP, Shanahan F, Hill C, Ross RP, O'Toole PW. Gut microbiota composition correlates with diet and health in the elderly. Nature. 2012;488:178-84. 
19. Hildebrandt MA, Hoffmann C, Sherrill-Mix SA, Keilbaugh SA, Hamady M, Chen YY, Knight R, Ahima RS, Bushman F, Wu GD. High-fat diet determines the composition of the murine gut microbiome independently of obesity. Gastroenterology. 2009;137:1716-24 e1711-12.

20. Singh R, Kaushik S, Wang Y, Xiang Y, Novak I, Komatsu M, Tanaka K, Cuervo AM, Czaja MJ. Autophagy regulates lipid metabolism. Nature. 2009;458:1131-5.

21. Saitoh T, Fujita N, Jang MH, Uematsu S, Yang BG, Satoh T, Omori H, Noda T, Yamamoto N, Komatsu M, Tanaka K, Kawai T, Tsujimura T, Takeuchi O, Yoshimori T, Akira S. Loss of the autophagy protein Atg16L1 enhances endotoxin-induced IL-1beta production. Nature. 2008;456:264-8.

22. Shi CS, Shenderov K, Huang NN, Kabat J, Abu-Asab M, Fitzgerald KA, Sher A, Kehrl JH. Activation of autophagy by inflammatory signals limits IL-1beta production by targeting ubiquitinated inflammasomes for destruction. Nat Immunol. 2012;13:255-63.

23. Harris J, Hartman M, Roche C, Zeng SG, O'Shea A, Sharp FA, Lambe EM, Creagh EM, Golenbock DT, Tschopp J, Kornfeld H, Fitzgerald KA, Lavelle EC. Autophagy controls IL-1beta secretion by targeting pro-IL-1beta for degradation. J Biol Chem. 2011;286:9587-97.

24. Gage J, Hasu M, Thabet M, Whitman SC. Caspase-1 deficiency decreases atherosclerosis in apolipoprotein E-null mice. Can J Cardiol. 2012;28:222-9.

25. Usui F, Shirasuna K, Kimura H, Tatsumi K, Kawashima A, Karasawa T, Hida S, Sagara J, Taniguchi S, Takahashi M. Critical role of caspase-1 in vascular inflammation and development of atherosclerosis in Western diet-fed apolipoprotein E-deficient mice. Biochem Biophys Res Commun. 2012;425:162-8.

26. Aparicio-Vergara M, Shiri-Sverdlov R, de Haan G, Hofker MH. Bone marrow transplantation in mice as a tool for studying the role of hematopoietic cells in metabolic and cardiovascular diseases. Atherosclerosis. 2010;213:335-44.

27. Racanelli V, Rehermann B. The liver as an immunological organ. Hepatology 2006;43:S54-62.

28. De Nardo D, Latz E. NLRP3 inflammasomes link inflammation and metabolic disease. Trends Immunol. 2011;32: 373-9.

29. Bieghs V, Rensen PC, Hofker MH, Shiri-Sverdlov R. NASH and atherosclerosis are two aspects of a shared disease: central role for macrophages. Atherosclerosis. 2012;220:287-93.

30. Bieghs V, van Gorp PJ, Walenbergh SM, Gijbels MJ, Verheyen F, Buurman WA, Briles DE, Hofker MH, Binder CJ, Shiri-Sverdlov R. Specific immunization strategies against oxidized low-density lipoprotein: A novel way to reduce nonalcoholic steatohepatitis in mice. Hepatology. 2012;56:894-903.

31. Ioannou GN, Haigh WG, Thorning D, Savard C. Hepatic cholesterol crystals and crown-like structures distinguish NASH from simple steatosis. J Lipid Res. 2013;54:1326-34.

32. Halle A, Hornung V, Petzold GC, Stewart CR, Monks BG, Reinheckel T, Fitzgerald KA, Latz E, Moore KJ, Golenbock DT. The NALP3 inflammasome is involved in the innate immune response to amyloid-beta. Nat Immunol. 2008;9:857-65.

33. Hornung V, Bauernfeind F, Halle A, Samstad EO, Kono H, Rock KL, Fitzgerald KA, Latz E. Silica crystals and aluminum salts activate the NALP3 inflammasome through phagosomal destabilization. Nat Immunol. 2008;9:847-56.

34. Tschopp J, Schroder K. NLRP3 inflammasome activation: The convergence of multiple signalling pathways on ROS production? Nat Rev Immunol. 2010;10: 210-15.

35. Cavelier C, Lorenzi I, Rohrer L, von Eckardstein A. Lipid efflux by the ATP-binding cassette transporters ABCA1 and ABCG1. Biochim Biophys Acta. 2006;1761:655-66.

36. Aiello RJ, Brees D, Bourassa PA, Royer L, Lindsey S, Coskran T, Haghpassand M, Francone OL. Increased atherosclerosis in hyperlipidemic mice with inactivation of ABCA1 in macrophages. Arterioscler Thromb Vasc Biol. 2002;22:630-7..

37. Klionsky DJ, Abeliovich H, Agostinis P, Agrawal DK, Aliev G, Askew DS, Baba M, Baehrecke EH, et al.. Guidelines for the use and interpretation of assays for monitoring autophagy in higher eukaryotes. Autophagy. 2008;4:151-75.

38. Ouimet M, Franklin V, Mak E, Liao X, Tabas I, Marcel YL. Autophagy regulates cholesterol efflux from macrophage foam cells via lysosomal acid lipase. Cell Metab. 2010;13:655-67.

39. Eskelinen EL, Illert AL, Tanaka Y, Schwarzmann G, Blanz J, Von Figura K, Saftig P. Role of LAMP-2 in lysosome biogenesis and autophagy. Mol Biol Cell. 2002;13: 3355-68. 
40. Nishino I, Fu J, Tanji K, Yamada T, Shimojo S, Koori T, Mora M, Riggs JE, Oh SJ, Koga Y, Sue CM, Yamamoto A, Murakami N, Shanske S, Byrne E, Bonilla E, Nonaka I, DiMauro S, Hirano M. Primary LAMP-2 deficiency causes $\mathrm{X}$-linked vacuolar cardiomyopathy and myopathy (Danon disease). Nature. 2000;406: 906-10.

41. Settembre C1, Fraldi A, Jahreiss L, Spampanato C, Venturi C, Medina D, de Pablo R, Tacchetti C, Rubinsztein DC, Ballabio A. A block of autophagy in lysosomal storage disorders. Hum Mol Genet. 2008;17:119-29.

42. Razani B1, Feng C, Coleman T, Emanuel R, Wen H, Hwang S, Ting JP, Virgin HW, Kastan MB, Semenkovich CF. Autophagy links inflammasomes to atherosclerotic progression. Cell Metab. 2012;15:534-44.

43. Singh R, Cuervo AM. Lipophagy: connecting autophagy and lipid metabolism. Int J Cell Biol. 2012: 282041.

44. Broz P, Monack DM. Noncanonical inflammasomes: caspase-11 activation and effector mechanisms. PLoS Pathog. 2013;9:e1003144.

45. Rajamäki K1, Lappalainen J, Oörni K, Välimäki E, Matikainen S, Kovanen PT, Eklund KK. Cholesterol crystals activate the NLRP3 inflammasome in human macrophages: a novel link between cholesterol metabolism and inflammation. PloS One. 2010;5:e11765.

46. Akhter A, Caution K, Abu Khweek A, Tazi M, Abdulrahman BA, Abdelaziz DH, Voss OH, Doseff Al, Hassan H, Azad AK, Schlesinger LS, Wewers MD, Gavrilin MA, Amer AO. Caspase-11 promotes the fusion of phagosomes harboring pathogenic bacteria with lysosomes by modulating actin polymerization. Immunity. 2012;37:35-47. 


\section{Chapter 4}

Bone marrow specific caspase-1/11 deficiency inhibits atherosclerosis development in $\mathrm{Ldll}^{-/-}$mice

T Hendrikx, ML Jeurissen, PJ van Gorp, MJ Gijbels, SMA Walenbergh, T Houben, CC Pöttgens, CJ Binder, R Stienstra, MG Netea, MH Hofker, MMPC Donners, $R$ Shiri-Sverdlov

Submitted 


\section{Abstract}

\section{Objective}

Recent investigations suggested that the inflammasome plays an important role during atherosclerosis. Upon activation, the inflammasome induces the processing and release of proinflammatory cytokines IL-1b and IL-18 via activation of caspase-1/11. Previously, it was described that complete caspase-1/11 deficiency is protective against atherosclerosis development. However, while macrophages are the main inflammatory cells involved in atherosclerosis, the exact role of macrophage-specific caspase-1/11 activation during the development of cardiovascular disease has never been investigated. We hypothesized that hematopoietic caspase-1/11 deficiency leads to reduced atherosclerosis development.

\section{Approach and results}

To investigate the specific contribution of hematopoietic caspase-1/11 activation to atherosclerosis development, LdIr/- mice were transplanted (tp) with wild-type (Wt) or caspase- $1 / 11^{-/}$bone marrow and fed a high-fat, high-cholesterol (HFC) diet for 12 weeks. In line with our hypothesis the anti-inflammatory blood leukocyte profile in caspase- $1 / 11^{-/-}$-tp mice was increased compared to Wt-tp mice as indicated by reduced Ly $6 \mathrm{C}^{\text {high }}$ and increased Ly $6 \mathrm{C}^{\text {low }}$ monocytes. Furthermore, hematopoietic deletion of caspase-1/11 resulted in a strong reduction in atherosclerotic plaque size. Finally, necrotic core content was dramatically decreased in caspase- $1 / 11^{-/-}$-tp mice.

\section{Conclusions}

Our data indicate that hematopoietic caspase-1/11 activation plays an important role in atherosclerosis development. 


\section{Introduction}

Currently, atherosclerosis is one of the leading causes of death worldwide. The main characteristic of atherosclerosis is the development of plaques in the vessel wall due to the accumulation of lipid-loaden macrophages (foam cells). Although the exact mechanisms that drive atherosclerosis are complex and still not fully understood, inflammation and cell death are known to play a pivotal role. ${ }^{1}$ Recent studies have indicated the involvement of inflammasomes to the progression of atherosclerosis. ${ }^{2-4}$ Phagocytosis of ox-LDL, the most important risk factor for atherosclerosis, by macrophages was shown to activate the NLRP3 inflammasome. ${ }^{5}$ Furthermore, cholesterol crystals, characteristic for advanced plaques, were found to activate NLRP3 inflammasomes thereby triggering the inflammatory response during atherosclerosis. $^{6}$

Upon activation by different stimuli, the inflammasome induces the processing and release of pro-inflammatory cytokines interleukin 1 beta (IL-1b) and interleukin 18 (IL-18) via caspase-1. Whereas caspase-1 is involved in the canonical pathway of inflammasome activation, caspase- 11 was found to trigger caspase-1 dependent IL-1b and IL-18 in response to non-canonical inflammasome activators. ${ }^{7,8}$ Previously, complete caspase-1 deficiency was described as protective against atherosclerosis development as reduced plaque size was observed in $\mathrm{ApoE}^{-/}$caspase- $1^{-1}$ mice compared to $\mathrm{ApoE}^{-/-}$mice upon Western type diet. ${ }^{9,10}$ However, so far, the specific contribution of hematopoietic specific caspase-1/11 to atherosclerosis development has not been established. We hypothesized that hematopoietic caspase- $1 / 11$ deficiency leads to reduced atherosclerosis development.

To test this hypothesis, bone marrow cells from wild type $(\mathrm{Wt})$ donor mice or mice lacking caspase-1/11 were transferred into lethally irradiated hyperlipidemic $\mathrm{Ldlr}^{-/}$ recipient mice and put on an high fat, high cholesterol (HFC) diet for 12 weeks. In line with our hypothesis, hematopoietic deletion of caspase-1/11 resulted in a substantial reduction in atherosclerotic plaque size. Additionally, caspase- $1 / 11^{-/-}$-tp mice had reduced cell death in the plaque area compared to controls. Our data indicate that hematopoietic caspase-1/11 activation plays an important role in vascular inflammation and atherosclerosis development.

\section{Methods}

\section{Mice, diet and bone marrow transplantation}

Mice were housed under standard conditions and given unlimited access to food and water. Experiments were performed according to Dutch regulations and approved by 
the Committee for Animal Welfare of Maastricht University. Female 10-12 week old $\mathrm{LdIr}^{-/}$mice were lethally irradiated and transplanted with $\mathrm{Wt}$ or caspase- $1 / 11^{-/}$bone marrow as previously described. ${ }^{11}$ Efficiency of the bone marrow transplantation was approximately $98 \%$ (data not shown). After 9 weeks of recovery, mice were given HFC diet for 12 weeks (Wt-tp HFC: $n=12$; caspase- $1 / 11^{-1-}$ tp HFC: $n=14$ ). The HFC diet contained $21 \%$ milk butter, $0.2 \%$ cholesterol, $46 \%$ carbohydrates and $17 \%$ casein. Collection of blood and tissue specimens, biochemical determination of plasma lipids, RNA isolation, cDNA synthesis and qPCR were performed as described previously. ${ }^{11-17}$

\section{Histological analysis and morphological analysis}

For histological analysis, aortic roots of Wt-tp and caspase- $1 / 11^{-1-}$-tp mice were cross sectional cryo-embedded. When the aortic valves were visible, serial sections $(7 \mu \mathrm{m})$ on a series of twenty-four slide was collected. For quantification of atherosclerotic plaque formation four slides were stained with Toluidine Blue for visualization of the atherosclerotic lesions inside the aortic root. To assess plaque size, the total area of the atherosclerotic plaque was determined by quantifying the plaque of each cusp separately. The average of four areas was calculated for each cusp and the sum of all three cusps was defined as total plaque area. As described before, early, moderate and advanced lesions classifications were assessed in atherosclerotic plaques. Monocytes/macrophage and collagen content in atherosclerotic plaques was assessed by immunohistochemistry with MOMA-2 and Sirius red, respectively according to standard protocol.

\section{Fluorescence activated cell sorting}

Via the tail vain, blood was drawn from Wt-tp and caspase- $1 / 11^{-/-}$-tp mice, at week 12 of HFC. All stainings were performed via manufacturer's protocol using Trucount bead (BD Biosciences, Breda, The Netherlands). In short, by using CD16/32 antibody (eBioscience, Halle-Zoersel, Belgium; (1:100)) we blocked the Fc-receptor. We diluted all antibodies in FACS buffer (PBS, 0.1\% BSA, 0.01\% sodiumazide). Anti-coagulated whole blood was added, shaken gently and incubated for $10 \mathrm{~min}$ in the dark at room temperature. Next, TruDifblood-mix was added to the blood, shaken gently and incubated for $20 \mathrm{~min}$ in the dark at room temperature. To lysate the red blood cells, erylysis solution (8.4 gr. NH4CL/0.84 gr. NaHCO solution; 7.2-7.4 pH) was added and incubated for $15 \mathrm{~min}$ in the dark at room temperature. Samples were measured within an hour by FACS (BD FACSCanto II flow cytometer). The following stainings were performed: granulocytes - Lys6G+CD11b+, monocytes - Lys6C-CD11b+ and inflammatory monocytes Lys6C+. 


\section{Efferocytosis assay}

Bone marrow cells were isolated from the bones of the hind limbs of Wt and caspase$1 / 11^{\%}$ mice. Cells were cultured for 8 days in RPMI 1640 cell culture medium supplemented with 10\% FCS, 1\% P/S, 1\% L-Glutamine, 20mM HEPES (RPMI-10) (GIBCO Invitrogen, Breda, the Netherlands) with 20\% LCM (L929-cell conditioned medium which contains M-CSF) to differentiate into bone marrow derived macrophages (BMDM). BMDM of Wt and caspase- $1 / 11^{-1}$ mice were seeded in a 24 wells plate in quadruplo, $0.2 * 10^{6}$ cells/well. Jurkat cells were labelled with Calcein-AM $(1 \mathrm{mg} / \mathrm{ml}$, 1:2000, Invitrogen) and incubated for 1 hour at $37^{\circ} \mathrm{C}$. To induce apoptosis, Jurkat cells were exposed to UV-light (15 $\mathrm{min} 254 \mathrm{~nm}$, UVS-26, 6W bulb $0.02 \mathrm{~J} / \mathrm{s} / \mathrm{cm}^{2}$ ). After a 4 hours recovery period, BMDM of Wt or caspase $-1 / 11^{-/-}$were added to the apoptotic Jurkat cells for $45 \mathrm{~min}$. After washing, the amount of efferocytosis was determined by FACS analysis by measuring the percentage Jurkat labelled positive macrophages.

\section{Statistical analysis}

The data were analyzed using Graphpad Prism 4.0.3 (GraphPad Software, Inc., La Jolla, CA, USA). The unpaired t-test was performed for comparing Wt-tp and caspase- $1 / 11^{-/}$ -tp mice. The data were expressed as the mean and standard error of the mean (SEM) and were considered significantly different at $* p<0.05 ;{ }^{* *} p<0.01 ; * * p<0.001$.

\section{Results}

\section{Increased anti-inflammatory blood leukocyte profile in caspase- $1 / 11^{-/-}$-tp mice compared to Wt-tp mice after 12 weeks of HFC}

To investigate the effect of hematopoietic deletion of caspase-1/11 on atherosclerosis development, bone marrow transplantation (BMT) was performed by injecting wild type (Wt-tp) and caspase- $1 / 11^{-/-}$(caspase-1/11 $1^{-/}$-tp) bone marrow cells into lethally irradiated $\mathrm{Ldlr}^{-/-}$mice and put on high fat, high cholesterol diet (HFC) for 12 weeks. As shown previously, after 12 weeks of HFC no differences were observed in triglycerides $(1.290 \pm 0.1452 \mathrm{mM}$ vs. $1.203 \pm 0.1827 \mathrm{mM})$, free fatty acids (FFA) $(1.099 \pm 0.1208 \mathrm{mM}$ vs. $1.140 \pm 0.06101 \mathrm{mM})$ and cholesterol $(99.57 \pm 13.18 \mathrm{mM}$ vs. $79.53 \pm 10.63 \mathrm{mM})$ in plasma of Wt-tp and caspase1/11/\%-tp mice ${ }^{18}$.

To elucidate the systemic effects of hematopoietic caspase-1/11 deficiency, FACS analysis was performed to characterize blood leukocyte profile of Wt-tp and caspase$1 / 11^{-1}$-tp mice after 12 weeks of HFC. There were no differences seen in numbers of leukocytes between Wt-tp and caspase- $1 / 11^{-/-}$-tp mice (Figure $4.1 \mathrm{~A}$ ). Interestingly, by examining different leukocyte subsets, the population of total monocytes was increased by 1.8 -fold in caspase- $1 / 11^{-/}$-tp mice compared to Wt-tp mice (Figure 4.1B). Monocytes, which are precursors of macrophages, have different monocyte 
subpopulations characterized with different functions. Relevantly, caspase- $1 / 11^{-/}$-tp mice had a reduction of 4.7 -fold in the pro-inflammatory Ly6C ${ }^{\text {high }}$ monocytes subpopulation whereas the Ly6 $\mathrm{C}^{\text {low }}$ subpopulation, known as residentially monocytes, showed a 3-fold increase compared to Wt-tp mice (Figure 4.1C+D). Taken together, these data indicate a reduced systemically inflammatory state in caspase- $1 / 11^{-/-}$-tp mice compared to Wt-tp mice upon HFC.
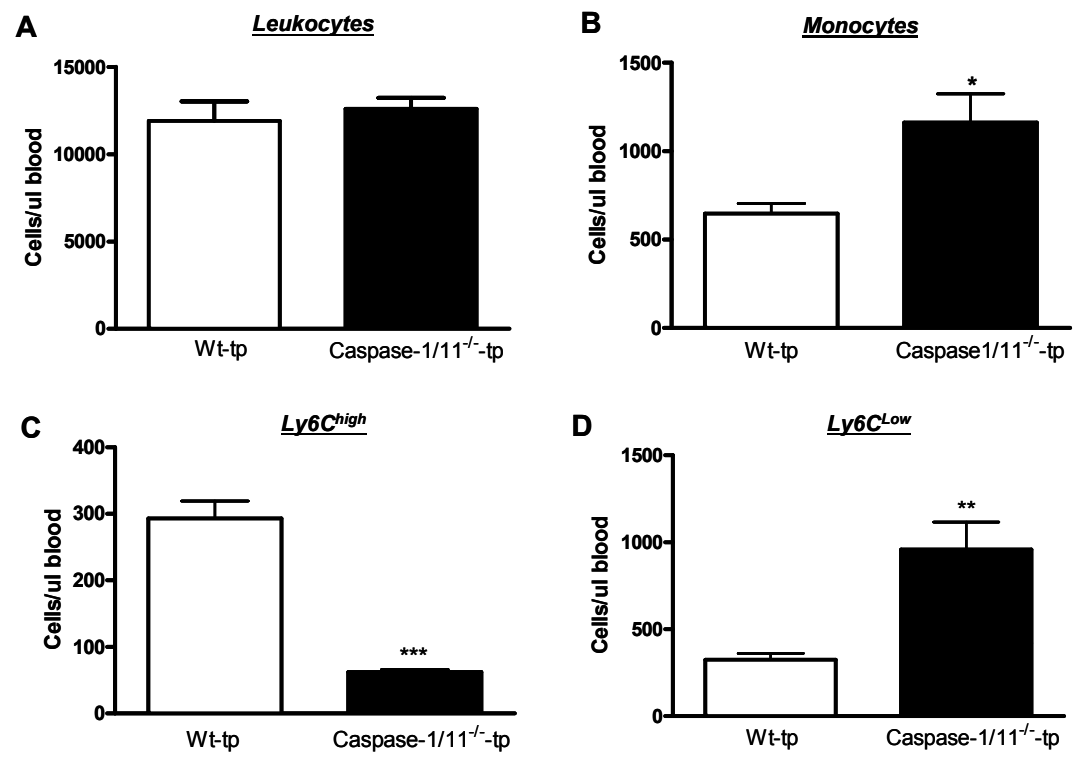

Figure 4.1 Blood leukocyte profile. Blood leukocytes (A) and monocytes (B) population in Wt-tp and caspase-1/11 $11^{--}$tp mice after 3 months on HFC diet. Monocyte subpopulations (C and D) in blood of Wt-tp and caspase-1/11 $1 /$-tp mice on HFC for 3 months. Data are represented as mean +/- SEM. $*, * *$ and $* * *$ Significantly different from Wt-tp. ${ }^{*} p<0.05,{ }^{*} p<0.01$, $* * * \mathrm{p}<0.001$.

\section{Hematopoietic caspase-1/11 deficiency leads to a substantial reduction in atherosclerotic plaque size and effects plaque development}

To examine the effect of hematopoietic caspase-1/11 on atherosclerosis development, histological sections of the aortic root of Wt-tp and caspase- $1 / 11^{-/}$-tp mice were quantified and analyzed. The aortic roots were stained with toluidine blue to determine plaque size (Figure 4.2A+B). Caspase- $1 / 11^{-/}$-tp mice showed a significant reduction of 1.5 -fold in plaque size when compared to Wt-tp mice. In addition, atherosclerotic lesions were classified as early, moderate and advanced lesions. This classification indicated that caspase- $1 / 11^{-/-}$-tp mice had more moderate and less advanced atherosclerotic lesions when compared to Wt-tp mice (Figure 4.2C). Taken 
together, these data indicate that atherosclerotic plaque development is considerably reduced in hematopoietic caspase-1/11 deficient mice.
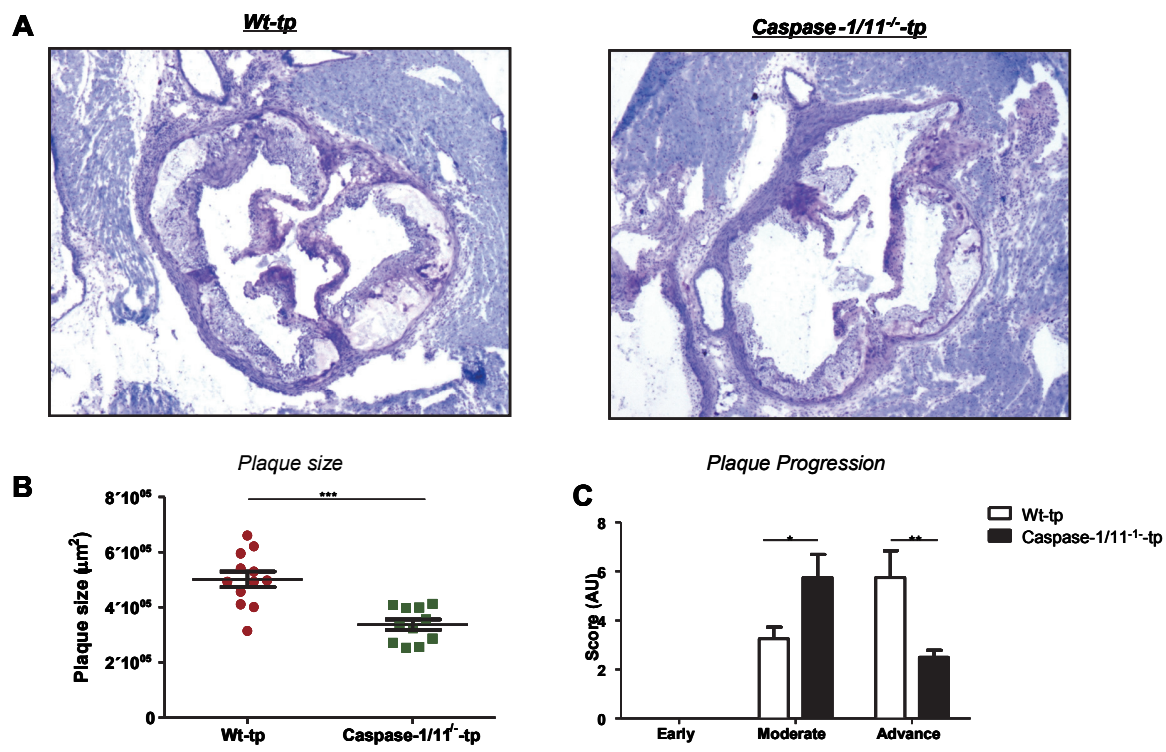

Figure 4.2 Atherosclerotic plaque size. Representative images of toluidine blue staining after 3 months of HFC diet in Wt-tp and caspase-1/11/ -tp mice, respectively $(A)$. Quantification of the total plaque size (B). Classification of atherosclerotic lesions in Wt-tp and caspase- $1 / 11^{-1-}$-tp mice as early, moderate and advanced lesions (C). Data are represented as mean +/- SEM. *, ** and $* * *$ Significantly different from Wt-tp. ${ }^{*} \mathrm{p}<0.05,{ }^{* *} \mathrm{p}<0.01,{ }^{* * *} \mathrm{p}<0.001$. Pictures are taken at 40x magnification.

\section{Reduced necrotic core content in mice with an hematopoietic deletion of caspase1/11}

To determine the effects of hematopoietic deletion of caspase-1/11 on plaque phenotype, (immuno)histological stainings for different aspects of atherosclerosis were performed. Although there were no changes seen in relative amount of monocytes/macrophages (data not shown), a significant reduction in the absolute amount of monocytes/macrophages was observed in caspase- $1 / 11^{-/-}$-tp mice compared to Wt-tp mice (Figure 4.3A). In contrast, there were no changes seen in relative collagen deposition (Sirius Red, Figure 4.3B) and foam cell formation (Figure 4.3C). Interestingly, the relative amount of necrosis (as determined by necrotic core measurement) in the plaque area was significantly reduced by 1.7 -fold in caspase$1 / 11^{/-}$-tp mice compared to Wt-tp mice (Figure $4.3 \mathrm{D}+\mathrm{E}$ ). These data are indicating that hematopoietic deletion of caspase-1/11 can affect plaque composition by lowering necrotic core content. 
A
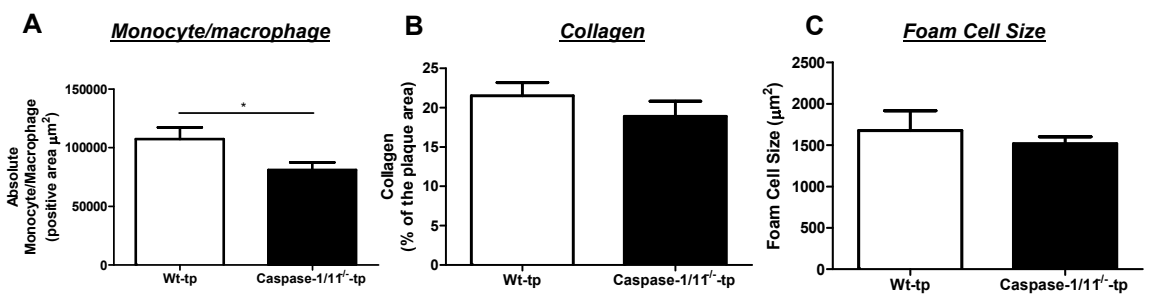

D
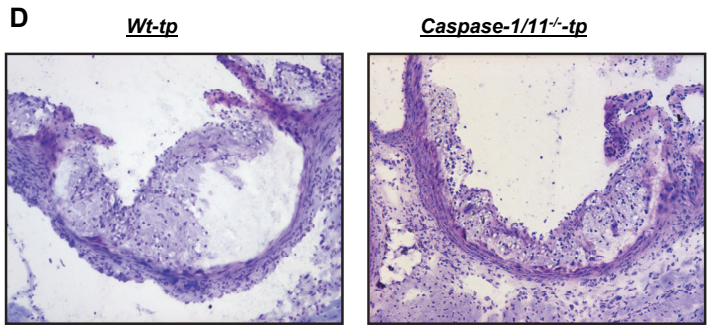

Figure 4.3 Plaque phenotype analysis. Representative figures and quantification of MOMA-2 staining for monocytes/macrophages (absolute) (A), Sirius red staining for collagen deposition $(B)$ and foam cell formation ( $C$ ) and necrosis ( $D$ and $E$ ) after 3 months of HFC feeding in Wt-tp and caspase- $1 / 11^{-/-}$-tp mice, respectively. Data are represented as mean $+/-$SEM. ${ }^{*}, * *$ and $* * *$. Significantly different from Wt-tp. ${ }^{*} \mathrm{p}<0.05,{ }^{*} \mathrm{p}<0.01,{ }^{* *} \mathrm{p}<0.001$. Pictures are taken at $100 \mathrm{x}$ magnification.

\section{Hematopoietic deletion of caspase-1/11 reduces apoptosis}

To elucidate whether hematopoietic deletion of caspase-1/11 can also affect apoptosis, a terminal deoxynucleotidyl transferase dUTP nick end labeling (TUNEL) staining on cryosections of the aortic root of Wt-tp and caspase- $1 / 11^{-1-}$-tp mice was performed. As expected, TUNEL positive staining was significantly reduced by 2.4 -fold in atherosclerotic plaques of caspase- $1 / 11^{-/-}$-tp mice when compared to Wt-tp mice (Figure $4.4 \mathrm{~A}+\mathrm{B}$ ). To investigate whether the reduction of apoptosis in the atherosclerotic plaques was due to an increase in efficiency of clearance of apoptotic cell debris, an efferocytosis assay was performed. The capacity of bone marrow derived macrophages (BMDM) from $\mathrm{Wt}$ and caspase-1/11 $1^{-/}$mice to take up apoptotic cells was analyzed in an in vitro setup. No significant difference in efferocytosis was observed between $\mathrm{Wt}$ and caspase-1/11/- BMDM (Figure 4.4C). These data suggest that cell death is reduced in caspase- $1 / 11^{-/-}$-tp mice while efferocytosis capacity is identical to Wt-tp mice. 
A

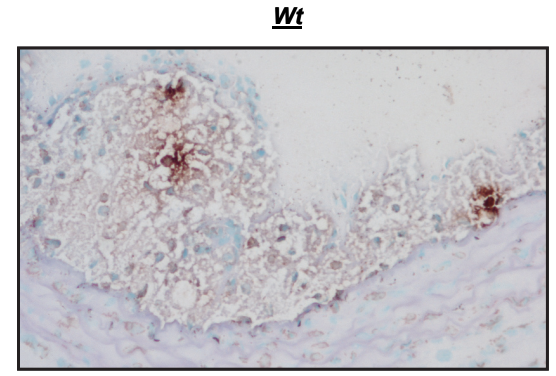

B

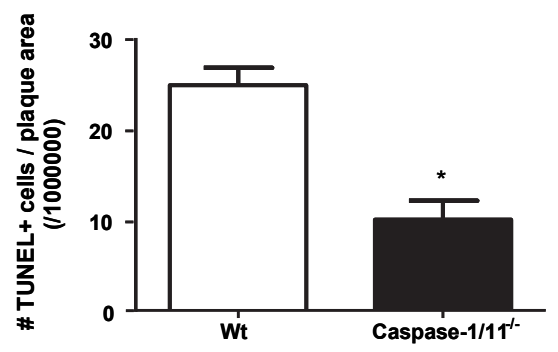

Caspase-1/11/

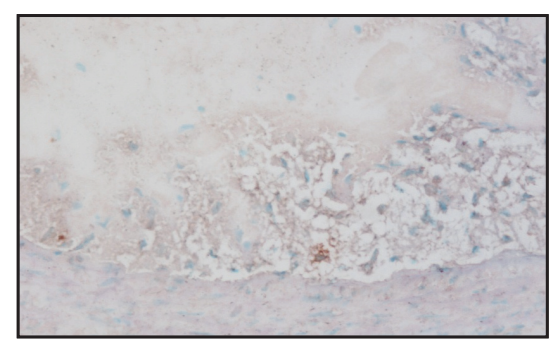

C

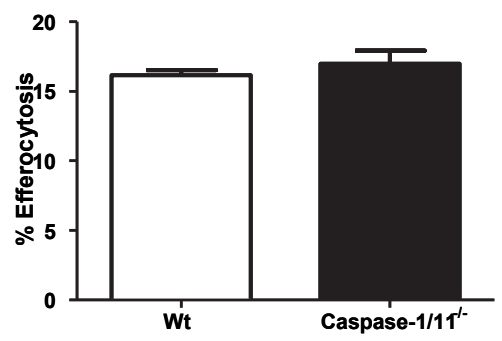

Figure 4.4 TUNEL staining and efferocytosis analysis. (A) Representative pictures of terminal deoxynucleotidyl transferase dUTP nick end labeling (TUNEL) staining after 3 months of HFC feeding in Wt-tp and caspase-1/11/ -tp mice. (B) Quantification of TUNEL staining. (C) In vitro efferocytosis assay of $\mathrm{Wt}$ and caspase- $1 / 11^{-/}$bone marrow-derived macrophages (BMDM). * Significantly different from Wt-tp. ${ }^{*} \mathrm{p}<0.05$. Pictures are taken at $100 x$ magnification.

\section{Discussion}

Atherosclerosis is one of the major risk factors for developing the clinical complications of cardiovascular disease. Our aim was to investigate the role of hematopoietic caspase-1/11 activation during atherosclerosis development. We hypothesized that hematopoietic caspase-1/11 deficiency is protective against vascular inflammation, thereby leading to reduced atherosclerosis. In the current manuscript, we describe for the first time that hematopoietic caspase-1/11 deficiency leads to a substantial reduction in atherosclerotic plaque size and necrotic core formation. Our data point towards the important contribution of the hematopoietic caspase-1/11 in shifting the systemic blood profile to a more pro-inflammatory state and initiating cell death in atherosclerotic lesions.

\section{Hematopoietic caspase-1/11 activation plays a major role in atherosclerosis development}

Previously it was shown that cholesterol crystals, which are present in arterial vessels during atherosclerotic plaques, activate inflammasomes thereby contributing to the 
development of atherosclerosis. ${ }^{19,20}$ Upon activation, inflammasomes trigger the inflammatory response by releasing active IL-1b and IL-18 as a result of caspase- $1 / 11$ activation. Recent studies showed that caspase-1/11 deficiency reduces vascular inflammation and atherosclerosis progression in the $\mathrm{ApoE}^{-/}$model. $^{9,10}$ Using ApoE ${ }^{-/}$ caspase $-1^{-1}$ double knockout mouse models, it was shown that caspase- 1 enhances the inflammatory state of the lesion as reduced numbers of macrophages and vascular smooth muscle cells were found in the plaques compared to $\mathrm{ApoE}^{-/-}$mice. ${ }^{10,22}$ Furthermore, $A p o E^{-1-}$ caspase- $1^{-1-}$ mice had significantly reduced plaques areas compared to controls and lower plasma levels of inflammatory cytokines i.e. IL-1b, CCL2, TNFa. ${ }^{10}$ In contrast, one report using ApoE-deficient mice studying the role of different components of the NLRP3 inflammasome showed that atherosclerosis progresses independently of the NLRP3 inflammasome. ${ }^{22}$ These discrepancies are most likely the consequence of different doses of cholesterol and durations of the atherogenic diet used in these studies. ${ }^{22}$ Strikingly, $L d / r^{-/-}$mice reconstituted with NLRP3, ASC, or IL- $1 \alpha / \beta$-deficient bone marrow have a significant reduction in the progression of atherosclerosis. Hematopoietic compartment-specific deletion of NLRP3 or its adaptor ASC results in a 70\% decrease in the formation of atherosclerotic plaques, with hematopoietic deficiency in both IL-1 $\alpha$ and IL-1 $\beta$ giving similar results. ${ }^{19}$ Interestingly, we observed that hematopoietic caspase-1/11 deficiency had a smaller effect on plaque size reduction. Although the reasons are not known, they may relate to the fact that the NLRP3 inflammasome can regulate IL-1 $\alpha$ secretion under certain conditions and that cholesterol crystals induce both IL- $1 \alpha$ and IL-1 $\beta$. Still, taken together, these data indicate that inflammasome activation and IL-1 secretion from the hematopoietic compartment are the key parameters in the early stages of plaque formation.

Importantly, besides in hematopoietic cells, caspase-1/11 activation in other cells may be involved during the progression of atherosclerosis. Vascular smooth muscle cells and endothelial cells are two other cell types important during atherosclerosis development. Previously it was found that inflammasome activation in endothelial cells leads to increased endothelial dysfunction, leading to increased expression of monocyte attractants, thereby stimulating atherosclerosis development. Moreover, NLRP3 activation was found to be involved in vessel wall calcification, indicating that inflammasome activation in vascular smooth muscle cells may play an important role. Although a clear picture has emerged as to the role of inflammasomes in the hematopoietic compartment in the pathogenesis of atherosclerosis, the role of inflammasome activation in different non-hematopoietic cells during atherosclerotic plaque formation warrants further research. 


\section{Caspase-1-mediated cell death as novel target during atherosclerosis development}

Whereas previous reports studying inflammasome activation during atherosclerosis did not investigate cell death, in the current study, hematopoietic caspase- $1 / 11$ deletion was found to ameliorate apoptosis and necrotic core formation in atherosclerotic lesions. The initial step to necrosis in atherosclerotic plaques is a balanced process between initiation of apoptosis and the clearance of apoptotic cells, also called efferocytosis. An increase in the capacity of efferocytosis could explain the decrease in apoptotic cells. However, despite the reduction in necrosis and apoptotic cells, the capacity of efferocytosis in caspase $1 / 11^{-1}$ BMDM was not affected in vitro. Therefore, these data suggest that other mechanisms may be involved leading to reduced cell death in caspase- $1 / 11^{-/-}$-tp mice.

Recently, pyroptosis was identified to play an important role during atherosclerosis and plaque stability. ${ }^{23,24}$ Pyroptosis is a novel form of cell death that differs from apoptosis by the unique dependency on caspase-1 and by the release of proinflammatory mediators (IL-1b, IL-18) that attract other innate immune cells. Whereas apoptosis is executed by caspase-3, caspase- 1 is not involved in apoptotic cell death and caspase-1-deficient cells respond normally to apoptotic signals. ${ }^{25,26}$ Previous research suggests that not only apoptosis but also pyroptotic cell death may contribute the macrophage death in atherosclerotic lesions and thereby contributing to plaque instability. Evidence shows that dying macrophages within ruptures plaques have high levels of caspase- 1 and little caspase- 3 compared to stable plaques and control tissue. ${ }^{27}$ Furthermore, oxLDL was recently shown to induce caspase-1mediated pyroptosis in macrophages in vitro. ${ }^{24}$ Our data suggest the involvement of macrophage pyroptosis in atherosclerosis progression and further research is needed to address its potential as drug target.

In the present study, for the first time, hematopoietic caspase-1/11 was shown to contribute to atherosclerosis development. Besides the inflammatory status during atherosclerosis development, our data suggest that caspase-1-mediated cell death plays an important role as well. Therefore, caspase-1 may be a promising target for the improvement of future therapy options. 


\section{References}

1. Libby P. Inflammation in atherosclerosis. Arterioscler Thromb Vasc Biol. 2012;32:2045-51.

2. Freigang S, Ampenberger F, Spohn G, Heer S, Shamshiev AT, Kisielow J, Hersberger M, Yamamoto M, Bachmann MF, Kopf M. Nrf2 is essential for cholesterol crystal-induced inflammasome activation and exacerbation of atherosclerosis. Eur J Immunol. 2011;41:2040-51.

3. Hansson GK, Klareskog L. Pulling down the plug on atherosclerosis: Cooling down the inflammasome. Nat Med. 2011;17:790-1.

4. Masters SL, Latz E, O'Neill LA. The inflammasome in atherosclerosis and type 2 diabetes. Sci Transl Med. 2011;3:81ps17.

5. Jiang $Y$, Wang $M$, Huang $K$, Zhang Z, Shao N, Zhang $Y$, Wang W, Wang S. Oxidized low-density lipoprotein induces secretion of interleukin-1beta by macrophages via reactive oxygen speciesdependent nlrp3 inflammasome activation. Biochem Biophys Res Commun. 2012;425:121-6.

6. Duewell $\mathrm{P}$, Kono $\mathrm{H}$, Rayner KJ, Sirois CM, Vladimer G, Bauernfeind FG, Abela GS, Franchi L, Nunez G, Schnurr M, Espevik T, Lien E, Fitzgerald KA, Rock KL, Moore KJ, Wright SD, Hornung V, Latz E. Nlrp3 inflammasomes are required for atherogenesis and activated by cholesterol crystals. Nature. 2010;464:1357-61.

7. Kayagaki N, Warming S, Lamkanfi M, Vande Walle L, Louie S, Dong J, Newton K, Qu Y, Liu J, Heldens S, Zhang J, Lee WP, Roose-Girma M, Dixit VM. Non-canonical inflammasome activation targets caspase11. Nature. 2011;479:117-21.

8. Wang S, Miura M, Jung YK, Zhu H, Li E, Yuan J. Murine caspase-11, an ice-interacting protease, is essential for the activation of ice. Cell. 1998;92:501-9.

9. Gage J, Hasu M, Thabet M, Whitman SC. Caspase-1 deficiency decreases atherosclerosis in apolipoprotein e-null mice. Can J Cardiol. 2012;28:222-9.

10. Usui F, Shirasuna K, Kimura H, Tatsumi K, Kawashima A, Karasawa T, Hida S, Sagara J, Taniguchi S, Takahashi M. Critical role of caspase-1 in vascular inflammation and development of atherosclerosis in western diet-fed apolipoprotein e-deficient mice. Biochem Biophys Res Commun. 2012;425:162-8.

11. Bieghs V, Wouters K, van Gorp PJ, Gijbels MJ, de Winther MP, Binder CJ, Lutjohann D, Febbraio M, Moore KJ, van Bilsen M, Hofker MH, Shiri-Sverdlov R. Role of scavenger receptor a and cd36 in dietinduced nonalcoholic steatohepatitis in hyperlipidemic mice. Gastroenterology. 2010;138:2477-86, 2486 e2471-3.

12. Bieghs V, Verheyen F, van Gorp PJ, Hendrikx T, Wouters K, Lutjohann D, Gijbels MJ, Febbraio M, Binder CJ, Hofker MH, Shiri-Sverdlov R. Internalization of modified lipids by cd36 and sr-a leads to hepatic inflammation and lysosomal cholesterol storage in kupffer cells. PLoS One. 2012;7:e34378.

13. Wouters K, van Gorp PJ, Bieghs V, Gijbels MJ, Duimel H, Lutjohann D, Kerksiek A, van Kruchten R, Maeda N, Staels B, van Bilsen M, Shiri-Sverdlov R, Hofker MH. Dietary cholesterol, rather than liver steatosis, leads to hepatic inflammation in hyperlipidemic mouse models of nonalcoholic steatohepatitis. Hepatology. 2008;48:474-86.

14. Wisse E, Braet F, Duimel H, Vreuls C, Koek G, Olde Damink SW, van den Broek MA, De Geest B, Dejong $\mathrm{CH}$, Tateno C, Frederik P. Fixation methods for electron microscopy of human and other liver. World J Gastroenterol. 2010;16:2851-66.

15. Bieghs V, Hendrikx T, van Gorp PJ, Verheyen F, Guichot YD, Walenbergh SM, Gijbels M, Rensen SS, Bast A, Plat J, Kalhan SC, Leitersdorf E, Hofker M, Lutjohann D, Shiri-Sverdlov R. The cholesterol derivative 27-hydroxycholesterol reduces steatohepatitis in mice. Gastroenterology. 2013;144:16778.e1.

16. Bieghs V, Van Gorp PJ, Wouters K, Hendrikx T, Gijbels MJ, van Bilsen M, Bakker J, Binder CJ, Lutjohann D, Staels B, Hofker MH, Shiri-Sverdlov R. Ldl receptor knock-out mice are a physiological model particularly vulnerable to study the onset of inflammation in non-alcoholic fatty liver disease. PLoS One. 2012;7:e30668.

17. Jansen HJ, van Essen P, Koenen T, Joosten LA, Netea MG, Tack CJ, Stienstra R. Autophagy activity is up-regulated in adipose tissue of obese individuals and modulates proinflammatory cytokine expression. Endocrinology. 2012;153:5866-74. 
18. Hendrikx T, Bieghs V, Walenbergh SM, van Gorp PJ, Verheyen F, Jeurissen ML, Steinbusch MM, Vaes N, Binder CJ, Koek GH, Stienstra R, Netea MG, Hofker MH, Shiri-Sverdlov R. Macrophage specific caspase-1/11 deficiency protects against cholesterol crystallization and hepatic inflammation in hyperlipidemic mice. PLoS One. 2013;8:e78792.

19. Duewell P, Kono H, Rayner KJ, Sirois CM, Vladimer G, Bauernfeind FG, Abela GS, Franchi L, Nunez G, Schnurr M, Espevik T, Lien E, Fitzgerald KA, Rock KL, Moore KJ, Wright SD, Hornung V, Latz E. NIrp3 inflammasomes are required for atherogenesis and activated by cholesterol crystals. Nature. 2010;464:1357-61.

20. Rajamaki K, Lappalainen J, Oorni K, Valimaki E, Matikainen S, Kovanen PT, Eklund KK. Cholesterol crystals activate the nlrp3 inflammasome in human macrophages: A novel link between cholesterol metabolism and inflammation. PLoS One. 2010;5:e11765.

21. Sheedy FJ, Grebe A, Rayner KJ, Kalantari P, Ramkhelawon B, Carpenter SB, Becker CE, Ediriweera HN, Mullick AE, Golenbock DT, Stuart LM, Latz E, Fitzgerald KA, Moore KJ. Cd36 coordinates nlrp3 inflammasome activation by facilitating intracellular nucleation of soluble ligands into particulate ligands in sterile inflammation. Nat Immunol. 2013;14:812-20.

22. Menu P, Pellegrin M, Aubert JF, Bouzourene K, Tardivel A, Mazzolai L, Tschopp J. Atherosclerosis in apoe-deficient mice progresses independently of the nlrp3 inflammasome. Cell Death Dis. 2011;2:e137.

23. Chang W, Lin J, Dong J, Li D. Pyroptosis: An inflammatory cell death implicates in atherosclerosis. Med Hypotheses. 2013;81:484-6.

24. Lin J, Shou X, Mao X, Dong J, Mohabeer N, Kushwaha KK, Wang L, Su Y, Fang H, Li D. Oxidized low density lipoprotein induced caspase-1 mediated pyroptotic cell death in macrophages: Implication in lesion instability? PLoS One. 2013;8:e62148.

25. Fink SL, Cookson BT. Apoptosis, pyroptosis, and necrosis: Mechanistic description of dead and dying eukaryotic cells. Infect Immun. 2005;73:1907-16.

26. Li P, Allen H, Banerjee S, Franklin S, Herzog L, Johnston C, McDowell J, Paskind M, Rodman L, Salfeld J, et al. Mice deficient in il-1 beta-converting enzyme are defective in production of mature il-1 beta and resistant to endotoxic shock. Cell. 1995;80:401-11.

27. Kolodgie FD, Narula J, Burke AP, Haider N, Farb A, Hui-Liang Y, Smialek J, Virmani R. Localization of apoptotic macrophages at the site of plaque rupture in sudden coronary death. Am J Pathol. 2000;157:1259-68.

28. Sagulenko V, Thygesen SJ, Sester DP, Idris A, Cridland JA, Vajjhala PR, Roberts TL, Schroder K, Vince JE, Hill JM, Silke J, Stacey KJ. Aim2 and nlrp3 inflammasomes activate both apoptotic and pyroptotic death pathways via asc. Cell Death Differ. 2013;20:1149-60. 


\section{Chapter 5}

\section{7-Hydroxycholesterol: a potential treatment for non-alcoholic steatohepatitis in mice}

V Bieghs, T Hendrikx, PJ van Gorp, F Verheyen, Y Dias Guichot, SMA Walenbergh, M Gijbels, SS Rensen, A Bast, J Plat, SC Kalhan, E Leitersdorf, M Hofker, D Lütjohann, R Shiri-Sverdlov

Gastroenterology 2013;144:167-178 


\section{Abstract}

\section{Background}

Non-alcoholic steatohepatitis (NASH) is characterized by hepatic steatosis in combination with inflammation. While steatosis itself is considered benign and reversible, the presence of inflammation can lead to further liver damage. We recently demonstrated a clear association between hepatic inflammation and lysosomal cholesterol accumulation inside Kupffer cells (KCs). 27-hydroxycholesterol (27HC), a derivative of cholesterol formed by CYP27A1, has been shown in vitro to mobilize cholesterol from the lysosomes to the cytoplasm. Here, we hypothesized that $27 \mathrm{HC}$ can redirect the intracellular cholesterol distribution in vivo, thereby influencing hepatic inflammation.

\section{Methods}

To investigate the role of CYP27A1 in NASH, irradiated $\mathrm{Ldlr}^{-/-}$mice were transplanted (tp) with Cyp27a1 1 and wild-type $(\mathrm{Wt})$ bone marrow. After 9 weeks recovery, mice were fed either regular chow or a high-fat, high-cholesterol (HFC) diet for 3 months. To examine whether exogenous $27 \mathrm{HC}$ influences intracellular cholesterol distribution and hepatic inflammation, $27 \mathrm{HC}$ was administered subcutaneously to $L d l r^{--}$mice that received regular chow or an HFC diet for 3 weeks.

\section{Results}

Electron microscopy analysis of KCs revealed more lysosomal cholesterol accumulation in Cyp27a1 $1 \%$-tp mice than in Wt-tp mice after HFC feeding. Liver histology and gene expression showed increased inflammation and liver damage in HFC-fed Cyp27a $1^{-1-}$-tp mice. In line with these data, administration of $27 \mathrm{HC}$ to $\mathrm{Ldll}^{--}$mice on an HFC diet led to reduced lysosomal cholesterol accumulation and hepatic inflammation.

\section{Conclusion}

These data support a causal role for lysosomal cholesterol accumulation in hepatic inflammation and underline the potential of using $27 \mathrm{HC}$ as a treatment for $\mathrm{NASH}$. 


\section{Introduction}

Non-alcoholic fatty liver disease (NAFLD) is the hepatic component of metabolic syndrome, a cluster of risk factors that contribute to the development of type 2 diabetes and cardiovascular disease. Non-alcoholic steatohepatitis (NASH) is considered to be the most severe form of NAFLD and is characterized by fat accumulation in the liver (steatosis) and hepatic inflammation. While steatosis itself is generally considered a rather benign and reversible condition, the presence of inflammation in a fatty liver is the key feature of NASH that precedes further disease progression and enables the development of more advanced stages of the disease such as fibrosis, cirrhosis or hepatocellular carcinoma - often leading to the need for liver transplantation. ${ }^{1}$ Knowledge of the intracellular mechanisms that trigger inflammation during NASH is therefore of utmost importance.

Various mechanisms have been proposed for the intracellular triggering of inflammation. In mice lacking the low-density lipoprotein receptor $\left(L d l r^{-/}\right)$, we have previously shown that hematopoietic deletion of the two main scavenger receptors (CD36 and SR-A), which are responsible for the uptake of modified lipoproteins, sets off a cascade of pro-inflammatory events leading to the initiation of the inflammatory response in the liver. ${ }^{2}$ Moreover, the reduced inflammatory response was associated with less lysosomal cholesterol accumulation inside Kupffer cells (KCs). ${ }^{3,4}$ However, a causal link between lysosomal cholesterol accumulation in KCs and hepatic inflammation has not yet been established.

Under normal conditions, lipoproteins circulating in the blood will be endocytosed by macrophages and initially directed to lysosomes, where the lipoproteins are hydrolyzed by lysosomal enzymes and transferred into the cytoplasm. ${ }^{5}$ However, in foamy macrophages of inflamed atherosclerotic plaques, cholesterol is not transferred into the cytoplasm, but rather accumulates in the lysosomes of the macrophages. ${ }^{6}$ Accumulation of cholesterol inside lysosomes is also a key feature of Niemann-Pick disease type C (NPC1), a lipid storage disease resulting from a deletion in the NPC1 gene, which encodes a key protein involved in the translocation of cholesterol from the lysosomes to the cytoplasm. NPC1 deficient cells have a severely reduced production of 27-hydroxycholesterol $(27 \mathrm{HC})$, one of the major oxysterols found in the human circulation, which is produced by the mitochondrial enzyme CYP27A1. Notably, the lysosomal cholesterol pool in NPC1 ${ }^{-1-}$ fibroblasts is dramatically reduced upon incubation with $27 \mathrm{HC}^{7,8}$ Thus, $27 \mathrm{HC}$ has been shown to reduce lysosomal cholesterol accumulation in vitro.

The aim of the current study was to investigate whether the mobilization of cholesterol inside the KCs from the lysosomes to the cytoplasm can reduce hepatic inflammation in vivo. We injected bone marrow cells from $C y p 27 a 1^{-1}$ mice into 
lethally irradiated $L d l r^{-/-}$hyperlipidemic host mice to generate bone-marrow chimeras with decreased production of $27 \mathrm{HC}$ specifically in hematopoietic cells. We hypothesized that this decreased production of $27 \mathrm{HC}$ by $\mathrm{KCs}$ would inhibit the translocation of cholesterol from the lysosomes to the cytoplasm, and thereby increase hepatic inflammation. In agreement with our hypothesis, we indeed

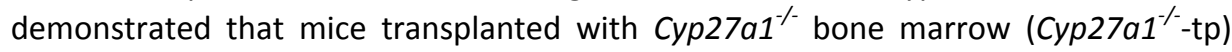
showed higher lysosomal cholesterol accumulation in KCs than mice transplanted with bone marrow from wild type (Wt) $\mathrm{C} 57 \mathrm{BI} / 6$. In addition, the increased lysosomal cholesterol accumulation in these mice was associated with increased inflammation and liver damage. Next, to examine whether exogenous administration of $27 \mathrm{HC}$ (25(R)26-hydroxycholesterol) would decrease inflammation, $\mathrm{Ldlr}^{-/}$mice were injected with $27 \mathrm{HC}$. These mice had reduced lysosomal cholesterol accumulation, which was associated with far less hepatic inflammation than in control injected $\mathrm{Ldll}^{-/}$mice. Altogether, these data support a causal role for lysosomal cholesterol accumulation in hepatic inflammation and highlight the potential of using $27 \mathrm{HC}$ as a novel treatment for NASH.

\section{Materials and methods}

\section{Mice, diet and bone marrow transplantation}

Mice were housed under standard conditions and given free access to food and water. Experiments were performed according to Dutch regulations and approved by the Committee for Animal Welfare of Maastricht University. In the first study, 12-weekold female $\mathrm{LdIr}^{-/}$mice were lethally irradiated and transplanted with Wt or Cyp27a ${ }^{-/}$ bone marrow as previously described. ${ }^{2}$ After a recovery period of 9 weeks, the mice were given either chow or HFC diet for 3 months (chow: $n=5 ; H F C: n=10$ ). In the second experiment, the effects of $27 \mathrm{HC}(25(\mathrm{R}) 26$-hydroxycholesterol) on NASH were investigated in female $\mathrm{Ldlr}^{-/}$mice by means of daily subcutaneous injections with $40 \mathrm{mg}$ per $\mathrm{kg}$ of body weight of $27 \mathrm{HC}$ for 3 weeks. Two-hydroxypropyl- $\beta$-cyclodextrin (Sigma-Aldrich $\mathrm{GmbH}$ H5784) was used as a vehicle to dissolve $27 \mathrm{HC}$, as described by De Caprio et al. ${ }^{9}$ Two-hydroxypropyl- $\beta$-cyclodextrin was also used for the control injections. The mice were given chow or HFC diet for 3 weeks ( $n=9$ for all groups). To investigate the therapeutic effect of $27 \mathrm{HC}$, one group of $\mathrm{Ldll}^{-1-}$ mice on HFC diet received control injections for 2 weeks and injections with $27 \mathrm{HC}$ in the third week $(n=9)$. In the chow diet, no evidence for $27 \mathrm{HC}$ was found (or it was below the detection limit). In the HFC diet, $27 \mathrm{HC}$ reached a concentration of $1.428 \mathrm{ng} / \mathrm{mg}$. The HFC diet contained $21 \%$ milk butter, $0.2 \%$ cholesterol, $46 \%$ carbohydrates and $17 \%$ casein. Collection of blood and tissue specimens, biochemical determination of lipids in plasma and liver, liver histology, electron microscopy, RNA isolation, cDNA synthesis and QPCR, aminotransferases and oxysterols were determined as described 
previously. ${ }^{2-4,10,11}$ Information about the obese NASH subjects, KC isolation, the cathepsin D activity assay, the MDA (malondialdehyde) assay, the anti-oxidant capacity assay and statistical analysis are described extensively in Supplementary Materials and Methods.

\section{Results}

\section{Steatosis is not affected by hematopoietic deletion of Cyp27a1, while plasma lipid levels are significantly reduced}

The role of CYP27A1 in diet-induced NASH was investigated by transplanting Cyp27a1 ${ }^{+/+}(\mathrm{Wt})$ and $\mathrm{Cyp}_{27 a 1^{-/}}$bone marrow into $\mathrm{Ldlr}^{-/}$mice. After a recovery period of 9 weeks, mice received chow or HFC diet for 3 months. Body weight did not differ significantly between groups (data not shown). After three months of HFC diet, equal levels of steatosis developed in the two transplanted groups. Neither hepatic triglyceride (TG) levels, nor hepatic cholesterol differed between the groups (Table 5.1A). Additionally, Oil Red O (ORO) staining showed no difference in the levels of liver lipids in Wt-tp and Cyp27a1 $1^{--}$-tp mice upon HFC diet (Figure S5.1). When comparing chow and HFC fed mice, hepatic $27 \mathrm{HC} /$ cholesterol levels were decreased upon HFC feeding (Wt-tp chow vs. HFC diet $\mathrm{p}<0.0001$; Cyp27a1 $1^{-1}$-tp chow vs. HFC diet: $\mathrm{p}<0.0001)$, although there were no differences between Wt-tp and Cyp27a1 ${ }^{-1}$-tp mice (Table 5.1A). In general, both groups developed equal levels of hepatic steatosis.

In mice on an HFC diet, plasma lipid levels were increased, while total cholesterol $(p=0.0014)$ as well as TG $(p=0.0004)$ levels were significantly lower in Cyp27a1 ${ }^{-1}$-tp mice than in their controls (Table 5.1A). In addition, the levels of $27 \mathrm{HC}$ in plasma were lower in Cyp27a1\%-tp mice than in Wt-tp mice $(p=0.048)$. There were no differences between the groups of mice fed a chow diet (Table 5.1A). 
Table 5.1 Liver and plasma lipid levels. A) Wt-tp and Cyp27a1 $1^{-1}$-tp mice, B) Control- and 27HC-injected mice.

\begin{tabular}{|c|c|c|c|c|c|}
\hline \multirow[t]{2}{*}{ A } & \multicolumn{2}{|l|}{ Chow } & \multicolumn{3}{|l|}{$\mathrm{HFC}$} \\
\hline & Wt-tp & Сур $27^{-1-}-$ tp & Wt-tp & \multicolumn{2}{|l|}{ Cyp $27^{-/-}-$tp } \\
\hline \multicolumn{6}{|l|}{ Liver } \\
\hline 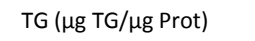 & $0.21(+-0.032)$ & $0.15(+-0.024)$ & $0.50(+-0.074)$ & \multicolumn{2}{|l|}{$0.49(+-0.072)$} \\
\hline 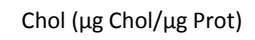 & $0.090(+-0.017)$ & $0.087(+-0.0049)$ & $0.26(+-0.024)$ & \multicolumn{2}{|l|}{$0.26(+-0.033)$} \\
\hline $27 \mathrm{HC} / \mathrm{Chol}$ & $0.46(+-0.082)$ & $0.51(+-0.10)$ & $0.15(+-0.026)$ & \multicolumn{2}{|l|}{$0.13(+-0.022)$} \\
\hline \multicolumn{6}{|l|}{ Plasma } \\
\hline TG (mM) & $0.46(+-0.093)$ & $0.42(+-0.086)$ & $1.7(+-0.50)$ & \multicolumn{2}{|l|}{$0.79(+-0.24)^{* * *}$} \\
\hline Chol (mM) & $6.79(+-0.31)$ & $6.39(+-0.54)$ & $36.71(+-1.65)$ & \multicolumn{2}{|l|}{$22.48(+-2.62)^{* *}$} \\
\hline $27 \mathrm{HC} / \mathrm{Chol}\left({ }^{*} 10^{-3}\right)$ & $0.047(+-0.00061)$ & $0.046(+-0.00071)$ & $0.051(+-0.0041)$ & \multicolumn{2}{|l|}{$0.045(+-0.0057)^{*}$} \\
\hline \multirow[t]{2}{*}{ B } & \multicolumn{2}{|c|}{ Chow } & \multicolumn{3}{|c|}{ HFC } \\
\hline & Control & $27 \mathrm{HC}$ & Control & $27 \mathrm{HC}$ & $2 \mathrm{w}$ Control $+1 \mathrm{w} 27 \mathrm{HC}$ \\
\hline \multicolumn{6}{|l|}{ Liver } \\
\hline TG ( $\mu \mathrm{g} T \mathrm{~T} / \mu \mathrm{g}$ Prot) & $0.29(+-0.084)$ & $0.28(+-0.11)$ & $0.64(+-0.14)$ & $0.64(+-0.13)$ & $0.63(+-0.15)$ \\
\hline 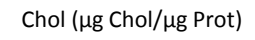 & $0.091(+-0.0086)$ & $0.088(+-0.0071)$ & $0.54(+-0.092)$ & $0.41(+-0.060 * *$ & $0.44(+-0.040) * *$ \\
\hline $27 \mathrm{HC} / \mathrm{Chol}$ & $0.36(+-0.067)$ & $7.73(+-1.55)^{* * *}$ & $0.10(+-0.014)$ & $1.70(+-0.39)^{* * *}$ & $0.96(+-0.16)^{* * *}$ \\
\hline \multicolumn{6}{|l|}{ Plasma } \\
\hline $\mathrm{TG}(\mathrm{mM})$ & $0.93(+-0.24)$ & $1.23(+-0.32)$ & $4.72(+-2.18)$ & $3.80(+-2.57)$ & $5.25(+-2.36)$ \\
\hline Chol (mM) & $8.28(+-0.19)$ & $7.31(+-0.16)$ & $42.02(+-2.39)$ & $29.74(+-2.06)^{*}$ & $36.99(+-2.27)$ \\
\hline $27 \mathrm{HC} / \mathrm{Chol}\left({ }^{*} 10^{-3}\right)$ & $0.43(+-0.034)$ & $19.15(+-7.33)^{* * *}$ & $0.60(+-0.026)$ & $6.65(+-1.07)^{* * *}$ & $6.20(+-0.64)^{* * *}$ \\
\hline
\end{tabular}

Liver and plasma triglycerides, cholesterol and $27 \mathrm{HC}$ levels after chow and HFC diet. ${ }^{*}$ indicates $p<0.05,{ }^{* *} p<0.01$ and ${ }^{* * *}$ $\mathrm{p}<0.001$.

\section{CYP27A1 influences the foamy appearance and lysosomal cholesterol storage of Kupffer cells}

To determine whether there was a difference in the foamy appearance of KCs, liver sections were stained for CD68, a macrophage marker that stains KCs. After dietary intervention, CD68 positive cells were swollen and increased in size, resembling the aggregation of lipoproteins in foamy macrophages during atherosclerotic lesion development. This foamy phenotype of $\mathrm{KC}$ s is similar to previous studies performed when Ldll $^{-/-}$mice are fed a HFC diet. ${ }^{10,12}$ Of note, the increased size was correlated with the increased lipid content within these cells. The comparison of CD68 positive cells revealed a clear difference between the KCs of the Cyp27a1 $1^{--}$-tp and Wt-tp mice. The KCs of Wt-tp mice on the HFC diet were extremely foamy, whereas the KCs of Cyp27a1 $1 \%$ tp mice were much less foamy after 3 months on the HFC diet (Figure 5.1A). These data were also confirmed by gene expression analysis of $C d 68$ ( $p=0.015)$, which demonstrated reduced expression of this macrophage marker in the livers of mice with hematopoietic deletion of Cyp27a1 (Figure 5.1B). These data suggest that Cyp $27 a 1^{-1-}$-tp mice on HFC diet have altered hepatic cholesterol metabolism. 

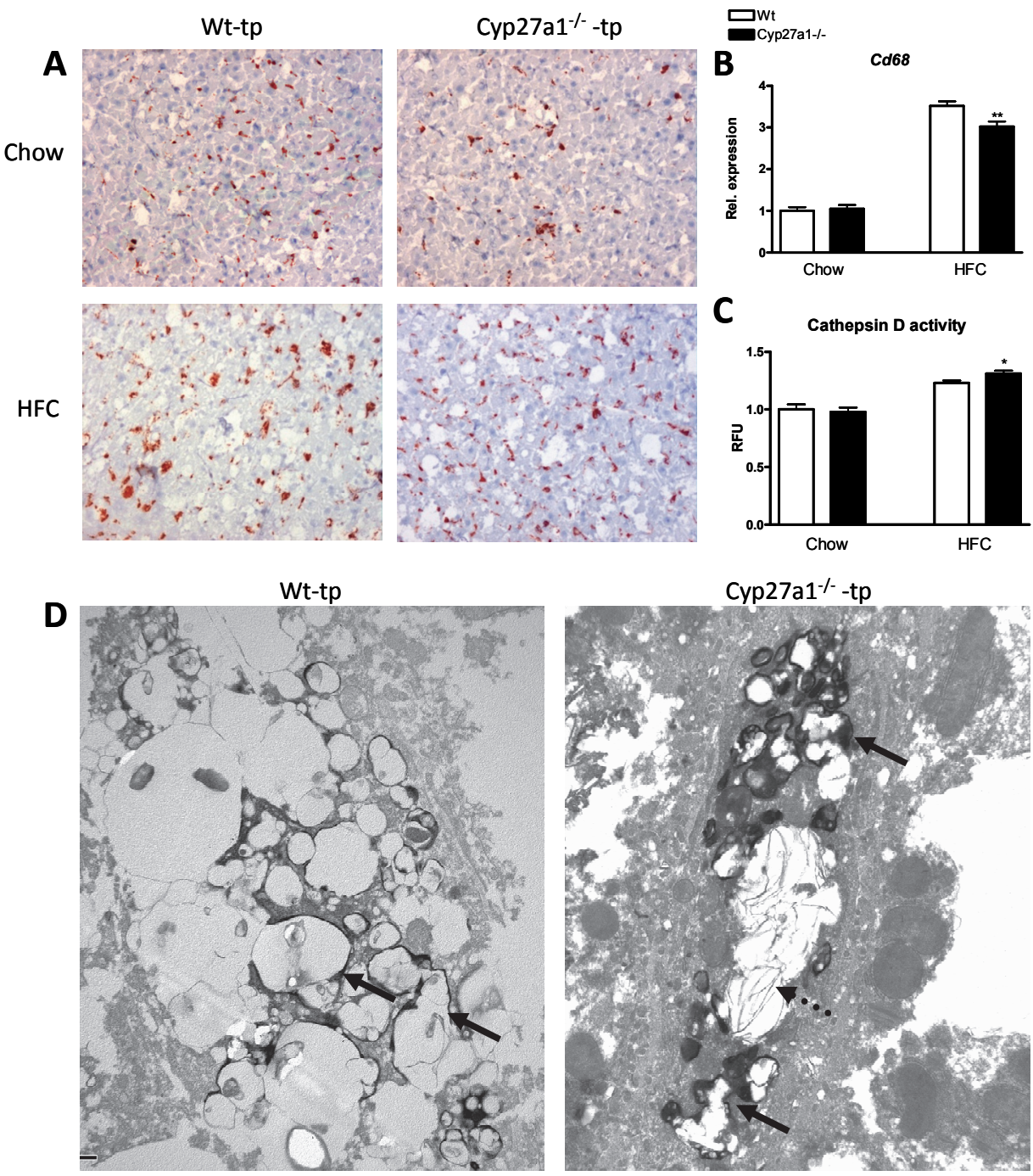

Figure 5.1 Foamy Kupffer cells in Wt-tp and Cyp27a1\%-tp mice. (A) Representative pictures of CD68 staining (200x magnification) after 3 months of chow or HFC diet. (B) Gene expression of the macrophage marker Cd68. (C) Hepatic activity of the lysosomal enzyme Cathepsin D. (D) Representative electron microscopy pictures of KCs after 3 months of HFC diet. Lysosomes are indicated in black by acid phosphatase staining (solid arrows). Abnormal lipid structures resembling cholesterol precipitations are indicated by the broken arrows. ${ }^{*}$ indicates $p<0.05$ and $* * \mathrm{p}<0.01$.

Next, electron microscopy was performed to explore the intracellular cholesterol distribution inside KCs. As demonstrated in Figure 5.1, Wt-tp mice on HFC diet had more lipid droplets inside KCs than the Cyp27a1 $1^{\%}$-tp mice. Although KCs of Cyp27a1\%tp mice were less foamy on HFC diet, these KCs had more lysosomal cholesterol 
accumulation than Wt-tp mice, as indicated by the lysosomal acid phosphatase staining (Figure 5.1D). Acid phosphatase staining also showed that a large amount of lipids was present outside the lysosomes in the KCs of the Wt-tp mice. We also saw more abnormal lipid structures resembling cholesterol precipitations in the KCs of Cyp $27 a 1^{-1}$-tp mice than in those of Wt-tp mice. The changes in intracellular lipid distribution in Cyp27a1 $1^{-}$-tp mice were accompanied by higher hepatic levels of the lysosomal enzyme cathepsin $D(p=0.031)$ than in Wt-tp mice on the HFC diet (Figure 5.1C). Altogether, these data demonstrate disturbed lysosomal storage in KCs of Cyp27a1 1 -tp mice.

\section{Increased LXR expression in Cyp27a1/-tp mice}

To investigate the effect of the Cyp27a1 deletion on cellular cholesterol homeostasis, gene expression of the nuclear receptor Liver $X$ receptor $(L x r)$ and its downstream target genes sterol regulatory element binding protein 1c (Srebp-1c), adenosine triphosphate (ATP)-binding cassette trasporter $A 1$ (Abca1) and $\mathrm{G1}$ (Abcg1) was analyzed in total liver. The expression of $\operatorname{Lxr}-\alpha(p=0.037)$, together with the target genes Srebp-1c $(p=0.033)$, Abca1 $(p=0.012)$ and Abcg1 $(p=0.016)$ was higher in Cyp27a1 $1^{-1}$-tp mice than in Wt-tp mice upon HFC diet (Figure S5.2). These data indicate that LXR is more active in Cyp27a1 $1^{--}$-tp mice than in Wt-tp mice.

\section{Cyp27a1\%-tp mice demonstrate increased hepatic inflammation and liver damage}

To investigate the effect of hematopoietic deletion of Cyp27a1 on hepatic inflammation, liver sections were stained with antibodies against several inflammatory markers. This revealed a significantly higher level of inflammation in the livers of Cyp27a1 $1^{-/}$-tp mice than in those of Wt-tp mice (Figure 5.2A), as indicated by the higher numbers of infiltrating macrophages $(p=0.0039)$, neutrophils $(p=0.031)$ and $T$ cells $(p=0.010)$ in these mice. Moreover, Mac-1-positive cells were more clustered in Cyp27a1\%-tp mice than in Wt-tp mice (Figure 5.2B). To further define the differences in hepatic inflammation, we analyzed gene expression of the pro-inflammatory cytokines tumor necrosis factor (Tnf), monocyte chemo-attractant protein 1 (Mcp-1), interleukin 1 beta (II-16) and II-6, which are known to be elevated in NASH patients and animals and to activate NFKB signaling and acute phase protein production in the liver. ${ }^{13,14}$ As shown in Figure 5.2C, gene expression of $\operatorname{Tnf}(p=0.043), M c p-1(p=0.050)$, $I I-16(p=0.037)$ and $I I-6(p=0.0034)$ was significantly higher in Cyp27a1 ${ }^{-1-}$-tp mice than in Wt-tp mice on the HFC diet, confirming the histological data.

To explore the role of CYP27 on oxidative stress, the lipid peroxidation marker malondialdehyde (MDA) and the anti-oxidant marker Trolox Equivalent Antioxidant Capacity (TEAC) were measured in livers of Wt- and Cyp27a1 $1^{-1-}$-tp mice. These data indicate that the level of oxidative stress was not affected in both $\mathrm{Wt}$ - and Cyp27a ${ }^{-1-}$. 
tp mice (Figure S5.3A). In addition, hepatic expression levels of several anti- and prooxidant genes such as Catalase, superoxide dismutase 2 (Sod-2), heme oxygenase (Hmox), glutathione s-transferase (Gst), cytochrome P450 2E1 (Cyp2E1) and C/EBP homologous protein (Chop) confirmed that there were no significant differences in oxidative stress between Wt- and Cyp27a1 $1^{--}$-tp mice (Figure S5.3B).
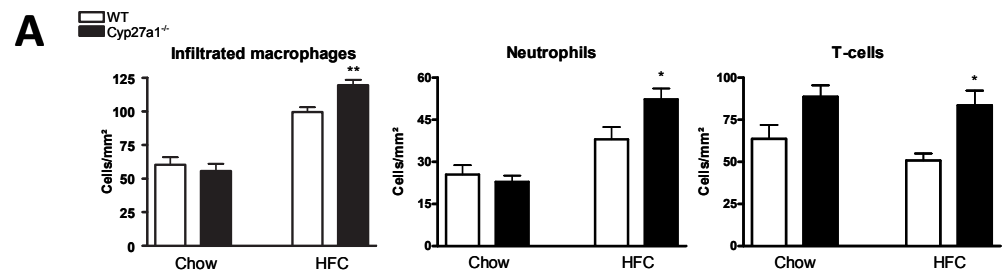

B

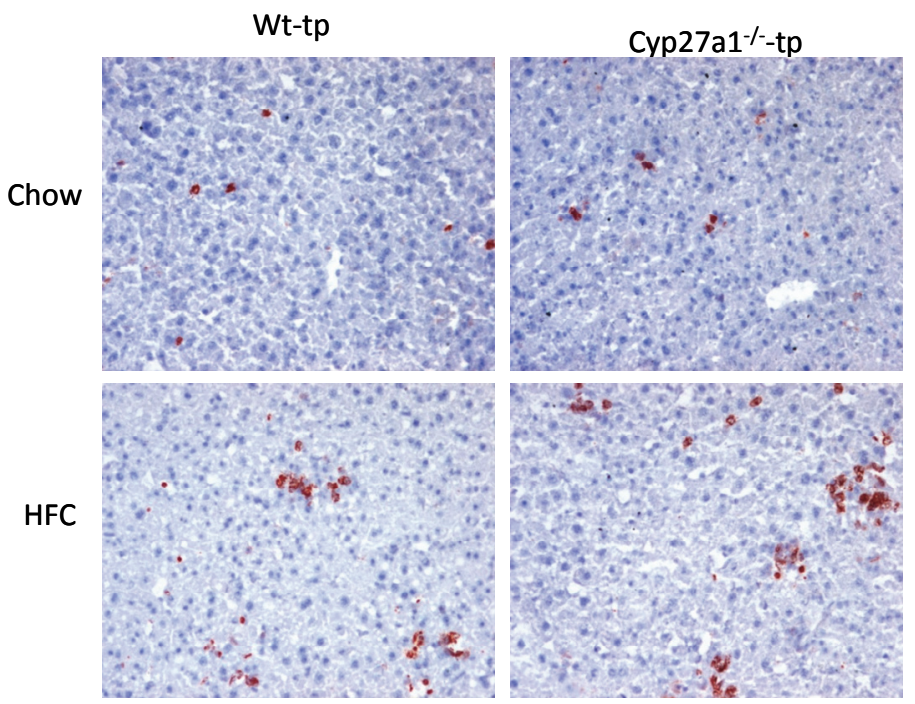

C

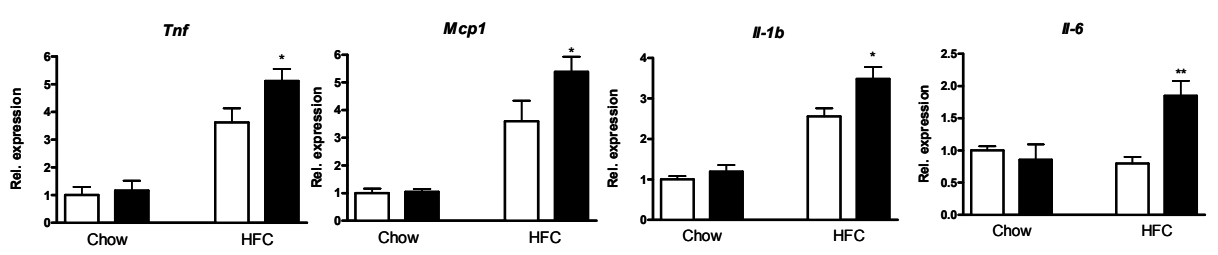

Figure 5.2 Parameters of hepatic inflammation in Wt-tp and Cyp27a1 ${ }^{-1}$-tp mice. (A) Liver sections were stained for infiltrating macrophages, neutrophils and T cells and the positive cells counted. (B) Representative pictures of Mac- 1 staining (200x magnification) after 3 months of HFC diet. (C) Gene expression analysis of Tnf, Mcp-1, II-16 and II-6. Gene expression data are shown relative to $\mathrm{Wt}$-tp mice on chow diet. * indicates $\mathrm{p}<0.05$ and $* * \mathrm{p}<0.01$. 
Elevated alanine aminotransferase (ALT) levels in plasma are considered to be sensitive indicators of liver damage. After 3 months of HFC diet, plasma ALT levels were higher in Cyp27a1 $1^{-}$-tp mice than in Wt-tp mice $(p=0.048)$ (Figure 5.3A). In line with these findings, hepatic fibrosis was also higher in Cyp27a1 $1^{-1}$-tp mice than in Wt-tp mice, as demonstrated by collagen staining with Sirius Red and gene expression analysis (Figure 5.3B-E). Although fibrosis was moderate, Cyp27a1 ${ }^{-1}$-tp mice had increased collagen content upon HFC diet than the Wt-tp mice (Figure 5.3B-C). After 3 months of HFC diet, hepatic gene expression of transforming growth factor $\beta$ (Tgf- $B$ ) $(p=0.044)$, metalloproteinase $9(\mathrm{Mmp}-9) \quad(p=0.050)$ and plasminogen activator inhibitor-1 (Pai-1) ( $\mathrm{p}=0.041)$ was higher in Cyp27a1\%-tp mice than in Wt-tp mice (Figure 5.3D). A similar trend was observed for the expression of collagen 1A1 (Col1a1) after 3 months of HFC diet; however, this did not reach statistical significance $(p=0.08)$. Activated hepatic stellate cells could not be observed in Wt- and Cyp27a1 $1^{-1}$ tp mice upon HFC diet, neither by $\alpha$-smooth muscle cell actin ( $\alpha$-SMA) staining, nor by gene expression of $\alpha$-Sma (Figure S5.4). Altogether, these data indicate that Cyp27a1 $1^{--}$-tp mice are more susceptible to hepatic inflammation and liver damage.

\section{Administration of $27 \mathrm{HC}$ does not affect steatosis, but lowers plasma cholesterol levels}

Next, to investigate whether exogenous administration of $27 \mathrm{HC}$ can reduce inflammation during $\mathrm{NASH}, \mathrm{Ldlr}^{-/}$mice were given daily injections of $27 \mathrm{HC}$ or control vehicle for 3 weeks and received either chow or HFC diet during this period. An extra group on the HFC diet received a control injection for two weeks, followed by $27 \mathrm{HC}$ injection in the last week. Plasma and liver $27 \mathrm{HC}$ levels increased significantly upon 27HC administration $(p<0.0001)$, while HFC diet caused a reduction in hepatic $27 \mathrm{HC} /$ cholesterol levels compared to chow (Control chow vs. HFC diet: $p<0.0001$; 27HC chow vs HFC diet: $p<0.0001$ ) (Table 5.1B). After 3 weeks of HFC diet, body weights did not differ significantly (data not shown) and equal levels of steatosis were observed in the different groups, as confirmed by ORO staining (Figure S5.5). Although hepatic TG levels were similar, hepatic cholesterol levels were significantly lower in the $27 \mathrm{HC}$-treated mice on HFC diet than in control mice (27HC vs. control: $p=0.0023$; $2 \mathrm{w}$ control $+1 \mathrm{w} 27 \mathrm{HC}$ vs. control: $\mathrm{p}=0.008$ ) (Table $5.1 \mathrm{~B}$ ). Plasma cholesterol levels were lower in 27HC-injected mice than in control mice on HFC diet $(p=0.013)$. There were no differences between the groups on chow diet (Table 5.1B). 
A $\varpi_{\text {Cyp27a1-/- }}^{W t}$

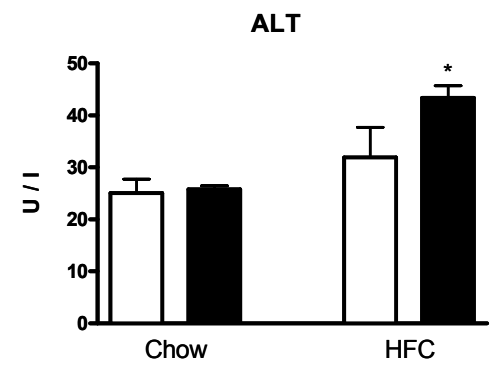

C

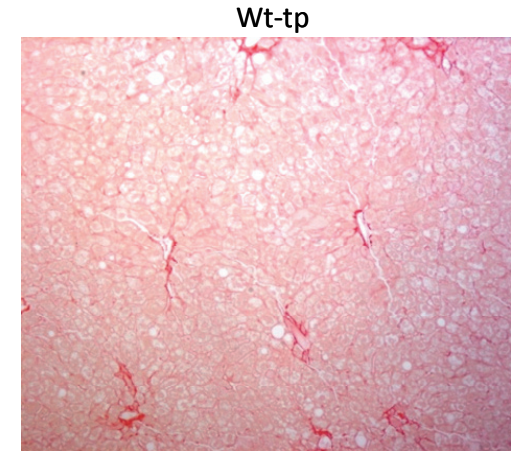

D

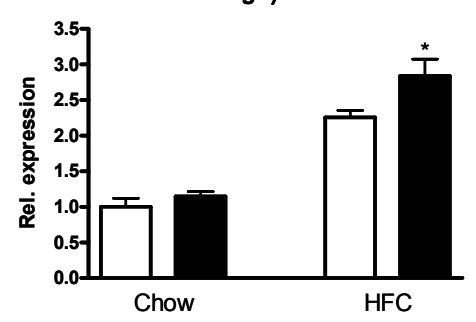

Mmp-9

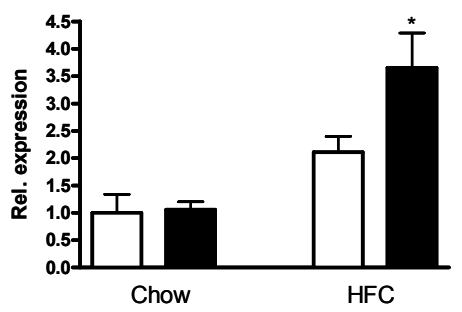

B
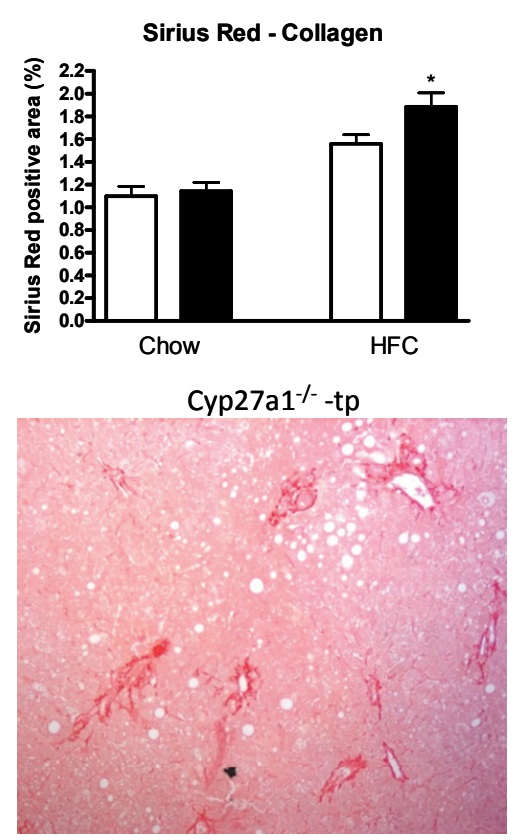

Col1a1

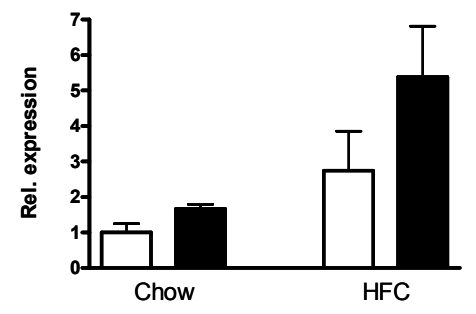

Pai-1

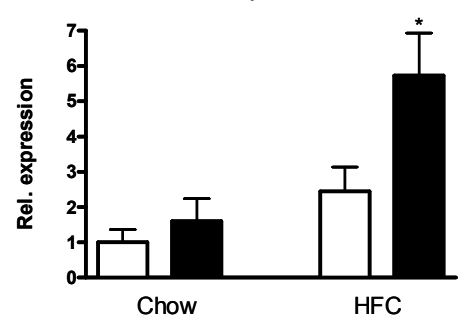

Figure 5.3 Liver damage and hepatic fibrosis in Wt-tp and Cyp27a1 ${ }^{-1}$-tp mice. (A) Plasma alanine aminotransferase (ALT) levels. (B) Quantification of Sirius Red staining after HFC diet. Livers were quantified by percentage of collagen present. (C) Representative pictures of Sirius Red staining (100x magnification) of Wt-tp and Cyp27a1 $1 \%$-tp mice on HFC diet. (D) Hepatic gene expression of $T g f-6$, Col1a1, Mmp-9 and Pai-1. Gene expression data are shown relative to Wt-tp mice on chow diet. * indicates $p<0.05$. 


\section{KCs are less foamy and have less lysosomal cholesterol storage after 27HC administration}

After daily administration of $27 \mathrm{HC}$ to $L d l r^{-/-}$mice, CD68 staining revealed a clear difference between $27 \mathrm{HC}$ and control-injected mice on HFC diet, with the KCs in 27HC-injected mice having a less foamy appearance (Figure 5.4A). These data are in line with reduced gene expression of $C d 68$ ( $27 \mathrm{HC}$ vs. control: $p=0.031 ; 2 \mathrm{w}$ control $+1 \mathrm{w}$ $27 \mathrm{HC}$ vs. control: $\mathrm{p}=0.050$ ) (Figure $5.4 \mathrm{~B}$ ). Electron microscopy of KCs from $27 \mathrm{HC}$ injected mice demonstrated fewer lipids present inside lysosomes, indicated by acid phosphatase staining, and lower numbers of abnormal lipid structures resembling cholesterol precipitations (Figure 5.4D). In addition, while cholesterol crystals were present in the KCs of control injected mice upon HFC diet, they were not detected in KCs of $27 \mathrm{HC}$-injected mice. The activity of the lysosomal enzyme cathepsin D in the livers of $27 \mathrm{HC}$-injected mice was also lower than in control mice (27HC vs. control: $\mathrm{p}=0.025$ ) (Figure 5.4C). Together, these data indicate that $27 \mathrm{HC}$ plays an important role in cellular cholesterol distribution.

\section{Increased LXR expression in Kupffer cells, but not in total liver, upon 27HC administration}

To investigate the role of $27 \mathrm{HC}$ as physiological LXR ligand, gene expression of $L x r$ and its downstream target genes Srebp-1c, Abca1 and Abcg1 were analyzed in total liver and isolated $\mathrm{KCS}$ upon $27 \mathrm{HC}$ administration. The expression in total liver of $L x r-\alpha$ ( $27 \mathrm{HC}$ vs. control: $\mathrm{p}=0.040 ; 2 \mathrm{w}$ control $+1 \mathrm{w} 27 \mathrm{HC}$ vs. control: $\mathrm{p}=0.0083$ ), together with the target genes Srebp-1c (27HC vs. control: $\mathrm{p}=0.050), A b c a 1$ (27HC vs. control: $\mathrm{p}=0.034 ; 2 \mathrm{w}$ control $+1 \mathrm{w} 27 \mathrm{HC}$ vs. control: $\mathrm{p}=0.041$ ) and $A b c g 1$ ( $27 \mathrm{HC}$ vs. control: $\mathrm{p}=0.021 ; 2 \mathrm{w}$ control $+1 \mathrm{w} 27 \mathrm{HC}$ vs. control: $\mathrm{p}=0.018$ ) was lower upon $27 \mathrm{HC}$ administration than in control mice after HFC feeding (Figure S5.6A). In isolated KCs, expression of $L x r-B$ ( $27 \mathrm{HC}$ vs. control: $\mathrm{p}=0.040)$, Srebp-1c ( $27 \mathrm{HC}$ vs. control: $\mathrm{p}=0.038$ ) and $A b c a 1$ ( $27 \mathrm{HC}$ vs. control: $p=0.044 ; 2 \mathrm{w}$ control $+1 \mathrm{w} 27 \mathrm{HC}$ vs. control: $p=0.025$ ) was higher upon 27HC administration than in control mice (Figure S5.6B). These data suggest that the agonistic effect of $27 \mathrm{HC}$ on LXR in KCs is not dominant in all liver cells, but is restricted to $\mathrm{KCs}$. 
A

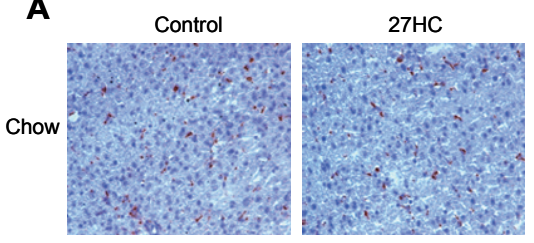

D

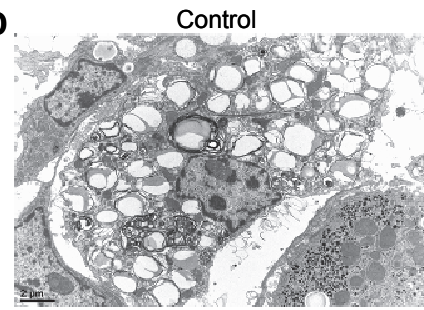

$27 \mathrm{HC}$

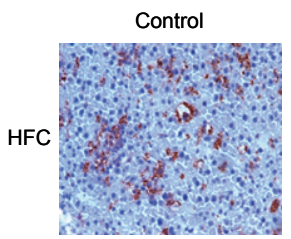

27HC

$2 \mathrm{w}$ Control $+1 \mathrm{w} 27 \mathrm{HC}$
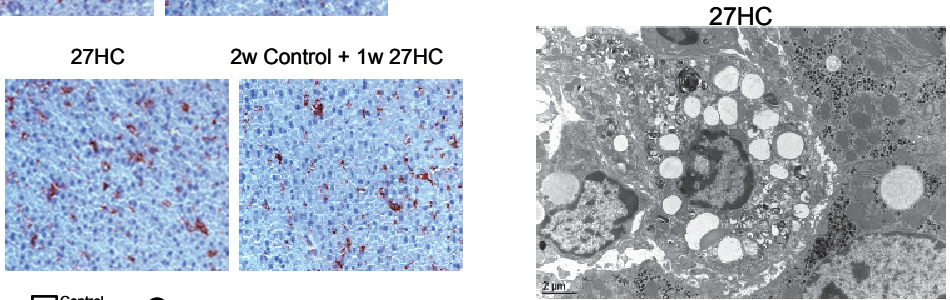

B $\square^{\text {Control }}$
$\square^{27 \mathrm{WC} C o n t r o l}+1 \mathrm{w}$ 27HC
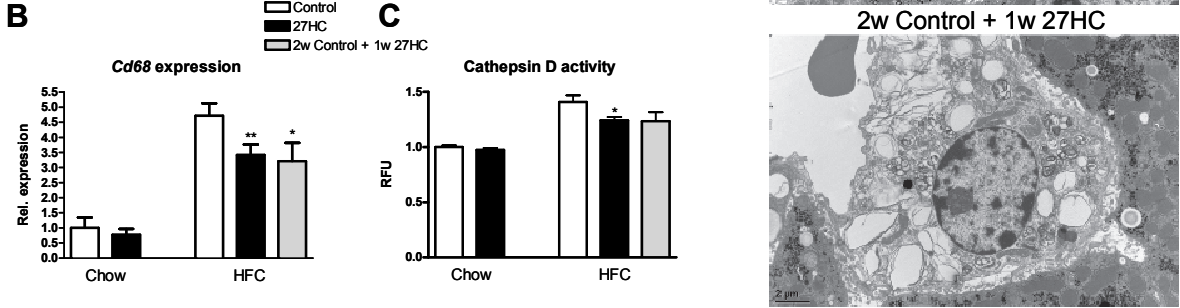

Figure 5.4 Foamy Kupffer cells, electron microscopy and Cathepsin D activity in control- and 27HCinjected mice. (A) Representative pictures of CD68 staining (200x magnification) after 3 weeks of chow or HFC diet. (B) Gene expression of the macrophage marker Cd68. (C) Hepatic activity of the lysosomal enzyme Cathepsin D. (D) Representative electron microscopy pictures of KCs. Lysosomes are indicated in black by acid phosphatase staining (solid arrows), abnormal lipid structures resembling cholesterol precipitations are indicated by the broken arrows and cholesterol crystals are indicated by asterisks. ${ }^{*}$ indicates $p<0.05$ and $* * p<0.01$.

\section{Hepatic inflammation is reduced upon $27 \mathrm{HC}$ treatment}

Injections with $27 \mathrm{HC}$ reduced the number of infiltrating macrophages (27HC vs. control: $p=0.0051 ; 2 w$ control $+1 w 27 \mathrm{HC}$ vs. control: $p=0.0097$ ), neutrophils ( $27 \mathrm{HC}$ vs. control: $p=0.021$ ) and T cells (for both $27 \mathrm{HC}$ vs. control and $2 \mathrm{w}$ control $+1 \mathrm{w} 27 \mathrm{HC}$ vs. control: $p<0.0001$ ) in mice fed HFC diet (Figure 5.5A+B), demonstrating the antiinflammatory properties of $27 \mathrm{HC}$. 


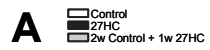

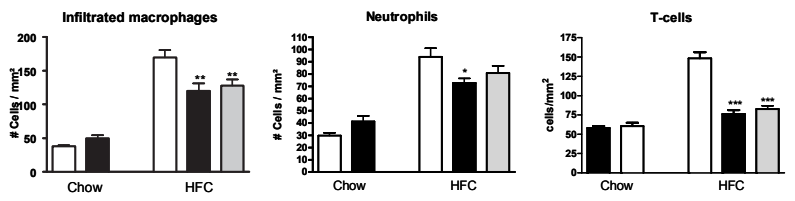

B
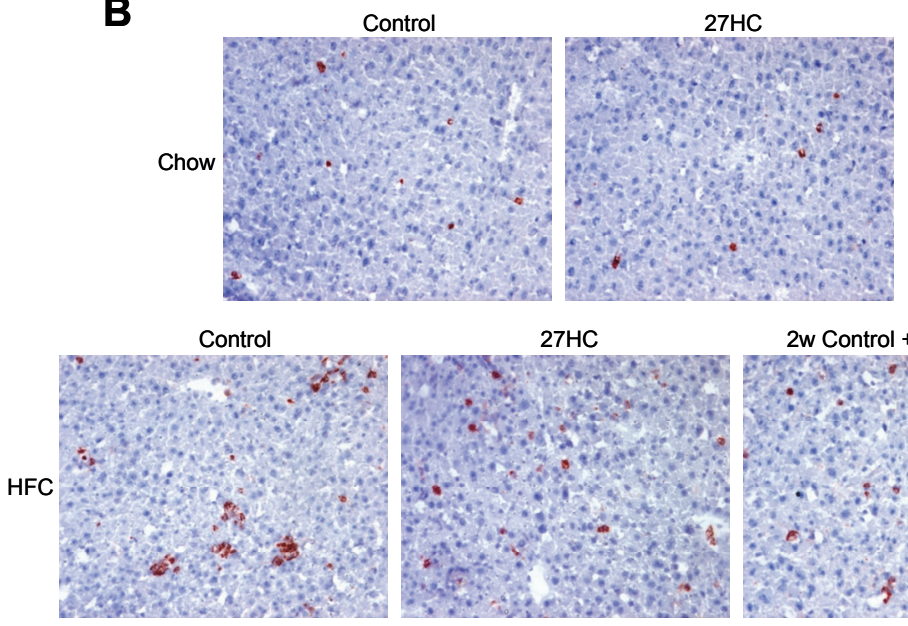

$2 \mathrm{w}$ Control $+1 \mathrm{w} 27 \mathrm{HC}$
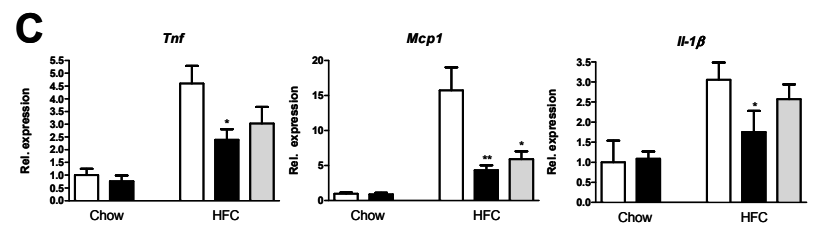

Figure 5.5 Parameters of hepatic inflammation in control- and 27HC-injected mice. (A) Liver sections were stained for infiltrating macrophages, neutrophils and $\mathrm{T}$ cells and the positive cells counted. (B) Representative pictures of Mac-1 staining (200x magnification) after 3 weeks of HFC diet. (C) Gene expression analysis of Tnf, Mcp-1 and II-16. Data are shown relative to control mice on chow diet. * indicates $p<0.05,{ }^{* *} p<0.01$ and $* * * p<0.001$.

In addition, gene expression of Tnf ( $27 \mathrm{HC}$ vs. control: $\mathrm{p}=0.030), \mathrm{Mcp}-1$ (27HC vs. control: $p=0.0027 ; 2 w$ control $+1 w 27 H C$ vs. control: $p=0.029)$ and $1 /-16$ ( $27 \mathrm{HC}$ vs. control: $p=0.050$ ) was lower in $27 \mathrm{HC}$-injected mice than in controls on HFC diet (Figure 5.5C). KCs isolated from 27HC-injected mice on HFC diet also had a lower expression of Tnf ( $27 \mathrm{HC}$ vs. control: $\mathrm{p}=0.038 ; 2 \mathrm{w}$ control $+1 \mathrm{w} 27 \mathrm{HC}$ vs. control: $\mathrm{p}=0.046), M c p-1$ ( $27 \mathrm{HC}$ vs. control: $p=0.050 ; 2 \mathrm{w}$ control $+1 \mathrm{w} 27 \mathrm{HC}$ vs. control: $p=0.038$ ) and $/ 1-16$ ( $27 \mathrm{HC}$ vs. control: $p=0.021 ; 2 \mathrm{w}$ control $+1 \mathrm{w} 27 \mathrm{HC}$ vs. control: $p=0.012$ ) (Figure S5.7), also demonstrating the effect of $27 \mathrm{HC}$ on KCs. Furthermore, expression of these inflammatory genes in isolated $\mathrm{KCs}$ is more than 10 -fold higher compared to total 
livers, demonstrating that the inflammatory response in the liver is mainly derived from KCs.

No differences were observed in plasma ALT levels or hepatic fibrosis after HFC diet (data not shown), which is probably related to the short duration of the HFC diet. In addition, the level of oxidative stress was not affected upon $27 \mathrm{HC}$ administration (Figure S5.8). In conclusion, 27HC plays an important role during hepatic inflammation.

\section{HC is not elevated in NASH patients}

To test the potential clinical utility of $27 \mathrm{HC}$ to NASH patients, we measured plasma $27 \mathrm{HC} /$ cholesterol levels in 69 obese subjects (average $\mathrm{BMI}=34.2$ ), classified into normal, steatosis or NASH according to the criteria of Kleiner, as described previously. ${ }^{15-18}$ Male subjects had $15 \%$ higher $27 \mathrm{HC}$ levels than females $(p=0.021)$, independent of plasma cholesterol (Figure S9A). Although a positive correlation between plasma cholesterol and $27 \mathrm{HC}$ levels was observed (males: $r=0.22, p<0.0001$; females: $r=0.58, p<0.0001$ ) (Figure S9B-C), there was no difference in 27HC levels in NASH patients compared to subjects with a healthy liver or steatosis (data not shown).

\section{Discussion}

Despite considerable efforts to unravel them, the mechanisms underlying the causes of inflammation in NASH are largely unknown, thereby limiting the treatment options for NASH. We have previously shown dietary cholesterol to be an important factor in the development of hepatic inflammation in mice. ${ }^{10}$ Here, we show that lysosomal cholesterol accumulation inside KCs may be a major trigger for the development of hepatic inflammation. This study also provides the first in vivo evidence that $27 \mathrm{HC}$ has an impact on intracellular cholesterol distribution in KCs. Finally, the current study points to the potential of $27 \mathrm{HC}$ as a novel treatment for $\mathrm{NASH}$.

\section{Association between lysosomal cholesterol accumulation and inflammation in NASH}

While the intracellular cholesterol distribution specifically in KCs has not yet been shown to affect hepatic inflammation, several lines of evidence have indicated a general association between lysosomal cholesterol accumulation and inflammation. One factor important in preventing such cholesterol accumulation in lysosomes is the enzyme lysosomal acid lipase (LAL), essential for the hydrolysis of triglycerides and cholesteryl esters in lysosomes. A deficiency in this enzyme leads to lysosomal 
cholesterol accumulation and inflammation in multiple organs, phenomena similar to our observations in hyperlipidemic mice $\left(\right.$ Ldlr $\left.^{--}\right)$. Likewise, patients with mutations in Niemann-Pick type C (NPC) 1 and 2, proteins which facilitate the movement of cholesterol from the lysosomes to the cytoplasmic compartment, commonly have a very poorly functioning liver, and about $10 \%$ of these patients die of liver failure. ${ }^{19}$ While lysosomes have been assigned a central role in many processes involving tissue injury and inflammation, ${ }^{20}$ the association between lysosomal cholesterol storage and inflammation in relation to the metabolic syndrome is not fully understood. In the present study, we show that increased lysosomal cholesterol storage leads to increased hepatic inflammation. These data are in line with the finding in $\mathrm{Ldll}^{-/}$mice on an HFC diet that a decrease in lysosomal cholesterol storage by means of exogenous LAL administration leads to significant reductions in hepatic inflammation, steatosis and atherosclerotic lesion size. ${ }^{21}$

By reducing lysosomal cholesterol storage and damage, $27 \mathrm{HC}$ can indirectly reduce inflammation by several mechanisms. Since we observed decreased hepatic cathepsin D activity and reduced lysosomal cholesterol storage upon $27 \mathrm{HC}$ treatment, lysosomal instability can also be a possible explanation for the inflammatory response observed in our experiments, since the stability and integrity of lysosomal membranes is important to maintain normal levels of lysosomal enzymes in tissues and body fluids. ${ }^{22}$ Furthermore, 27HC administration resulted in reduced formation of cholesterol crystals inside KCs. Since these crystals can induce rupture of phagolysosomes leading to the release of the proteolytic lysosomal contents into the cytosol and thereby activation of the NLRP3 inflammasome, treatment with $27 \mathrm{HC}$ can prevent the proinflammatory effects of inflammasome activation. ${ }^{23}$ Therefore, the reduced activity of cathepsin D and the absence of cholesterol crystals inside KCs upon 27HC administration can be a possible explanation for the beneficial effects of $27 \mathrm{HC}$ on lysosomal cholesterol storage and inflammatory gene expression. Since KCs are a primary source of inflammatory cytokines in the liver, ${ }^{24}$ and can indirectly influence the phenotype of neighboring hepatocytes and other immune cells via the production of inflammatory cytokines and cross-talking with other liver cell types, ${ }^{25}$ it is very likely that $27 \mathrm{HC}$ is also contributing (indirectly) to the inflammatory properties on hepatocytes.

\section{HC has the potential to lower plasma cholesterol levels}

Our study makes use of hematopoietic cells from knockout mice lacking the Cyp27a1 gene. In humans, CYP27A1 deficiency leads to cerebrotendinous xanthomatosis (CTX), a disease associated with the accumulation of cholesterol and cholestanol in many organs. However, Cyp27a1 ${ }^{-1-}$ mice lack the classic symptoms of CTX. ${ }^{26}$ They have either normal plasma lipid levels, similar to CTX patients, ${ }^{27}$ or are hyperlipidemic. ${ }^{28}$ These $^{2}$ findings are supported by our current data: although on normal diet plasma 
cholesterol levels were similar in Cyp27a1 ${ }^{-1}$-tp mice and Wt-tp mice, as well as in both 27HC and control-injected mice, after an HFC diet, plasma cholesterol levels were dramatically lower in Cyp27a1 $1^{--}$-tp and $27 \mathrm{HC}$-injected mice than in the control groups. Despite the reduced foamy appearance of $\mathrm{KCs}$ in $\mathrm{Cyp} 27 \mathrm{a} 1^{-}$-tp mice, hepatic inflammation was still higher than in control mice. Thus, the inflammation observed in Cyp $27 a 1^{-1-}$-tp occurs despite the reduction in cholesterol levels. In keeping with these observations, Zhang et al. demonstrated that in $N p c 1^{-/-}$-tp $L d l r^{-/}$mice, serum cholesterol and triglycerides levels are reduced after an HFC diet in the presence of increased aortic atherosclerosis. ${ }^{29}$ Altogether, the data suggest that $27 \mathrm{HC}$ can affect cholesterol metabolism in mice fed an HFC diet.

By measuring the expression of $27 \mathrm{HC} /$ cholesterol in plasma of patients with a wide variety of fatty liver disease, no differences in $27 \mathrm{HC}$ levels in NASH patients compared to subjects with a healthy liver or steatosis were observed. The absence of correlation between $27 \mathrm{HC}$ levels to severity of NAFLD is likely related to the tight regulation of $27 \mathrm{HC}$ synthesis by the mitochondria, which prevents a decrease in $27 \mathrm{HC}$ levels. ${ }^{30}$ Nevertheless, in patients with CTX, the extremely low $27 \mathrm{HC}$ levels are correlated with increased liver damage. ${ }^{31}$ Relevantly, a study using chimeric $N p c 1^{-/-}$mice, where 27HC synthesis by macrophages is decreased, reveals an association between the lowered $27 \mathrm{HC}$ levels in macrophages and elevated cholesterol oxidation products and oxidative stress in macrophages and plasma. ${ }^{29}$ Altogether, these data suggest that although plasma $27 \mathrm{HC}$ levels cannot be used as marker for NASH, elevating $27 \mathrm{HC}$ levels in NASH patients might be beneficial. Therefore, further experiments are needed to test the efficiency of $27 \mathrm{HC}$ in humans.

\section{Potential of $27 \mathrm{HC}$ to reduce hepatic inflammation}

Treatment options for NASH are currently limited, due to lack of understanding regarding the mechanisms which triggers hepatic inflammation in these patients. In the present study, we have shown for the first time that $27 \mathrm{HC}$ potentially reduces hepatic inflammation in $\mathrm{Ldll}^{-/}$mice, apparently associated with reduced lysosomal cholesterol storage inside KCs. In line with our findings, lysosomal cholesterol accumulation in Niemann-Pick disease type $\mathrm{C}$ is associated with considerably reduced $27 \mathrm{HC}$ production in human $\mathrm{NPC1}^{-/}$fibroblasts; incubation with $27 \mathrm{HC}$ dramatically reduces lysosomal cholesterol in these cells. ${ }^{7,8}$ One possible explanation for this phenomenon is that the added oxysterol somehow eliminates the excess cholesterol in the cytoplasm and therefore cholesterol is transferred from lysosomes to the cytoplasm to maintain homeostasis. However, intriguing recent findings that $27 \mathrm{HC}$ binds to the N-terminal luminal loop of NPC1 also suggest a direct molecular link between oxysterols and NPC function. ${ }^{32} \mathrm{~A}$ further explanation involves the suggestion that $27 \mathrm{HC}$ is a physiological LXR ligand, similar to other oxysterols. ${ }^{33}$ LXRs, together with other members of the nuclear receptor superfamily, contribute to cellular 
cholesterol homeostasis by regulating genes that control the storage, transport and catabolism of cholesterol. ${ }^{34}$ However, it is also demonstrated that oxysterols can function as antagonistic ligands for LXR. ${ }^{35} 27 \mathrm{HC}$ is found in large amounts in foam cells of atherosclerotic plaques, where it is thought to eliminate excess cholesterol by stimulating reverse cholesterol transport via LXR and inhibiting cholesterol synthesis and uptake via SREBP. ${ }^{36}$ Therefore, a possible mechanism for the reduced expression of inflammatory genes upon $27 \mathrm{HC}$ administration can be related to LXR activation. In the present study, we observed that the agonistic effects of $27 \mathrm{HC}$ were restricted to KCs and were mainly LXR- $\beta$ dependent, while $27 \mathrm{HC}$ acted as an antagonistic ligand of LXR in total liver and was mainly LXR- $\alpha$ driven. Therefore, the agonistic as well as antagonistic actions of $27 \mathrm{HC}$ on LXR are cell specific, indicating that $27 \mathrm{HC}$ functions as an endogenous selective LXR modulator. Taken together, these studies provide a possible explanation for the controversial data in literature regarding the role of $27 \mathrm{HC}$ in cholesterol metabolism.

Oxysterols such as $27 \mathrm{HC}$ are therefore already considered to be potential candidates for the reduction of cellular toxicity. Although some in vitro studies have demonstrated that oxysterols may have some cytotoxic, oxidative, and/or inflammatory effects, ${ }^{37}$ most data are highly controversial and more appropriate in vivo and in vitro models of investigation as well as clinical investigations are required to improve knowledge of oxysterol activities. The current study demonstrates that $27 \mathrm{HC}$ administration can reduce hepatic inflammation and modulate intracellular cholesterol distribution inside KCs. The potential of $27 \mathrm{HC}$ as a novel tool for the treatment of NASH should therefore be tested.

\section{Conclusions}

In the present study, lysosomal cholesterol accumulation in KCs was associated with increased hepatic inflammation. These data support a mechanism by which lysosomal cholesterol accumulation can act as a trigger for hepatic inflammation and point to the potential of using $27 \mathrm{HC}$ as a novel treatment for $\mathrm{NASH}$. 


\section{References}

1. Angulo P. Nonalcoholic fatty liver disease. N Engl J Med. 2002;346:1221-31.

2. Bieghs V, Wouters K, van Gorp PJ, Gijbels MJ, de Winther MP, Binder CJ, Lütjohann D, Febbraio M, Moore KJ, van Bilsen M, Hofker MH, Shiri-Sverdlov R. Role of scavenger receptor A and CD36 in dietinduced nonalcoholic steatohepatitis in hyperlipidemic mice. Gastroenterology. 2010;138:2477-86, 2486 e1-3.

3. Bieghs V, Verheyen F, van Gorp PJ, Hendrikx T, Wouters K, Lütjohann D, Gijbels MJ, Febbraio M, Binder CJ, Hofker MH, Shiri-Sverdlov R. Internalization of modified lipids by CD36 and SR-A leads to hepatic inflammation and lysosomal cholesterol storage in Kupffer cells. PLoS One. 2012;7:e34378.

4. Bieghs V, van Gorp PJ, Walenbergh SM, Gijbels MJ, Verheyen F, Buurman WA, Briles DE, Hofker MH, Binder CJ, Shiri-Sverdlov R. Specific immunization strategies against oxidized low-density lipoprotein: A novel way to reduce nonalcoholic steatohepatitis in mice. Hepatology. 2012;56:894-903.

5. Brown MS, Goldstein JL. Lipoprotein metabolism in the macrophage: implications for cholesterol deposition in atherosclerosis. Annu Rev Biochem. 1983;52:223-61.

6. Griffin EE, Ullery JC, Cox BE, Jerome WG. Aggregated LDL and lipid dispersions induce lysosomal cholesteryl ester accumulation in macrophage foam cells. J Lipid Res. 2005;46:2052-60.

7. Lange $\mathrm{Y}, \mathrm{Ye}$ J, Rigney M, Steck T. Cholesterol movement in Niemann-Pick type $\mathrm{C}$ cells and in cells treated with amphiphiles. J Biol Chem. 2000;275:17468-75.

8. Frolov A, Zielinski SE, Crowley JR, Dudley-Rucker N, Schaffer JE, Ory DS. NPC1 and NPC2 regulate cellular cholesterol homeostasis through generation of low density lipoprotein cholesterol-derived oxysterols. J Biol Chem. 2003;278:25517-25.

9. De Caprio J, Yun J, Javitt NB. Bile acid and sterol solubilization in 2-hydroxypropyl-beta-cyclodextrin. J Lipid Res. 1992;33:441-3.

10. Wouters K, van Gorp PJ, Bieghs V, Gijbels MJ, Duimel H, Lütjohann D, Kerksiek A, van Kruchten R, Maeda N, Staels B, van Bilsen M, Shiri-Sverdlov R, Hofker MH. Dietary cholesterol, rather than liver steatosis, leads to hepatic inflammation in hyperlipidemic mouse models of nonalcoholic steatohepatitis. Hepatology. 2008;48:474-86.

11. Wisse E, Braet F, Duimel H, Vreuls C, Koek G, Olde Damink SW, van den Broek MA, De Geest B, Dejong $\mathrm{CH}$, Tateno C, Frederik P. Fixation methods for electron microscopy of human and other liver. World J Gastroenterol. 2010;16:2851-66.

12. Shiri-Sverdlov R, Wouters K, van Gorp PJ, Gijbels MJ, Noel B, Buffat L, Staels B, Maeda N, van Bilsen M, Hofker MH. Early diet-induced non-alcoholic steatohepatitis in APOE2 knock-in mice and its prevention by fibrates. J Hepatol. 2006;44:732-41.

13. Diehl AM, Li ZP, Lin HZ, Yang SQ. Cytokines and the pathogenesis of non-alcoholic steatohepatitis. Gut. 2005;54:303-6.

14. Moshage H. Cytokines and the hepatic acute phase response. J Pathol. 1997;181:257-66.

15. Kalhan SC, Edmison J, Marczewski S, Dasarathy S, Gruca LL, Bennett C, Duenas C, Lopez R. Methionine and protein metabolism in non-alcoholic steatohepatitis: evidence for lower rate of transmethylation of methionine. Clin Sci (Lond). 2011;121:179-89.

16. Kasumov T, Edmison JM, Dasarathy S, Bennett C, Lopez R, Kalhan SC. Plasma levels of asymmetric dimethylarginine in patients with biopsy-proven nonalcoholic fatty liver disease. Metabolism. 2011;60:776-81.

17. Dasarathy S, Kasumov T, Edmison JM, Gruca LL, Bennett C, Duenas C, Marczewski S, McCullough AJ, Hanson RW, Kalhan SC. Glycine and urea kinetics in nonalcoholic steatohepatitis in human: effect of intralipid infusion. Am J Physiol Gastrointest Liver Physiol. 2009;297:G567-75.

18. Kalhan SC, Guo L, Edmison J, Dasarathy S, McCullough AJ, Hanson RW, Milburn M. Plasma metabolomic profile in nonalcoholic fatty liver disease. Metabolism. 2011;60:404-13.

19. Vanier MT, Millat G. Niemann-Pick disease type C. Clin Genet. 2003;64:269-81.

20. Weissmann G. The role of lysosomes in inflammation and disease. Annu Rev Med. 1967;18:97-112.

21. Du H, Schiavi S, Wan N, Levine M, Witte DP, Grabowski GA. Reduction of atherosclerotic plaques by Iysosomal acid lipase supplementation. Arterioscler Thromb Vasc Biol. 2004;24:147-54.

22. George J. Elevated serum beta-glucuronidase reflects hepatic lysosomal fragility following toxic liver injury in rats. Biochem Cell Biol. 2008;86:235-43. 
23. Hornung V, Bauernfeind F, Halle A, Samstad EO, Kono H, Rock KL, Fitzgerald KA, Latz E. Silica crystals and aluminum salts activate the NALP3 inflammasome through phagosomal destabilization. Nat Immunol. 2008;9:847-56.

24. Baffy G. Kupffer cells in non-alcoholic fatty liver disease: the emerging view. J Hepatol. 2009;51: 212-23.

25. Racanelli $V$, Rehermann B. The liver as an immunological organ. Hepatology 2006;43:S54-62.

26. Rosen H, Reshef A, Maeda N, Lippoldt A, Shpizen S, Triger L, Eggertsen G, Björkhem I, Leitersdorf E. Markedly reduced bile acid synthesis but maintained levels of cholesterol and vitamin $D$ metabolites in mice with disrupted sterol 27-hydroxylase gene. J Biol Chem. 1998;273:14805-12.

27. Dubrac S, Lear SR, Ananthanarayanan M, Balasubramaniyan N, Bollineni J, Shefer S, Hyogo $H$, Cohen DE, Blanche PJ, Krauss RM, Batta AK, Salen G, Suchy FJ, Maeda N, Erickson SK.I. Role of CYP27A in cholesterol and bile acid metabolism. J Lipid Res. 2005;46:76-85.

28. Repa JJ, Lund EG, Horton JD, Leitersdorf E, Russell DW, Dietschy JM, Turley SD. Disruption of the sterol 27-hydroxylase gene in mice results in hepatomegaly and hypertriglyceridemia. Reversal by cholic acid feeding. J Biol Chem. 2000;275:39685-92.

29. Zhang JR, Coleman T, Langmade SJ, Scherrer DE, Lane L, Lanier MH, Feng C, Sands MS, Schaffer JE, Semenkovich CF, Ory DS. Niemann-Pick C1 protects against atherosclerosis in mice via regulation of macrophage intracellular cholesterol trafficking. J Clin Invest. 2008;118:2281-90.

30. Lange Y, Ory DS, Ye J, Lanier MH, Hsu FF, Steck TL.. Effectors of rapid homeostatic responses of endoplasmic reticulum cholesterol and 3-hydroxy-3-methylglutaryl-CoA reductase. I Biol Chem. 2008;283:1445-55.

31. Boehme DH, Sobel HJ, Marquet E, Salen G.. Liver in cerebrotendinous xanthomatosis (CTX)--a histochemical and EM study of four cases. Pathol Res Pract. 1980;170:192-201.

32. Infante RE, Abi-Mosleh L, Radhakrishnan A, Dale JD, Brown MS, Goldstein JL. Purified NPC1 protein. I. Binding of cholesterol and oxysterols to a 1278-amino acid membrane protein. J Biol Chem. 2008;283:1052-63.

33. Chen W, Chen G, Head DL, Mangelsdorf DJ, Russell DW. Enzymatic reduction of oxysterols impairs LXR signaling in cultured cells and the livers of mice. Cell Metab. 2007;5:73-9.

34. Ory DS. Nuclear receptor signaling in the control of cholesterol homeostasis: have the orphans found a home? Circ Res. 2004;95:660-70.

35. Song C, Hiipakka RA, Liao S. Auto-oxidized cholesterol sulfates are antagonistic ligands of liver $\mathrm{X}$ receptors: implications for the development and treatment of atherosclerosis. Steroids. 2001;66: 473-9.

36. Gill S, Chow R, Brown AJ. Sterol regulators of cholesterol homeostasis and beyond: the oxysterol hypothesis revisited and revised. Prog Lipid Res. 2008;47:391-404.

37. Vejux A, Malvitte L, Lizard G. Side effects of oxysterols: cytotoxicity, oxidation, inflammation, and phospholipidosis. Braz J Med Biol Res. 2008;41:545-56. 


\section{Supplementary materials and methods}

\section{Subjects}

69 obese patients ( 41 females, 28 males) were recruited from the metabolic clinics at MetroHealth Medical Center and at the Cleveland Clinic. NASH was confirmed by liver biopsy according to the criteria of Kleiner et al.. ${ }^{1}$ All subjects in the present study were evaluated by the investigators and were abstinent from alcohol for at least 6 months. Their possible remote consumption of alcohol was less than that suggested to cause liver injury. The study protocol was approved by the Institutional Review Boards at Cleveland Clinic and MetroHealth Medical Center. Written informed consent was obtained from all subjects after fully explaining the procedure.

\section{$\mathrm{KC}$ isolation}

Small pieces of liver from all mice were pooled per experimental group and digested in digestion buffer containing Liberase TM $(33.3 \mu \mathrm{g} / \mathrm{ml})$ and $0.002 \%$ DNasel for $20 \mathrm{~min}$ at $37^{\circ} \mathrm{C}$. Tissue was further disrupted by pushing it through a $100 \mu \mathrm{m}$ cell strainer using wash buffer (PBS, 1\% FCS, $2.5 \mathrm{mM}$ EDTA), then the cells were pelleted at $1500 \mathrm{rpm}$, $10 \mathrm{~min}$, at $4^{\circ} \mathrm{C}$. After resuspension of cells in wash buffer, hepatocytes were removed by one low-spin centrifugation step at $300 \mathrm{rpm}, 3 \mathrm{~min}$. Supernatant was collected and centrifuged and red blood cells were lysed. Next, KCs were selected using magnetic beads coated with a macrophage-specific monoclonal antibody (F4/80). After incubation of cells with these F4/80-APC ( $1 \mu \mathrm{l} / 80 \times 10^{6}$ cells) (Biolegend) for $20 \mathrm{~min}$ at $4^{\circ} \mathrm{C}$, cells were washed and anti-APC microBeads $\left(200 \mu \mathrm{l} / 100 \times 10^{6}\right.$ cells) (Miltenyi Biotec, Auburn, CA) were added, followed by incubation in the dark for 20 min at $4^{\circ} \mathrm{C}$. After washing, samples were run into LS columns, put on a Quadro MACS magnet (Miltenyi Biotec, Auburn, CA) and rinsed with wash buffer. Positively selected cells were flushed using wash buffer and collected for further analysis.

\section{Cathepsin $D$ activity assay}

Cathepsin D activity was measured using the cathepsin D activity assay kit (MBL International, Woburn, MA) according to the manufacturers' protocol. In summary, $50 \mu \mathrm{g}$ of liver homogenate was lysed in cathepsin D lysis buffer on ice for $10 \mathrm{~min}$. Following centrifugation for $5 \mathrm{~min}$ at top speed, $5 \mu \mathrm{l}$ of clear cell lysate was transferred to a well of a 96-well plate and the total volume was made up to $50 \mu \mathrm{l}$ with cathepsin D cell lysis buffer. To each assay, $52 \mu$ l of master mix $(50 \mu)$ of CD Reaction Buffer and $2 \mu$ of CD Substrate) was added and the plate was incubated at $37^{\circ} \mathrm{C}$ for $1 \mathrm{~h}$. Samples were then measured using a fluorescence plate reader with a 328-nm excitation filter and 460-nm emission filter. Cathepsin D activity is expressed by the relative fluorescence units (RFU). 


\section{MDA (malondialdehyde) assay}

The assay is based on the formation of a colored adduct of MDA-like breakdown products of lipids with 2-TBA (thiobarbituric acid) ${ }^{2,3}$ and is performed as recently described. ${ }^{4}$ In brief, liver tissue was added to $1 \mathrm{ml}$ of reagent, containing $12 \mathrm{mmol} / \mathrm{I}$ TBA, $0.32 \mathrm{~mol} / \mathrm{I}$ o-phosphoric acid, $0.68 \mathrm{mmol} / \mathrm{I} \mathrm{BHT}$ and $0.01 \%$ EDTA, and the mixture was incubated for $1 \mathrm{~h}$ at $100^{\circ} \mathrm{C}$ in a water bath. After cooling, the TBA product was extracted with $100 \mu \mathrm{l}$ of butanol. A portion $(30 \mu \mathrm{l})$ of the butanol layer was injected on to an HPLC system (Agilent) equipped with a fluorescence detector, set at an excitation wavelength of $530 \mathrm{~nm}$ and emission wavelength of $560 \mathrm{~nm}$, and a Nucleosil C18 column (150 mm×3.2 mm; particle size, $5 \mu \mathrm{m}$; Supelco). Samples were eluted with $35 \%(\mathrm{v} / \mathrm{v})$ methanol containing $0.05 \%$ trifluoric acid. A calibration curve was constructed using MDA bis(diethylacetal) as a standard.

\section{Anti-oxidant capacity assay}

The anti-oxidant capacity in liver was assayed using the method described by Fischer et $a .^{5}$ Briefly, $950 \mu \mathrm{l}$ of $\mathrm{ABTS}^{\circ+}$ radical solution was incubated for $1 \mathrm{~min}$ at $37^{\circ} \mathrm{C}$, thereafter $50 \mu \mathrm{l}$ of deproteinized liver was added. After incubation for $5 \mathrm{~min}$, the absorption at $734 \mathrm{~nm}$ was measured. The resulting value is expressed as TEAC (trolox equivalent anti-oxidant capacity). As TEAC is partly determined by the uric acid concentration, the raw data from this assay were corrected for the uric acid content of the sample.

\section{Statistical analysis}

Data were analyzed using Graphpad Prism 4.0.3 software. Groups were compared using the unpaired t-test. The data were expressed as the mean and standard error of the mean and were considered significantly different at ${ }^{*} \mathrm{p}<0.05 ;{ }^{* *} \mathrm{p}<0.01$ or $* * *$ $p<0.001$.

\section{References}

1. Kleiner DE, Brunt EM, Van Natta M, Behling C, Contos MJ, Cummings OW, Ferrell LD, Liu YC, Torbenson MS, Unalp-Arida A, Yeh M, McCullough AJ, Sanyal AJ. Design and validation of a histological scoring system for nonalcoholic fatty liver disease. Hepatology. 2005;41:1313-21.

2. Lepage G, Munoz G, Champagne J, Roy CC. Preparative steps necessary for the accurate measurement of malondialdehyde by high-performance liquid chromatography. Anal Biochem. 1991;197:277-83.

3. Guillen-Sans R, Guzman-Chozas M. The thiobarbituric acid (TBA) reaction in foods: a review. Crit Rev Food Sci Nutr. 1998;38:315-30.

4. van de Poll MC, Dejong CH, Fischer MA, Bast A, Koek GH. Decreased hepatosplanchnic antioxidant uptake during hepatic ischaemia/reperfusion in patients undergoing liver resection. Clin Sci (Lond). 2008;114:553-60.

5. Fischer MA, Gransier TJ, Beckers LM, Bekers O, Bast A, Haenen GR. Determination of the antioxidant capacity in blood. Clin Chem Lab Med. 2005;43:735-40. 


\section{Supplemental figures}
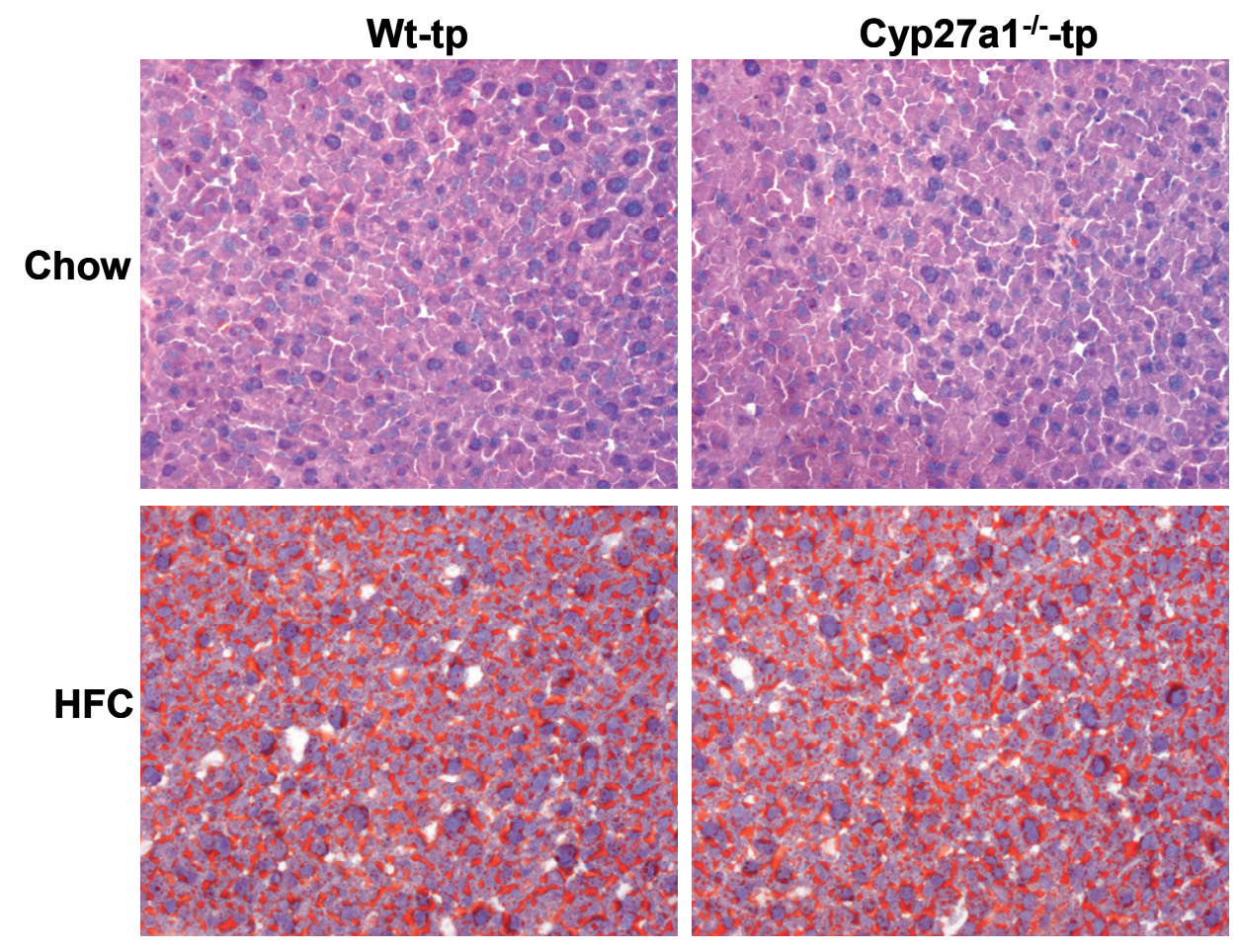

Figure S5.1 Hepatic steatosis in Wt-tp and Cyp27a ${ }^{-/}$-tp mice. Oil Red O staining in liver of Wt-tp and Cyp27a $1^{-1-}$-tp mice after 3 months of HFC diet. 


\section{$\square \mathrm{Wt}$}

Cyp27a1-/-

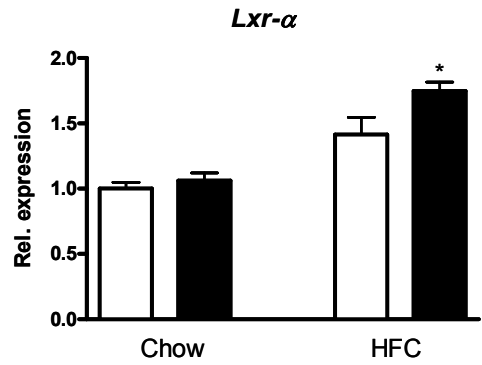

Abca1

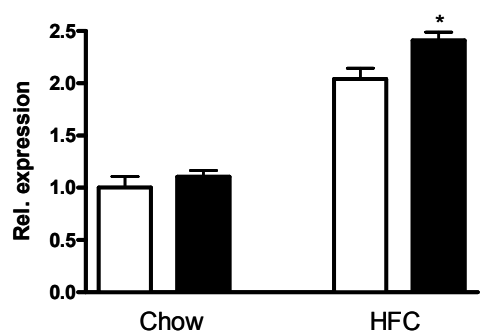

$L x r-\beta$

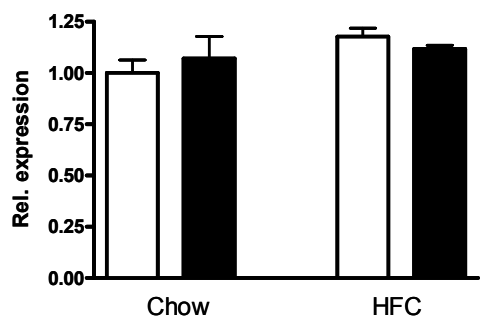

Srebp1c

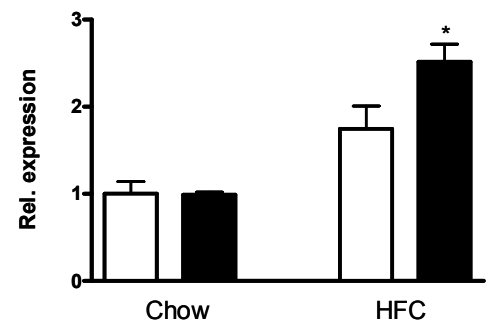

Abcg1

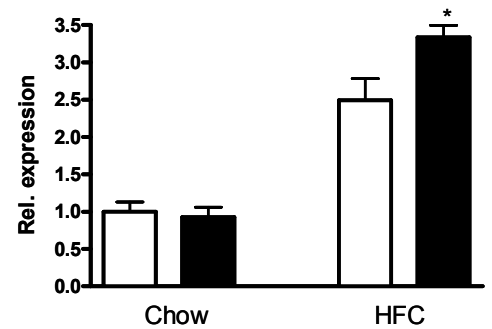

Figure S5.2 Gene expression of LXR and target genes in Wt-tp and Cyp27a $1^{-/}$-tp mice. Gene expression analysis of Liver $X$ receptor $\alpha$ and $\beta(\operatorname{Lxr}-\alpha$ and $-\beta)$ and its downstream target genes sterol regulatory element binding protein $1 c$ (Srebp-1c), adenosine triphosphate (ATP)-binding cassette transporter A1 (Abca1) and G1 (Abcg1) in total liver of Wt-tp and Cyp27a $1^{-1-}$-tp mice. Data were relative to control mice on chow diet. * indicates $p<0.05, * * p<0.01$ and *** $\mathrm{p}<0.001$. 
A

$\square_{\text {Cyp27a1- }}^{W t}$
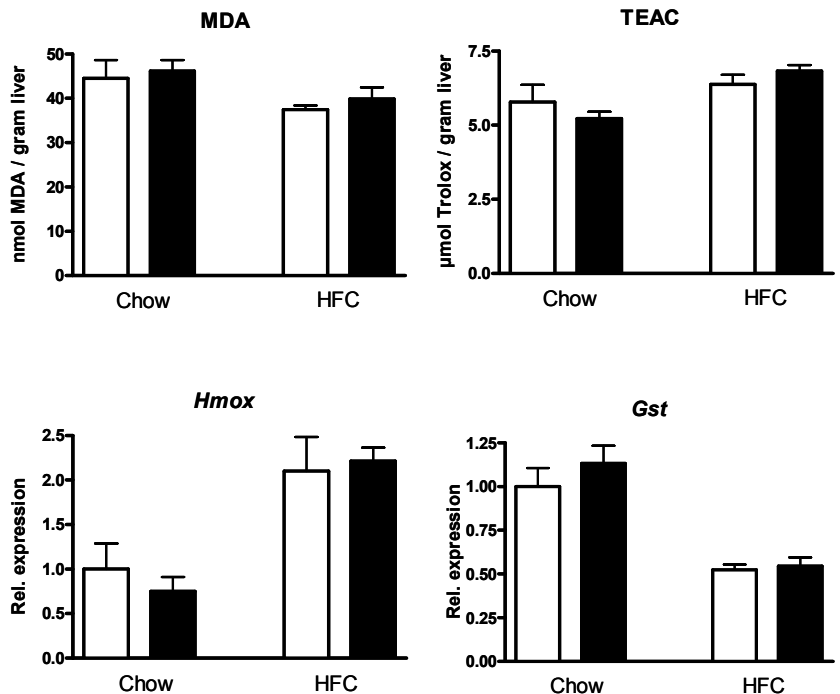

B
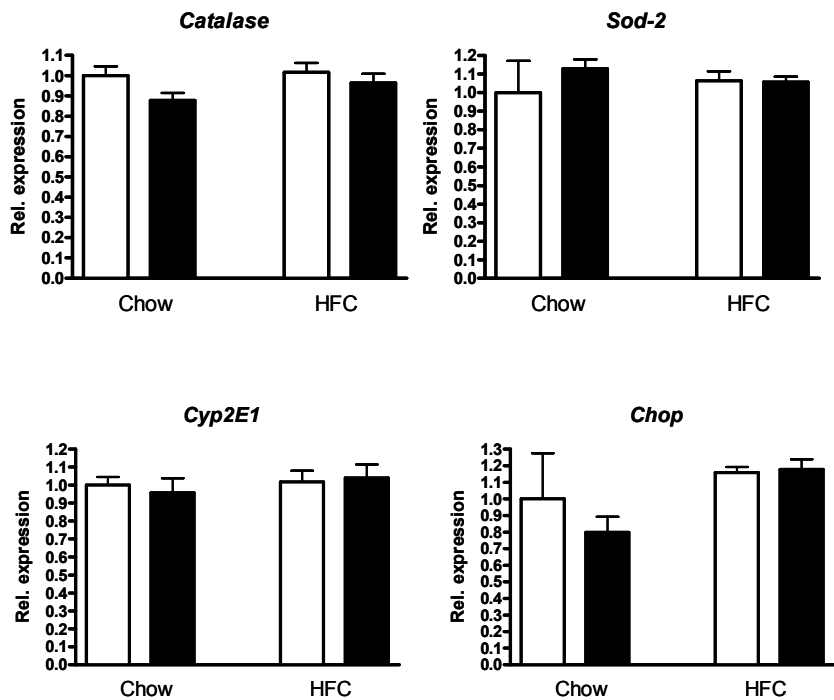

Figure S5.3 Measurements of oxidative stress in Wt-tp and Cyp27a $1^{-1-}$-tp mice. (A) The lipid peroxidation marker malondialdehyde (MDA) and the anti-oxidant marker Trolox Equivalent Anti-oxidant Capacity (TEAC) were measured in liver homogenates of Wt-tp and Cyp27a $1^{-1}$-tp mice. (B) Hepatic gene expression of several anti- and pro- oxidant genes such as Catalase, superoxide dismutase 2 (Sod-2), heme oxygenase (Hmox), glutathione s-transferase (Gst), cytochrome P450 2E1 (Cyp2E1) and C/EBP homologous protein (Chop) in Wt-tp and Cyp27a1 ${ }^{-1-}$-tp mice. Data were relative to control mice on chow diet. 

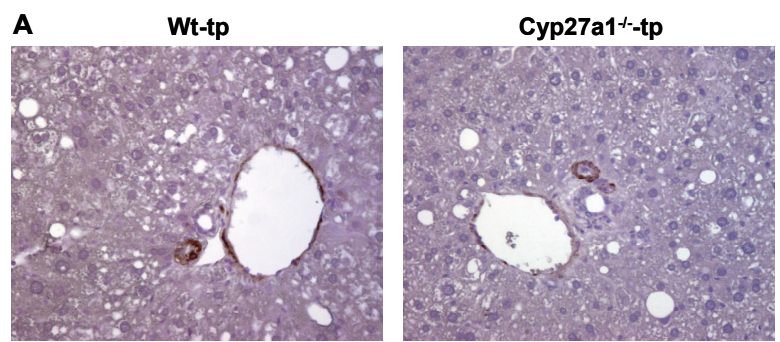

B

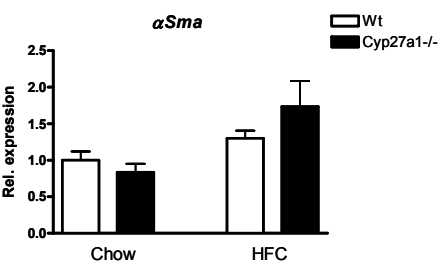

Figure S5.4 No activated hepatic stellate cells in Wt-tp and Cyp27a1 $1^{-1}$-tp mice. (A) Representative pictures of $\alpha$-smooth muscle cell actin ( $\alpha$-SMA) staining in Wt-tp and Cyp27a $1^{-1-}$-tp mice upon HFC diet (200x magnification). (B) Hepatic gene expression of $\alpha$-Sma in Wt-tp and Cyp27a $1^{-1-}$-tp mice. Data were relative to control mice on chow diet.
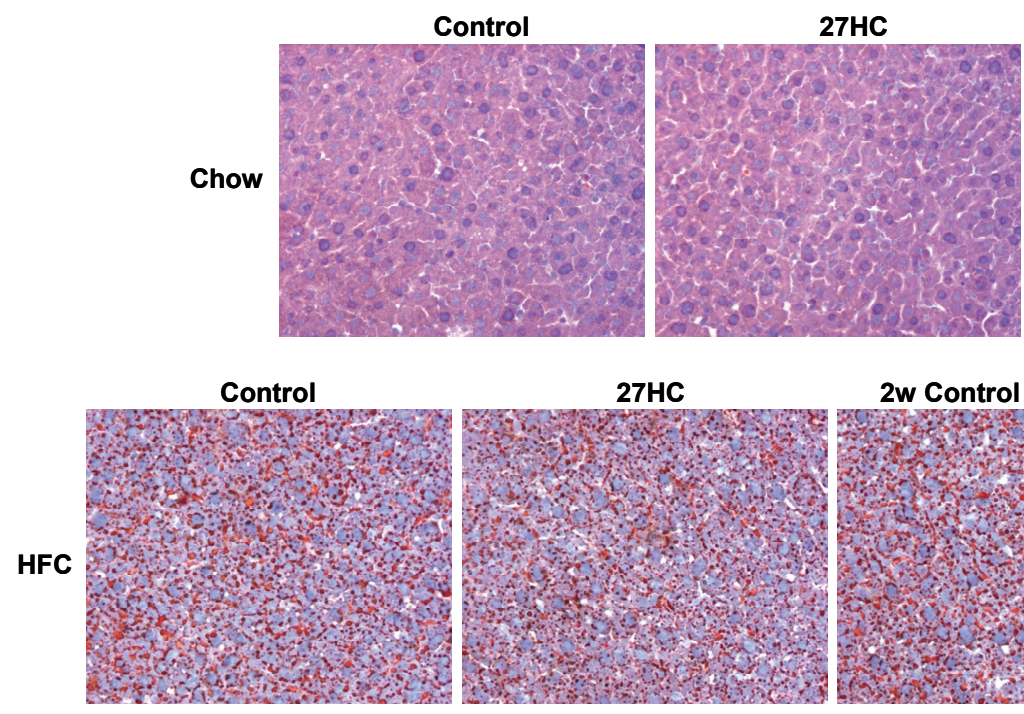

\section{2w Control + 1w 27HC}

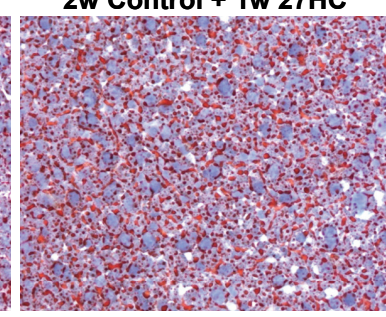

Figure S5.5 Hepatic steatosis in control- and 27HC-injected mice. Oil Red O staining in liver of control- and 27HC-injected mice after 3 weeks of HFC diet. 
A

\section{Contro \\ 2w Control + 1w 27HC}
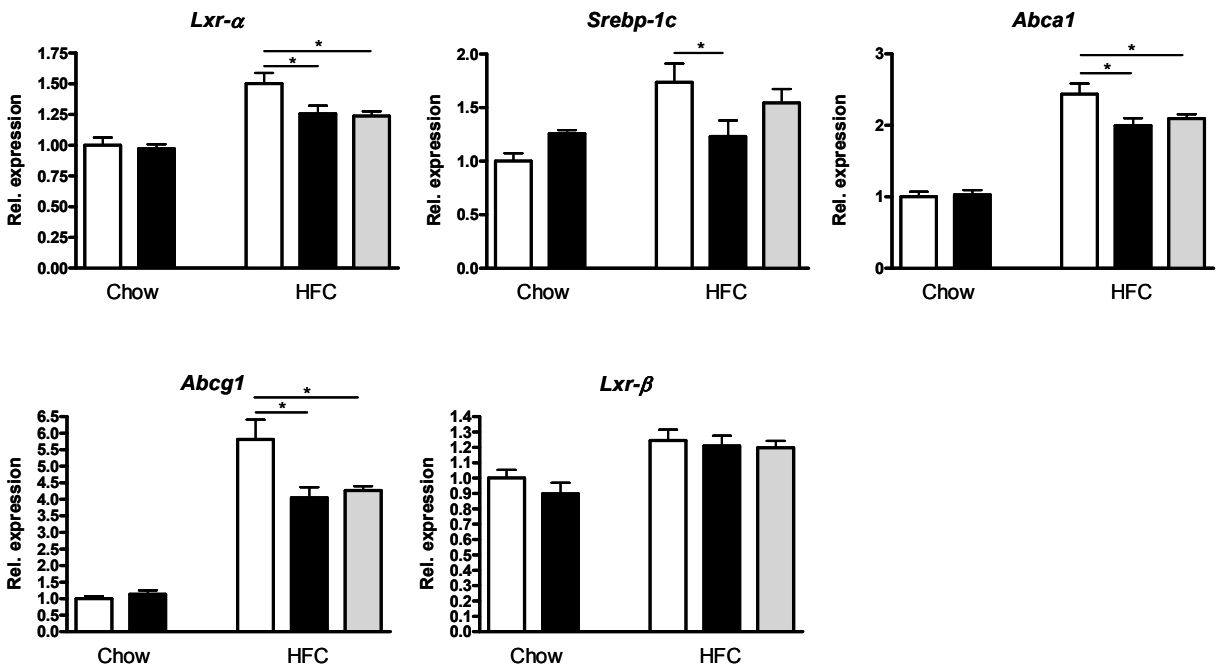

B
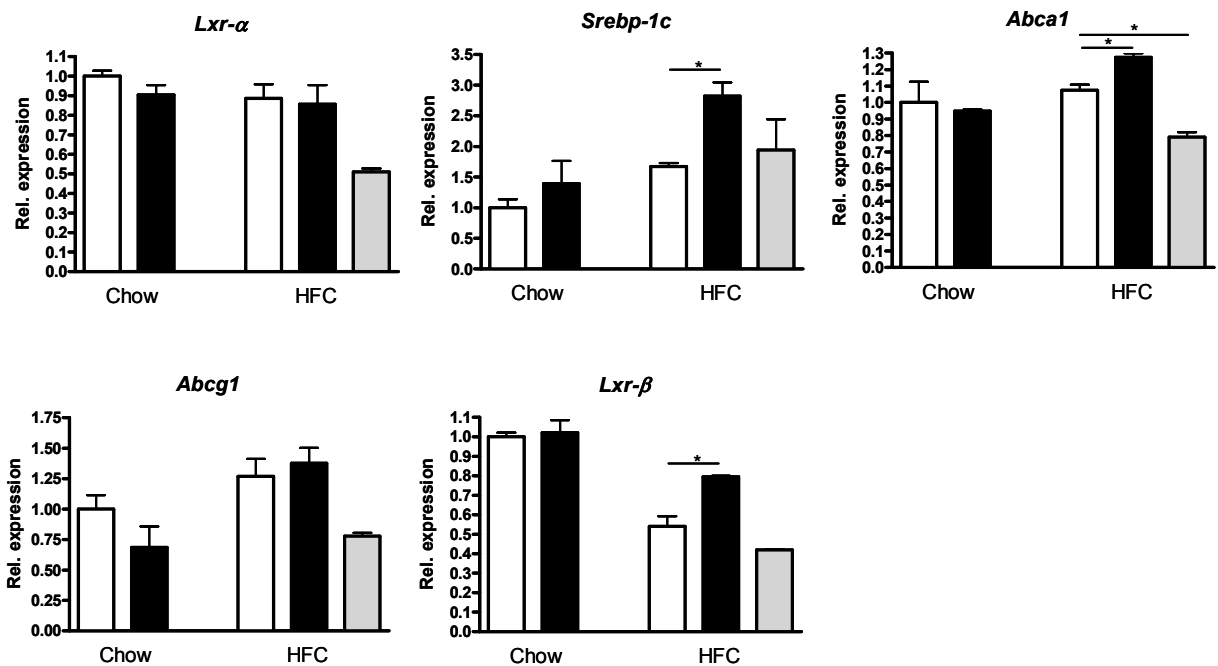

Figure S5.6 Gene expression of LXR and target genes in control- and 27HC-injected mice. (A) Gene expression analysis of Liver $X$ receptor $\alpha$ and $\beta$ (Lxr- $\alpha$ and $-\beta)$ and its downstream target genes sterol regulatory element binding protein $1 c$ (Srebp-1c), adenosine triphosphate (ATP)binding cassette transporter $\mathrm{A} 1$ (Abca1) and $\mathrm{G1}$ (Abcg1) in total liver and (B) isolated KCs of control- and $27 \mathrm{HC}$-injected mice. Data were relative to control mice on chow diet. ${ }^{*}$ indicates $p<0.05$. 
吕

2w Control + 1w 27HC

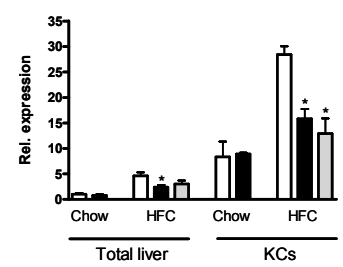

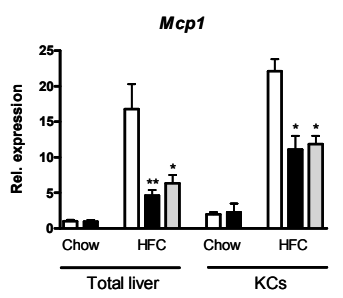

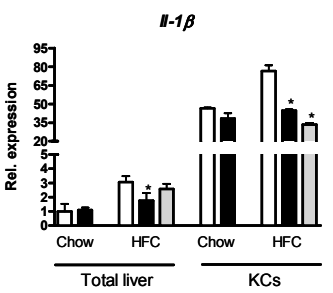

Figure S5.7 Inflammatory gene expression of Kupffer cells in control- and 27HC-injected mice. Comparison of gene expression in total liver vs. isolated KCs of the inflammatory markers tumor necrosis factor (Tnf), monocyte chemoattractant protein 1 (Mcp1) and interleukin $1 \beta$ (II-1ß). Data were relative to control mice on chow diet. * indicates $p<0.05$ and $* * p<0.01$. 
A

A

$27 \mathrm{HC}$

$2 \mathrm{w}$ control $+1 \mathrm{w} 27 \mathrm{HC}$
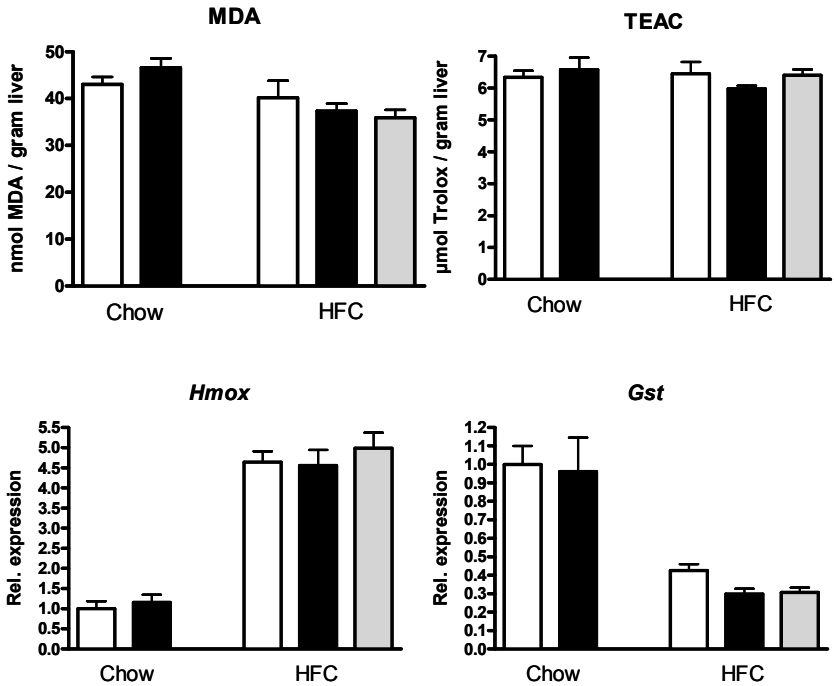

B
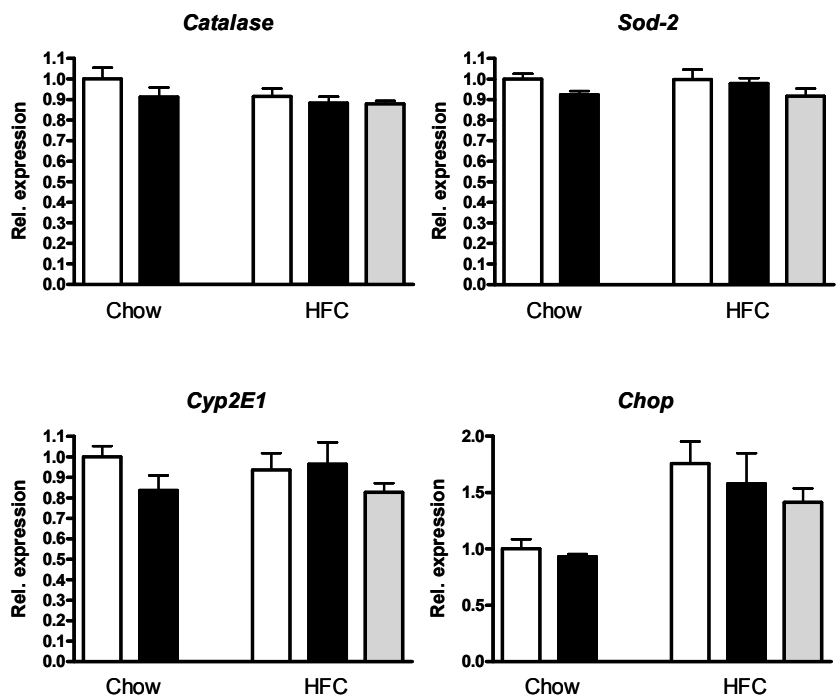

Figure S5.8 Measurements of oxidative stress in control- and 27HC-injected mice. (A) The lipid peroxidation marker malondialdehyde (MDA) and the anti-oxidant marker Trolox Equivalent Anti-oxidant Capacity (TEAC) were measured in liver homogenates of control- and 27HCinjected mice. (B) Hepatic gene expression of several anti- and pro- oxidant genes such as Catalase, superoxide dismutase 2 (Sod-2), heme oxygenase (Hmox), glutathione s-transferase (Gst), cytochrome P450 2E1 (Cyp2E1) and C/EBP homologous protein (Chop) in control- and $27 \mathrm{HC}$-injected mice. Data were relative to control mice on chow diet. 
A Males vs Females $27 \mathrm{HC} / \mathrm{Chol}$

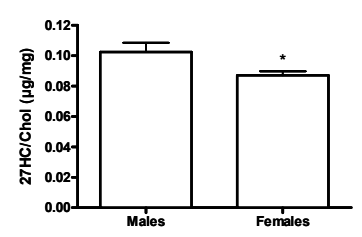

B $27 \mathrm{HC}$ vs Cholesterol Males

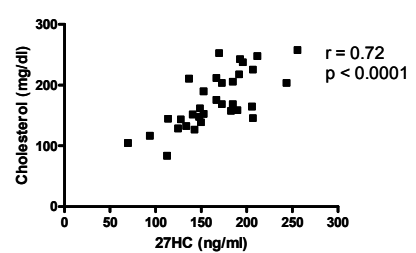

C $27 \mathrm{HC}$ vs Cholesterol Females

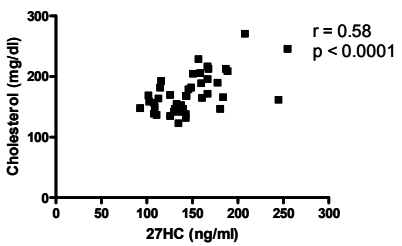

Figure S5.9 27HC levels in human subjects with NAFLD. (A) Difference in 27HC/cholesterol levels between males and females. $(B+C)$ Correlation between $27 \mathrm{HC}$ and plasma cholesterol levels in male and female subjects with different degrees of NAFLD. * indicates $p<0.05$. 


\section{Chapter \\ 6}

\section{Hematopoietic overexpression of Cyp27a1 reduces}

hepatic inflammation independently of 27hydroxycholesterol levels in $\mathrm{Ldll}^{-/-}$mice

T Hendrikx, ML Jeurissen, V Bieghs, SMA Walenbergh, PJ van Gorp, F Verheyen, T Houben, Y Dias Guichot, MJJ Gijbels, E Leitersdorf, M Hofker, D Lütjohann, R Shiri-Sverdlov

J Hepatol 2014 Oct 1. pii: S0168-8278(14)00718-1 


\section{Abstract}

\section{Background and aims}

Non-alcoholic steatohepatitis (NASH) is characterized by hepatic lipid accumulation and inflammation. Currently, the underlying mechanisms leading to hepatic inflammation are still unknown. The breakdown of free cholesterol inside Kupffer cells (KCs) by the mitochondrial enzyme CYP27A1 produces 27-hydroxycholesterol (27HC). We recently demonstrated that administration of $27 \mathrm{HC}$ to hyperlipidemic mice reduced hepatic inflammation. In line, hematopoietic deletion of CYP27A1 resulted in increased hepatic inflammation. In the current manuscript, the effect of hematopoietic overexpression of CYP27A1 on the development of NASH and cholesterol trafficking was investigated. We hypothesized that CYP27A1 overexpression in KCs will lead to reduced hepatic inflammation.

\section{Methods}

Irradiated $\mathrm{Ldll}^{-/}$mice were transplanted (tp) with bone marrow from mice overexpressing CYP27A1 (Cyp27a1 ${ }^{\text {over }}$ ) and wild-type (Wt) mice and fed either chow or high-fat, highcholesterol (HFC) diet for 3 months. Additionally, gene expression was assessed in bone marrow derived macrophages (BMDM) from Cyp27a1 ${ }^{\text {over }}$ and Wt mice.

\section{Results}

In line with our hypothesis, hepatic inflammation in HFC-fed Cyp27a1 ${ }^{\text {over }}$-tp mice was reduced and KCs were less foamy compared to Wt-tp mice. Remarkably, these changes occurred even though plasma and liver levels of $27 \mathrm{HC}$ did not differ between both groups. BMDM from Cyp27a1 ${ }^{\text {over }}$ mice revealed reduced inflammatory gene expression and increased expression of cholesterol transporters compared to Wt BMDM after LPS stimulation.

\section{Conclusions}

Our data suggest that overexpression of CYP27A1 in KCs reduces hepatic inflammation independently of $27 \mathrm{HC}$ levels in plasma and liver, further pointing towards $\mathrm{KCs}$ as specific target for improving therapy of NASH. 


\section{Introduction}

Non-alcoholic fatty liver disease (NAFLD) is considered the hepatic event of the metabolic syndrome and is characterized by the deposition of fat in the liver (steatosis). NAFLD covers a broad spectrum of diseases ranging from steatosis to nonalcoholic steatohepatitis (NASH). NASH is distinguished from simple steatosis by the added presence of inflammation in the liver. Whereas steatosis is generally considered a relatively benign and reversible condition, inflammation adversely affects the long-term prognosis of liver diseases as this enables the development of more advanced stages of the disease, including fibrosis, cirrhosis or hepatocellular carcinoma, ultimately requiring liver transplantation. ${ }^{1}$ So far, the intracellular mechanisms that trigger the inflammatory response are not known. Hence, therapy options are very poor and lack specificity.

The uptake of dietary cholesterol by Kupffer cells (KCs), the resident macrophages of the liver, was found to play an important role during NASH development. ${ }^{2}$ Similar to previously reported observations during atherosclerosis ${ }^{3,4}$, the accumulation of cholesterol leading to a swollen appearance of the macrophages, termed foam cells, was associated with an increased inflammatory response in the liver. ${ }^{5}$ Upon uptake by macrophages, cholesterol is initially directed to lysosomes for hydrolyzation and then further transported to the cytoplasm. Here, cholesterol can be converted into 27hydroxycholesterol $(27 \mathrm{HC})$ by the action of the mitochondrial enzyme CYP27A1 as the first step in the alternative pathway of bile acid formation. ${ }^{6}$ Recently, we demonstrated that exogenous administration of $27 \mathrm{HC}$ dramatically reduced hepatic inflammation in hyperlipidemic $\mathrm{Ldll}^{-/}$mice upon high-fat, high-cholesterol (HFC) feeding. ${ }^{7}$ In line with this observation, hematopoietic deletion of CYP27A1 resulted in increased hepatic inflammation. ${ }^{7}$

We hypothesized that hematopoietic overexpression of CYP27A1 will lead to reduced hepatic inflammation. In order to investigate the effect of overexpression of CYP27A1 in KCs on hepatic inflammation, bone-marrow chimeras were generated by injecting bone marrow cells from mice overexpressing CYP27A1 (Cyp27a1 ${ }^{\text {over }}$ ) into lethally irradiated $\mathrm{Ldll}^{-/}$hyperlipidemic host mice. In the current study we show that overexpression of CYP27A1 in KCs reduces hepatic inflammation independently of hepatic and plasma $27 \mathrm{HC}$ levels. 


\section{Materials and methods}

\section{Bone marrow-derived macrophages}

Bone marrow-derived macrophages were isolated from the tibiae and femurs of C57BL/ 6 or Cyp27a $1^{\text {over }}$ mice (kindly provided by E. Leitersdorf ${ }^{8}$ ). Cells were cultured in RPMI-1640 (GIBCO Invitrogen, Breda, the Netherlands) with 10\% heat-inactivated fetal calf serum (Bodinco B.V. Alkmaar, the Netherlands), penicillin (100 U/ml), streptomycin $(100 \mu \mathrm{g} / \mathrm{ml})$ and L-glutamine $2 \mathrm{mM}$ (all GIBCO Invitrogen, Breda, the Netherlands) supplemented with 20\% L929-conditioned medium (LCM) for 8-9 days to generate bone marrow-derived macrophages. After attachment, the macrophages were seeded at 350,000 cells per well in 24 wells plates and incubated $24 \mathrm{hrs}$ with medium (control), cyclodextrin (carrier control) or $27-\mathrm{HC}(0,25 \mu \mathrm{M} ; 1 \mu \mathrm{M})$. Then cells were washed and stimulated with LPS $(100 \mathrm{ng} / \mathrm{ml})$ for 4 hours. Finally, cells were lysed for mRNA expression analysis. For protein expression analysis and electron microscopy analysis, cells were seeded at $2,000,000$ cells per well in 6 wells plates and incubated under the same conditions.

\section{Mice, diet and bone marrow transplantation}

Mice were housed under standard conditions and given free access to food and water. Experiments were performed according to Dutch regulations and approved by the Committee for Animal Welfare of Maastricht University. Female 12-week-old Ld/rmice were lethally irradiated and transplanted with Wt or Cyp27a1 ${ }^{\text {over }}$ bone marrow as previously described. ${ }^{9}$ After a recovery period of 9 weeks, the mice were given either chow or HFC diet for 3 months (chow: $n=5$; HFC: $n=10$ ). The HFC diet contained $21 \%$ milk butter, $0.2 \%$ cholesterol, $46 \%$ carbohydrates and $17 \%$ casein. Collection of blood and tissue specimens, biochemical determination of lipids in plasma and liver, liver histology, electron microscopy, RNA isolation, cDNA synthesis, qPCR and oxysterol levels were determined as described previously., 70

\section{Statistical analysis}

Data were analyzed using Graphpad Prism 4.0.3 software. Groups were compared using the unpaired t-test for comparing two groups or one way ANOVA for comparing multiple groups. The data were expressed as the mean and standard error of the mean and were considered significantly different at * $p<0.05$; ${ }^{* *} p<0.01$; or $* * * \mathrm{p}<0.001$. 


\section{Results}

\section{Cyp27a1over-tp mice have less hepatic inflammation compared to Wt-tp mice}

The effect of hematopoietic overexpression of CYP27A1 in diet-induced NASH was investigated by transplanting bone marrow from wild type (Wt) and CYP27A1 overexpressing (Cyp27a1 $\left.{ }^{\text {over }}\right)$ mice into $\mathrm{Ldll}^{-/-}$mice. After a recovery period of 9 weeks, mice received chow or HFC diet for 3 months. Body weight did not differ significantly between groups (data not shown). To investigate the effect of hematopoietic overexpression of Cyp27a1 on hepatic inflammation, liver sections were stained with antibodies against several inflammatory markers including macrophages and neutrophils. Lower numbers of infiltrating macrophages $(p=0.0206)$ and neutrophils $(p=0.0146)$ were observed in the livers of Cyp27a1 $1^{\text {over }}$-tp mice compared to Wt-tp mice after HFC (Figure 6.1A), as further illustrated by representative pictures from the Mac1 staining for infiltrating macrophages and neutrophils (Figure 6.1B). These findings were confirmed by reduced hepatic gene expression of monocyte chemoattractant protein $1(M c p-1)(p=0.0083)$, chemokine (C-X-C motif) ligand 1 (CXCL1) $(p=0.046)$ and CXCL2 ( $p=0.039)$ in Cyp27a1 ${ }^{\text {over }}$-tp mice compared to Wt-tp mice upon HFC (Figure 6.1C), whereas gene expression for tumor necrosis factor-alpha (Tnf $\alpha$ ) showed the same trend, although it did not reach significance $(p=0.07)$. Taken together, these data indicate that hematopoietic overexpression of CYP27A1 reduces hepatic inflammation.

To investigate the effect of overexpression of Cyp27a1 in hematopoietic cells on apoptosis, hepatic expression of genes important during apoptosis was determined. Compared to animals on chow diet, the expression of apoptotic genes Bfl1 and TRAF1 were increased after 3 months of HFC diet. However, no difference was observed between Wt-tp and Cyp27a $1^{\text {over }}$-tp mice (Figure S6.1A). In line with these findings, no difference between Wt-tp and Cyp27a $1^{\text {over }}$-tp mice was found in hepatic expression of Catalase, SOD2, Hmox and Cyp2E1, markers for oxidative stress (Figure S6.1B). To further characterize the two genotypes, markers for liver damage and fibrosis were analyzed. As expected, plasma alanine transaminase (ALT) levels were increased in mice after 3 months of HFC feeding. No difference was observed between Wt-tp and Cyp27a $1^{\text {over }}$-tp mice. Additionally, hepatic gene expression of Tgf- 6 , a marker for fibrosis development, was unchanged between Wt-tp and Cyp27a ${ }^{\text {over }}$-tp mice upon HFC diet (Figure S6.1C). To evaluate macrophage polarization in the livers of both transplanted groups, hepatic gene expression analysis of $I L-12$, a M1 macrophage marker, was measured and revealed no difference between the two groups. Likewise, no difference was observed in the expression of the $M 2$ macrophage markers Arginase-1 (Arg-1) and IL-10 after 3 months of HFC feeding (Figure S6.1D). Taken together, these data indicate that hematopoietic overexpression of CYP27A1 reduces 
hepatic inflammation independent of the level of apoptosis, oxidative stress, liver damage or macrophage subset polarization.
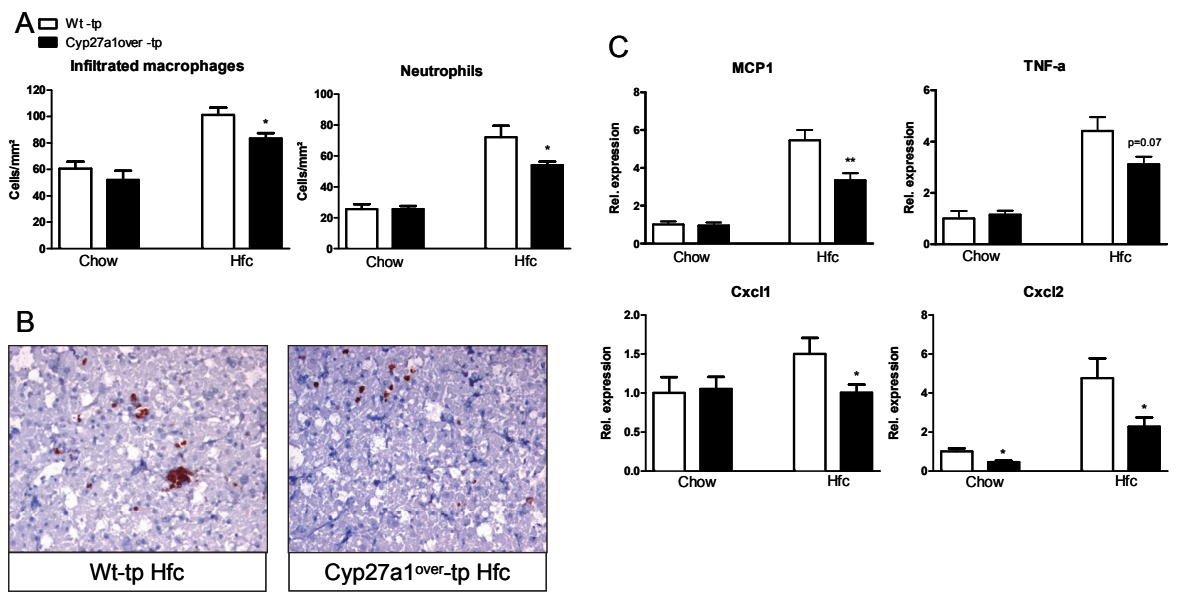

Figure 6.1 Parameters of hepatic inflammation in Wt-tp and Cyp27a1over-tp mice. (A) Liver sections were stained for infiltrating macrophages and neutrophils (Mac-1), neutrophils (NIMP) and the positive cells counted. (B) Representative pictures of Mac-1 staining (200x magnification) after 3 months of HFC diet in Wt-tp and Cyp27a1over-tp mice. (C) Gene expression analysis of monocyte chemoattractant protein 1 (Mcp-1), tumor necrosis factor alpha (Tnf-a), chemokine (C-X-C motif) ligand 1 (CXCL1) and CXCL2. Gene expression data were set relative to Wt-tp mice on chow diet. * indicates $\mathrm{p}<0.05$ and ${ }^{* *} \mathrm{p}<0.01$.

\section{Levels of 27-hydroxycholesterol in liver and plasma are not affected by hematopoietic Cyp27a1 overexpression}

After three months of HFC diet, no difference was found between the transplanted groups in hepatic levels of triglycerides (TG), cholesterol and free fatty acids (FFA) (Figure S6.2A). In addition, while plasma lipid levels were increased in mice receiving HFC for 3 months, hematopoietic overexpression of CYP27A1 did not affect plasma lipid levels. Total cholesterol, TG and FFA levels in plasma were not different in Cyp27a1 ${ }^{\text {over }}$-tp mice than in their controls, both in mice on chow as well as on HFC (Figure S6.2B). Altogether, hematopoietic overexpression of CYP27A1 does not affect plasma and liver lipid levels.

In order to study the effect of overexpression of CYP27A1 in hematopoietic cells on 27-hydroxycholesterol levels, 27-hydroxycholesterol in liver and plasma was measured in Wt-tp and Cyp27a1 ${ }^{\text {over }}$-tp mice. Surprisingly, no differences in the levels of 27-hydroxycholesterol in liver and plasma between both transplanted groups were observed (Figure 6.2A). 


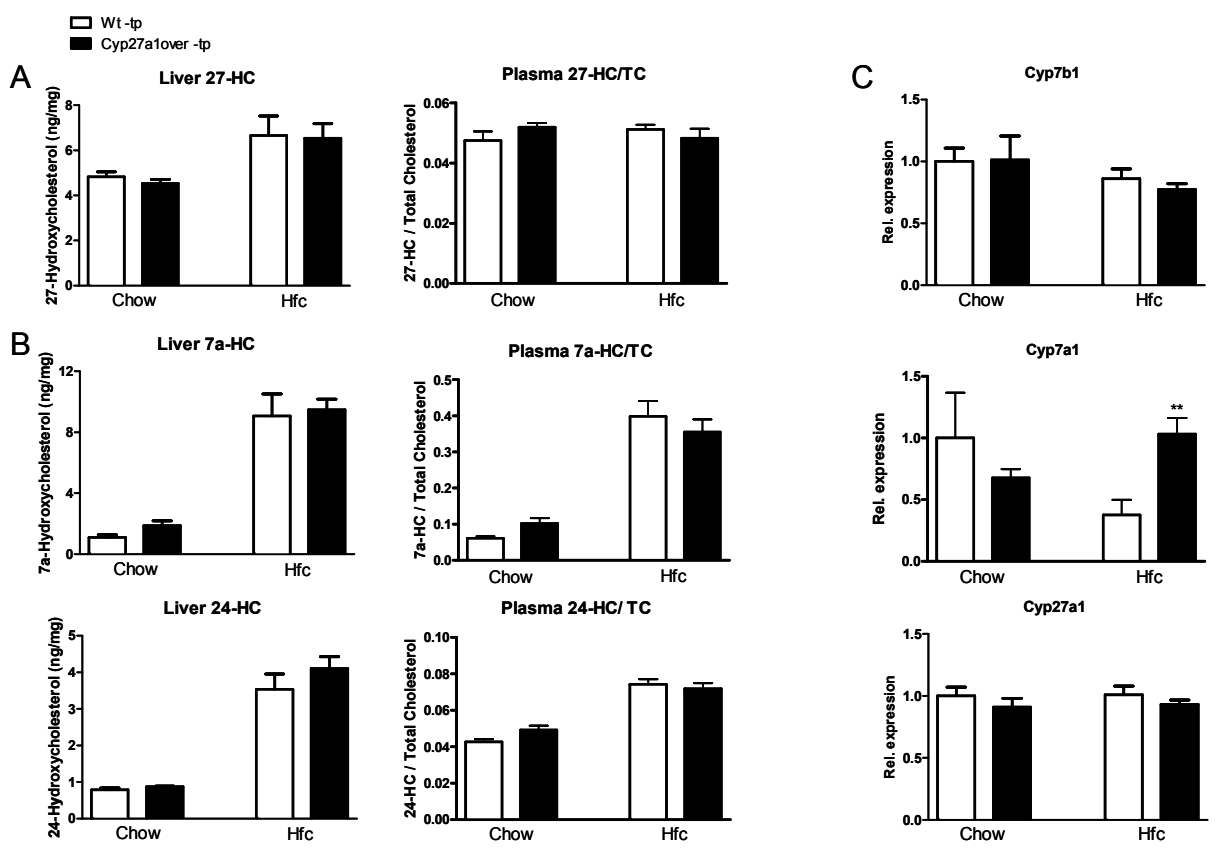

Figure 6.2 Liver and plasma oxysterol levels in Wt-tp and Cyp27a1 ${ }^{\text {over }}$-tp mice. (A) Liver and plasma 27hydroxycholesterol levels after chow and HFC diet. (B) Liver and plasma 7ahydroxycholesterol and 24-hydroxycholesterol levels after chow and HFC diet. (C) Gene expression analysis of hepatic Cyp7b1, Cyp7a1 and Cyp27a1 in Wt and Cyp27a $1^{\text {over }}$ mice. Gene expression data were set relative to $\mathrm{Wt}$-tp mice on chow diet. * indicates $p<0.05$

Additionally, in order to investigate whether hematopoietic overexpression of CYP27A1 is related to changes in the level of other oxysterols, levels of $7 \alpha$ - and 24hydroxycholesterol in liver and plasma were measured. There were no differences observed in $7 \alpha$ - and 24- hydroxycholesterol levels in the livers and plasma of Cyp27a1 ${ }^{\text {over }}$-tp mice compared to Wt-tp mice (Figure 6.2B). Taken together, these data indicate that the observed anti-inflammatory effect is not related to changes in oxysterol levels in liver and plasma.

To further investigate the similar levels of systemic and hepatic levels of $27 \mathrm{HC}$ between the groups, gene expression analysis of hepatic Cyp7b1, Cyp7a1 and Cyp27a1 was performed. No difference in the expression of Cyp7b1 between Wt-tp and Cyp27a $1^{\text {over }}$-tp mice was found, suggesting that degradation of $27 \mathrm{HC}$ is not different between the groups (Figure 6.2C). Hepatic gene expression levels of Cyp7a1 were increased in Cyp27a $1^{\text {over }}$-tp mice compared to control mice (Figure 6.2C), suggesting that more cholesterol is broken down in the classic pathway and therefore production of hepatic and systemic $27 \mathrm{HC}$ is not significantly increased in 
Cyp27a $1^{\text {over }}$-tp mice. Furthermore, gene expression of Cyp27a1 in total liver was not different between Wt-tp and Cyp27a $1^{\text {over }}$-tp mice (Figure 6.2C). Altogether, these data suggest that the increased systemic and hepatic production of $27 \mathrm{HC}$ is prevented by upregulation of the classical pathway.

\section{Less foamy Kupffer cells in Cyp27a1 ${ }^{\text {over }}$-tp mice compared to Wt-tp mice}

To analyze the effect of overexpression of CYP27A1 on the foamy appearance of KCS, a CD68 staining (for $\mathrm{KC}$ ) was performed and revealed a clear difference between Cyp27a1 $1^{\text {over }}$-tp mice and Wt-tp mice upon HFC diet. In Cyp27a1 ${ }^{\text {over }}$-tp mice, KCs are less swollen and foamy compared to KCs in Wt-tp animals (Figure S6.4A). These data are in line with reduced gene expression of $C d 68$ in the livers of $C y p 27 a 1^{\text {over }}$-tp mice compared to Wt-tp mice after 3 months of HFC feeding (Figure S6.4B).

To investigate whether the difference in the foamy appearance of KCs is related to changes in cholesterol uptake or cholesterol efflux, gene expression analysis was performed. For cholesterol uptake, hepatic expression of $C d 36$, scavenger receptor a $(S R-A)$, low density lipoprotein receptor-related protein 1 (LRP1) and SR-B1 did not differ between Wt-tp and Cyp27 $7^{\text {over }}$-tp mice upon HFC (Figure S6.4C). Next to that, no difference in hepatic expression of two well-known cholesterol efflux transporters, Abca1 and Abcg1, was observed between Wt-tp and Cyp2 $27^{\text {over }}$-tp mice (Figure S6.4D). Together, these data indicate that changes in the foamy appearance of KCs are not related to cholesterol uptake and reverse cholesterol transport in total liver.

\section{Bone marrow-derived macrophages (BMDM) from Cyp27a1 ${ }^{\text {over }}$ mice have increased intracellular cholesterol trafficking}

In order to investigate the mechanism by which CYP27A1 reduces inflammation, bone marrow cells were isolated from $\mathrm{Wt}$ and Cyp27a1 ${ }^{\text {over }}$ mice and cultured to macrophages. After stimulation with lipopolysaccharide (LPS) for $4 \mathrm{~h}$, the expression of Tnfa was significantly lower in BMDM from Cyp27a1 ${ }^{\text {over }}$ mice compared to those from Wt mice, confirming our in vivo findings that CYP27A1 overexpression in macrophages results in a reduced inflammatory response (Figure 6.3A).

To study the specific effect of CYP27A1 overexpression on cholesterol uptake by macrophages, the expression of $C d 36$ and SR-A was analyzed with and without LPS stimulation. No difference was observed between BMDM from $\mathrm{Wt}$ and from Cyp27a1 ${ }^{\text {over }}$ mice (Figure 6.3B). On the other hand, the expression of liver $\mathrm{X}$ receptor alpha $(L X R \alpha)(p=0.025)$, Abca1 $(p=0.0094)$ and Abcg1 $(p=0.0462)$, genes involved in cholesterol efflux, was increased in BMDM from Cyp27a1 $1^{\text {over }}$ mice compared to $\mathrm{Wt}$ BMDM after LPS stimulation (Figure 6.3C). These data indicate that CYP27A1 
overexpression in macrophages leads to an increase of cholesterol efflux transport during an inflammatory response.
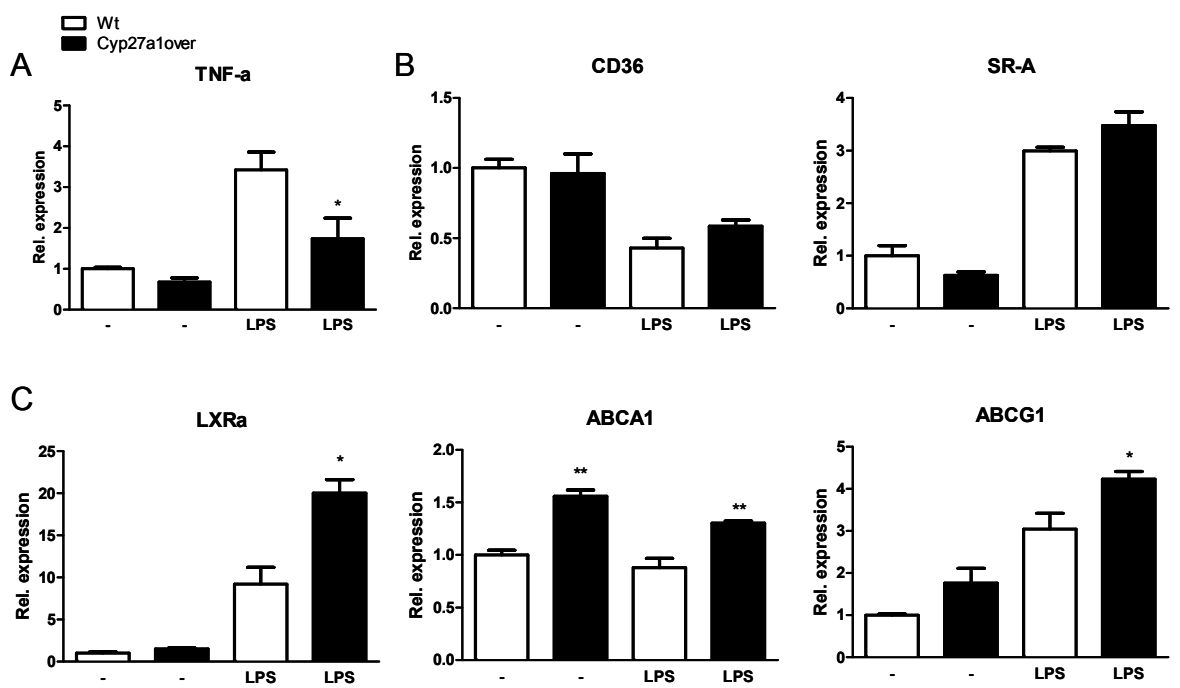

Figure 6.3 Gene expression in bone marrow derived macrophages from Wt and Cyp27a1 $1^{\text {over }}$ mice after LPS stimulation. Gene expression analysis of the inflammatory marker tumor necrosis factor alpha (Tnfo) (A), scavenger receptors Cd36 and SR-A (B), liver X receptor alpha (LXRa) and ATP-binding cassette transporter A1 (Abca1) and G1 (Abcg1) (C) in BMDM from Wt and Cyp27a1 $1^{\text {over }}$ mice after $4 \mathrm{~h}$ LPS stimulation. Data were set relative to BMDM from Wt mice incubated with medium. ${ }^{*}$ indicates $p<0.05$ and ${ }^{* *} p<0.01$.

To further examine the effect of CYP27A1 overexpression on intracellular cholesterol trafficking in macrophages, gene expression analysis for genes important for lysosomal cholesterol transport (Npc1 and Npc2) was assessed. Whereas Npc1 expression was not affected by LPS stimulation, the expression of $\mathrm{Npc2}$ increased dramatically after stimulation with LPS in both BMDM from Wt and Cyp27a $1^{\text {over }}$ mice (Figure 6.4A). Notably, macrophages overexpressing CYP27A1 showed increased expression of Npc2 compared to Wt BMDM after LPS stimulation (Figure 6.4A). Additionally, to study the effect of 27HC specific on macrophages, protein levels of $\mathrm{Npc1}$ and Npc2 were determined in BMDM from Wt mice that were incubated with $27 \mathrm{HC}$ and cyclodextrin (carrier control). Interestingly, 27HC incubation led to a significant induction of NPC1 and NPC2 protein levels compared to control condition (Figure 6.4B). This increase was accompanied by a reduction in lysosomal cholesterol accumulation in BMDM incubated with $27-\mathrm{HC}$ as shown in electron microscopy pictures (Figure 6.4C). While adding cyclodextrin resulted in a trend towards a reduction in lysosomal cholesterol accumulation, adding $27 \mathrm{HC}$ was able to 
dramatically reduce lysosomal cholesterol accumulation in comparison to control and compared to the cyclodextrin condition. Thus, $27 \mathrm{HC}$ is more effective in reducing lysosomal cholesterol accumulation than its vehicle cyclodextrin. Taken together, these data suggest that CYP27A1 and $27 \mathrm{HC}$ are able to modulate intracellular cholesterol trafficking in macrophages via NPC proteins.
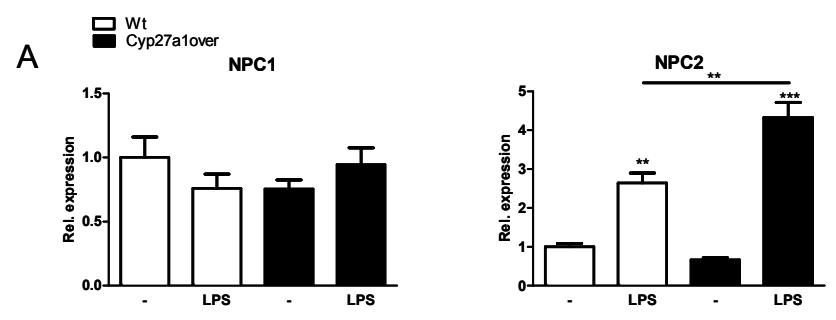

B
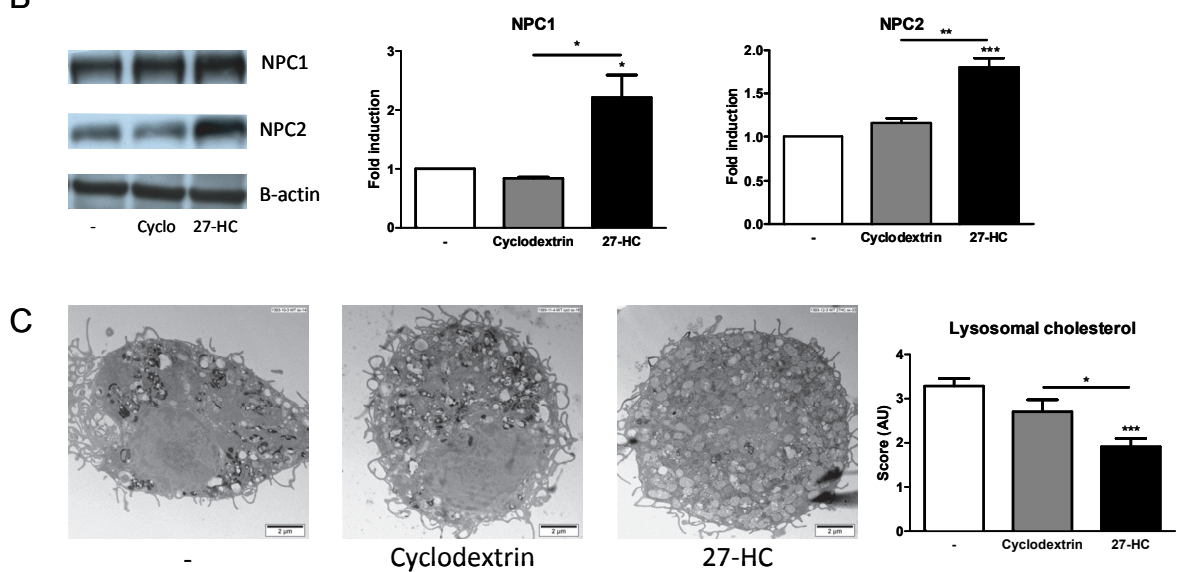

Figure 6.4 Gene expression and protein levels in bone marrow-derived macrophages from Wt and Cyp27a1 $1^{\text {over }}$ mice of genes important in intracellular cholesterol trafficking. (A) Niemann-Pick C1 (Npc1) and Npc2 gene expression in BMDM from Wt and Cyp27a1 $1^{\text {over }}$ mice after $4 \mathrm{~h}$ LPS stimulation. (B) Representative pictures of 5 independent Western blot measurements. Western blot analysis of Npc1 and Npc2 proteins in BMDM from Wt mice after $4 \mathrm{~h}$ LPS stimulation and incubation with cyclodextrin (carrier control) and 27-hydroxycholesterol. Bactin was used as loading control. (C) Representative electron microscopy pictures (acid phosphatase staining) of Wt BMDM incubated with medium, cyclodextrin or 27-HC. Pictures of approximately 25 BMDM were scored for lysosomal cholesterol accumulation. Data were set relative to BMDM from Wt mice incubated with medium. * indicates $\mathrm{p}<0.05 ; * * \mathrm{p}<0.01$; $* * * \mathrm{p}<0.001$. 


\section{Discussion}

Our results indicate that CYP27A1 overexpression in hematopoietic cells reduces dietinduced hepatic inflammation. Remarkably, the reduction in hepatic inflammation was independent of plasma and liver levels of 27-hydroxycholesterol and other oxysterols. Mechanistically, our data suggest that CYP27A1 can reduce hepatic inflammation via modulation of intracellular cholesterol trafficking in macrophages. Furthermore, our data provide further evidence to the importance of KCs in triggering hepatic inflammation.

\section{CYP27A1 is able to reduce hepatic inflammation independent of circulating $27 \mathrm{HC}$ levels}

Currently, most data are highly controversial regarding the activities of oxysterols. Although some in vitro studies have demonstrated that oxysterols have some cytotoxic, oxidative, and/or inflammatory effects ${ }^{11}$, the most abundant oxysterol, being $27 \mathrm{HC}$, is considered to be a potential candidate for the reduction of inflammation during NASH. ${ }^{7}$ Daily injection of $27 \mathrm{HC}$ was found to result in reduced hepatic inflammation in a dietary model for NASH. As expected, in addition to the reduced inflammatory response upon $27 \mathrm{HC}$ administration, increased levels of $27 \mathrm{HC}$ in liver and plasma were detected. ${ }^{7}$ Importantly, $27 \mathrm{HC}$ was found to be a selective estrogen receptor modulator that can serve as a competitive antagonist for the estrogen receptor. ${ }^{12,13}$ As such, circulating levels of $27 \mathrm{HC}$ levels may directly antagonize the functions of estrogen receptors in vascular endothelial and smooth muscle cells, thereby leading to a loss of the cardioprotective effect of estrogen. ${ }^{14}$ Furthermore, increased levels of 27HC, as occurs during hypercholesterolemia, have recently been shown to be involved in different pathologies. In a mouse model for breast cancer, it was shown that $27 \mathrm{HC}$ increases estrogen receptor dependent growth and LXR dependent metastasis. ${ }^{15}$ Mice that had increased circulating levels of $27 \mathrm{HC}$ showed increased metastasis of breast cancer cells to the lung. Besides the involvement in breast cancer, it was shown that increased concentrations of $27 \mathrm{HC}$ led to decreased bone mineral density that was associated with decreased bone formation and increased bone resorption. ${ }^{12}$ Our current data indicate that increased CYP27A1 expression, specifically in hematopoietic cells, does not alter circulating $27 \mathrm{HC}$ levels while inflammation is reduced. Our data suggest that the increased systemic and hepatic production of $27 \mathrm{HC}$ is prevented by upregulation of the classical pathway. Another explanation for the similar levels of systemic and hepatic levels of $27 \mathrm{HC}$ between the groups is the fact that parenchymal cells compromise about $80 \%$ of all liver cells. In our study, gene expression of Cyp27a1 in total liver was not different between Wt-tp and Cyp27a1 $1^{\text {over }}$-tp mice. Therefore, hematopoietic overexpression of CYP27A1 is not likely to be reflected in increased $27 \mathrm{HC}$ levels in plasma and liver. 
Therefore, our data further point towards therapy options wherein CYP27A1 is specifically targeted in KCs.

\section{CYP27A1 modulates intracellular cholesterol trafficking via NPC proteins}

The observation that hematopoietic CYP27A1 overexpression leads to a reduced foamy appearance of KCs while neither cholesterol uptake, nor reverse cholesterol transport was modulated in total liver suggests that overexpression of CYP27A1 only affected intracellular cholesterol trafficking inside KCs. Our current observations are in line with our previous findings that indicated that the agonistic effect of $27 \mathrm{HC}$ on the liver $\mathrm{X}$ receptor (LXR) in KCs is not dominant in all liver cells, but is restricted to KCs. ${ }^{7}$ In line with our data it was shown that introducing the expression of CYP27A1 in vitro by transfecting cells, stimulated cholesterol efflux compared to un-transfected control cells. ${ }^{16}$ Additionally, pre-incubation of non-transfected cells with $27 \mathrm{HC}$ led to increased cholesterol efflux by $24-60 \% .{ }^{16}$ Others have reported that this process may occur via LXR stimulation, as it is known that $27 \mathrm{HC}$ and possibly another product of CYP27A1, cholestenoic acid, may be ligands of LXR, regulating a number of genes involved in lipid metabolism including Abca1. ${ }^{17}$ Interestingly, hepatic levels of cholesteryl esters were dramatically reduced in Cyp27a $1^{\text {over }}$-tp mice compared to the levels in Wt-tp mice in our study. In line with our findings, it was demonstrated that reduced cholesteryl esters, by transgenic overexpression of cholesteryl ester hydrolase (CEH) in macrophages, polarizes Kupffer cells to a more anti-inflammatory phenotype that attenuates hepatic lipid synthesis and accumulation. ${ }^{18}$ Furthermore, macrophage $\mathrm{CEH}$ overexpression was found to reduce atherosclerosis and necrosis in LdIr $^{-1}$ mice, while free cholesterol levels were unchanged. ${ }^{19,20}$ In addition, accumulation of cholesteryl esters during cholesteryl ester storage disease is known to be associated with increased inflammation in different tissues and accelerated atherosclerosis. ${ }^{21}$

Although $27 \mathrm{HC}$ was previously shown to be able to influence intracellular cholesterol transport from lysosomes to the cytoplasm ${ }^{7,22}$, the mechanism involved is not yet known. The two main proteins that are involved in cholesterol transport from lysosomes to the cytoplasm are Niemann-Pick C1 (NPC1) and NPC2. While NPC1 is a multiple membrane spanning domain protein containing a sterol sensing domain, NPC2 is a small intralysosomal protein that has been characterized biochemically as a cholesterol binding and transport protein. ${ }^{23} \mathrm{~A}$ defect in either of these proteins results in Niemann-Pick disease type $\mathrm{C}$, characterized by lysosomal cholesterol accumulation and inflammation in different tissues including the liver. Interestingly, it was shown that NPC1 and NPC2 deficient cells have a severely reduced production of $27 \mathrm{HC}$, and that upon incubation with $27 \mathrm{HC}$ the lysosomal cholesterol pool in $\mathrm{NPC1}^{-1-}$ fibroblasts is dramatically reduced. ${ }^{22}$ In line with these data, we observed for the first time that 
CYP27A1 overexpression is able to increase NPC1 and NPC2 gene expression and protein levels. After binding, NPC2 is able to deliver cholesterol intracellular via interaction with the phospholipid bilayer, thereby reaching a putative transmembrane transporter via lateral diffusion in the plane of the membrane, or it could flip across the limiting lysosomal membrane and become accessible for transportation to the plasma membrane. ${ }^{24}$ Alternatively, NPC2 is able to directly interact with NPC1 or other lysosomal membrane proteins, resulting in the removal of cholesterol from the lysosome. ${ }^{25}$ In this way, NPC1 and NPC2 function as a tag team duo to mobilize cholesterol. $^{24,26}$ Our data suggest that $27 \mathrm{HC}$ can stimulate NPC-mediated cholesterol binding and transportation to the lysosomal membrane, where it can be released out of the lysosomes. Taken together, our studies provide a new mechanism by which CYP27A1 can modulate intracellular cholesterol trafficking in macrophages, thereby leading to reduced inflammation.

While both intracellular cholesterol trafficking and cholesterol efflux can modulate inflammation, the increased NPC expression observed in the Cyp27a $1^{\text {over }}$-tp mice is probably the main reason for the reduced inflammatory response observed in the Cyp27a $1^{\text {over }}$-tp mice. Increased cholesterol efflux was shown to modulate the immune response and inflammation through direct and indirect anti-inflammatory mechanisms. ${ }^{17}$ However, it was reported previously that the total amount of cholesterol in cells is not correlated directly with inflammation, but rather the amount of cholesterol trapped inside lysosomes ${ }^{2}$, suggesting an important role for NPC proteins in the inflammatory response. Moreover, studies in both arteries and cells in culture have shown that the accumulated cholesterol in lysosomes cannot be decreased simply by inhibiting further uptake of lipoproteins or by increasing efflux of extra-lysosomal cholesterol stores. ${ }^{27-29}$ On the other hand, increasing the expression of the NPC1 protein led to increased cholesterol efflux and the inhibition of atherosclerosis. ${ }^{30}$ Thus, increased cholesterol efflux can also be a consequence of increased NPC expression. To conclude, while both pathways contribute to the reduced inflammatory response observed in the Cyp27a ${ }^{\text {over }}$-tp mice, stimulating the transport of cholesterol out of the lysosomes seems to play a more dominant role.

In summary, we have shown for the first time that overexpression of CYP27A1, specifically in macrophages, is able to reduce hepatic inflammation. Mechanistically, our data suggest that CYP27A1 can modulate intracellular cholesterol trafficking by increasing NPC1 and NPC2 expression. This effect is likely regulated via increased intracellular levels of $27 \mathrm{HC}$ while circulating levels of $27 \mathrm{HC}$ are unchanged between the transplanted groups. Taken together, our data point towards the potential of targeted therapy options during the development of NASH and other inflammatoryrelated disorders, such as atherosclerosis. 


\section{References}

1. Wree A, Broderick L, Canbay A, Hoffman HM, Feldstein AE. From NAFLD to NASH to cirrhosis-new insights into disease mechanisms. Nat Rev Gastroenterol Hepatol. 2013;;10:627-36.

2. Bieghs V, Verheyen F, van Gorp PJ, Hendrikx T, Wouters K, Lütjohann D, Gijbels MJ, Febbraio M, Binder CJ, Hofker MH, Shiri-Sverdlov R. Internalization of modified lipids by CD36 and SR-A leads to hepatic inflammation and lysosomal cholesterol storage in Kupffer cells. PLoS One. 2012;7:e34378.

3. Cox BE, Griffin EE, Ullery JC, Jerome WG. Effects of cellular cholesterol loading on macrophage foam cell lysosome acidification. J Lipid Res. 2007;48:1012-21.

4. Jerome WG, Cox BE, Griffin EE, Ullery JC. Lysosomal cholesterol accumulation inhibits subsequent hydrolysis of lipoprotein cholesteryl ester. Microsc Microanal. 2008;14:138-49.

5. Wouters K, van Gorp PJ, Bieghs V, Gijbels MJ, Duimel H, Lütjohann D, Kerksiek A, van Kruchten R, Maeda N, Staels B, van Bilsen M, Shiri-Sverdlov R, Hofker MH. Dietary cholesterol, rather than liver steatosis, leads to hepatic inflammation in hyperlipidemic mouse models of nonalcoholic steatohepatitis. Hepatology. 2008;48:474-86.

6. Hall E, Hylemon P, Vlahcevic Z, Mallonee D, Valerie K, Avadhani N, et al. Overexpression of CYP27 in hepatic and extrahepatic cells: role in the regulation of cholesterol homeostasis. Am J Physiol Gastrointest Liver Physiol. 2001;281:G293-301.

7. Bieghs V, Hendrikx T, van Gorp PJ, Verheyen F, Guichot YD, Walenbergh SM, et al. The cholesterol derivative 27-hydroxycholesterol reduces steatohepatitis in mice. Gastroenterology. 2013;144:167178 e161.

8. Meir K, Kitsberg D, Alkalay I, Szafer F, Rosen H, Shpitzen S, Avi LB, Staels B, Fievet C, Meiner V, Björkhem I, Leitersdorf E. Human sterol 27-hydroxylase (CYP27) overexpressor transgenic mouse model. Evidence against 27-hydroxycholesterol as a critical regulator of cholesterol homeostasis. $J$ Biol Chem. 2002;277:34036-34041.

9. Bieghs V, Wouters K, van Gorp PJ, Gijbels MJ, de Winther MP, Binder CJ, Lütjohann D, Febbraio M, Moore KJ, van Bilsen M, Hofker MH, Shiri-Sverdlov R. Role of scavenger receptor A and CD36 in dietinduced nonalcoholic steatohepatitis in hyperlipidemic mice. Gastroenterology. ;138:2477-2486, 2486 e2471-2473.

10. Hendrikx T, Bieghs V, Walenbergh SM, van Gorp PJ, Verheyen F, Jeurissen ML, Steinbusch MM, Vaes $\mathrm{N}$, Binder CJ, Koek GH, Stienstra R, Netea MG, Hofker MH, Shiri-Sverdlov R. Macrophage specific caspase-1/11 deficiency protects against cholesterol crystallization and hepatic inflammation in hyperlipidemic mice. PLoS One. 2013;8:e78792.

11. Vejux A, Montange T, Martine L, Zarrouk A, Riedinger JM, Lizard G. Absence of oxysterol-like side effects in human monocytic cells treated with phytosterols and oxyphytosterols. J Agric Food Chem. 2012;60:4060-6.

12. DuSell CD, Nelson ER, Wang X, Abdo J, Mödder UI, Umetani M, Gesty-Palmer D, Javitt NB, Khosla S, McDonnell DP. The endogenous selective estrogen receptor modulator 27-hydroxycholesterol is a negative regulator of bone homeostasis. Endocrinology. 2010;151:3675-85.

13. DuSell CD, Umetani M, Shaul PW, Mangelsdorf DJ, McDonnell DP. 27-hydroxycholesterol is an endogenous selective estrogen receptor modulator. Mol Endocrinol. 2008;22:65-77.

14. Umetani M, Domoto H, Gormley AK, Yuhanna IS, Cummins CL, Javitt NB, Korach KS, Shaul PW, Mangelsdorf DJ. 27-Hydroxycholesterol is an endogenous SERM that inhibits the cardiovascular effects of estrogen. Nat Med. 2007;13:1185-92.

15. Nelson ER, DuSell CD, Wang X, Howe MK, Evans G, Michalek RD, Umetani M, Rathmell JC, Khosla S, Gesty-Palmer D, McDonnell DP. The oxysterol, 27-hydroxycholesterol, links cholesterol metabolism to bone homeostasis through its actions on the estrogen and liver $\mathrm{X}$ receptors. Endocrinology. 2011;152:4691-705.

16. Escher G, Krozowski Z, Croft KD, Sviridov D. Expression of sterol 27-hydroxylase (CYP27A1) enhances cholesterol efflux. J Biol Chem. 2003;278:11015-11019.

17. Fu X, Menke JG, Chen Y, Zhou G, MacNaul KL, Wright SD, Sparrow CP, Lund EG. 27-hydroxycholesterol is an endogenous ligand for liver $X$ receptor in cholesterol-loaded cells. J Biol Chem. 2001;276: 38378-87. 
18. Bie J, Zhao B, Marqueen KE, Wang J, Szomju B, Ghosh S. Macrophage-specific transgenic expression of cholesteryl ester hydrolase attenuates hepatic lipid accumulation and also improves glucose tolerance in ob/ob mice. Am J Physiol Endocrinol Metab 2012;302:E1283-91.

19. Zhao B, Song J, Chow WN, St Clair RW, Rudel LL, Ghosh S. Macrophage-specific transgenic expression of cholesteryl ester hydrolase significantly reduces atherosclerosis and lesion necrosis in Ldlr mice. J Clin Invest 2007;117:2983-92.

20. Zhao B, Song J, St Clair RW, Ghosh S. Stable overexpression of human macrophage cholesteryl ester hydrolase results in enhanced free cholesterol efflux from human THP1 macrophages. Am J Physiol Cell Physiol 2007;292:C405-12.

21. Bernstein DL, Hulkova H, Bialer MG, Desnick RJ. Cholesteryl ester storage disease: review of the findings in 135 reported patients with an underdiagnosed disease. J Hepatol 2013;58:1230-43.

22. Frolov A, Zielinski SE, Crowley JR, Dudley-Rucker N, Schaffer JE, Ory DS. NPC1 and NPC2 regulate cellular cholesterol homeostasis through generation of low density lipoprotein cholesterol-derived oxysterols. J Biol Chem 2003;278:25517-25.

23. Ramirez CM, Liu B, Aqul A, Taylor AM, Repa JJ, Turley SD, et al. Quantitative role of LAL, NPC2, and NPC1 in lysosomal cholesterol processing defined by genetic and pharmacological manipulations. J Lipid Res 2011;52:688-98.

24. Infante RE, Wang ML, Radhakrishnan A, Kwon HJ, Brown MS, Goldstein JL. NPC2 facilitates bidirectional transfer of cholesterol between NPC1 and lipid bilayers, a step in cholesterol egress from lysosomes. Proc Natl Acad Sci U S A 2008;105:15287-92.

25. Storch J, Xu Z. Niemann-Pick C2 (NPC2) and intracellular cholesterol trafficking. Biochim Biophys Acta 2009;1791:671-8.

26. Subramanian K, Balch WE. NPC1/NPC2 function as a tag team duo to mobilize cholesterol. Proc Natl Acad Sci U S A 2008;105:15223-4.

27. Jerome WG, Lewis JC. Early atherogenesis in White Carneau pigeons: effect of a short-term regression diet. Exp Mol Pathol 1990;53:223-38.

28. Yancey PG, Jerome WG. Lysosomal cholesterol derived from mildly oxidized low density lipoprotein is resistant to efflux. J Lipid Res 2001;42:317-27.

29. Yancey PG, Miles S, Schwegel J, Jerome WG. Uptake and trafficking of mildly oxidized LDL and acetylated LDL in THP-1 cells does not explain the differences in lysosomal metabolism of these two lipoproteins. Microsc Microanal 2002;8:81-93.

30. Ma X, Hu YW, Mo ZC, Li XX, Liu XH, Xiao J, et al. NO-1886 up-regulates Niemann-Pick C1 protein (NPC1) expression through liver $X$ receptor alpha signaling pathway in THP-1 macrophage-derived foam cells. Cardiovasc Drugs Ther 2009;23:199-206. 


\section{Supplemental figures}

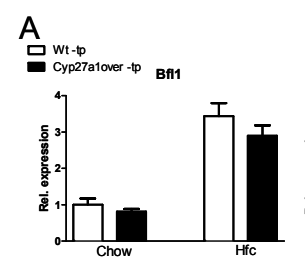

B

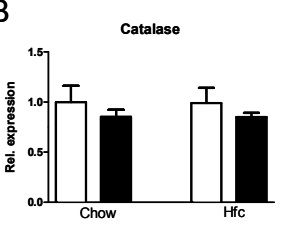

Hmox

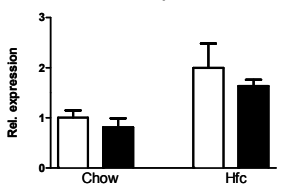

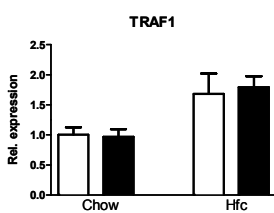

SOD2

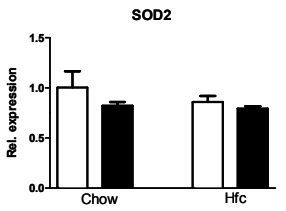

Cyp2e1

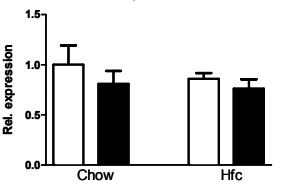

C
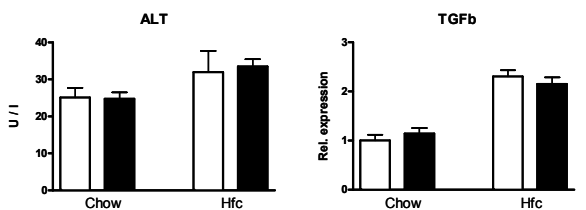

D
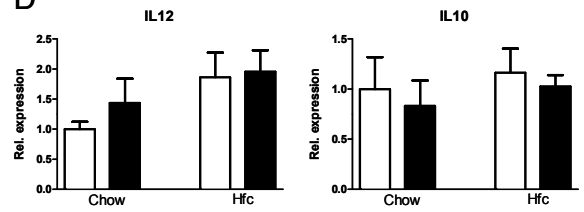

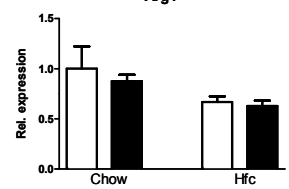

Figure S6.1 Characterization for apoptosis, oxidative stress, liver damage and macrophage polarization of Wt-tp and Cyp27a1 ${ }^{\text {over }}$-tp mice. (A) Hepatic expression analysis of apoptotic genes Bfl1 and TRAF1 in Wt-tp and Cyp27a1 $1^{\text {over }}$-tp mice. (B) Hepatic gene expression analysis of Catalase, SOD2, Hmox and Cyp2E1, markers for oxidative stress. (C) Plasma alanine transaminase (ALT) levels and hepatic gene expression of Tgf- 6 in Wt-tp and Cyp27a $1^{\text {over }}$-tp mice after chow and HFC diet. (D) Hepatic gene expression analysis of IL-12, IL-10 and Arginase-1 (Arg-1) as markers for macrophage polarization in Wt-tp and Cyp27a $1^{\text {over }}$-tp mice. Gene expression data were set relative to Wt-tp mice on chow diet. 
A 므 Cyp27a1over-tp $_{\text {Wt }}$
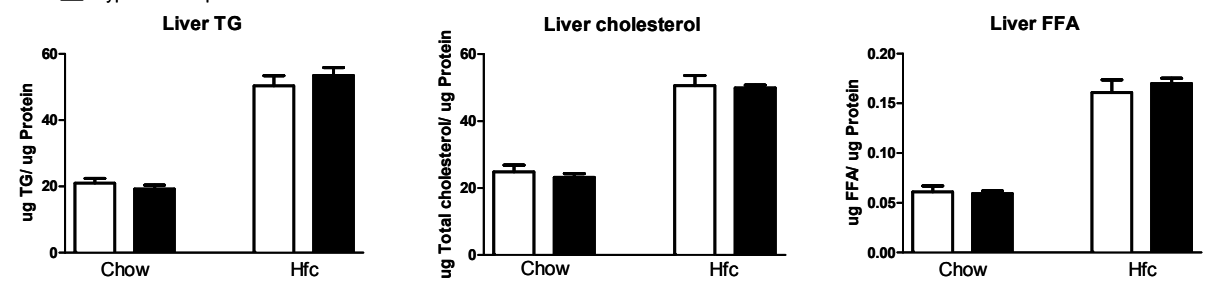

B
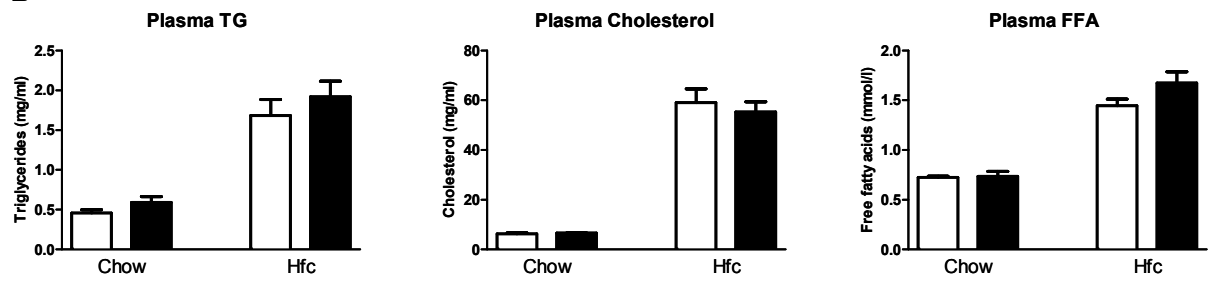

Figure S6.2 Liver and plasma lipid levels in Wt-tp and Cyp27a1 ${ }^{\text {over }}$-tp mice. (A) Liver triglyceride, cholesterol and free fatty acid levels after chow and HFC diet in Wt-tp and Cyp27a $1^{\text {over }}$-tp mice. (B) Plasma triglyceride, cholesterol and free fatty acid levels after chow and HFC diet in Wt-tp and Cyp27a $1^{\text {over }}$-tp mice. 

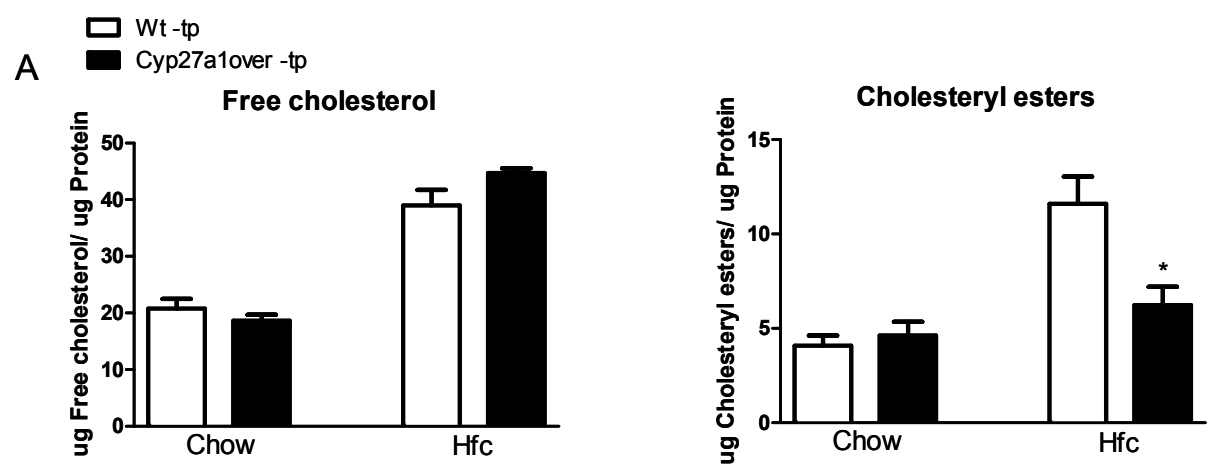

B ACAT2

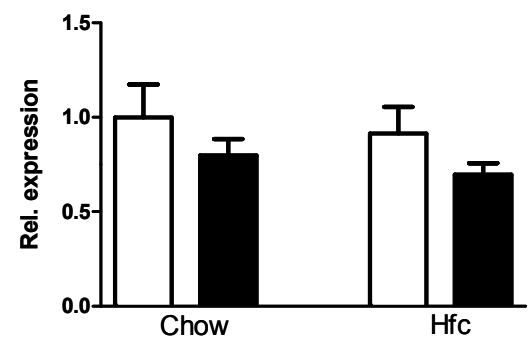

Figure S6.3 Liver cholesterol measurements and ACAT2 expression in Wt-tp and Cyp27a1 ${ }^{\text {over }}$-tp mice. (A) Liver free cholesterol and cholesteryl esters after chow and HFC diet in Wt-tp and Cyp27a ${ }^{\text {over }}$ tp mice. (B) Hepatic gene expression analysis of ACAT2 in liver of Wt-tp and Cyp27a $1^{\text {over }}$-tp mice. Gene expression data were set relative to Wt-tp mice on chow diet. * indicates $p<0.05$. 
A

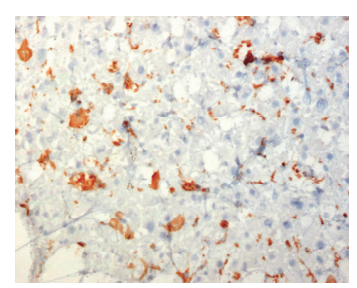

Wt-tp Hfc

C

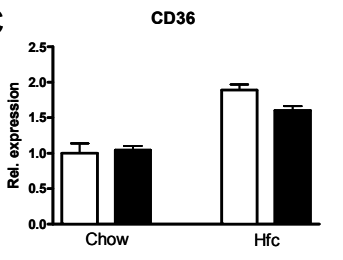

LRP1

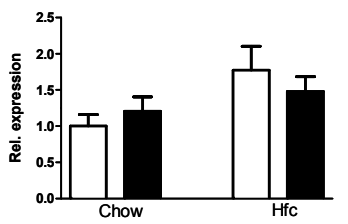

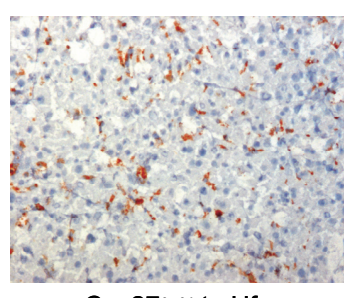

Cyp27over-tp Hfc

SR-A

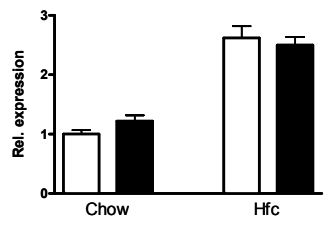

SR-B1

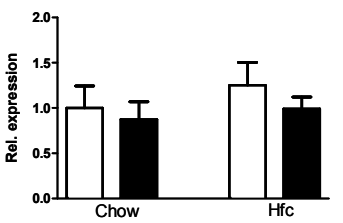

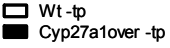

B CD68

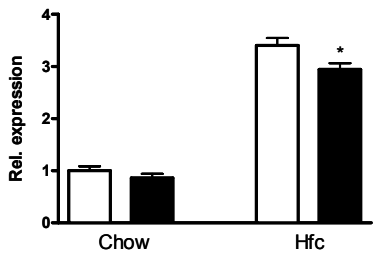

D

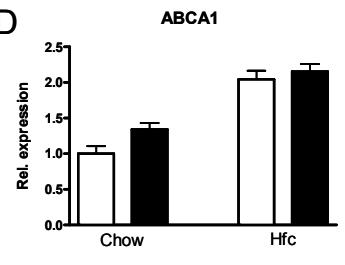

ABCG1

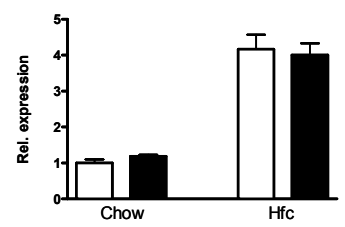

Figure S6.4 Foamy appearance of KCs and hepatic cholesterol metabolism gene expression in Wt-tp and Cyp27a ${ }^{\text {over }}$-tp mice. (A) Representative pictures of Cd68 staining (200x magnification) after 3 months of HFC diet in Wt-tp and Cyp27a1 $1^{\text {over }}$-tp mice. Hepatic gene expression analysis of macrophage marker Cd68 (B), scavenger receptors Cd36, SR-A, LRP1 and SR-B1 (C), and ATPbinding cassette transporter A1 (Abca1) and G1 (Abcg1) (D) in liver of Wt-tp and Cyp27a1 ${ }^{-}$-tp mice. Gene expression data were set relative to Wt-tp mice on chow diet. ${ }^{*}$ indicates $p<0.05$. 


\section{Chapter \\ 7}

\section{Protective role of plant sterol and stanol esters in}

liver inflammation: insights from mice and humans

J Plat, T Hendrikx, V Bieghs, MLJ Jeurissen, SMA Walenbergh, PJ van Gorp, E De Smet, M Konings, ACE Vreugdenhil, Y Dias Guichot, SS Rensen, WA Buurman, JWM Greve, D Lütjohann, RP Mensink, R Shiri-Sverdlov

PLoS One 2014;9:e110758 


\section{Abstract}

The inflammatory component of non-alcoholic steatohepatitis (NASH) can lead to irreversible liver damage. Therefore there is an urgent need to identify novel interventions to combat hepatic inflammation. In mice, omitting cholesterol from the diet reduced hepatic inflammation. Considering the effects of plant sterol/stanol esters on cholesterol metabolism, we hypothesized that plant sterol/stanol esters reduces hepatic inflammation. Indeed, adding plant sterol/stanol esters to a high-fat-diet reduced hepatic inflammation as indicated by immunohistochemical stainings and gene expression for inflammatory markers. Finally, adding sterol/stanol esters lowered hepatic concentrations of cholesterol precursors lathosterol and desmosterol in mice, which were highly elevated in the HFD group similarly as observed in severely obese patients with NASH. In vitro, in isolated LPS stimulated bone marrow derived macrophages desmosterol activated cholesterol efflux whereas sitostanol reduced inflammation. This highly interesting observation that plant sterol/stanol ester consumption leads to complete inhibition of HFD-induced liver inflammation opens new venues in the treatment and prevention of hepatic inflammation. 


\section{Introduction}

NASH is generally recognized as the hepatic event of the metabolic syndrome. The current prevalence of NASH within the general population is estimated to be as high as $2-3 \%$. However, among obese subjects the prevalence is far higher, ${ }^{1}$ and therefore the number of NASH patients is expected to increase dramatically due to the increasing prevalence of obesity. Most importantly, not only adults are at risk, but also the increasing prevalence of child obesity is a major threat. It is generally accepted that steatosis is probably benign and reversible, whereas the introduction of inflammation can lead to further progression into $\mathrm{NASH}$, ultimately resulting in liver fibrosis, cirrhosis and in some cases eventually liver failure and hepatocellular carcinoma. Pharmacological possibilities to interfere with hepatic inflammation are hardly available and information on dietary determinants is limited. Therefore, there is an urgent need to identify novel (dietary) strategies with the capacity to lower liver inflammation.

Plant sterols and plant stanols are natural dietary ingredients, sharing structural similarities with cholesterol. The average intake of plant sterols from habitual diets is approximately $250 \mathrm{mg} /$ day, which is mainly derived from vegetable oils, grain products, nuts, seeds, fruits and vegetables. The intake of plant stanols (the saturated derivatives) originates from the same sources, but is considerably lower. Quantitatively, the most abundant plant sterols in the human diet are $\beta$-sitosterol, campesterol and stigmasterol, while plant stanols are less abundant and consist mainly of sitostanol and campestanol. ${ }^{2}$ It is well established that plant sterols and stanols interfere with intestinal cholesterol absorption and the consequent cholesterol-lowering effect of plant sterols was already observed in 1950 . Nowadays it is generally accepted that a daily intake of $2.5 \mathrm{~g}$ plant sterols or stanols lowers serum cholesterol concentrations up to $10 \%{ }^{3}$ While evidence suggests a crucial role of (dietary) cholesterol in hepatic inflammation, ${ }^{4}$ the role of plant sterol and stanol esters in liver inflammation is not yet established. Considering the beneficial effects of plant sterol and stanol esters on cholesterol metabolism, we hypothesized that consumption of plant sterol and stanol esters will lead to reduced hepatic inflammation. In addition, the recent observation that serum desmosterol concentrations were elevated exclusively in NASH but not in NAFLD patients ${ }^{5}$ together with the recent finding of Spann et al. ${ }^{6}$ suggesting a prominent role for desmosterol as a master regulator of inflammation in macrophages prompted us to test this idea by measuring the same precursor concentrations not only in the livers of the HFD fed mice but also in another cohort of 57 severely obese patients (i.e. patients were classified as control ( $<5 \%$ steatosis), NAFLD or NASH). Using this cohort, we could directly link the data obtained in our hyperlipidemic mouse model for NASH with the human situation making translational assumptions more likely. 
In this study, we show for the first time that adding plant sterol or stanol esters to the HFD in hyperlipidemic mice dramatically lowered the development of hepatic inflammation. This protective effect of plant sterol and stanol esters on liver inflammation could open new venues in the treatment or prevention of hepatic inflammation. The fact that we observed a pronounced increase both in hepatic desmosterol and lathosterol concentrations in HFD mice as well as in serum desmosterol and lathosterol concentrations in NASH but not in NAFLD patients, suggested a prominent role for these cholesterol precursors in the pathogenesis of liver inflammation. Interestingly, the increased desmosterol and lathosterol concentrations in the HFD mice were completely absent after plant sterol and stanol ester consumption indicating the preventive nature of these dietary compounds. To further substantiate the direct cellular effects of desmosterol and sitostanol we showed in vitro in LPS triggered BMM that desmosterol activated cholesterol efflux whereas sitostanol reduced inflammation.

\section{Materials and methods}

\section{Mice}

Forty 10-12 weeks old female low-density lipoprotein (LDL) receptor deficient mice $\left(\right.$ Ldll $\left.^{-/}\right)$were housed together in groups of 3 or 4 under standard conditions having ad libitum access to food and water. Ten mice were consuming plant sterol poor chow diets, whereas the remaining 30 mice received a plant sterol poor high fat diet (HFD) containing beef fat for 3 weeks. The composition of the three experimental high fat and chow diets is presented in Table 7.1. After these 3 weeks these 30 mice were randomly allocated to one of the 3 experimental groups $(n=10)$. The first group continued using the HFD for another 3 weeks, while the second and third groups used the same HFD but now enriched with plant sterol esters (2\%) or plant stanol esters (2\%). The chow group continued the same plant sterol poor chow diet and served as control. Experiments were performed in accordance with Dutch law for animal experimentation and approved by the Committee for Animal Welfare of the University of Maastricht. Collection of blood and tissue specimens, biochemical determination of plasma and liver lipids, liver histology, RNA isolation, cDNA synthesis and qPCR were performed as described previously. ${ }^{7,8}$ Hepatic plant sterol and stanol as well as cholesterol precursor concentrations were quantified by GC-MS as described ${ }^{9}$.

\section{In vitro studies in bone marrow derived macrophages}

To evaluate whether effects of plant sterols and stanols on inflammatory parameters in the liver were present without the potentially interfering effect of changes in cholesterol and lipid concentrations, bone-marrow derived macrophages were cultured with and without sitostanol as a typical example of plant sterols or stanols. 
For this, bone-marrow derived macrophages were isolated from the tibiae and femurs of C57BL/6 mice. Cells were cultured in RPMI-1640 (GIBCO Invitrogen, Breda, the Netherlands) with $10 \%$ heat-inactivated fetal calf serum (Bodinco B.V. Alkmaar, the Netherlands), penicillin $(100 \mathrm{U} / \mathrm{ml})$, streptomycin $(100 \mu \mathrm{g} / \mathrm{ml})$ and L-glutamine $2 \mathrm{mM}$ (all GIBCO Invitrogen, Breda, the Netherlands) supplemented with 20\% L929conditioned medium (LCM) for 8-9 days to generate bone marrow-derived macrophages, as described previously. ${ }^{10}$ After attachment, the macrophages were seeded at 350000 cells per well in 24 wells plates and incubated $24 \mathrm{hrs}$ with medium (control), cyclodextrin (carrier control), $0.6 \mu \mathrm{M}$ sitostanol or $1.2 \mu \mathrm{M}$ sitostanol. Then cells were washed and stimulated with LPS $(100 \mathrm{ng} / \mathrm{ml})$ for 4 hours. Finally, the supernatant was frozen until cytokine analysis and the cells were lysed for mRNA expression analysis. In additional experiments using the same set up, cells were cultured with desmosterol $0.25,0.5$ and $1.0 \mu \mathrm{M}$.

Table 7.1 Composition of the experimental and chow diets.

\begin{tabular}{|c|c|c|c|c|}
\hline & $\mathrm{HFD}^{1}$ & $\begin{array}{l}\text { HFD + Plant } \\
\text { sterol esters }\end{array}$ & $\begin{array}{l}\text { HFD + Plant } \\
\text { stanol esters }\end{array}$ & Chow \\
\hline & \multicolumn{4}{|c|}{ Composition (\%) } \\
\hline Sucrose & 39.75 & 38.97 & 38.97 & 29.38 \\
\hline Casein & 23.64 & 23.18 & 23.18 & 20.00 \\
\hline Beef fat & 15.78 & 15.47 & 15.47 & - \\
\hline Cellulose & 5.91 & 5.79 & 5.79 & 5.00 \\
\hline Olive Oil ${ }^{4}$ & 2.94 & 2.07 & 2.07 & 2.00 \\
\hline Soybean oil ${ }^{4}$ & 2.27 & 2.07 & 2.07 & 2.00 \\
\hline Corn Starch & 2.59 & 2.54 & 2.54 & 35.92 \\
\hline Vitamin $\mathrm{Mix}^{2}$ & 0.58 & 0.58 & 0.58 & 0.50 \\
\hline Mineral Mix ${ }^{3}$ & 5.44 & 5.33 & 5.33 & 4.60 \\
\hline Choline & 0.47 & 0.46 & 0.46 & 0.40 \\
\hline DL Methionine & 0.24 & 0.23 & 0.23 & 0.20 \\
\hline Cholesterol $^{4}$ & 0.20 & 0.20 & 0.20 & - \\
\hline Linseed Oil ${ }^{5}$ & 0.19 & - & - & - \\
\hline Plant sterol esters ${ }^{6}$ & - & 3.10 & - & - \\
\hline Plant stanol esters ${ }^{6}$ & - & - & 3.10 & - \\
\hline
\end{tabular}

${ }^{1}$ HFD: high fat diet; ${ }^{2}$ Vitamin mix: vitamins premix, trace elements premix; ${ }^{3}$ Mineral mix: calcium hydrogen phosphate, calcium carbonate, potassium chloride, potassium dihydrogen phosphate, magnesium sulphate heptahydrate, sodium chloride, magnesium oxide; ${ }^{4}$ This added amount of $0.2 \%$ cholesterol together with the $0.015 \%$ cholesterol from beef fat makes that the diet contains $0.22 \%$ cholesterol; ${ }^{5}$ The small amounts of olive oil, soybean oil and linseed oil were added to the HFD and not to the HFD + sterol or stanol esters to make the amount and type of fatty acids in the three HF diets comparable since the fatty acids in the sterol and stanol esters (rapeseed oil fatty acids) become available during digestion. ${ }^{6}$ The $3.1 \%$ plant sterol or stanol esters correspond to $\pm 2 \%$ free plant sterols or stanols. The plant stanols used are a mixture of mainly sitostanol and campestanol $85 / 15$ and the plant sterols used are a mixture of mainly sitosterol and campesterol $70 / 30$. The chow diet contains \pm 10.2 en $\%$ fat, whereas the HFD contains \pm 41.5 en $\%$ fat. 


\section{Patient population}

Fifty-three severely obese patients undergoing bariatric surgery at the Maastricht University Medical Centre were included. The study was approved by the local Ethics Committee of Maastricht University and conducted in line with the 1975 Declaration of Helsinki guidelines and the Seoul 2008 amendments. All subjects gave written informed consent. Plasma samples and liver wedge biopsies were obtained as previously described. ${ }^{11}$ Biopsies were evaluated for histological features (criteria of Brunt $^{12}$ and Kleiner ${ }^{13}$ by an experienced pathologist.

\section{Statistics}

Results are presented as mean \pm standard error of the mean ( \pm SEM). Differences between groups were assessed by ANOVA and significant effects were analyzed by post hoc Bonferroni corrections. All analyses were performed using a commercially available statistics package (GraphPad Prism version 5; GraphPad Software Inc, San Diego, CA, U.S; www.graphpad.com).

\section{Results}

\section{Plant sterol and plant stanol esters lead to dramatic reduction in hepatic inflammation}

To investigate the effect of plant sterol and stanol esters on hepatic inflammation, liver sections of mice that consumed the different diets were used for immunohistochemical stainings to detect the presence of infiltrated macrophages (Mac-1), neutrophils (NIMP), and T-cells (CD3) (Figure 7.1). In line with the reduced inflammation observed on the Hematoxylin and Eosin (HE) staining (Figure 7.1C), less infiltrating macrophages (Mac-1) and neutrophils (NIMP) were observed in the livers of mice receiving plant sterol or stanol esters compared to mice receiving only the HFD (Figures 7.1A+B). T-cell numbers were not significantly changed upon treatments with plant sterol or stanol esters (Figure 7.1D).

To further define the differences in hepatic inflammation, gene expression analysis of the pro-inflammatory markers Cd68, Mcp-1, IL-16, Tnf- $\alpha$ and Icam was performed. Importantly, adding plant sterol or stanol esters to the HFD completely blocked the increase in hepatic expression of these inflammatory markers. For each of these inflammatory genes, the expression was significantly lowered in the plant sterol or stanol ester groups compared to the HFD alone and actually returned to values comparable to the chow condition (Figure 7.2A-E). Altogether, these data indicate the strong inhibitory effect of plant sterol or stanol esters on hepatic inflammation induced by HFD. 


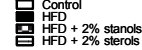

A

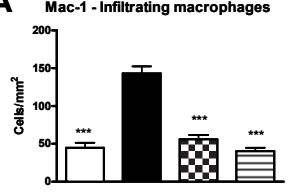

E

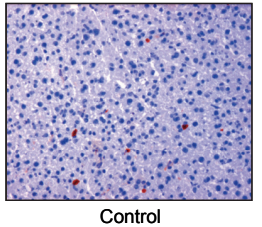

F

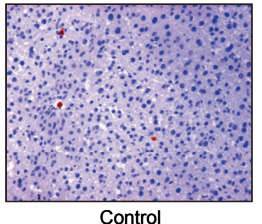

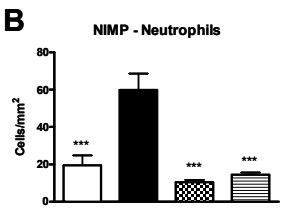
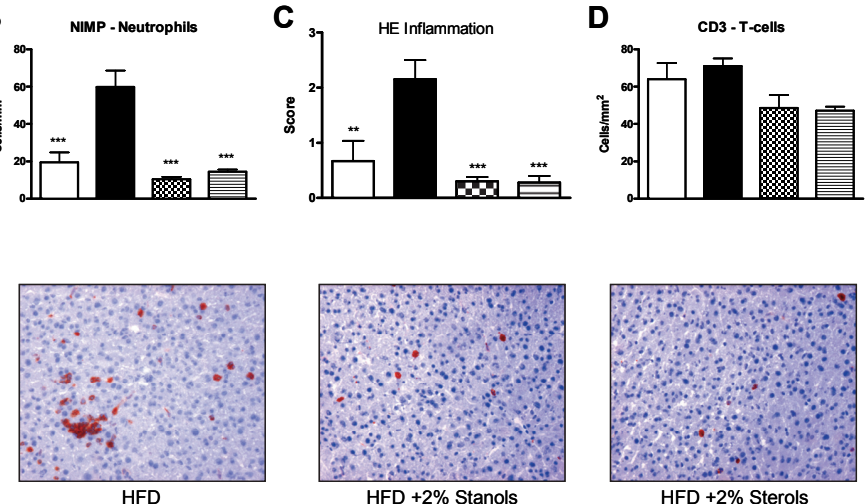

HFD $+2 \%$ Stanols
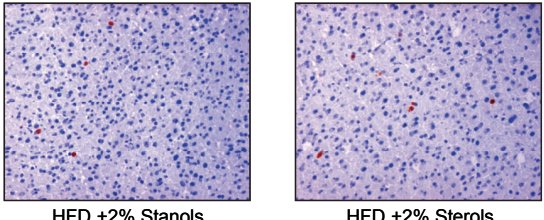

HFD $+2 \%$ Sterols

Figure 7.1 Parameters of hepatic inflammation. (A, B) Liver sections were stained for infiltrating macrophages and neutrophils (Mac-1) and neutrophils (NIMP) and the positive cells counted. (C) Result of scoring the HE staining in all groups. (D) Liver sections were stained for T-cells (CD3) and positive cells counted. (E, F) Representative pictures of Mac-1 staining and NIMP staining in the four experimental groups (200x magnification). ${ }^{* *} p<0.01$, and ${ }^{* * *} p<0.001$, respectively.

To determine whether there was a difference in the foamy appearance of Kupffer cells, besides evaluating the CD68 mRNA expression, we also scored CD68 positive sections, a macrophage marker that stains both Kupffer cells and infiltrated macrophages. In line with the effects described for inflammatory markers, there was a significant increase in the size of CD68 positive cells in the HFD group which was completely reversed to the level of the chow control group after addition of plant sterol or stanol esters to the HFD (Figure 7.3A-C). Based on this data it is tempting to suggest that the reduced inflammatory response in the livers of mice treated with plant sterol or stanol esters could be ascribed to reduced lipid levels in the Kupffer cells. Altogether, we clearly showed that hepatic inflammation and most likely uptake of lipids into hepatic macrophages was strongly inhibited in the mice receiving plant sterol or stanol ester compared to mice receiving HFD diet alone. 


\section{口 Control \\ 曋 $\mathrm{HFD}+2 \%$ stanols}
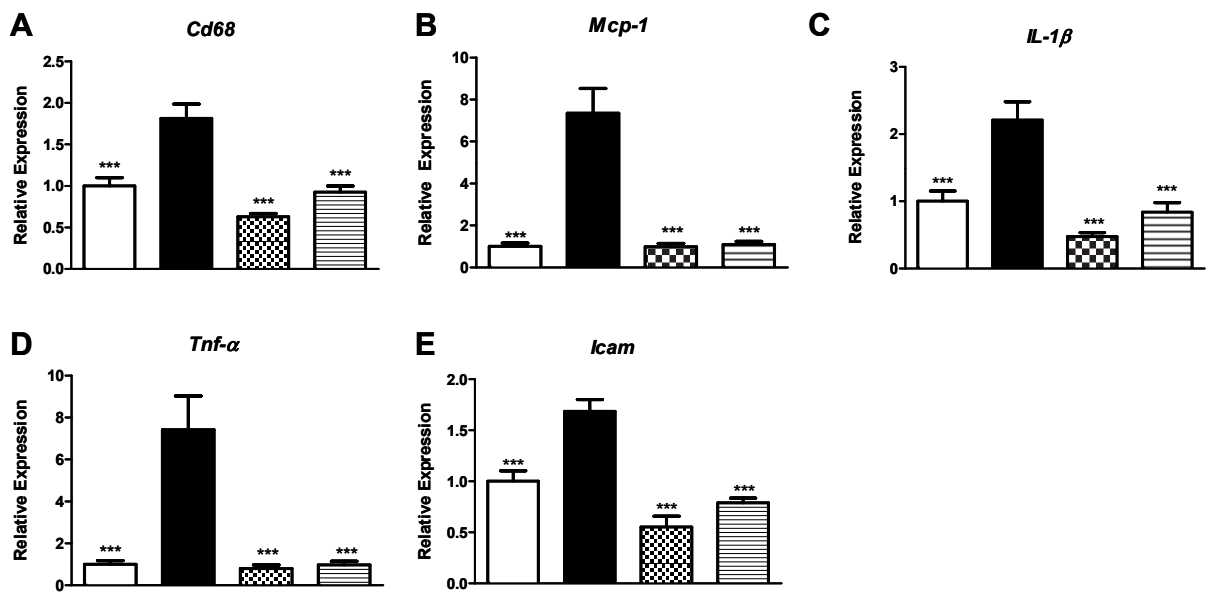

Figure 7.2 Hepatic gene expression. (A-E) Gene expression analysis of the macrophage marker Cd68, monocyte chemoattractant protein $1(M c p-1)$, interleukin $1 \beta(I L-16)$, tumor necrosis factor $\alpha$ (Tnf- $\alpha$ ) and intercellular adhesion molecule 1 (Icam). Relative expression was normalized to endogenous control gene Cyclophilin A. Data were set relative to group on chow diet. $* * * \mathrm{p}<0.001$.

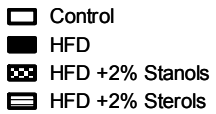

A

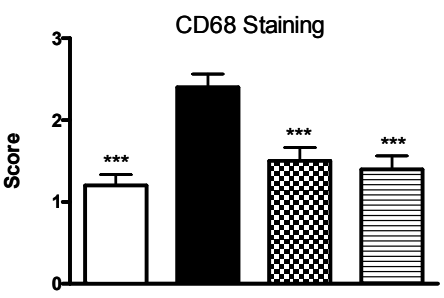

B

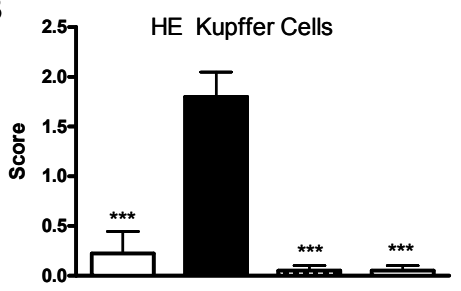

C

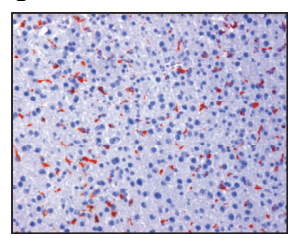

Control

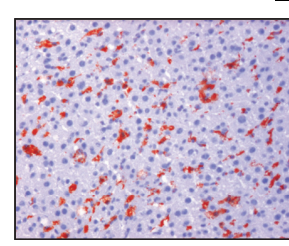

HFD

$\underline{\mathrm{CD} 68}$

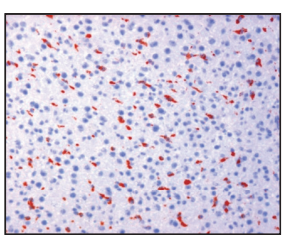

HFD $+2 \%$ Stanols

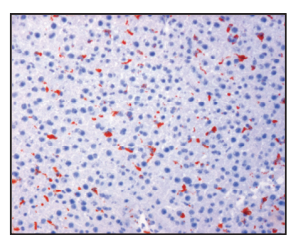

HFD $+2 \%$ Sterols

Figure 7.3 Foamy Kupffer Cells. (A) Scoring of immunohistochemical staining for Kupffer cells (CD68). (B) Scoring for the size and foamy appearance of Kupffer cells using HE staining. (C) Representative pictures of the foamy Kupffer cell appearance with CD68 staining (200x magnification). $* * * p<0.001$. 


\section{Plant sterol and plant stanol esters reduce plasma lipid levels, without lowering liver TAG}

As expected, we observed a strong increase in serum and hepatic cholesterol levels of mice fed an HFD as compared to the chow group. Compared to HFD alone, adding plant sterol or stanol esters to the HFD resulted in reduced serum and hepatic cholesterol concentrations to the levels found in controls (Figure 7.4A+B). As shown in the FPLC profiles (Figure 7.5A), the reductions in serum cholesterol can be found primarily in the VLDL and LDL fractions. Additionally, we found a reduction in serum TAG concentrations in animals receiving plant sterol and stanol esters enriched HFD (Figure 7.4C). Surprisingly, despite the effect of plant sterol and stanol esters on plasma TAG concentrations and VLDL particles (Figure 7.5B), liver TAG concentrations were not significantly different between the groups (Figure 7.4D).
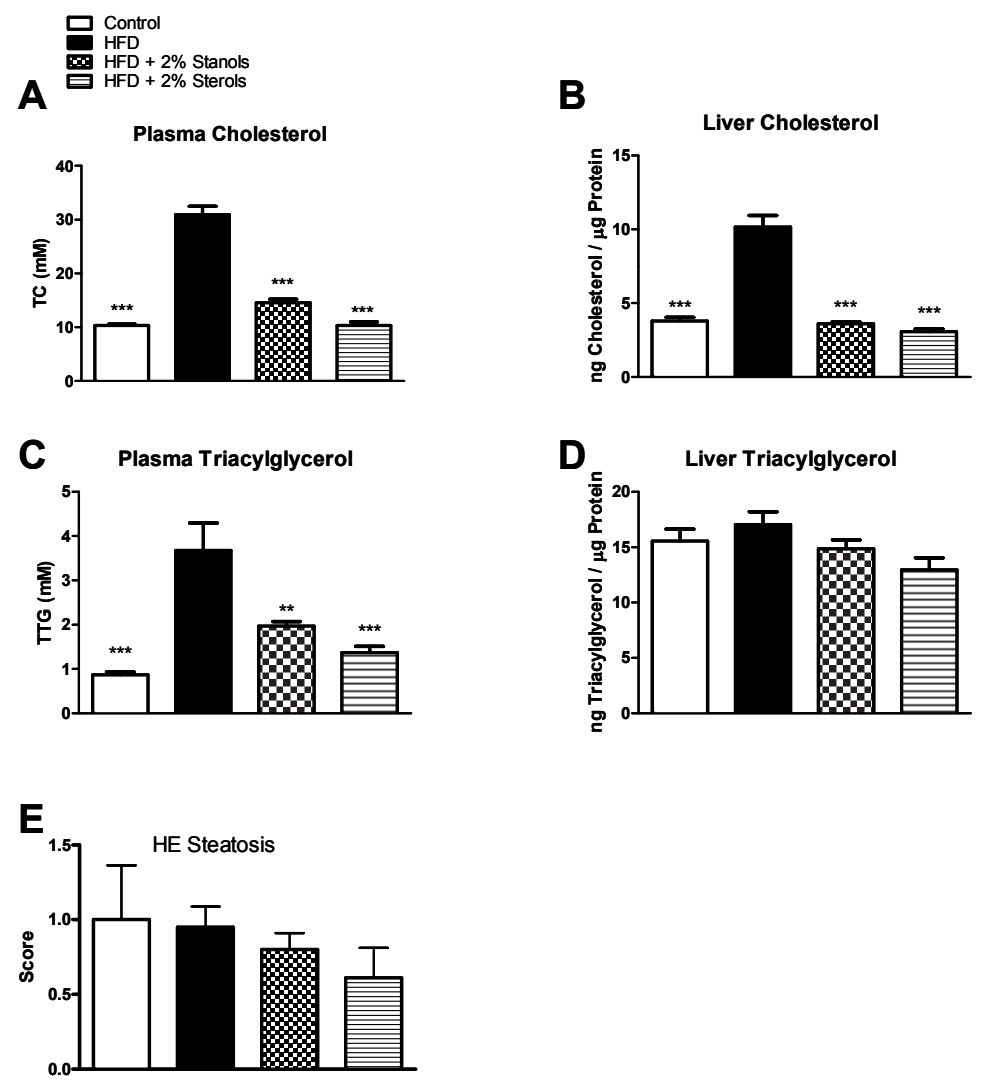

Figure 7.4 Lipid Measurements. (A, B) Plasma and liver cholesterol measurements. (C, D) Plasma and liver triacylglycerol levels. ${ }^{* *} p<0.01$, and ${ }^{* * *} p<0.001$, respectively. 
A

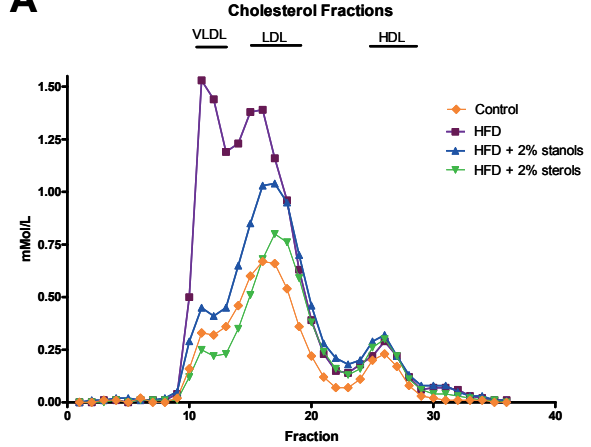

B

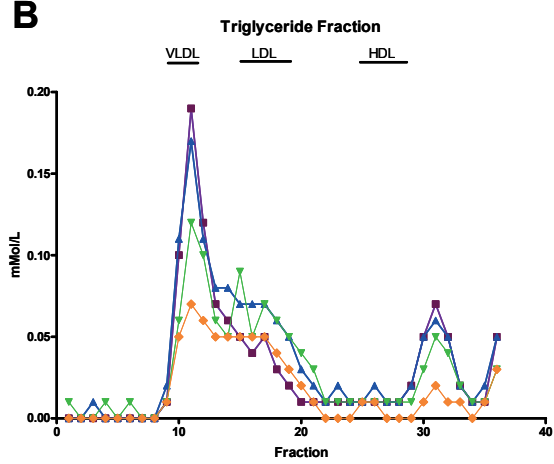

Figure 7.5 Serum lipid and lipoprotein profiles. (A, B) Using FPLC, serum lipid and lipoprotein profiles were analyzed in all experimental groups.

Upon consumption, it is well accepted that plant sterols and stanols are distributed into different tissues, including the liver. ${ }^{7}$ As shown in supplementary Figure 7.6A, hepatic campesterol concentrations increased upon plant sterol feeding and slightly decreased after plant stanol ester feeding. Remarkably, there was no increase in hepatic sitosterol concentrations after plant sterol ester feeding as compared to chow, whereas the expected reduction in hepatic sitosterol concentrations after plant stanol ester feeding was evident (Figure 7.6B). Regarding hepatic plant stanol concentrations, there was a significant increase in campestanol and sitostanol concentrations after plant stanol ester feeding (Figure 7.6C+D). This data clearly indicates that hepatic plant sterol and stanol concentrations increase upon consumption and might in theory have local effects. Finally, feeding the HFD severely elevated hepatic lathosterol as well as desmosterol concentrations suggesting a strong increase in endogenous cholesterol synthesis (Figure 7.6E+F). The recent observations that desmosterol is an important regulator of inflammatory processes in macrophages ${ }^{6}$ might also suggest a local effect on inflammation in the Kupffer cells. Moreover, as compared to the HFD, adding plant sterol or stanol esters to the diet lowered hepatic lathosterol and desmosterol concentrations, an indication of a lower endogenous cholesterol synthesis. Finally, hepatic cholestanol concentrations were lowered in the HFD + stanol and sterol ester groups as compared to the HFD group alone (data not shown), indicative of a lowered intestinal cholesterol absorption. Next to that, the expression of enzymes regulating endogenous cholesterol synthesis either via the Kandutch Russel pathway or the Bloch pathway suggested increased synthesis in the stanol and sterol ester conditions. As compared to the control condition, the expression of Cyp51 and LSS was higher both in the sterol and stanol ester condition, the expression of Dhcr24 in the sterol ester condition and Dhcr7 in the stanol ester condition (data not shown). This finding suggests that endogenous cholesterol synthesis in general is increased after plant sterol or stanol ester consumption without 
a specific preference for the desmosterol or lathosterol containing pathways. Interestingly the HFD condition did not show significant differences in expression of these 4 genes.

Control

HFD

HFD $+2 \%$ Stanols

HFD $+2 \%$ Sterols

\section{A}

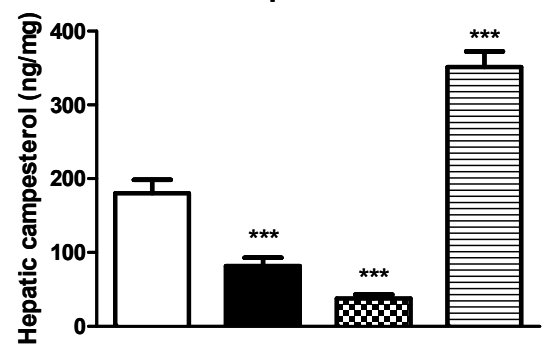

C

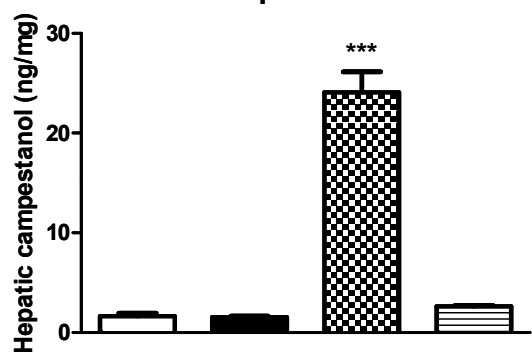

E

Lathosterol

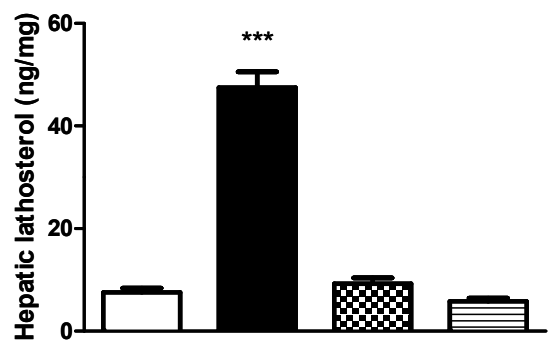

B

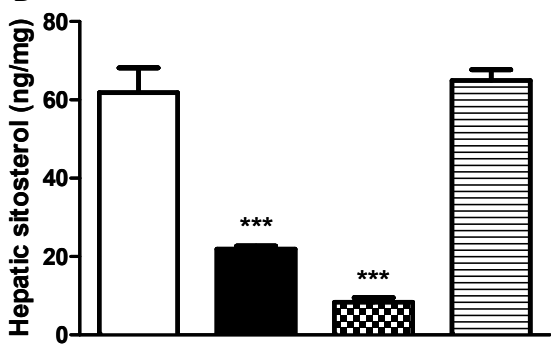

D

Sitostanol

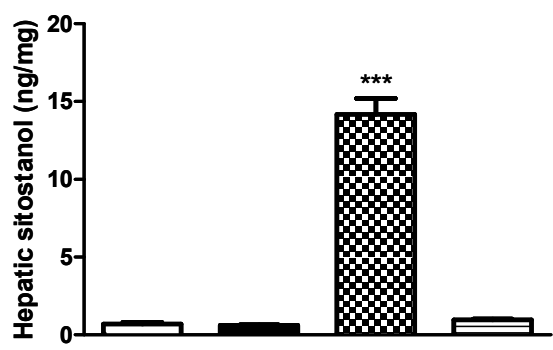

$\mathbf{F}$

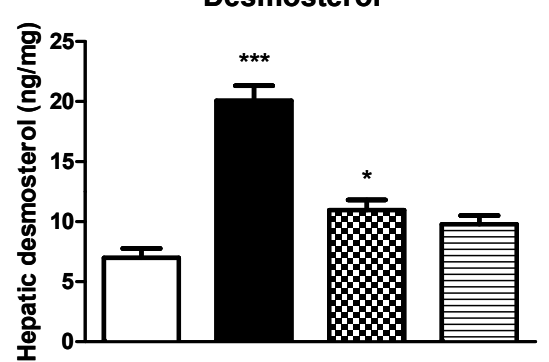

Figure 7.6 Hepatic non-cholesterol sterol concentrations. Hepatic concentrations of (A) campesterol, (B) sitosterol, (C) campestanol and (D) sitostanol were measured. To analyze endogenous cholesterol synthesis, hepatic (E) lathosterol and (F) desmosterol were measured. All values are shown as absolute concentrations (ng/mg tissue). ${ }^{*} p<0.05,{ }^{* * *} p<0.001$. 


\section{Plant stanols lower Tnf- $\alpha$ secretion in vitro in bone marrow macrophages but do not affect expression of lipid transporter genes}

To investigate whether plant stanols may affect Kupffer cells directly independent of changes in cholesterol or lipid concentrations and the presence of communicating hepatocytes, isolated bone-marrow derived macrophages were incubated with LPS and plant stanols, and levels of Tnf- $\alpha$ secreted in culture medium were measured. Macrophages incubated with plant stanols produced less Tnf- $\alpha$ after exposure to sitostanol, both after 0.6 and $1.2 \mu \mathrm{m}$ concentrations as compared to cyclodextrin (carrier control) (Figure 7.7A). On the other hand, there was no significant change in the mRNA expression of lipid transporter genes like $L X R \alpha, A b c a 1$ and $A b c g 1$ (Figure 7.7B-D). Since we observed the strong increase in desmosterol concentrations in the livers of the HFD mice, we also cultured the isolated bone-marrow derived macrophages with desmosterol to better understand the effect of these changes. In contrast to sitostanol, supplying desmosterol did not have an effect on the expression of Tnf- $\alpha$ (Figure 7.7E) and cellular Mcp-1 production (data not shown) but instead increased the expression of $L X R \alpha$ and the LXR target genes Abca1 and Abcg1 (Figure $7 F-H)$ indicating increased cholesterol efflux. Altogether, these data suggest that (1) plant stanols could directly affect inflammation in macrophages independent of lipid and/or cholesterol metabolism and (2) the increased desmosterol concentration in the HFD condition serves to remove excess cellular cholesterol, a situation that was absent in the HDF + plant sterol or stanol ester condition.

\section{Plasma desmosterol and lathosterol concentrations are elevated in NASH patients}

To investigate whether an inflammatory state in the liver is correlated with altered levels of cholesterol precursors in the human setting, plasma desmosterol and lathosterol concentrations were measured in 53 severely obese patients. As shown in Table 7.2, there were no statistically significant differences in metabolic and clinical parameters between controls, patients with simple steatosis and NASH except from BMI. In Table 7.3, a detailed description of the histological scoring of the liver biopsies within the NASH group $(\mathrm{N}=25)$ is provided. It appears that we have a mostly mild to moderate NASH population with predominantly steatosis score 2, ballooning score 1 , lobular inflammation score 1 , and fibrosis score 1. Interestingly, the concentrations of both desmosterol and lathosterol were significantly higher in serum from these NASH patients $(n=25)$ as compared to patients with simple steatosis $(n=8)$ or control patients without steatosis $(n=20)$ (Figure $7.8 A+B)$. These data are in line with earlier observations in these patients, ${ }^{5}$ and also aligns with observations in the HFD fed mice and therefore might be suggestive for a link between elevated concentrations of endogenous cholesterol synthesis markers and the presence of liver inflammation. Moreover, serum cholestanol levels were identical between the different patient groups, indicating no difference in fractional cholesterol absorption (Figure 7.8C). 
A

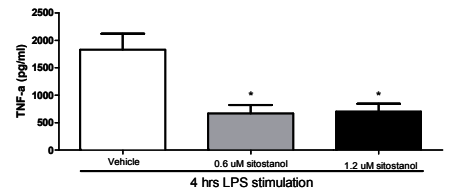

B

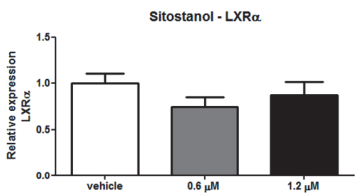

C

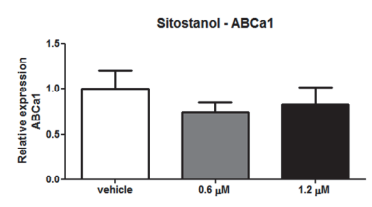

D

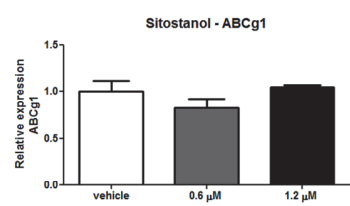

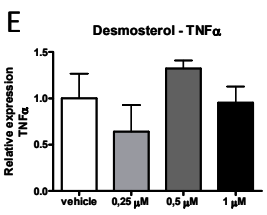

G

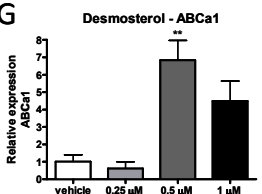

F

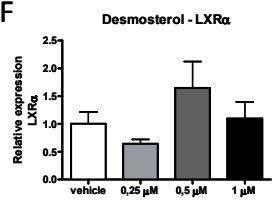

$\mathrm{H}$

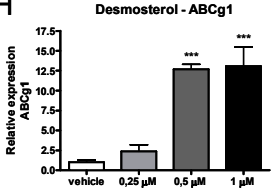

Figure 7.7 Effect of plant stanols on macrophages in vitro. Changes in Tnf- $\alpha$ concentrations in supernatant and LXR target gene expression of bone marrow derived macrophages after incubation with sitostanol $(0.6$ and $1.2 \mu \mathrm{m})$ or desmosterol $(0.25,0.5$ and $1.0 \mu \mathrm{m})$ and $4 \mathrm{~h}$ LPS stimulation. (A) Tnf- $\alpha$ concentrations, (B) LXR $\alpha$ mRNA, (C) Abca1 mRNA, and (D) Abcg1 mRNA expression after sitostanol exposure, (E) Tnf- $\alpha$ mRNA, (F) LXR $\alpha$ mRNA, (G) Abca1 mRNA, and (H) Abcg1 mRNA expression after desmosterol exposure. Data were set relative to cells incubated with cyclodextrin (carrier control). ${ }^{*} p<0.05 ;{ }^{* *} p<0.01 ;{ }^{* * *} p<0.001$.

Table 7.2 Population characteristics.

\begin{tabular}{lccc}
\hline & Normal & Steatosis & NASH \\
\hline $\mathrm{n}$ & 20 & 8 & 25 \\
Sex, male/female & $8 / 12$ & $2 / 6$ & $10 / 16$ \\
$\mathrm{Age}, \mathrm{y}$ & $45 \pm 1.7$ & $50 \pm 3.2$ & $44 \pm 2.1$ \\
$\mathrm{BMI}, \mathrm{kg} / \mathrm{m}^{2}$ & $42.4 \pm 1.5$ & $42.7 \pm 2.5$ & $47.9 \pm 1.6^{*}$ \\
Total cholesterol, mmol/I & $4.8 \pm 0.2$ & $5.6 \pm 0.5$ & $5.2 \pm 0.2$ \\
$\mathrm{HDL}, \mathrm{mmol} / \mathrm{l}$ & $1.1 \pm 0.1$ & $1.2 \pm 0.1$ & $1.0 \pm 0.1$ \\
$\mathrm{LDL}, \mathrm{mmol} / \mathrm{l}$ & $2.8 \pm 0.2$ & $3.1 \pm 0.5$ & $3.4 \pm 0.2$ \\
Triglycerides, mmol/IL & $1.8 \pm 0.3$ & $1.7 \pm 0.5$ & $2.0 \pm 0.2$ \\
Free fatty acids, mmol/I & $0.5 \pm 0.06$ & $0.6 \pm 0.2$ & $0.7 \pm 0.06$ \\
$\mathrm{CRP}, \mathrm{mmol} / \mathrm{l}$ & $9.5 \pm 1.8$ & $9.9 \pm 3.5$ & $9.5 \pm 1.4$ \\
ALT, IU/l & $23.9 \pm 3.5$ & $23.7 \pm 4.4$ & $35.3 \pm 6.6$ \\
AST, IU/l & $18.7 \pm 2.3$ & $21.8 \pm 1.6$ & $28.8 \pm 3.7$ \\
AST/ALT ratio & $0.9 \pm 0.1$ & $1.2 \pm 0.4$ & $1.0 \pm 0.1$ \\
\hline
\end{tabular}

Data are represented as mean \pm SEM. * Significantly different from Normal, * indicates $p<0.05$. 
Table 7.3 Histological scoring of liver biopsies from NASH subjects.

\begin{tabular}{lll}
\hline Brunt score & Definition & NASH subjects (n=25) \\
\hline Grade 1 & Mild & 12 \\
Grade 2 & Moderate & 11 \\
Grade 3 & Severe & 2 \\
Kleiner score & & \\
Steatosis & $<5 \%$ (score 0) & 0 \\
& $5-33 \%$ (score 1) & 4 \\
& $33-66 \%$ (score 2) & 15 \\
Ballooning & $>66 \%$ (score 3) & 3 \\
& None (score 0) & 5 \\
Lobular inflammation & Few balloon cells (score 1) & 20 \\
& Prominent ballooning (score 2) & 0 \\
& None (score 0) & 2 \\
& $<2$ foci per 200x field (score 1) & 14 \\
& 2-4 foci per 200x field (score 2) & 5 \\
Fibrosis & $>4$ foci per 200x field (score 3) & 4 \\
& None (score 0) / Nondefined & $11 / 3$ \\
& Perisinusoidal or periportal (score 1) & 6 \\
& Perisinusoidal and portal/periportal (score 2) & 3 \\
& Bridging fibrosis (score 3) & 2 \\
& Extensive bridging fibrosis, cirrhosis (score 4) & 1 \\
\hline
\end{tabular}

A

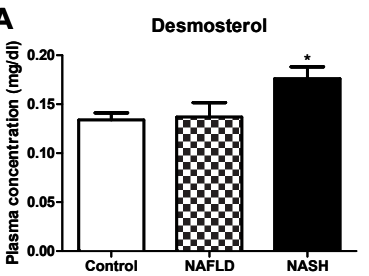

B

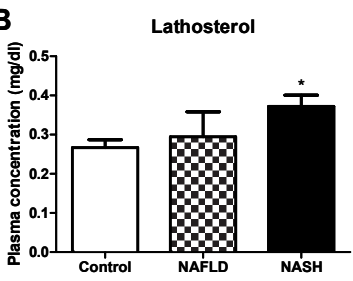

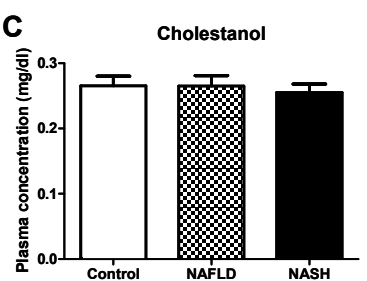

Figure 7.8 Plasma cholesterol precursor levels in severely obese patients. Serum levels of (A) desmosterol, (B) lathosterol and (C) cholestanol were measured. All values are shown as absolute levels (mg/dl serum). ${ }^{*} \mathrm{p}<0.05$.

\section{Discussion}

Plant sterol- and stanol esters are known for several decades as serum cholesterollowering functional food ingredients. However, their effects on hepatic inflammation have never been evaluated. Here we show for the first time the strong ability of dietary plant sterol and stanol esters to suppress the development of hepatic inflammation. The fact that plant sterol and plant stanol esters are natural constituents of food, combined with the lack of adverse side effects upon increased intake in clinical intervention studies, strongly warrants human studies to examine the potential of plant sterol and plant stanol esters as a novel tool for prevention and 
intervention in of hepatic inflammation. Especially the observation that both in our HFD fed mice as well as in the NASH - but not in simple steatosis - patients desmosterol concentrations are increased, illustrates the validity of our mouse model suggesting the likelihood of extrapolating a successful outcome of such an intervention towards the clinical setting. Moreover, if the increase in hepatic desmosterol concentrationsis is a characteristic of an inflamed liver, the finding that plant sterol or stanol ester consumption showed lower desmosterol and lathosterol concentrations (comparable to the chow condition) is indicative for the protective nature of these dietary compounds.

Considering the beneficial effects of plant sterol and stanol ester consumption on health only from the perspective of serum LDL-cholesterol lowering is without doubt a strong simplification. Interestingly, there are several reports describing effects of plant sterols and stanols on activity of our immune system. For example, our group recently showed that plant stanols induce a Th1 shift in human peripheral mononuclear blood cells from asthma patients, which is most likely due to an activation of the regulatory T-cells. ${ }^{8,914,15}$ The relevance of this observation in the context of the present study concerns the fact that regulatory T-cells also play a critical role in regulating inflammatory processes in liver inflammation, at least in the situation of NASH.

Another explanation for the effects of plant sterols and stanols on liver inflammation might relate to the very recent observation that serum desmosterol concentrations were elevated exclusively in NASH but not in NAFLD patients. ${ }^{5}$ Indeed we were able to confirm this observation in a cohort of 57 severely obese patients classified either as control ( $<5 \%$ steatosis), NAFLD or NASH. This increase in desmosterol concentrations was also present in our HFD mouse group as compared to the chow fed mice, illustrating that our model mimics human pathology also in this respect. Rather unexpectedly, hepatic desmosterol concentrations were lowered in mice fed a HFD enriched with plant sterol or stanol esters. The generally accepted assumption is that lowering intestinal cholesterol absorption induces a compensatory increase in endogenous cholesterol synthesis, which is reflected by increased cholesterol precursor concentrations such as desmosterol and lathosterol. Relevantly, Spann et al. ${ }^{6}$ recently suggested a prominent role for desmosterol as a master regulator of inflammation and cholesterol metabolism in macrophages. In our in vitro experiments in isolated bone-marrow derived macrophages we were indeed able to confirm the effect of desmosterol on cholesterol efflux but not on inflammation. In contrast, sitostanol showed completely the opposite pattern as compared to desmosterol (Figure 7.9), i.e a reduced inflammatory response but no effect on LXR target gene expression and efflux.

An additional potential explanation to support possible direct effects of plant sterols and stanols on inflammation is related to the finding that plant sterols and stanols can activate LXR. Pharmacological LXR activation was shown to lower dietary cholesterol 
uptake and to reverse hepatic inflammation. ${ }^{16}$ Indeed, both sitosterol and sitostanol were shown to be potent LXR ligands, at least in a cell free in vitro system, ${ }^{17}$ a finding that was later confirmed for other plant sterols like stigmasterol. ${ }^{18}$ However, it must be considered that plant sterols and stanols are poorly absorbed from the intestinal tract and the question is whether the increase in hepatic plant sterol or stanol concentrations exceeds the threshold needed to trigger local hepatic LXR activation in the in vivo situation.

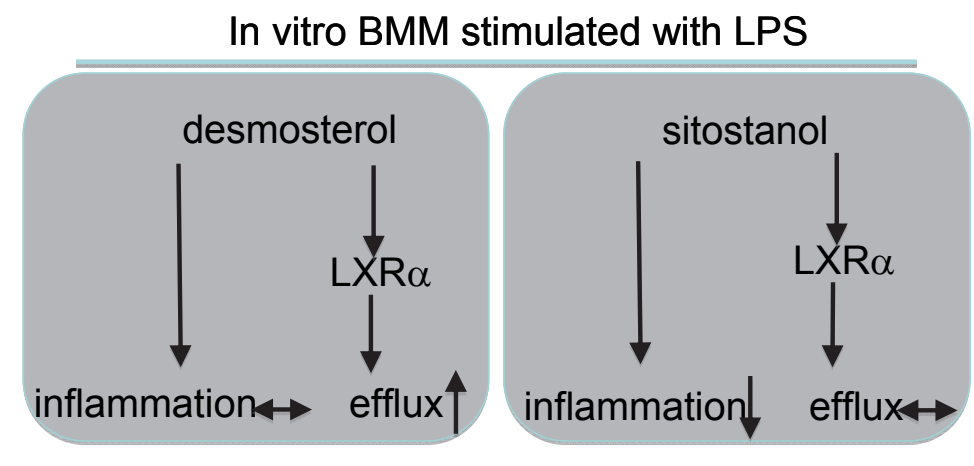

Figure 7.9 Schematic representation of direct effects of sitostanol vs desmosterol.

A final potential explanation for a direct effect of plant sterols or stanols on liver inflammation relates to their effect on the composition of our intestinal microbiota. Indeed an association between the pathogenesis of NASH and gut microbiota composition has been suggested. ${ }^{19}$ Patients with NASH showed a lower abundance of Bacteroidetes as compared to those with only steatosis or healthy controls. Recently, it was described that plant sterol ester intake induced dramatic shifts in the fecal microbiota composition of hamsters showing reductions in Coriobacteriacea and Erysipelotrichaceae. ${ }^{20}$ Unfortunately, to the best of our knowledge, these effects have never been studied in humans. Altogether, these data support the notion that plant sterols and stanols affect several different (patho)-physiological processes. We here add another effect suggesting strong anti-inflammatory actions in Kupffer cells. The ultimate challenge is now to see whether these intriguing observations can be extrapolated to the human situation.

Besides the above-mentioned possible direct effects the most likely explanation for the protective effects of plant sterol and stanol ester consumption on hepatic inflammation relates to a changed cholesterol flux from the intestine to the liver. This is fully in line with earlier observations suggesting a crucial role of (dietary) cholesterol in hepatic inflammation. ${ }^{4}$ Moreover, Yoneda and coworkers earlier showed in a small pilot experiment that six months ezetimibe treatment $(10 \mathrm{mg} / \mathrm{day})$, which lowered 
intestinal cholesterol absorption pharmacologically, not only improved serum aspartate aminotransferase, alanine aminotransferase, gamma-glutamyl transpeptidase, and high-sensitivity C-reactive protein but most importantly also improvements in histological observations in follow-up liver biopsies in NAS score and steatosis grade. ${ }^{21}$ This clearly suggests that cholesterol fluxes are important in this respect.

Interestingly, the observed improvement in hepatic inflammation in the plant sterol and stanol occurred without a change in liver TAG concentrations. These data support our previous observations indicating that progression and regression of steatosis are not correlated with inflammation. ${ }^{4}$ In contrast to the unaffected hepatic TAG concentrations there was a highly significant reduction in liver cholesterol concentrations. These data are in line with our previous observations indicating that omitting cholesterol from the diet directly leads to a reduction in hepatic inflammation and hepatic foam cell formation. ${ }^{4}$ In this context, it was recently suggested that especially the Kupffer cells take up modified cholesterol-rich lipoproteins via scavenger receptors, and due to the accumulation of cholesterol instead of TAG, they become activated and initiate an inflammatory reaction. ${ }^{7,22}$ In line with these assumptions, we also observed a significant reduction in the prevalence of foamy Kupffer cells after adding plant sterol or stanol esters to the HFD.

In conclusion, we here demonstrate that consumption of plant sterol or stanol esters leads to a complete absence of HFD-induced liver inflammation. The fact that hepatic desmosterol concentrations were increased in morbidly obese NASH patients as well as in the HFD mice with liver inflammation suggests that hepatic desmosterol is an indication of hepatitis. Our finding that hepatic desmosterol concentrations are not at all increased in the plant sterol and stanol ester groups is in line with the protective phenotype observed in these groups. This highly significant effect is of great interest since plant sterol or stanol esters may be used as dietary intervention to treat and/or prevent hepatic inflammation. 


\section{References}

1. Bayard M, Holt J, Boroughs E. Nonalcoholic fatty liver disease. Am Fam Physician. 2006;73:1961-8.

2. Ostlund RE, Jr. Phytosterols in human nutrition. Annu Rev Nutr. 2002;22:533-549.

3. Baumgartner S, Mensink RP, Plat J. Plant sterols and stanols in the treatment of dyslipidemia: new insights into targets and mechanisms related to cardiovascular risk. Curr Pharm Des. 2011;17:922-32.

4. Wouters K, van Gorp PJ, Bieghs V, Gijbels MJ, Duimel H, Lütjohann D, Kerksiek A, van Kruchten R, Maeda N, Staels B, van Bilsen M, Shiri-Sverdlov R, Hofker MH. Dietary cholesterol, rather than liver steatosis, leads to hepatic inflammation in hyperlipidemic mouse models of nonalcoholic steatohepatitis. Hepatology. 2008;48:474-86.

5. Simonen M, Männistö V, Leppänen J, Kaminska D, Kärjä V, Venesmaa S, Käkelä P, Kuusisto J, Gylling H, Laakso M, Pihlajamäki. Desmosterol in human nonalcoholic steatohepatitis. Hepatology. 2013;58: 976-82.

6. Spann NJ, Garmire LX, McDonald JG, Myers DS, Milne SB, Shibata N, Reichart D, Fox JN, Shaked I, Heudobler D, Raetz CR, Wang EW, Kelly SL, Sullards MC, Murphy RC, Merrill AH Jr, Brown HA, Dennis EA, Li AC, Ley K, Tsimikas S, Fahy E, Subramaniam S, Quehenberger O, Russell DW, Glass CK. Regulated accumulation of desmosterol integrates macrophage lipid metabolism and inflammatory responses. Cell. 2012;151:138-52.

7. Bieghs V, Verheyen F, van Gorp PJ, Hendrikx T, Wouters K, Lütjohann D, Gijbels MJ, Febbraio M, Binder CJ, Hofker MH, Shiri-Sverdlov R. Internalization of modified lipids by CD36 and SR-A leads to hepatic inflammation and lysosomal cholesterol storage in Kupffer cells. PloS One. 2012;7:e34378.

8. Bieghs V, Hendrikx T, van Gorp PJ, Verheyen F, Guichot YD, Walenbergh SM, Jeurissen ML, Gijbels M, Rensen SS, Bast A, Plat J, Kalhan SC, Koek GH, Leitersdorf E, Hofker MH, Lütjohann D, Shiri-Sverdlov R. The cholesterol derivative 27-hydroxycholesterol reduces steatohepatitis in mice. Gastroenterology. 2013;144:167-78 e1.

9. De Jong A, Plat J, Bast A, Godschalk RW, Basu S, Mensink RP. Effects of plant sterol and stanol ester consumption on lipid metabolism, antioxidant status and markers of oxidative stress, endothelial function and low-grade inflammation in patients on current statin treatment. Eur J Clin Nutr. 2008;62:263-73.

10. Kanters E, Pasparakis M, Gijbels MJ, Vergouwe MN, Partouns-Hendriks I, Fijneman RJ, Clausen BE, Förster I, Kockx MM, Rajewsky K, Kraal G, Hofker MH, de Winther MP. Inhibition of NF-kappaB activation in macrophages increases atherosclerosis in LDL receptor-deficient mice. $J$ Clin Invest. 2003;112:1176-85.

11. Rensen SS, Slaats Y, Driessen A, Peutz-Kootstra CJ, Nijhuis J, Steffensen R, Greve JW, Buurman WA. Activation of the complement system in human nonalcoholic fatty liver disease. Hepatology. 2009;50:1809-17.

12. Brunt EM, Janney CG, Di Bisceglie AM, Neuschwander-Tetri BA, Bacon BR. Nonalcoholic steatohepatitis: a proposal for grading and staging the histological lesions. Am J Gastroenterol. 1999;94:2467-74.

13. Kleiner DE, Brunt EM, Van Natta M, Behling C, Contos MJ, Cummings OW, Ferrell LD, Liu YC, Torbenson MS, Unalp-Arida A, Yeh M, McCullough AJ, Sanyal AJ; Nonalcoholic Steatohepatitis Clinical Research Network. Design and validation of a histological scoring system for nonalcoholic fatty liver disease. Hepatology. 2005;41:1313-21.

14. Brull F, Mensink RP, Steinbusch MF, Husche C, Lutjohann D, Wesseling GJ, Plat J. Beneficial effects of sitostanol on the attenuated immune function in asthma patients: results of an in vitro approach. PloS One. 2012;7:e46895.

15. Brull F, Mensink RP, van den Hurk K, Duijvestijn A, Plat J. TLR2 activation is essential to induce a Th1 shift in human peripheral blood mononuclear cells by plant stanols and plant sterols. J Biol Chem. 2010;285:2951-8.

16. Wouters K, van Bilsen M, van Gorp PJ, Bieghs V, Lütjohann D, Kerksiek A, Staels B, Hofker MH, ShiriSverdlov R. Intrahepatic cholesterol influences progression, inhibition and reversal of non-alcoholic steatohepatitis in hyperlipidemic mice. FEBS Lett. 2010;584:1001-5.

17. Plat J, Mensink RP. Increased intestinal $A B C A 1$ expression contributes to the decrease in cholesterol absorption after plant stanol consumption. FASEB J. 2002;16:1248-1253. 
18. Yu L, Cao G, Repa J, Stangl H. Sterol regulation of scavenger receptor class B type I in macrophages. J Lipid Res. 2004;45:889-899.

19. Mouzaki M, Comelli EM, Arendt BM, Bonengel J, Fung SK, Fischer SE, McGilvray ID, Allard JP. Intestinal microbiota in patients with nonalcoholic fatty liver disease. Hepatology. 2013;58:120-7.

20. Martínez I, Perdicaro DJ, Brown AW, Hammons S, Carden TJ, Carr TP, Eskridge KM, Walter J. Dietinduced alterations of host cholesterol metabolism are likely to affect the gut microbiota composition in hamsters. Appl Environ Microbiol. 2013;79:516-24.

21. Yoneda M, Fujita K, Nozaki Y, Endo H, Takahashi H, Hosono K, Suzuki K, Mawatari H, Kirikoshi H, Inamori M, Saito S, Iwasaki T, Terauchi Y, Kubota K, Maeyama S, Nakajima A. Efficacy of ezetimibe for the treatment of non-alcoholic steatohepatitis: An open-label, pilot study. Hepatol Res. 2010;40: 566-73.

22. Bieghs V, Wouters K, van Gorp PJ, Gijbels MJ, de Winther MP, Binder CJ, Lütjohann D, Febbraio M, Moore KJ, van Bilsen M, Hofker MH, Shiri-Sverdlov R.. Role of scavenger receptor A and CD36 in dietinduced nonalcoholic steatohepatitis in hyperlipidemic mice. Gastroenterology. 2010;138:2477-86, 2486 e2471-73. 
Chapter 7 
Chapter 8

General discussion 
Chapter 8 


\section{General discussion}

The metabolic syndrome (MetS) represents a combination of cardiometabolic risk determinants including obesity (central adiposity), insulin resistance, hypertension, glucose intolerance and dyslipidemia. ${ }^{1}$ Due to the continued obesity "epidemic", the prevalence of the MetS is rapidly increasing worldwide and consequently the global incidence of cardiovascular disease and NASH is also increasing. While low-grade chronic inflammation is known to be an important component in both atherosclerosis and $\mathrm{NASH}^{2,3}$ so far the mechanisms that trigger inflammation in this context are not fully understood. Recent evidence indicates the involvement of lysosomal cholesterol accumulation in macrophages in stimulating the inflammatory status in both diseases. ${ }^{4-6}$ In this thesis, we aimed to unravel the mechanism by which lysosomal cholesterol trapping leads to inflammation. In addition, the effect of manipulation of cholesterol accumulation in lysosomes on inflammation was studied in order to identify new therapeutic targets.

\section{Intracellular traffic jam leading to inflammation}

Foamy macrophages, which are formed by the massive uptake of modified low-density lipoproteins (LDL), are known to play an important role in triggering inflammation during atherosclerosis. ${ }^{7,8}$ Under healthy conditions, circulating nonmodified cholesterol-rich LDL are initially directed to the lysosomes for further degradation by lysosomal enzymes and then transferred to the cytoplasm. Under these conditions, the levels of circulating oxidized cholesterol-rich lipoproteins (oxLDL) are low. However, in patients with the metabolic syndrome the levels of plasma oxLDL are often increased. ${ }^{9}$ While non-modified LDL is degraded normally and transported to the cytoplasm, cholesterol delivered in the form of oxLDL fails to efflux normally and is trapped inside the lysosomes. In an in vitro setting, it was shown that the uptake of oxLDL is associated with increased cholesterol storage inside lysosomes. ${ }^{10-12}$ Further, the uptake of oxLDL by macrophages was found to be associated with an inflammatory response. ${ }^{13-16}$ Thus, the uptake of oxLDL by macrophages is associated with lysosomal cholesterol accumulation and inflammation.

Observations in foamy macrophages found in atherosclerotic plaques have shown that much of the accumulated lipids are present in large, lipid-engorged lysosomes. ${ }^{5}$ These findings were confirmed in atherosclerotic lesions from human and in animal models of the disease. ${ }^{17-19}$ Similar to the findings in foam cells of atherosclerotic plaques, we could show that also in NASH cholesterol is mainly trapped inside the lysosomes. Our group observed the appearance of bloated Kupffer cells, the resident macrophages of the liver, in hyperlipidemic mice fed a high-fat, high-cholesterol diet developing $\mathrm{NASH}^{20}$ We showed that mainly the uptake of modified lipoproteins by Kupffer cells via scavenger receptors is involved in hepatic inflammation. Mice lacking Cd36 and/or Msr1, the two most important scavenger receptors that are responsible 
for the uptake of modified lipoproteins, were shown to have reduced hepatic inflammation and less lysosomal cholesterol accumulation after high fat feeding. ${ }^{4,20,21}$ Moreover, we identified that LDL in the form of oxLDL is causally responsible for the accumulation inside lysosomes during hepatic inflammation. While non-oxLDL injections did not lead to trapping of lipids in lysosomes or to inflammation, injections with oxLDL resulted in increased lysosomal cholesterol accumulation and hepatic inflammation. ${ }^{14}$ Altogether, these data indicated that accumulation of oxLDL in lysosomes is an important trigger for the development of inflammation. In this thesis we described several potential mechanisms by which intracellular disturbances in cholesterol trafficking can trigger the inflammatory response (chapter 2).

\section{Lysosomal cholesterol trapping leads to inflammation via inflammasome activation}

Previous reports indicate that cholesterol accumulation in lysosomes of macrophages can trigger an inflammatory response via the activation of inflammasomes. ${ }^{22-24}$ The inflammasomes are a family of different cytosolic multi-protein complexes that serve as sensors of either pathogens or cellular stress and work via triggering caspase-1/11 mediated IL-1 $\beta$ and IL-18 processing and release. Both IL- $1 \alpha$ and IL-1 $\beta$ exert their proinflammatory effects via the activation of IL-1 receptor type 1 (IL-1R1), whereas IL-1 receptor antagonist (IL-1Ra) competitively inhibits their binding. ${ }^{25}$ The involvement of IL-1 signaling in inflammation during obesity-related diseases was extensively shown before. ${ }^{26}$ Among the different stimuli for the activation of the inflammasome are cholesterol crystals and lysosomal enzymes such as cathepsins. ${ }^{22,27-29}$ Interestingly, lysosomal cholesterol trapping leads to the formation of cholesterol crystals and disturbed plasma cathepsin levels, thereby triggering the activation of the inflammasome.

In atherosclerotic lesions, cholesterol crystals were found to be formed in macrophages and were shown to induce phagolysosomal membrane rupture, which in turn leads to the release of the phagolysosomal content into the cytosol. ${ }^{22}$ Phagolysosomal damage caused by cholesterol crystals, both in vitro and in vivo, activates the NLRP3 inflammasome, indicating a potential mechanism by which atherosclerosis can be triggered. Further, while normal arteries express little or no cathepsins, in atherosclerotic vessels these proteins are abundantly expressed and secreted, thereby potentially activate inflammasomes. ${ }^{30}$ The contribution of different inflammasome members to atherosclerosis was studied extensively. Mice susceptible to atherosclerosis reconstituted with inflammasome deficient bone marrow exhibited reduced atherogenesis, indicating the importance of inflammasome activation in cells derived from the hematopoietic system. ${ }^{22,31-33}$ Mechanistically, it was recently found that cholesterol crystals employ the complement system to induce cytokines and that the complement system is necessary to activate the inflammasome/caspase- 1 in 
human monocytes. ${ }^{34}$ In addition, the IL-1 cytokine system was previously been found to link atherogenic environmental stimuli with arterial inflammation, oxidative stress and atherosclerosis. Apoe $e^{-/} / \mathrm{IL}-1 \mathrm{R} 1^{-/-}$mice had significantly less atheroma than Apoe ${ }^{-/-}$ mice and selective loss of IL-1 signaling in the vessel wall by bone marrow transplantation was shown to reduce plaque burden. ${ }^{35}$ Likewise, mice deficient for IL$1 \beta$ were shown to be protective against atherosclerosis development as indicated by a significant reduction in plaque size and less inflammatory cytokine levels in the plasma. ${ }^{22,36}$ These data suggest that during atherosclerosis, macrophages may trigger inflammation via inflammasome activation as a result of lysosomal cholesterol accumulation followed by cholesterol crystallization.

Recently, cholesterol crystals and crown-like structures were also found to be present in the liver of NASH patients. In contrast, patients with simple steatosis did not have these crown-like structures in their liver and did not exhibit cholesterol crystals. ${ }^{37}$ In line with these findings, we observed in our experiments cholesterol crystallization in inflamed livers of $\mathrm{Ldll}^{-/}$mice during NASH development. In addition, we found increased cathepsin activity and upregulation of IL-1 $\beta$ gene expression in association with hepatic inflammation. ${ }^{4,21,38}$ Likewise, mice lacking scavenger receptor CD36 on the Kupffer cells showed less hepatic inflammation and cholesterol crystal formation. Apart from its scavenging function, CD36 was recently also identified as a central regulator of inflammasome activation in sterile inflammation. The CD36-mediated uptake of soluble ligands and the intracellular conversion of these soluble ligands to crystals resulted in lysosomal disruption and NLRP3-inflammasome activation. ${ }^{39}$ Although several studies showed a protective anti-inflammatory effect on NASH in mice deficient for different inflammasome members, ${ }^{41-43}$, one study found opposite results. ${ }^{40}$ Possible explanations for the discrepancies between the obtained results could be the differences in the animal model that were used, the composition of the gut microbiota in these mice, or the diet used to induce NASH. Whereas the effect of complete deficiency of caspase-1/11 was studied before, ${ }^{41,42}$ we investigated the specific contribution of caspase-1/11 activation in hematopoietic cells during NASH (chapter 3). Specific deletion of caspase-1/11 in hematopoietic cells resulted in reduced formation of cholesterol crystal, less cathepsin D activity and diminished hepatic inflammation. Our data suggest that during NASH development, disturbed autophagy may lead to a vicious cycle in which newly formed cholesterol crystals are activating inflammasomes, thereby leading to increased hepatic inflammation (chapter 3) (Figure 8.1). Furthermore, we found that hematopoietic caspase-1/11 activation plays also a key role in the pathogenesis of atherogenesis (chapter 4). Taken together, multiple data highlight the importance of inflammasome activation during NASH. 

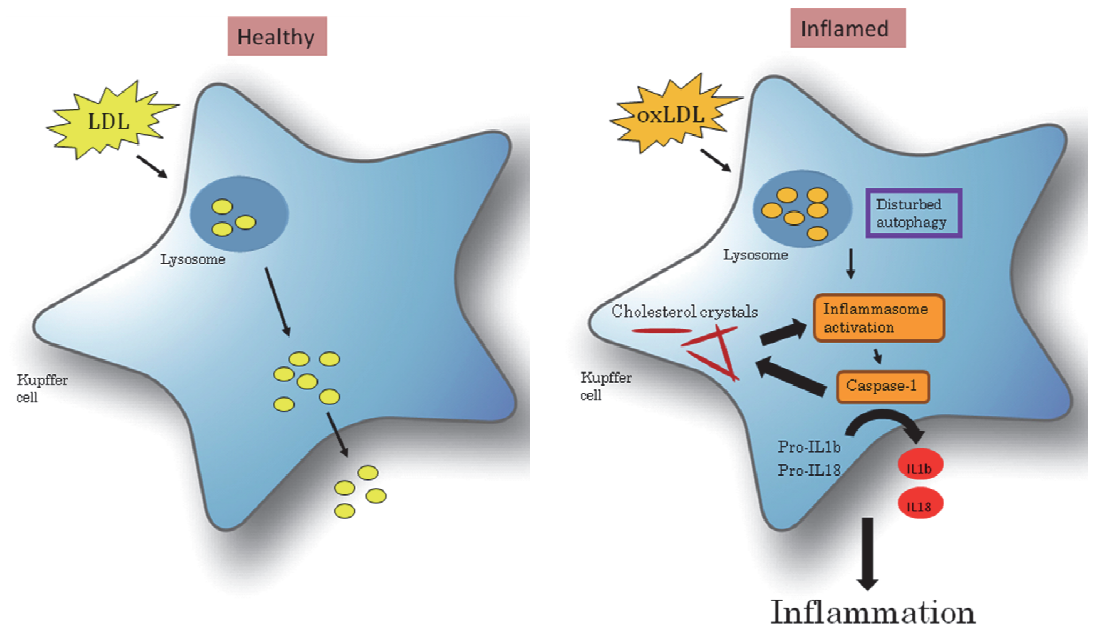

Figure 8.1 Cholesterol distribution in healthy and inflamed conditions. (A) Normal conditions: circulating non-modified low-density lipoproteins (LDL) are taken up by macrophages and initially directed to lysosomes. After hydrolysis, cholesterol is transported to the cytoplasm where it can be further degraded or excreted via cholesterol efflux pathways. Under these conditions, autophagy is functioning and activation of the inflammasome is inhibited. (B) Inflamed conditions: Increased levels of circulating oxidized lipids (oxLDL) are taken up by macrophages via scavenger receptors (CD36 and MSR1) and directed to lysosomes. However, unlike nonmodified LDL, oxLDL is not transported to the cytoplasm, but rather accumulates in lysosomes. Under these conditions, disturbed autophagy leads to a vicious cycle in which newly formed cholesterol crystals are activating inflammasomes, thereby leading to the maturation of the pro-inflammatory cytokines interleukin-1 $\beta$ and interleukin-18, which then engage in the innate immune defense.

\section{Lysosomal cholesterol accumulation triggers inflammation by interfering with autophagy}

In addition to cholesterol crystals, disturbances in autophagy also mediate inflammasome activation. Autophagy defines an evolutionary conserved process of recycling, whereby intracellular macromolecules are broken down into their constituent parts within the lysosomes. ${ }^{45}$ An intriguing new facet to autophagy has emerged due to its involvement in lipid breakdown and cholesterol efflux. ${ }^{46}$ Singh et al. showed that autophagy targets lipid droplets for the delivery to lysosomes in hepatocytes. This discovery increased interest in autophagy as being a key process in lipid-involving diseases such as obesity, atherosclerosis and NASH. In lysosomal storage disorders, in which cholesterol is trapped inside the lysosomes, autophagy was found to be decreased, indicating the link between cholesterol trapping in lysosomes and autophagy. ${ }^{45,47,48}$ Altogether, these data suggest that lysosomal 
cholesterol accumulation leads to dysfunctional autophagy, thereby triggering inflammation during obesity-related disorders.

An important indication for the significant role of autophagy in the MetS is the observation that autophagy is involved in formation of foam cells. ${ }^{49}$ In oxLDL-treated vascular smooth muscle cells, foam cell formation was impeded by inducing autophagy. ${ }^{50,51}$ During atherogenesis, macrophage-specific ATG5 deficient mice, a common mouse model for autophagy deficiency generated by crossing mice with floxed ATG5 locus with LysM Cre mice, showed enlarged atherosclerotic plaques with increased cholesterol crystal content. ${ }^{32}$ Furthermore, macrophages deficient in autophagy had increased cholesterol crystal-mediated inflammasome activation resulting in an enhanced pro-atherogenic IL-1 $\beta$ response. Additionally, Razani et al. showed that autophagy becomes dysfunctional upon plaque progression in $\mathrm{ApoE}^{-/}$ mice during atherogenesis. ${ }^{32}$ Next, rabbits with increased autophagy had lower plaque rupture incidence and lower plaque burden. ${ }^{52}$ Mechanistically, disruption of autophagy in macrophages increases apoptosis and oxidative stress, thereby worsening efferocytosis and promoting plaque necrosis. ${ }^{53}$. The increase in plaque formation by dysfunctional autophagy in macrophages is partly due to inflammasome activation, suggesting that intact autophagy is required for suppressing inflammasomes, which is essential in atheroprotection. As a consequence, successful autophagy could stabilize the atherosclerotic plaques and reduce adverse vascular effects. These data indicate a protective role for macrophage autophagy during atherogenesis.

In the liver, a failure of autophagy could be either a cause for lipid accumulation or a consequence, as an abnormal increase in lipid content was previously reported to exert an inhibitory effect on autophagy. ${ }^{46,54}$. The role of autophagy in the mobilization of hepatic lipids supports a protective role of autophagy against NAFLD and explains why hepatocytes upregulate autophagy in response to dietary lipid challenges as a mechanism of defence against lipotoxicity. Whereas autophagy levels are elevated upon starvation and short-term exposure to high lipid levels, chronic lipid exposure was found to be correlated with impaired autophagy. ${ }^{46,54}$ Both in genetic (ob/ob) and dietary (high-fat induced) mice models having long term lipid availability resulted in inhibition of hepatic autophagy. ${ }^{55}$ Mice upon HFC diet were found to have impaired hepatic autophagic function as demonstrated by decreased mobilization of lipid into the autophagic compartment. Thus, besides the fact that dysfunctional autophagy may promote hepatic steatosis, excessive lipid accumulation in hepatocytes may be a mechanism leading to decreased autophagic function.

This view is in line with our observations that disturbed autophagy is associated with lysosomal cholesterol accumulation during diet-induced NASH in $\mathrm{Ldlr}^{-/-}$mice (chapter 3). The ability of excessive lysosomal lipid accumulation to impair autophagy provides 
another mechanism for the progression of simple steatosis to NASH and its complications. Relevantly, autophagic dysfunction was found to be associated with a decrease in hepatic cathepsin expression during NAFLD, further pointing to the critical importance of balanced autophagy and lysosomal function to prevent liver disease. ${ }^{56}$ Further evidence for the involvement of autophagy dysfunction during fatty liver disease comes from recent findings that loss of autophagy in hepatocytes causes cell death resulting in liver inflammation, fibrosis and tumorigenesis. Mechanistically, persistent activation of Nrf2 was demonstrated to be critical for liver inflammation, fibrosis and eventual tumorigenesis that occur in mice with defects in hepatocyte autophagy. ${ }^{57}$ Taken together, these data indicate that lysosomal cholesterol accumulation can lead to inflammation via disturbed autophagy during atherosclerosis and NASH.

\section{Modulation of lysosomal cholesterol accumulation as therapeutic target}

Treatment options for atherosclerosis and NASH are currently limited due to poor understanding of the mechanisms that trigger inflammation in these patients. The involvement of lysosomal cholesterol trapping in macrophages in triggering inflammation makes it an interesting target for the improvement of therapy options in the MetS. A possible way to elucidate the inflammatory response as a result of lysosomal cholesterol accumulation is stimulation of cholesterol transport from the lysosome into the cytoplasm. However, this is a challenging issue as it was previously shown that lysosomal cholesterol derived from oxLDL is resistant to efflux. ${ }^{58-60}$ Potential mediators of intracellular cholesterol transport are oxysterols such as, 27-hydroxycholesterol (27HC), an intermediate in bile acid synthesis and the major oxysterol present in the human circulation. Interestingly, lysosomal cholesterol accumulation in Niemann-Pick disease type $\mathrm{C}$ is associated with reduced $27 \mathrm{HC}$ production in human NPC1 $1^{-/}$fibroblasts. Interestingly, incubation of these $\mathrm{NPC} 1^{-1-}$ fibroblasts with $27 \mathrm{HC}$ led to increased cholesterol transport from lysosomes to cytoplasm. ${ }^{61}$ In line with these findings, we found that injecting $\mathrm{Ldll}{ }^{-/-}$mice with $27 \mathrm{HC}$ during or after an HFC diet resulted in reduced lysosomal cholesterol accumulation in Kupffer cells and consequently reduced hepatic inflammation (chapter 5). Recently, also 25-hydroxycholesterol $(25 \mathrm{HC})$, another oxysterol, was shown to correct the transport defect in NPC1 mutant cells. ${ }^{62}$ These data demonstrate that oxysterols are capable of lowering lysosomal cholesterol levels.

So far, the mechanisms by which oxysterols can lower the lysosomal cholesterol pool are not yet known. A potential explanation is that oxysterols can influence the lysosomal cholesterol pool by modulating the NPC function in a direct molecular link, as suggested by the finding that $27 \mathrm{HC}$ binds to the N-terminal luminal loop of NPC1. ${ }^{63}$ In line, we found that overexpression of Cyp27a1, the enzyme responsible for 27HC production, results in a reduced inflammatory response, associated with increased 
NPC expression in macrophages (chapter 6). In $\mathrm{Ldll}^{-/-}$mice with hematopoietic Cyp27a1 overexpression a reduction in hepatic inflammation was found, while circulating $27 \mathrm{HC}$ levels were unchanged, suggesting that the intracellular $27 \mathrm{HC}$ levels in macrophages are important and can modulate NPC function.

Another mechanism by which oxysterols could affect inflammation is via liver $X$ receptor (LXR) activation. ${ }^{64}$ LXRs, together with other members of the nuclear receptor superfamily, contribute to cellular cholesterol homeostasis by regulating genes that control the storage, transport and catabolism of cholesterol. In our study, we showed that the agonistic as well as antagonistic actions of 27HC on LXR are cellspecific, indicating that $27 \mathrm{HC}$ functions as an endogenous selective LXR modulator (chapter 5). Nevertheless, it has previously been shown that by simply reducing the amount of cholesterol in the cytoplasm, lysosomal cholesterol accumulation remained similar. In fact, studies in both arteries and cells in culture suggest that the lysosomal cholesterol pool cannot be decreased simply by increasing efflux of extra-lysosomal cholesterol stores. ${ }^{60,65}$ As the total amount of cholesterol in the cells is not correlated directly with inflammation, but rather the amount of cholesterol trapped inside lysosomes, ${ }^{4,38}$ it is likely that the increased expression of NPC1 and NPC2 is the main trigger for the reduced inflammatory response. In fact, the improvement in reverse cholesterol transport could also be a consequence of the reduced lysosomal cholesterol accumulation, since it was shown that by reducing lysosomal cholesterol accumulation, the cholesterol pool inside the cytoplasm was also reduced.

The potential protective effect of LXR activation may also explain the dramatic reduction in hepatic inflammation observed in mice receiving plant sterol or stanol esters supplementation (chapter 7). Both sitosterol and sitostanol were shown to be potent LXR ligands in a cell free in vitro system, ${ }^{66}$ a finding that was later confirmed for other plant sterols like stigmasterol. ${ }^{67}$ Although we observed a reduction in hepatic inflammation as a result of plant sterol/stanol consumption, the effect on lysosomal cholesterol accumulation still needs to be clarified. Taken together, these data support the view that oxysterols can prevent and reduce lysosomal cholesterol accumulation in macrophages, thereby reducing the inflammatory response.

Another way to decrease lysosomal cholesterol accumulation is to reduce the uptake of oxLDL to lysosomes in Kupffer cells. For this purpose, $\mathrm{Ldll}^{-/-}$mice were immunized with heat-inactivated pneumococci, which have been shown to induce the production of anti-oxLDL immunoglobulin $\mathrm{M}$ (IgM) antibodies, due to molecular mimicry with phosphorylcholine; a specific epitope of oxLDL. As expected, immunization with pneumococci increased anti-oxLDL IgM levels and led to a reduction in hepatic inflammation. In immunized mice, Kupffer cells were smaller and showed fewer cholesterol crystals compared with non-immunized mice, indicating reduced lysosomal cholesterol accumulation inside the Kupffer cells. ${ }^{13}$ These data indicate that targeting the cholesterol uptake may also be beneficial in preventing or treating chronic, lipid-associated inflammatory diseases, such as atherosclerosis and NASH.

Finally, it was recently demonstrated that triglycerides delivered to cultured 
macrophages as part of triglyceride-rich particles (TRPs), dramatically reduced lysosomal cholesteryl ester accumulation and improves lysosomal function, possibly by decreasing lysosomal $\mathrm{pH}$ and restoring lysosomal CE hydrolysis. ${ }^{68}$ These observations are in line with previous data from our group indicating that the effect of foamy Kupffer cells on inflammation is not dependent on the total amount of lipids within the cells but rather on the type and localization of lipids. While the potential protective effect of TRPs on NASH development is not studied in this thesis, it is a promising target for future studies.

Taken together, a major conclusion from this thesis is that therapy should focus on cholesterol, its modifications, and its intracellular distribution. Furthermore, macrophages and Kupffer cells should be the main target for future therapies of atherosclerosis and NASH respectively. 


\section{Novel findings of this thesis}

Circumstantial evidence points to the build-up of cholesterol within lysosomes of foamy macrophages in atherosclerotic plaques and inside Kupffer cells during NASH as being detrimental. However, knowledge regarding the molecular mechanisms by which lysosomal cholesterol accumulation triggers inflammation is lacking. In the present thesis, we aimed to unravel the mechanism by which lysosomal cholesterol trapping leads to inflammation in the context of atherosclerosis and NASH. The novel findings of the studies presented in this thesis are listed below.

- Lysosomal cholesterol accumulation in macrophages is a driver of inflammation during atherosclerosis and NASH. (Chapter 2)

- Hematopoietic caspase-1/11 activation is involved in cholesterol crystallization and triggers inflammation during NASH development. (Chapter 3 )

- Disturbed autophagy may lead to a vicious cycle in which newly formed cholesterol crystals further activate the inflammasome, thereby sustaining chronic inflammation. (Chapter 3)

- Besides triggering inflammation, caspase-1/11-mediated cell death in hematopoietic cells plays an important role in atherosclerotic disease progression. (Chapter 4)

- Oxysterols, such as $27 \mathrm{HC}$, can stimulate the transport of cholesterol out of the lysosomes and lower hepatic inflammation. (Chapter 5)

- Increasing the expression of NPC proteins can modulate lysosomal cholesterol accumulation inside Kupffer cells, thereby affecting hepatic inflammation. (Chapter 6)

- Plant sterol/stanol esters consumption reduces hepatic inflammation in a hyperlipidemic mouse model for NASH. (Chapter 7)

\section{List of suggested novel targets for intervention}

Besides studying the underlying mechanisms by which lysosomal cholesterol accumulation can lead to inflammation, our aim was to unravel new targets for therapy. Therefore, our main focus was to manipulate cholesterol accumulation in lysosomes in order to reduce inflammation. The results of these studies suggested novel targets for intervention, which are listed below.

- $\quad$ Caspase-1/11

- Autophagy

- Cyp27a1 


\section{References}

1. Grundy SM. Metabolic syndrome: a multiplex cardiovascular risk factor. J Clin Endocrinol Metab. 2007;92:399-404.

2. Bieghs V, Rensen PC, Hofker MH, Shiri-Sverdlov R. NASH and atherosclerosis are two aspects of a shared disease: central role for macrophages. Atherosclerosis. 2012;220:287-93.

3. Libby P. Inflammation in atherosclerosis. Nature. 2002;420:868-74.

4. Bieghs V, Verheyen F, van Gorp PJ, Hendrikx T, Wouters K, Lütjohann D, Gijbels MJ, Febbraio M, Binder CJ, Hofker MH, Shiri-Sverdlov R. Internalization of modified lipids by CD36 and SR-A leads to hepatic inflammation and lysosomal cholesterol storage in Kupffer cells. PLoS One. 2012;7:e34378.

5. Haley NJ, Shio H, Fowler S. Characterization of lipid-laden aortic cells from cholesterol-fed rabbits. I. Resolution of aortic cell populations by metrizamide density gradient centrifugation. Lab Invest. 1977; 37:287-96.

6. Jerome WG. Lysosomes, cholesterol and atherosclerosis. Clin Lipidol. 2010;5:853-865.

7. Gerrity RG. The role of the monocyte in atherogenesis: II. Migration of foam cells from atherosclerotic lesions. Am J Pathol. 1981;103:191-200.

8. Gerrity RG, The role of the monocyte in atherogenesis: I. Transition of blood-borne monocytes into foam cells in fatty lesions. Am J Pathol. 1981;103:181-90.

9. Holvoet P, Kritchevsky SB, Tracy RP, Mertens A, Rubin SM, Butler J, Goodpaster B, Harris TB. The metabolic syndrome, circulating oxidized LDL, and risk of myocardial infarction in well-functioning elderly people in the health, aging, and body composition cohort. Diabetes. 2004; 53:1068-73.

10. Griffin EE, Ullery JC, Cox BE, Jerome WG. Aggregated LDL and lipid dispersions induce lysosomal cholesteryl ester accumulation in macrophage foam cells. J Lipid Res. 2005;46:2052-60.

11. Jerome WG, Cash C, Webber R, Horton R, Yancey PG. Lysosomal lipid accumulation from oxidized low density lipoprotein is correlated with hypertrophy of the Golgi apparatus and trans-Golgi network. $J$ Lipid Res. 1998;39:1362-71.

12. Yancey PG, Jerome WG. Lysosomal sequestration of free and esterified cholesterol from oxidized low density lipoprotein in macrophages of different species. J Lipid Res. 1998;39:1349-61.

13. Bieghs V, van Gorp PJ, Walenbergh SM, Gijbels MJ, Verheyen F, Buurman WA, Briles DE, Hofker MH, Binder CJ, Shiri-Sverdlov R. Specific immunization strategies against oxidized low-density lipoprotein: a novel way to reduce nonalcoholic steatohepatitis in mice. Hepatology. 2012;56:894-903.

14. Bieghs V, Walenbergh SM, Hendrikx T, van Gorp PJ, Verheyen F, Olde Damink SW, Masclee AA, Koek $\mathrm{GH}$, Hofker MH, Binder CJ, Shiri-Sverdlov R. Trapping of oxidized LDL in lysosomes of Kupffer cells is a trigger for hepatic inflammation. Liver Int. 33:1056-61.

15. Jerome WG, Cox BE, Griffin EE, Ullery JC. Lysosomal cholesterol accumulation inhibits subsequent hydrolysis of lipoprotein cholesteryl ester. Microsc Microanal. 2008;14:138-49.

16. Walenbergh SM, Koek GH, Bieghs V, Shiri-Sverdlov R. Non-alcoholic steatohepatitis: the role of oxidized low-density lipoproteins. J Hepatol. 2013;58:801-10.

17. Goldfischer S, Schiller B, Wolinsky H. Lipid accumulation in smooth muscle cell lysosomes im primate atherosclerosis. Am J Pathol. 1975;78:497-504.

18. Jerome WG, Lewis JC. Early atherogenesis in White Carneau pigeons. II. Ultrastructural and cytochemical observations. Am J Pathol. 1985;119:210-22.

19. Peters TJ, Muller M, De Duve C. Lysosomes of the arterial wall. I. Isolation and subcellular fractionation of cells from normal rabbit aorta. J Exp Med. 1972;136:1117-39.

20. Wouters K, van Gorp PJ, Bieghs V, Gijbels MJ, Duimel H, Lütjohann D, Kerksiek A, van Kruchten R, Maeda N, Staels B, van Bilsen M, Shiri-Sverdlov R, Hofker MH. Dietary cholesterol, rather than liver steatosis, leads to hepatic inflammation in hyperlipidemic mouse models of nonalcoholic steatohepatitis. Hepatology. 2008;48:474-86.

21. Bieghs V, Wouters K, van Gorp PJ, Gijbels MJ, de Winther MP, Binder CJ, Lütjohann D, Febbraio M, Moore KJ, van Bilsen M, Hofker MH, Shiri-Sverdlov R. Role of scavenger receptor $A$ and CD36 in dietinduced nonalcoholic steatohepatitis in hyperlipidemic mice. Gastroenterology. 2010;138:2477-86, 2486 e1-3. 
22. Duewell P, Kono H, Rayner KJ, Sirois CM, Vladimer G, Bauernfeind FG, Abela GS, Franchi L, Nuñez G, Schnurr M, Espevik T, Lien E, Fitzgerald KA, Rock KL, Moore KJ, Wright SD, Hornung V, Latz E. NLRP3 inflammasomes are required for atherogenesis and activated by cholesterol crystals. Nature. 2010;464:1357-61.

23. Hornung V, Latz E. Critical functions of priming and lysosomal damage for NLRP3 activation. Eur J Immunol. 2010;40:620-3.

24. Latz E. The inflammasomes: mechanisms of activation and function. Curr Opin Immunol. 2010;22: 28-33.

25. Weber A, Wasiliew P, Kracht M. Interleukin-1 (IL-1) pathway. Sci Signal. 2010;3:cm1.

26. Osborn O, Gram H, Zorrilla EP, Conti B, Bartfai T. Insights into the roles of the inflammatory mediators IL-1, IL-18 and PGE2 in obesity and insulin resistance. Swiss Med Wkly. 2008;138:665-73.

27. Bruchard $M$, Mignot $G$, Derangère $V$, Chalmin $F$, Chevriaux $A$, Végran $F$, Boireau $W$, Simon $B$, Ryffel $B$, Connat JL, Kanellopoulos J, Martin F, Rébé C, Apetoh L, Ghiringhelli F. Chemotherapy-triggered cathepsin B release in myeloid-derived suppressor cells activates the Nlrp3 inflammasome and promotes tumor growth. Nat Med. 2013;19:57-64.

28. Chu J, Thomas LM, Watkins SC, Franchi L, Núñez G, Salter RD. Cholesterol-dependent cytolysins induce rapid release of mature IL-1beta from murine macrophages in a NLRP3 inflammasome and cathepsin B-dependent manner. J Leukoc Biol. 2009;86:1227-38.

29. Rajamäki K, Lappalainen J, Oörni K, Välimäki E, Matikainen S, Kovanen PT, Eklund KK. Cholesterol crystals activate the NLRP3 inflammasome in human macrophages: a novel link between cholesterol metabolism and inflammation. PLoS One. 2010;5:e11765.

30. Lutgens SP, Cleutjens KB, Daemen MJ, Heeneman S Cathepsin cysteine proteases in cardiovascular disease. FASEB J. 2007;21:3029-41.

31. Gage J, Hasu M, Thabet M, Whitman SC. Caspase-1 deficiency decreases atherosclerosis in apolipoprotein E-null mice. Can J Cardiol. 2012;28:222-9.

32. Razani B, Feng C, Coleman T, Emanuel R, Wen H, Hwang S, Ting JP, Virgin HW, Kastan MB, Semenkovich CF. Autophagy links inflammasomes to atherosclerotic progression. Cell Metab. 2012;15:534-44.

33. Usui F, Shirasuna K, Kimura H, Tatsumi K, Kawashima A, Karasawa T, Hida S, Sagara J, Taniguchi S, Takahashi M. Critical role of caspase-1 in vascular inflammation and development of atherosclerosis in Western diet-fed apolipoprotein E-deficient mice. Biochem Biophys Res Commun. 2012;425:162-8.

34. Samstad EO, Niyonzima N, Nymo S, Aune MH, Ryan L, Bakke SS, Lappegård KT, Brekke OL, Lambris JD, Damås JK, Latz E, Mollnes TE, Espevik T. Cholesterol crystals induce complement-dependent inflammasome activation and cytokine release. J Immunol. 2014;192:2837-45.

35. Chamberlain J, Francis S, Brookes Z, Shaw G, Graham D, Alp NJ, Dower S, Crossman DC. Interleukin-1 regulates multiple atherogenic mechanisms in response to fat feeding. PLoS One. 2009;4:e5073.

36. Kirii H, Niwa T, Yamada Y, Wada H, Saito K, Iwakura Y, Asano M, Moriwaki H, Seishima M. Lack of interleukin-1beta decreases the severity of atherosclerosis in ApoE-deficient mice. Arterioscler Thromb Vasc Biol. 2003;23:656-60.

37. Ioannou GN, Haigh WG, Thorning D, Savard C. Hepatic cholesterol crystals and crown-like structures distinguish NASH from simple steatosis. J Lipid Res. 2013;54:1326-34.

38. Bieghs V, Hendrikx T, van Gorp PJ, Verheyen F, Guichot YD, Walenbergh SM, Jeurissen ML, Gijbels M, Rensen SS, Bast A, Plat J, Kalhan SC, Koek GH, Leitersdorf E, Hofker MH, Lütjohann D, Shiri-Sverdlov R. The cholesterol derivative 27-hydroxycholesterol reduces steatohepatitis in mice. Gastroenterology. 2013;144:167-78 e1.

39. Sheedy FJ, Grebe A, Rayner KJ, Kalantari P, Ramkhelawon B, Carpenter SB, Becker CE, Ediriweera HN, Mullick AE, Golenbock DT, Stuart LM, Latz E, Fitzgerald KA, Moore KJ. CD36 coordinates NLRP3 inflammasome activation by facilitating intracellular nucleation of soluble ligands into particulate ligands in sterile inflammation. Nat Immunol. 2013;14:812-20.

40. Henao-Mejia J, Elinav E, Jin C, Hao L, Mehal WZ, Strowig T, Thaiss CA, Kau AL, Eisenbarth SC, Jurczak MJ, Camporez JP, Shulman GI, Gordon JI, Hoffman HM, Flavell RA. Inflammasome-mediated dysbiosis regulates progression of NAFLD and obesity. Nature. 2012;482:179-85.

41. Dixon L, Berk M, Thapaliya S, Papouchado BG, Feldstein AE. Caspase-1-mediated regulation of fibrogenesis in diet-induced steatohepatitis. Lab Invest. 2012;92:713-23. 
42. Dixon L, Flask CA, Papouchado BG, Feldstein AE, Nagy LE. Caspase-1 as a central regulator of high fat diet-induced non-alcoholic steatohepatitis. PLoS One. 2013;8:e56100.

43. Szabo G, Csak T. Inflammasomes in liver diseases. J Hepatol. 2012;57:642-54.

44. Kamari Y, Shaish A, Vax E, Shemesh S, Kandel-Kfir M, Arbel Y, Olteanu S, Barshack I, Dotan S, Voronov E, Dinarello CA, Apte RN, Harats D. Lack of interleukin-1alpha or interleukin-1beta inhibits transformation of steatosis to steatohepatitis and liver fibrosis in hypercholesterolemic mice. J Hepatol. 2011;55:1086-94.

45. Choi AM, Ryter SW, Levine B. Autophagy in human health and disease. N Engl J Med. 2013;368: 1845-6.

46. Singh R, Kaushik S, Wang Y, Xiang Y, Novak I, Komatsu M, Tanaka K, Cuervo AM, Czaja MJ. Autophagy regulates lipid metabolism. Nature. 2009;458:1131-5.

47. Settembre C Fraldi A, Jahreiss L, Spampanato C, Venturi C, Medina D, de Pablo R, Tacchetti C, Rubinsztein DC, Ballabio A. A block of autophagy in lysosomal storage disorders. Hum Mol Genet. 2008;17:119-29.

48. Settembre C, Fraldi A, Rubinsztein DC, Ballabio A. Lysosomal storage diseases as disorders of autophagy. Autophagy. 2008;4:113-4.

49. Feng X, Yuan Y, Wang C, Feng J, Yuan Z, Zhang X, Sui W, Hu P, Zheng P, Ye J. Autophagy involved in lipopolysaccharide-induced foam cell formation is mediated by adipose differentiation-related protein. Lipids Health Dis. 2014;13:10.

50. Li Y, Li S, Qin X, Hou W, Dong H, Yao L, Xiong L. The pleiotropic roles of sphingolipid signaling in autophagy. Cell Death Dis. 2014;5:e1245.

51. Wang X, Li L, Niu X, Dang X, Li P, Qu L, Bi X, Gao Y, Hu Y, Li M, Qiao W, Peng Z, Pan L. mTOR enhances foam cell formation by suppressing the autophagy pathway. DNA Cell Biol. 2014;33:198-204.

52. Zhai C, Cheng J, Mujahid H, Wang H, Kong J, Yin Y, Li J, Zhang Y, Ji X, Chen W. Selective inhibition of $\mathrm{PI3K} / \mathrm{Akt} / \mathrm{mTOR}$ signaling pathway regulates autophagy of macrophage and vulnerability of atherosclerotic plaque. PLoS One. 2014;9:e90563.

53. Liao X, Sluimer JC, Wang Y, Subramanian M, Brown K, Pattison JS, Robbins J, Martinez J, Tabas I. Macrophage autophagy plays a protective role in advanced atherosclerosis. Cell Metab. 2012;15: 545-53.

54. Koga H, Kaushik S, Cuervo AM. Altered lipid content inhibits autophagic vesicular fusion. FASEB J. 2010;24:3052-65.

55. Yang L, Li P, Fu S, Calay ES, Hotamisligil GS. Defective hepatic autophagy in obesity promotes ER stress and causes insulin resistance. Cell Metab. 2010;11:467-78.

56. Fukuo Y, Yamashina S, Sonoue H, Arakawa A, Nakadera E, Aoyama T, Uchiyama A, Kon K, Ikejima K, Watanabe $\mathrm{S}$. Abnormality of autophagic function and cathepsin expression in the liver from patients with non-alcoholic fatty liver disease. Hepatol Res. 2013 Dec Epub ahead of print.

57. Ni HM, Woolbright BL, Williams J, Copple B, Cui W, Luyendyk JP, Jaeschke H, Ding WX. Nrf2 Promotes the Development of Fibrosis and Tumorigenesis in Mice with Defective Hepatic Autophagy. J Hepatol. 2014 May Epub ahead of print.

58. Dhaliwal BS, Steinbrecher UP. Cholesterol delivered to macrophages by oxidized low density lipoprotein is sequestered in lysosomes and fails to efflux normally. J Lipid Res. 2000;41:1658-65.

59. Lougheed M, Zhang HF, Steinbrecher UP. Oxidized low density lipoprotein is resistant to cathepsins and accumulates within macrophages. J Biol Chem. 1991;266:14519-25.

60. Yancey PG, Jerome WG. Lysosomal cholesterol derived from mildly oxidized low density lipoprotein is resistant to efflux. J Lipid Res. 2001;42:317-27.

61. Frolov A, Zielinski SE, Crowley JR, Dudley-Rucker N, Schaffer JE, Ory DS. NPC1 and NPC2 regulate cellular cholesterol homeostasis through generation of low density lipoprotein cholesterol-derived oxysterols. J Biol Chem. 2003;278:25517-25.

62. Ohgane K, Karaki F, Dodo K, Hashimoto Y. Discovery of oxysterol-derived pharmacological chaperones for NPC1: implication for the existence of second sterol-binding site. Chem Biol. 2013;20:391-402.

63. Infante RE, Abi-Mosleh L, Radhakrishnan A, Dale JD, Brown MS, Goldstein JL. Purified NPC1 protein. I. Binding of cholesterol and oxysterols to a 1278-amino acid membrane protein. J Biol Chem. 2008; 283:1052-63.

64. Janowski BA, Willy PJ, Devi TR, Falck JR, Mangelsdorf DJ. An oxysterol signalling pathway mediated by the nuclear receptor LXR alpha. Nature. 1996;383:728-31. 
65. Yancey PG, Miles S, Schwegel J, Jerome WG. Uptake and trafficking of mildly oxidized LDL and acetylated LDL in THP-1 cells does not explain the differences in lysosomal metabolism of these two lipoproteins. Microsc Microanal. 2002;8:81-93.

66. Plat J, Mensink RP. Increased intestinal ABCA1 expression contributes to the decrease in cholesterol absorption after plant stanol consumption. FASEB J. 2002;16:1248-53.

67. Yu L, Cao G, Repa J, Stangl H. Sterol regulation of scavenger receptor class B type I in macrophages. J Lipid Res. 2004;45:889-99.

68. Ullery-Ricewick JC, Cox BE, Griffin EE, Jerome WG. Triglyceride alters lysosomal cholesterol ester metabolism in cholesteryl ester-laden macrophage foam cells. J Lipid Res. 2009;50:2014-26. 
Summary 


\section{Summary}

Chapter 1 provides a general overview about the pathogenesis of atherosclerosis and $\mathrm{NASH}$. Furthermore, the central hypothesis regarding the role of disturbed cholesterol trafficking in macrophages in the development of chronic inflammation is briefly introduced. Finally, the general aim and the outline of the thesis are described.

In chapter 2 the central hypothesis of this thesis is discussed in more details and recent evidence that shows the involvement of lysosomal cholesterol accumulation in driving inflammation during atherosclerosis and NASH are described. In addition, this chapter discusses the challenges in improving cholesterol trafficking in macrophages and recent successful research directions.

One potential mechanism by which lysosomal cholesterol accumulation can lead to inflammation is via the activation of inflammasomes. In chapter 3, we hypothesized that activated inflammasomes in Kupffer cells (KCs) stimulate cholesterol crystallization, thereby leading to hepatic inflammation during $\mathrm{NASH}$. In order to test this hypothesis, $L d l r^{-/}$mice were transplanted with bone marrow from caspase- $1 / 11^{-/}$ mice and fed a high-fat, high-cholesterol (HFC) diet for 12 weeks. As expected, less severe hepatic inflammation was present in caspase- $1 / 11^{-/-}$-tp mice compared to Wttp mice. Furthermore, KCs from caspase- $1 / 11^{-/-}$-tp mice showed less cholesterol crystals, enhanced cholesterol efflux and increased autophagy. We concluded that hepatic inflammation during NASH is maintained by a vicious cycle whereby disturbed autophagy and reduced cholesterol efflux leads to newly formed cholesterol crystals, thereby further activating inflammasomes.

As lysosomal cholesterol accumulation is also observed during atherosclerosis, inflammasome activation may be involved in the progression of atherosclerosis. Therefore, in chapter 4, we hypothesized that hematopoietic caspase- $1 / 11^{-/}$ deficiency leads to reduced atherosclerosis development. For this purpose, caspase$1 / 11^{\%-}$ bone marrow cells were transplanted into $\mathrm{Ldll} \mathrm{r}^{-/}$mice and fed a HFC diet for 12 weeks. Hematopoietic deletion of caspase-1/11 resulted in a strong reduction in atherosclerotic plaque size and decreased necrotic core content. The data in this chapter indicate that hematopoietic caspase-1/11 activation plays an important role in vascular inflammation and atherosclerosis development.

Previously, 27-hydroxycholesterol (27HC), a derivative of cholesterol formed by Cyp27a1, has been shown to mobilize cholesterol from the lysosomes to the cytoplasm in vitro. In chapter 5, we hypothesized that $27 \mathrm{HC}$ can redirect the intracellular cholesterol distribution in vivo, thereby influencing hepatic inflammation. To test this hypothesis, $\mathrm{Ldll}^{-/-}$mice were depleted from Cyp27a1 in their hematopoietic system by bone marrow transplantation and fed a HFC diet for 12 
weeks. Furthermore, $27 \mathrm{HC}$ was administered subcutaneously to $L d l r^{-/-}$mice that received regular chow or an HFC diet for 3 weeks. We demonstrated that Cyp27a1 $1^{--}$ tp mice show increased hepatic inflammation and lysosomal cholesterol accumulation, while $27 \mathrm{HC}$ administration led to reduced hepatic inflammation and lysosomal cholesterol trapping. Therefore, we conclude that $27 \mathrm{HC}$ may be a potential target to reduce lysosomal cholesterol and to treat NASH.

In chapter 6, we hypothesized that Cyp27a1 overexpression (the enzyme involved in the production of $27 \mathrm{HC}$ ) in $\mathrm{KCs}$ reduces hepatic inflammation. To test our hypothesis, $\mathrm{Ld}_{\mathrm{I}} \mathrm{r}^{-}$mice were transplanted with bone marrow from mice overexpressing Cyp27a1 and given a HFC diet for 12 weeks. In line with our expectations, hepatic inflammation was reduced in mice with hematopoietic overexpression of Cyp27a1. These changes occurred even though $27 \mathrm{HC}$ levels in plasma and liver were not different from Wt-tp mice. Therefore, we concluded that hematopoietic Cyp27a1 reduces hepatic inflammation independently of 27-hydroxycholesterol levels in plasma and liver.

In chapter 7, we hypothesized that dietary plant sterol and stanol esters, which are similar to $27 \mathrm{HC}$, will also reduce hepatic inflammation. In order to test our hypothesis, $\mathrm{Ldlr}^{-/}$mice were given HFC diet with or without supplementation of plant sterols or stanols. We demonstrated that adding plant sterol/stanol esters reduced hepatic inflammation dramatically. This protective effect of plant sterol and stanol esters on hepatic inflammation is expected to open new venues in the treatment or prevention of NASH.

Finally, in chapter $\mathbf{8}$ we discuss the major findings of this thesis in the context of the current status in the field. 
Samenvatting 


\section{Samenvatting}

Hoofdstuk 1 geeft een algemeen overzicht over het ziekteverloop van atherosclerose en NASH. Verder wordt de centrale hypothese met betrekking tot de rol van verstoord cholesterol transport in macrofagen tijdens de ontwikkeling van chronische ontsteking geïntroduceerd. Tenslotte zijn de algemene doelstelling en het overzicht van de thesis beschreven.

In hoofdstuk 2 wordt de centrale hypothese van de thesis in meer detail besproken en wordt er een update gegeven van recente aanwijzingen die de betrokkenheid van lysosomale cholesterol stapeling aantonen in het aandrijven van ontsteking tijdens atherosclerose en NASH. Daarnaast zijn in dit hoofdstuk de uitdagingen om cholesterol transport in macrofagen te verbeteren en recente succesvolle onderzoeksrichtingen besproken.

Een mogelijk mechanisme waarop lysosomale cholesterol stapeling kan leiden to ontsteking is door de activatie van inflammasomen. In hoofdstuk 3, werd de hypothese gesteld dat inflammasoom activatie in Kupffer cellen (KC) de vorming van cholesterol kristallen stimuleert, en op die manier zal leiden tot leverontsteking tijdens NASH. Om deze hypothese te testen werden $\mathrm{Ldll}^{-/-}$muizen getransplanteerd met beenmerg van caspase- $1 / 11^{\%}$ muizen en kregen ze een hoog vet, hoog cholesterol (HFC) dieet voor 12 weken. In lijn met onze verwachting was er minder leverontsteking in caspase- $1 / 11^{-/}$getransplanteerde muizen in vergelijking met wildtype getransplanteerde muizen. Verder toonden KC van caspase- $1 / 11^{-/}$ getransplanteerde muizen minder cholesterol kristallen, meer cholesterol efflux en toegenomen autophagy. We concludeerden dat leverontsteking tijdens NASH onderhouden is door een vicieuze cirkel waarin verstoorde autophagy en verminderde cholesterol efflux leiden tot nieuw gevormde cholesterol kristallen, die op hun beurt inflammasomen verder activeren.

Aangezien lysosomale cholesterol stapeling ook voorkomt tijdens atherosclerose, kan inflammasoom activatie ook plaatsvinden tijdens de progressie van atherosclerose. Daarom hadden we in hoofdstuk 4 de hypothese dat hematopoietische caspase-1/11 deficiëntie leidt tot minder atherosclerose ontwikkeling. Om deze hypothese te testen werden caspase- $1 / 11^{-/}$beenmergcellen getransplanteerd in $\mathrm{Ldll} \mathrm{r}^{-/-}$muizen en werd een HFC dieet toegediend voor 12 weken. Hematopoietische deletie van caspase-1/11 resulteerde in een sterke reductie in de grootte van de atherosclerotische plaques en een daling in de hoeveelheid necrose in de plaques. De data in dit hoofdstuk duiden er op dat hematopoietische caspase-1/11 activatie een belangrijke rol speelt in vaatwandontsteking en de ontwikkeling van atherosclerose. 
Voorheen werd aangetoond dat 27-hydroxycholesterol (27HC), een afbraakproduct van cholesterol gevormd door Cyp27a1, cholesterol kan verplaatsen van de lysosomen naar het cytoplasma. In hoofdstuk 5 stelden we de hypothese dat $27 \mathrm{HC}$ in vivo de intracellulaire cholesterolverdeling kan moduleren, en daardoor leverontsteking kan beïnvloeden. Om deze hypothese te testen werd Cyp27a1 in het hematopoietisch systeem van $\mathrm{Ldll}^{-/-}$muizen verwijderd door middel van beenmergtransplantatie en vervolgens op een HFC dieet geplaatst gedurende 12 weken. Daarnaast werd $27 \mathrm{HC}$ subcutaan toegediend aan $\mathrm{Ldlr}^{-/}$muizen die een controle dieet of HFC dieet kregen voor 3 weken. We toonden aan dat $\mathrm{Cyp}_{27 a 1^{-1}}$ getransplanteerde muizen meer leverontsteking en lysosomale cholesterol stapeling hebben, terwijl toediening van $27 \mathrm{HC}$ resulteerde in vermindere leverontsteking en een daling in lysosomale cholesterol stapeling. Daarom concludeerden we dat $27 \mathrm{HC}$ een mogelijk target is om lysosomale cholesterol stapeling te verminderen en voor de behandeling van NASH.

In hoofdstuk 6 werd de hypothese gesteld dat Cyp27a1 overexpressie (het enzyme dat instaat voor $27 \mathrm{HC}$ productie) in $\mathrm{KC}$ leverontsteking reduceert. Daarom werden $\mathrm{Ldlr}^{-/}$muizen getransplanteerd met beenmerg van muizen die Cyp27a1 tot overexpressie brengen en vervolgens op een HFC dieet gezet voor 12 weken. In lijn met onze verwachtingen was leverontsteking vermindert in muizen met hematopoietische overexpressie van Cyp27a1. Deze daling gebeurde terwijl $27 \mathrm{HC}$ levels in plasma en lever niet verschillend waren van controle muizen. Daarom concludeerden we dat hematopoietische Cyp27a1 overexpressie leverontsteking doet dalen, onafhankelijk van $27 \mathrm{HC}$ levels in plasma en lever.

In hoofdstuk 7 hadden we de hypothese dat plant sterolen/stanolen esters uit de voeding, die gelijk zijn aan $27 \mathrm{HC}$, leverontsteking kunnen verminderen. Om deze hypothese te testen werden $\mathrm{Ld}_{\mathrm{r}} \mathrm{r}^{-/}$muizen een HFC dieet gegeven, al dan niet gesupplementeerd met plant sterolen of stanolen. We toonden aan dat de toevoeging van plant sterolen/stanolen esters leverontsteking dramatisch kan verlagen. Dit beschermend effect van plant sterolen en stanolen esters op leverontsteking geeft mogelijk nieuwe inzichten in de behandeling of preventie van NASH.

Tenslotte werden in hoofdstuk 8 alle bevindingen van dit proefschrift beschreven en in de context geplaatst van de huidige status van het onderzoeksgebied. 
Valorisation 


\section{Valorisation}

\section{Societal relevance}

NASH is a disease frequently associated with obesity. In Western countries it is becoming increasingly prevalent and is even seen in children. The current prevalence of NASH within the general population is estimated to be as high as $2-3 \%$. However, among obese subjects the prevalence is much higher and it is estimated to be present in $50-100 \%$ of these patients. Furthermore, the number of NASH patients is expected to increase dramatically due to the increasing prevalence of obesity. The propensity of NASH to progress to advanced liver disease is a primary concern. Studies suggest that $16-30 \%$ of affected individuals will have a progressive course, resulting in fibrosis and cirrhosis and an increased risk of liver cancer (www.liverfoundation.org). NASH is by far the most prevalent liver disease and is one of the main causes for liver transplantation. In view of the prevalence of $\mathrm{NASH}$, even a low rate of progression to end-stage liver disease has enormous public health implications. Therefore, there is a critical need to improve diagnosis and therapy for NASH. The potential economic impact of our successful data described in this thesis is therefore expected to be exceptionally high. The results obtained are expected to affect a wide area of research related to metabolic syndrome including diabetes and cardiovascular diseases, and fields with similar mechanisms (such as lysosomal storage diseases and alcoholic fatty liver).

\section{Potential clinical relevance}

Results found in this thesis have enormous potential clinical relevance. Indeed, our research group has registered 6 patents, partially based on data described in this thesis: two patents related to non-invasive diagnosis of NASH and four others related to the treatment of hepatic inflammation (concerning antibodies against oxLDL, oxysterols, $27 \mathrm{HC}$ and NPC). NASH is emerging as a major clinical problem worldwide. In line, several leading pharmaceutical companies have already shown interest in these patents.

Our research is also of relevance to other fields of medicine. In analogy with our novel observations in the liver, much of the cholesterol in foam cells of advanced atherosclerotic plaques appears to be trapped in lysosomes, highlighting the general significance of these observations. It should be noted that the net effect of lysosomal cholesterol accumulation on inflammation in the arteries has never been established. Therefore, as well as contributing to the NASH field, the obtained results are also expected to be highly valuable for future research into cardiovascular diseases, obesity and gut function, including their diagnosis and therapy. Finally, given the general relevance of the mechanistic understanding, linking lysosomal dysfunction to inflammation is also expected to have an important impact in several fields of medicine outside of the metabolic syndrome (i.g. lysosomal storage diseases). In 
summary, this thesis will open new avenues for the study of the complex link between lipid metabolism and inflammation, as manifested in the metabolic syndrome.

\section{Originality and/or innovative elements of the topic}

In most studies in the fatty liver field, it is the total amount of lipids within the liver that is viewed as a main trigger for inflammation. Yet, this point of view does not explain the lack of correlation between steatosis and inflammation in human NASH. In contrast, my thesis focuses on the intracellular distribution of cholesterol inside Kupffer cells/macrophages. This novel approach is promising since there is a strong correlation between lysosomal cholesterol accumulation in Kupffer cells and hepatic inflammation. This conceptually innovative view on the pathogenesis of NASH predicts that therapy and prevention should not concentrate on fighting steatosis, as stated by current views on the problem, but in contrast should focus directly on lysosomal cholesterol accumulation in Kupffer cells as an initial trigger for inflammation and liver damage. Similarly, reducing plasma lipids levels are currently the main focus for prevention and treatment of atherosclerosis but more focus should be on directly targeting the underling mechanisms for initiation of inflammation. Finally, in contrast to the current non-invasive markers for NASH that focus on liver damage at late stages of the disease, the focus on early events will yield early markers to detect inflammation before substantial liver damage occurred.

\section{Potential applications of results}

The involvement of lysosomal cholesterol trapping in macrophages in triggering inflammation makes it an interesting target for the improvement of diagnostic and therapy options in diseases characterized by the presence of chronic inflammation. First of all, data from this thesis indicate the potential of (oxy)sterols to be used as therapy against NASH by stimulating transport of cholesterol from lysosomes to the cytoplasm. Further research has to be performed to translate our findings regarding $27 \mathrm{HC}$ to the human situation. As we indicate the potential of diet interventions by adding plant sterol or plant stanol esters to prevent the development of hepatic inflammation, it is of great interest to also study the potential of dietary supplementation of $27 \mathrm{HC}$ to reduce hepatic inflammation. Besides that, our data further point towards specifically targeting macrophages in order to improve therapy options. Raising intracellular $27 \mathrm{HC}$ levels specifically in macrophages may have great potential in treating NASH. In addition, as we found that inflammasome activation in macrophages plays an important role in both NASH and atherosclerosis, specifically targeting inflammasomes in macrophages or blocking the IL-1 receptor is promising in reducing the inflammatory response. Future studies are needed to identify optimal application conditions of the different modulators described in this thesis. 
Dankwoord 


\section{Dankwoord}

Via deze weg zou ik graag iedereen nogmaals willen bedanken die een bijdrage heeft geleverd aan het bereiken van deze nieuwe mijlpaal in mijn leven, namelijk het afronden en behalen van mijn doctoraat. Zonder jullie hulp en steun de afgelopen jaren zou me dit nooit gelukt zijn, BEDANKT!

Eerst en vooral mijn dank aan de leden van de beoordelingscommissie voor het nalezen, verbeteren en goedkeuren van mijn thesis.

Then, I would like to thank the most important person for me during the past years. Ronit, thank you for giving me the opportunity to be part of your group, to be always there for a talk (scientific or not), meaning to be the listening ear I sometimes needed. I will never forget all the great times we had together (Dublin, New York, Hollywood, ...), always a lot of fun! Most importantly, you are the one that made it possible to increase my life quality with enormous amounts of fireworks! :) For me it is out of question, you are definitely the best supervisor one can imagine! Thank you for everything!

Dan kom ik vervolgens aan bij mijn paranimfen. Patrick, ik zou niet weten wat ik zonder $u$ in het lab had gedaan. Gij zijt echt het-mannetje-van-alles op MolGen en daar zou iedereen $u$ dankbaar voor moeten zijn. Ik vond het steeds een plezier om met $u$ te werken op het lab, of bij de muizen (ja ik kan de Belgen mopjes ondertussen wel verdragen), of zelfs om een kamer te delen (remember Spier?). Dan Sofie, mijn buurvrouw in de aio-kamer. Supertoffe collega om mee samen te werken. Altijd klaar voor hulp te bieden en zeker steeds klaar voor een party $(;)$ Ik wens je succes met je thesis alvast, maar dat komt zeker goed! En ik heb $u$ alvast kunnen overtuigen dat Belgen toch niet zo slecht zijn dan eerst gedacht, veel geluk samen! :)

Om dan onze Liver-Lover club te vervolledigen bedank ik Mike en Tom. Beide opeens ook kamergenoten, al was dat jammer genoeg van korte duur. Bedankt voor jullie inzet en hulp tijdens progress meetings of in het lab. Ik zal de leuke momenten met jullie erbij zeker en vast niet snel vergeten (nogmaals, remember Spier? ()). Veel succes met jullie lopende projecten mannen! Mike, geniet verder ook genoeg van je verre reizen $:$ En Tom, hou de Belgische eer een beetje hoog op de afdeling!

Vervolgens, mijn beide promotores, Marten en Jan, bedankt voor al jullie input, richtlijnen, suggesties en hulp tijdens de afgelopen periode.

Daarnaast heb ik heel veel te danken aan Veerle. Gij waart de beste leermeester die ik kon hebben. Steeds paraat om mijn vragen te beantwoorden, eerst nog als student, 
daarna ook nog als aio. Ge zijt zeker en vast altijd een voorbeeld voor me geweest. Bedankt voor al uw hulp en succes verder!

Dan ga ik verder met mijn voormalige kamergenoten. Yvonne, respect voor uw inzet die niet te stoppen blijkt. Maar als ge dan toch eens tijd had, bedankt voor de leuke babbels in de kamer. Die mis ik nu al! Alle success wens ik u met uw project en ik hoop zeker contact met $u$ te houden! Karen, it was nice to have you in the same aio-room. Always a pleasure talking to you and I'm still waiting for the Chinese food invitation (:) Jieyi, although time together was quit short, nice to know you. Success with your project! Then of course the other PhD students in our department: Marie and Yilin, nice to have you in our department and I wish you further all the success! Verder bedank ik ook alle andere collega's van onze afdeling. Petra, bedankt voor alle zorgen en hulp bij alle organisatie van vanalles en nog wat! Met $u$ het lab-uitje organiseren was een geschenk! Super secretaresse! Willem, bedankt voor je input tijdens de labchats! Dietbert, pleasure knowing you and having you around at MolGen. In two years we watch the final Belgium-Germany at your place? (;) Dipanjan, Dip, pleasure having you in the lab! Will en Viviane bedank ik voor de ondersteuning op het lab indien ik die nogmaals nodig had (en Patrick er niet was). Joost, ik train voorlopig nog om nogmaals tegen je te worstelen. Misschien moet ik wat meer bananen eten? :) Marion bedankt voor je hulp met alle histologie (en andere) vragen. En zeker en vast voor het organiseren van de jaarlijkse BBQ, super!

Special thanks to Christoph Binder, for giving me the opportunity to visit his lab for 6 months during my PhD and to welcome me back to continue my scientific career.

En natuurlijk ook alle collega's die voorheen op onze afdeling werkten wil ik kort bedanken: Ellen, mijn eerste buurvrouw op MolGen $;$ (: (tot op Werchter nogmaals?). Ine, leuk $u$ te kennen al sinds de opleiding! Pieter, bedankt dat ik uw plaats in de kamer mocht innemen. Ik heb dezelfde eer trachten hoog te houden. Nadine, altijd klaar voor een grap. Bedankt voor de gezellige tijd in onze kamer. Hoop dat verder alles prima gaat. Keep up the good spirit! Lauran, thanks voor alle hulp destijds. Laura, ik zie het een beetje via facebook tegenwoordig, maar ik volg ongeveer hetzelfde pad als u qua avontuur, super! Peggy, ik heb u altijd een leuke collega gevonden die klaar stond met een glimlach. Alle succes nu verder (zeker met de twins)! Guus, ook al even niet meer gezien maar altijd leuk gehad samen op de afdeling! Emiel, die altijd klaar staat om iedereen verder te helpen. Topkerel! Marten, lang geleden ondertussen, maar echt wel leuke tijd samen gehad. Verder nog Bram waarmee ik als student een leuke tijd mee heb gehad. Daarnaast bedank ik ook nog Robert (misschien kan ik een lesje Duits krijgen?) en Ricardo voor onze tijd samen de afdeling. Dan nog Chantal (op naar een nieuw goed-fout feest?) bedankt voor je hulp bij opofferingen. Tenslotte nog Marjo (ook super om het lab-uitje mee te mogen organiseren) en Menno, bedankt voor jullie hulp en input in ons vroegere macrofaagclubje $(;)$. Tenslotte bedank ik ook 
alle studenten die in de tussentijd in onze groep/afdeling hebben gewerkt: Mandy, Lennart, Yasmin, Joris, Samantha, Rick, Robin, Kosta, Armand en Nathalie.

Dan bedank ik verder mijn vrienden voor de morele ondersteuning en de momenten om even werk te vergeten. Vooral de vrijdagavonden met Pinanti zal ik zeker en vast missen maar ook de weekends of late donderdagavonden om te kaarten en meer $(;) \mathrm{lk}$ kijk er naar uit iedereen zien af te komen naar Oostenrijk om daar een feestje te bouwen!

De twee personen waar ik uiteindelijk alles aan te danken heb, mijn ouders. Mama en papa, ik dank u voor alle steun, door dik en dun, in goede en slechte tijden. Zonder uw geloof in mij was ik hier nooit geraakt. Ik vergeet nooit dat ik op het punt stond om de studies op te geven aan de universiteit, maar gij deed mij doorbijten en er het beste van maken. Kijk waar ik nu sta. Verder ben ik zeker niet altijd het makkelijkste kind geweest. Wel, ik kan u verzekeren dat gij mij steeds gelukkig gemaakt hebt en ik het zeker niet zonder $\mathrm{u}$ had kunnen doen allemaal. Bedankt voor alles!

And ultimately... fireworks! Sabrinake, mijne witte, my model! Thank you for guiding me through the last difficult part of my PhD. Writing my thesis, performing experiments, analyzing data.... you made everything going so easy. It was a pleasure working with you in the lab, but most of all, I enjoyed every single moment we could spent together. Getting to know you was by far the best part of my whole period in Vienna. It turned out to be the start of something special. As from the start, we do everything step by step. By now, I am already looking forward to our next step. So far, all went above and beyond all my expectations. I just can't imagine a life without you anymore... Thank you for being my true number one! 
Curriculum Vitae 


\section{Curriculum Vitae}

Tim Hendrikx was born on March 25 $5^{\text {th }}, 1986$ in Bree, Belgium. In 2004, he acquired his high school diploma (Science-Mathematics) at the Stedelijke Humaniora Dilsen, Belgium. He started his bachelor education in Biomedical Sciences at Hasselt University (Hasselt, Belgium) in September 2004 and finalized his bachelor study in 2008. Subsequently, he participated in the master of "clinical molecular life sciences" at Hasselt University, Belgium. For this degree, he performed twice an internship of 2 and 7 months respectively at the department of Molecular Genetics, Maastricht University, where he started to investigate non-alcoholic steatohepatitis (NASH) and graduated in July 2010. For the master thesis he was awarded with the Dr. Jan Huynen Award, being the best thesis making the bridge between science and industry. In October 2010, he started his PhD program at the department of Molecular Genetics within the school of Health, Medicine and Life Sciences, under supervision of Dr. Ronit Shiri-Sverdlov. The topic of his research was to unravel the molecular pathways whereby lysosomal cholesterol accumulation can lead to the inflammatory response observed during NASH. During this period, he mentored several master students during their internships. He also actively attended international and national conferences, among which the European Lipoprotein Club (ELC), European Association for the study of the Liver (EASL), Nederlandse Lipoproteinen Conferentie (NLC), and the Dutch Liver Science Retraite (DLSR). During these conferences, he was able to present his research both orally and by poster presentation. He obtained the first price for best poster presentation at Plenary Meeting of the Department of Genetics and Cell Biology, Maastricht University Medical Centre (MUMC), in Maastricht 2012. Moreover, he won the price for best poster at the annual NUTRIM symposium (Maastricht, 2012) and at the yearly NVGE meeting (Veldhoven, 2014). Further, he was awarded for writing the best research project proposal at the Dutch Liver Science Retrait (2013). In addition, he obtained a Boehringer-Ingelheim travel grant and an EMBO short term fellowship to visit and work in the lab of Prof. Dr. Christoph Binder for a period of 6 months to broaden his knowledge about the role of innate immunity in NASH and to gain experience in working abroad. 


\section{CURRICULUM VITAE}

\section{Personal information}

\begin{tabular}{|c|c|}
\hline Name: & Hendrikx Tim \\
\hline \multirow[t]{2}{*}{ Living address: } & Smoutweg 8 \\
\hline & 3680 Maaseik (B) \\
\hline Mobile number: & +32 496/72.03.96. \\
\hline E-mail: & tim.hendrikx@hotmail.com \\
\hline Date and place of birth: & March 25th 1986, Bree (B) \\
\hline Nationality: & Belgian \\
\hline Sex: & M \\
\hline Marital status: & Unmarried \\
\hline \multicolumn{2}{|l|}{ Professional address } \\
\hline Name University: & Maastricht University \\
\hline Department: & Molecular Genetics \\
\hline \multirow[t]{2}{*}{ Post address: } & Universiteitssingel 50 \\
\hline & 6229 ER Maastricht (NL) \\
\hline Tel.: & +31433881697 \\
\hline E-mail: & t.hendrikx@maastrichtuniversity.nl \\
\hline
\end{tabular}

\section{Education}

Sept. 2008- July 2010

University Hasselt, Diepenbeek

Master in Biomedical Sciences - Clinical Molecular

Life Sciences

(Master thesis awarded with Dr. Jan Huynen Award)

Sept. 2004- July 2008

University Hasselt, Diepenbeek

Bachelor in Biomedical Sciences

Sept. 1998- June 2004

Stedelijke Humaniora, Dilsen

Science- Mathematics

\section{Certificates}

- $\quad$ Certificate: Article 9, Working with animals, Maastricht University 2010

- Certificate: Radiation protection, University Hasselt 2009

- Certificate: Working with animals, FELASA “C" module 1, University Hasselt 2008 


\section{Current employment}

Oct. 2010 - today:

PhD student, Dep. Of Molecular Genetics, Maastricht University

Title of PhD thesis "Intracellular traffic jam: cholesterol accumulation as cause for chronic inflammatory diseases".

\section{Language skills}

- Dutch: native

- English: fluent speaking, reading and writing

- $\quad$ French: average speaking, reading and writing

- German: average speaking, reading and writing

\section{Personal characteristics}

- Highly motivated to perform high quality research

- Team worker, supporting other group members

- Confident in presenting scientific work

- Easy in learning and understanding new techniques

- Flexible work mentality

- Innovative and take initiative

- Ready to take new challenges

- Leadership potential and excellent decision taking skills

- Able to work independently

\section{Extra curriculum activities}

- 2004- today: Secretary soccer club ZVC Pinanti Opglabbeek

- 2003-2004: Member of the Student Council at S.H. Dilsen

\section{International activities}

- December 2013 - March 2014: Performed 3 months research in the lab of Prof. Dr. Binder at the Medical University of Vienna (Austria). (Awarded with Boehringer Ingelheim Fonds Travel Grant)

- April 2014 - July 2014: Performed 3 months research in the lab of Prof. Dr. Binder at the Medical University of Vienna (Austria). (Awarded with EMBO Short Term Fellowship Travel Grant) 


\section{International network}

- $\quad$ Prof. Dr. M. Hofker, RUG Gronigen, the Netherlands

- Prof. Dr. C. Binder, Medical University of Vienna, Austria

- $\quad$ Prof. Dr. P. Rensen, University Leiden, the Netherlands

- Prof. Dr. E. Latz, University of Bonn, Germany

- Prof. Dr. D. Lütjohan, University of Bonn, Germany

- Prof. Dr. I. Tabas, Columbia University New York, USA

- Prof. Dr. J. Plat, Maastricht University, the Netherlands

- Dr. R. Stienstra, Radboud University Nijmegen, the Netherlands

- Dr. M. Netea, Radboud University Nijmegen, the Netherlands

- Dr. G. Koek, MUMC Maastricht, the Netherlands

- Dr. S. Olde Damink, MUMC Maastricht, the Netherlands

\section{Student supervision}

- October 2013 - July 2014: Supervision of Master students N. Vaes and T. Houben. Project titles: "Cholesterol in hepatic inflammation: innocent bystander or still a heavily suspect?" and "Oxidized cholesterol taking the lead in hepatic inflammation".

- October 2012 - July 2013: Supervision of Master students M. Steinbusch and L. Huizing.

Project titles: "Involvement of inflammasomes in hepatic inflammation: a quest for the liver enflaming frontiers of NASH" and "Macrophages in non-alcoholic steatohepatitis; the answer to diagnostic and therapeutic questions?".

- October 2011 - July 2012: Supervision of Master students J. Schreurs and Y. Dias Guichot.

Project titles: "Do not touch: does liver mobilization induce damage through inflammation?" and "Inhibiting Hepatic Inflammation Utilizing Cholesterol Derivatives".

\section{List of publications}

1. Tim Hendrikx, Mike $L J$ Jeurissen, Veerle Bieghs, Sofie MA Walenbergh, Patrick van Gorp, Fons Verheyen, Yasmin Dias Guichot, Marion Gijbels, Eran Leitersdorf, Marten Hofker, Dieter Lütjohann, Ronit Shiri-Sverdlov. Kupffer cell specific Cyp27a1 overexpression reduces hepatic inflammation in hyperlipidemic Ldlr-/mice. J Hepatol. 2014 Oct 1. doi: 10.1016/j.jhep.2014.09.027. (IF: 10.4)

2. J Plat, T Hendrikx, V Bieghs, M L.J. Jeurissen, $S$ M.A. Walenbergh, P J. van Gorp, E De Smet, M Konings, A C.E. Vreugdenhil, Y Dias Guichot, S S Rensen, W A Buurman, JW M. Greve, D Lütjohann, R P. Mensink, R Shiri-Sverdlov. Protective effects of plant sterol and stanol esters in diet-induced non-alcoholic 
steatohepatitis in hyperlipidemic mice. PLoS One. 2014 Oct 30;9(10):e110758. doi: 10.1371/journal.pone.0110758. (IF:3.5)

3. T Hendrikx, S MA Walenbergh, M H Hofker and R Shiri-Sverdlov. Lysosomal cholesterol accumulation: driver on the road to inflammation during atherosclerosis and non-alcoholic steatohepatitis. Obes Rev. 2014 Mar 16. doi: 10.1111/obr.12159. (IF: 7.9)

4. T Hendrikx, V Bieghs, S MA Walenbergh, P J van Gorp, F Verheyen, M L Jeurissen, M MF Steinbusch, N Vaes, C J Binder, G H Koek, R Stienstra, M G Netea, M H Hofker and $R$ Shiri-Sverdlov. Macrophage specific caspase-1/11 deficiency protects against cholesterol crystallization and hepatic inflammation in hyperlipidemic mice. PLoS One. 2013 Dec 2;8(12):e78792. doi: 10.1371/journal.pone.0078792. eCollection 2013. (IF: 3.5)

5. Bieghs V, Walenbergh SM, Hendrikx T, van Gorp PJ, Verheyen F, Olde Damink SW, Masclee AA, Koek GH, Hofker MH, Binder CJ, Shiri-Sverdlov R. Trapping of oxidized LDL in lysosomes of Kupffer cells is a trigger for hepatic inflammation. Liver Int. 2013 Mar 16. doi: 10.1111/liv.12170. (IF: 4.4)

6. Bieghs V, Hendrikx T, van Gorp PJ, Verheyen F, Guichot YD, Walenbergh SM, Gijbels M, Rensen SS, Bast A, Plat J, Kalhan SC, Leitersdorf E, Hofker M, Lütjohann D, Shiri-Sverdlov R. The Cholesterol Derivative 27-Hydroxycholesterol Reduces Steatohepatitis in Mice. Gastroenterology. 2013 Jan;144(1):167-178.e1. doi: 10.1053/j.gastro.2012.09.062. (IF: 13.9)

7. Bieghs V, Van Gorp PJ, Wouters K, Hendrikx T, Gijbels MJ, van Bilsen M, Bakker J, Binder CJ, Lütjohann D, Staels B, Hofker MH, Shiri-Sverdlov R. LDL receptor knockout mice are a physiological model particularly vulnerable to study the onset of inflammation in non-alcoholic fatty liver disease. Plos One. 2012;7(1):e30668 (IF: 3.5)

8. Bieghs V, Verheyen F, van Gorp PJ, Hendrikx T, Wouters K, Lütjohann D, Gijbels MJ, Febbraio M, Binder CJ, Hofker MH, Shiri-Sverdlov R. Internalization of Modified Lipids by CD36 and SR-A Leads to Hepatic Inflammation and Lysosomal Cholesterol Storage in Kupffer Cells. PLoS One. 2012;7(3):e34378 (IF: 3.5)

\section{Submitted/ in preparation}

- Tim Hendrikx, Mike LJ Jeurissen, Marion J Gijbels, Patrick J van Gorp, Sofie MA Walenbergh, Veerle Bieghs, Christoph J Binder, Rinke Stienstra, Mihai G Netea, Marten H Hofker, Marjo Donners and Ronit Shiri-Sverdlov. Macrophage caspase1/11 deficiency protects against atherosclerosis development in Ldlr-/- mice. Conditionally accepted to FEBS Journal (IF: 3.9)

- T. Hendrikx, J.J.W. Schreurs, D.K. Dhar, L. Mpabanzi, M. Malagó, C.H.C. Dejong, R. Shiri-Sverdlov, S.W.M. Olde Damink. Liver mobilisation during liver resection induces profound hepatic inflammation: a mouse model. In preparation 
- Tim Hendrikx, Sofie MA Walenbergh, Patrick J van Gorp, Veerle Bieghs, Mike L Jeurissen, Sander S Rensen, Wim A Buurman, Jan Willem M Greve, Steven W Olde Damink, Patrick Lindsey, Ger H Koek, Marten H Hofker, Ronit Shiri-Sverdlov. Plasma interleukin 1 receptor antagonist levels as a non-invasive diagnostic tool for the detection of non-alcoholic steatohepatitis. In preparation

- T Hendrikx, S Amir, S MA Walenbergh, S Gruber, D Jonkers, A CE Vreugdenhil, S Kalhan, C J Binder, R Shiri-Sverdlov. Protective effects of natural antibodies against oxidation specific epitopes against hepatic inflammation during NASH. In preparation

- Sofie MA Walenbergh, Sander S Rensen, Veerle Bieghs, Tim Hendrikx, Patrick J van Gorp, Mike LJ Jeurissen, Wim A Buurman, Anita CE Vreugdenhil, Ann Driessen, Jan Willem M Greve, Jogchum Plat, Marten H Hofker, Satish Kalhan, Patrick Lindsey, Ger H Koek, Ronit Shiri-Sverdlov. Plasma cathepsin D: a novel marker for non-invasive diagnosis of non-alcoholic steatohepatitis. Under Review

- Sofie MA Walenbergh, Tim Hendrikx, Tom Houben, Mike LJ Jeurissen, Patrick J van Gorp, Veerle Bieghs, Marie-Hélène Lenders, Marion JJ Gijbels, Marten H Hofker, Christoph J Binder, Dieter Lütjohann, Fons Verheyen, Ger H Koek, Ronit Shiri-Sverdlov. Oxidized lipids are a leading factor in lysosomal cholesterol accumulation and hepatic inflammation in a Niemann-Pick type C1 mouse model. In preparation

- Sofie MA Walenbergh, Tim Hendrikx, Nathalie Vaes, Patrick J van Gorp, Mike L Jeurissen, Tom Houben, Fons Verheyen, Marten H Hofker, Ger H Koek, Eicke Latz, Ronit Shiri-Sverdlov. Weekly administration of two-hydroxypropyl- $\beta$-cyclodextrin is not sufficient in reducing hepatic inflammation in LDL receptor knock-out mice. In preparation

- $\quad$ K Reesink, T Hendrikx, P van Gorp, L Huizing, A Hoeks, R Shiri-Sverdlov. Echogenic monocytes as diagnostic tool for non-alcoholic steatohepatitis. In preparation

\section{Oral presentations}

- September 2013: Dutch Liver Science Retraite (Nederlandse Vereniging voor Hepatologie), Spier, the Netherlands

Title: Kupffer cell specific Cyp27a1 overexpression reduces hepatic inflammation in hyperlipidemic Ldlr-/- mice.

- March 2013: Dutch Experimental Gastroenterology and Hepatology (voorjaarsvergadering), Veldhoven, the Netherlands Title: Cyp27: a novel player in diet-induced NASH.

- March 2013: Maastricht Inflammation in Metabolic Syndrome and Atherosclerosis symposia, Maastricht, the Netherlands

Title: The role of caspase- 1 in non-alcoholic steatohepatitis 
- January 2013: Keystone symposia: Metabolic control of inflammation and immunity, Breckenridge, Colorado, USA.

Title: Caspase-1 as a novel target for the treatment of NASH

(Selected abstract)

- November 2012: NLC, Leiden, the Netherlands

Title: The inflammasome as a novel target for the detection and treatment of non-alcoholic steatohepatitis

- September 2012: ECLCB-5, Spier, the Netherlands

Title: The inflammasome as a novel target for the detection and treatment of non-alcoholic steatohepatitis

- October 2011: Dutch Liver Science Retraite (Nederlandse Vereniging voor Hepatologie), Spier, the Netherlands

Title: Cyp27: a novel player in diet-induced NASH

- September 2011: CTMM-Predicct: WP2 meeting, Utrecht, the Netherlands Title: Unraveling the mechanisms leading to hepatic inflammation in NASH

- May 2011: Plenary meeting, Department of Genetics and Cell Biology, Maastricht University Medical Centre (MUMC), Maastricht, the Netherlands Title: Cyp27: a novel key modulator in hepatic inflammation

\section{Poster presentations}

- March 2014: Voorjaarsvergadering Nederlandse Vereniging voor Gastroenterologie (MVGE), Veldhoven, the Netherlands.

Title: Overexpression of Cyp27a1 in hematopoietic cells reduces hepatic inflammation independently of 27-hydroxycholesterol levels in liver and plasma

(Awarded with a poster price)

- April 2013: European Association of the Study of the Liver (EASL) meeting, Amsterdam, the Netherlands.

Title: Caspase-1 as a novel target for the detection and treatment of non-alcoholic steatohepatitis

- January 2013: Keystone symposia: Metabolic control of inflammation and immunity, Breckenridge, Colorado, USA.

Title: Caspase- 1 as a novel target for the detection and treatment of non-alcoholic steatohepatitis

- December 2012: Annual NUTRIM Symposium, Maastricht University Medical centre (MUMC)

Title: Caspase-1 as a novel target for the treatment of NASH

(Awarded with a poster price)

- November 2012: Annual Predicct meeting, Arnhem, the Netherlands

Title: The inflammasome: new target for detection and therapy of non-alcoholic steatohepatitis 
- November 2012: $3^{\text {rd }}$ Diabetes Day Maastricht - Dusseldorf, Maastricht, the Netherlands

Title: The inflammasome: new target for detection and therapy of non-alcoholic steatohepatitis

- September 2012: Annual CTMM meeting, Utrecht, the Netherlands

Title: The inflammasome: new target for detection and therapy of non-alcoholic steatohepatitis

- March 2012: Deuel Conference on Lipids, Palm Springs,California

Title: Anti-oxLDL antibodies: a novel treatment for non-alcoholic steatohepatitis

- February 2012: Plenary meeting, Department of Genetics and Cell Biology, Maastricht University Medical Centre (MUMC)

Title: Lysosomal enzymes: a novel non-invasive way to detect hepatic inflammation in NASH

\section{(Awarded with a poster price)}

- November 2011: CTMM Predicct meeting, Arnhem, the Netherlands

Title: Lysosomal enzymes: a novel non-invasive way to detect hepatic inflammation in NASH

- November 2011: Annual NUTRIM Symposium, Maastricht University Medical centre (MUMC)

Title: Role of oxidized LDL in hepatic inflammation

- September 2011: European Lipid Conference (ELC), Tutzing, Germany

Title: Role of oxidized LDL in hepatic inflammation

- April 2010: Maastricht Medical Students Research Conference, Maastricht, the Netherlands

Title: Cyp27: a novel key player in hepatic inflammation

\section{Awards}

- Poster presentation award at NVGE Voorjaarsvergadering, Veldhoven, the Netherlands (March 2014)

- Awarded for a EMBO Short term fellowship to visit the lab of Prof. Dr. CJ Binder at Vienna Medical Centre (February 2014)

- Awarded for a Boehringer Ingelheim Fonds Travel Grant to visit the lab of Prof. Dr. CJ Binder at Vienna Medical Centre (November 2013)

- Awarded for best Research Project Proposal 'So you think you can heal the liver', Dutch Liver Retreat, Spier (October 2013)

- Poster presentation award at annual NUTRIM symposium, Maastricht University Medical centre (MUMC), Maastricht (December 2012)

- Poster presentation award at Plenary meeting, Department of Genetics and Cell Biology, Maastricht University Medical Centre (MUMC), Maastricht (February 2012)

- Dr. Jan Huynen Award 2011; Maastricht (March 2011) 


\section{Participation}

- April 2012: R\&D Systems Symposium: The role of cytokines and signaling in inflammation, Cambridge, England

- October 2011: Ernst Klenk Symposium in Molecular Medicine: Lipid metabolic diseases:

novel developments in molecular pathology and therapy, Cologne, Germany

- September 2011: IL-1 family members and the inflammasome, Dublin, Ireland

- November 2010: NUTRIM day, Maastricht University Medical centre (MUMC)

- October 2010: Dutch Liver Science Retraite (Nederlandse Vereniging voor Hepatologie), Westerbork, the Netherlands 
